\author{
Universidad Nacional de La Plata \\ Facultad de Ciencias Exactas \\ Departamento de Ciencias Biológicas
}

\author{
Requisitos Farmacofóricos \\ para la Actividad Antiepiléptica. \\ Acido Valproico \\ y Compuestos Relacionados.
}

Lic. Silvina Mabel Tasso

Año 2003

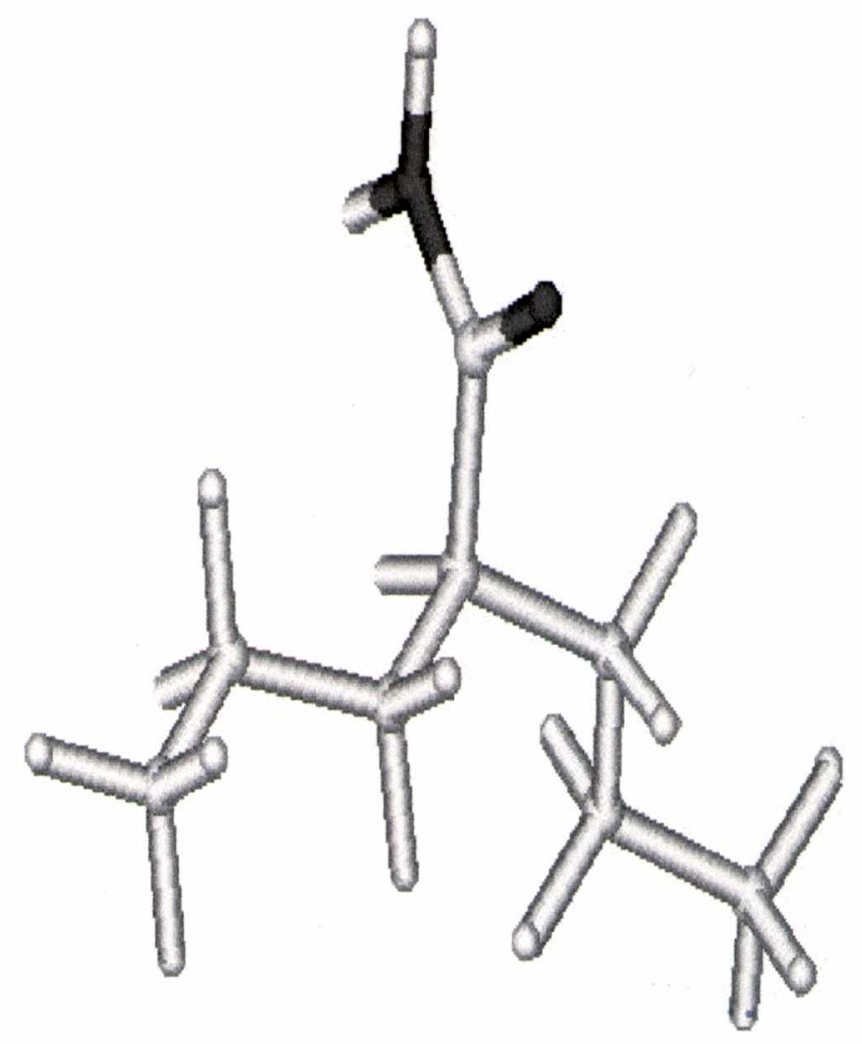


Trabajo de Tesis

para optar al grado de Doctor

Directores de Tesis:

Dr. Luis Enrique Bruno Blanch

Dra. Guillermina Lucia Estiú 
Un grupo de científicos colocó cinco monos en una jaula, en cuyo centro colocaron una escalera y, sobre ella, un montón de bananas.

Cuando un mono subía la escalera para agarrar las bananas, los cientificos lanzaban un chorro de agua fría sobre los que quedaban

en el suelo.

Después de algún tiempo, cuando un mono iba a subir la escalera, los otros no dudaban en golpearlo. Pasado algún tiempo más, ningún mono subía la escalera, a pesar de la tentación de las bananas. Entonces, los científicos sustituyeron uno de los monos. La primera cosa que hizo fue subir la escalera, siendo rápidamente bajado por los otros, quienes le pegaron. Después de algunas palizas, el nuevo integrante del grupo ya no subió más la escalera.

Un segundo mono fue sustituido, y ocurrió lo mismo. El primer sustituto participó con entusiasmo de la paliza al novato. Un tercero fue cambiado, y se repitió el hecho. El cuarto y, finalmente, el último de los veteranos fue sustituido.

Los científicos quedaron, entonces, con un grupo de cinco monos que, aún cuando nunca recibieron un baño de agua fría, continuaban golpeando a aquel que intentase llegar a las bananas. Si fuese posible preguntar a algunos de ellos por qué le pegaban a quien intentase subir la escalera, con certeza la respuesta sería: "No sé, las cosas siempre se han hecho asi aquí..."

Suena conocido? ojalá que no...

el hombre de ciencia NUNCA debería creer y acomodarse a las ideas sin replanteárselas..... 
Agradezco por la posibilidad de realizar este trabajo, a mis Directores, Luis y Guillermina, que siempre me han guiado y aconsejado con la mayor dedicación y buena voluntad, $y$ han compartido conmigo y sabido entender todos los momentos dificiles, y por supuesto también las alegrías. 
Dedico este trabajo a mi abuelo Pedro,

que siempre fue, y seguirá siendo, un ejemplo de vida. 


\section{INDICE \&}

\section{INTRODUCCIÓN $\quad 1$}

\section{OBJETIVOS Y DESARROLLO DE ESTA INVESTIGACION 4}

\section{Capítulo 1:}

\section{DESCUBRIMIENTO DE NUEVAS DROGAS 7}

Drogas surgidas a partir de productos naturales $\quad 8$

Hallazgos por azar 9

Screening 10

Elección de los ensayos biológicos 11

Optimización de la estructura líder 13

El impacto de la tecnología genética en el descubrimiento de drogas 14

El uso de la química computacional en el descubrimiento de drogas $\quad 15$

$\checkmark$ Métodos de Mecánica Molecular 16

$\checkmark$ Métodos Químico Cuánticos 16

$\checkmark$ Análisis conformacional 22

Diseño Racional de nuevas drogas 24

$\checkmark$ Métodos directos 25

$\checkmark$ Métodos indirectos 27

$\checkmark$ Análisis QSAR 29

Capítulo 2:

EPILEPSIA 35

Qué es la epilepsia? 35

Causas de la epilepsia $\quad 36$

Tipos de convulsiones $\quad 38$

$\checkmark$ Convulsiones generalizadas $\quad 39$

Diagnóstico 41

Tratamiento $\quad 42$

\section{Capítulo 3:}

\section{DROGAS ANTIEPILÉPTICAS 47}

Panorama histórico $\quad 48$

$\checkmark$ Surgimiento de las drogas antiepilépticas clásicas $\quad 48$

$\checkmark$ El ocaso del desarrollo de nuevos antiepilépticos $\quad 50$

$\checkmark$ Resurgimiento del interés por el descubrimiento de nuevos agentes antiepilépticos 
Mecanismos de acción de las drogas antiepilépticas $\quad 57$

$\checkmark$ Modulación directa de los canales iónicos $\quad 60$

$\checkmark$ Disminución de la excitación mediada por glutamato $\quad 62$

$\checkmark$ Incremento de la inhibición gabaérgica 63

Mono y politerapia con fármacos antiepilépticos 65

Capítulo 4:

DESCUBRIMIENTO DE NUEVAS DROGAS

CON ACCION ANTICONVULSIVA 69

1. Elección del compuesto líder y

planteo de las metodologías de optimización $\quad 70$

2. Nuevos compuestos obtenidos por

variación estructural del Acido Valproico $\quad 72$

$\checkmark$ Estado de la investigación en el tema 72

$\checkmark$ Planteo de nuevos derivados 85

3. Sintesis de derivados de Valpramida 92

4. Elección de los ensayos biológicos para la evaluación anticonvulsiva y neurotóxica 94

5. Descripción de la metodología de evaluación anticonvulsiva y neurotóxica

$\checkmark$ Animales 100

$\checkmark$ Preparación y administración de las drogas a ensayar $\quad 101$

$\checkmark$ Ensayo MES 103

$\checkmark$ Ensayo PTZ 105

$\checkmark$ Ensayo RotoRod 106

$\checkmark$ Tratamiento estadístico de los datos $\quad 107$

6. Resultados de la evaluación anticonvulsiva y neurotóxica 110

$\checkmark$ Acido Valproico 111

$\checkmark$ Fenitoína 116

$\checkmark$ Valpramida 118

$\checkmark$ N-Isopropilvalpramida

$\checkmark$ N-Butilvalpramida 123

$\checkmark$ N-Valproilmorfolina 125

$\checkmark$ N-Ciclohexilvalpramida 127

$\checkmark$ Acido 4-(valproilamido)benzoico 129

$\checkmark$ Discusión 131

7. Modelado molecular de Valpramidas y otras drogas anti-MES

$\checkmark$ Descripción de la metodología teórica 136

$\checkmark$ Resultados y discusión del estudio teórico 140

8. Diseño de nuevos derivados en base al farmacóforo propuesto 158

9. Estudio teórico, síntesis y evaluación biológica de los nuevos derivados

$\checkmark$ Estudio teórico 161

$\checkmark$ Síntesis 162

$\checkmark$ Resultados de la evaluación anticonvulsiva y neurotóxica

- N,N-Dimetilvalpramida 163

- N-Etilvalpramida 166

- N-(4-sulfonamidofenil)valpramida 169

- Propilvalproato 172

- Discusión 176 
10. QSAR de drogas anti-MES 180

$\checkmark$ Descripción de la metodología 181

$\checkmark$ Resultados y discusión 183

\section{Capítulo 5:}

MODELADO DE LIGANDOS BLOQUEANTES DEL CANAL DE SODIO

Descripción del canal de sodio $\quad 188$

Elección del conjunto de compuestos a estudiar $\quad 190$

Descripción de la metodología 191

$\checkmark$ Análisis conformacional 191

$\checkmark$ Búsqueda de la conformación activa $\quad 192$

$\checkmark$ Método de cálculo 193

$\checkmark$ Densidades de carga 193

Resultados y discusión 193

Acción bloqueante del canal de sodio de derivados de valpramida

\section{Capítulo 6:}

MODELADO DE LIGANDOS DEL RECEPTOR

DE GLUTAMATO MGLUR1 203

Descripción del receptor mGluR 204

Elección del conjunto de compuestos a estudiar 206

Descripción de la metodología 209

$\checkmark$ Análisis conformacional 210

$\checkmark$ Método de cálculo 210

$\checkmark$ Selección de la conformación activa $\quad 211$

$\checkmark$ Cálculo de los descriptores moleculares 211

Resultados y discusión $\quad 214$

$\checkmark$ Requerimientos estructurales y conformacionales $\quad 215$

$\checkmark$ Descriptores moleculares y análisis lineal discriminante $\quad 218$ 


\section{\& INTRODUCCIÓN}

En su afán por lograr una mejor calidad de vida, el hombre ha estudiado y adaptado no sólo a su entorno, sino también a él mismo. Muchas son las metas que ha alcanzado, pero en nuestra era, el surgimiento de nuevas drogas ha sido el principal y mayor responsable de disminuir la morbilidad y mortalidad humanas, más que cualquier otro esfuerzo científico.

Los fármacos han mejorado radicalmente la calidad de vida del hombre, a todas las edades y en distintos sectores socioeconómicos.

Las drogas pueden ser descubiertas de muchas formas distintas. A veces se descubren por accidente. También pueden surgir de la variación estructural de compuestos ya conocidos, a los cuales se les quiere mejorar su potencia, o bien disminuir sus efectos colaterales o adversos. Otras veces se realiza la evaluación farmacológica de un gran número de fármacos ya establecidos con el objeto de encontrarles nuevas acciones. Pero hoy en día las drogas se desarrollan fundamentalmente como parte de un esfuerzo organizado para descubrir nuevas formas de tratar determinadas enfermedades. Esta última situación constituye el Diseño Racional, que comienza con la comprensión del proceso fisiopatológico en sí.

El conocimiento, a nivel molecular, de los ligandos fisiológicos y de las drogas que los imitan, así como también el conocimiento de la estructura tridimensional de los receptores ó enzimas con los que interactúan es de vital importancia. Una vez conocidos estos objetivos biológicos, se pueden diseñar entidades químicas que interaccionen con una determinada región de la macromolécula y así influencien específicamente un determinado proceso patológico.

El diseño implica el manejo de gran cantidad de información. Debido a ello, se aborda frecuentemente mediante el estudio teórico de las moléculas implicadas en la interacción droga-receptor, usando la información recabada para el diseño de nuevas moléculas. En este marco, el empleo de computadoras se ha convertido en un requerimiento fundamental de este proceso. Por esta razón, muchas veces se asocia al Diseño Racional con el Diseño Asistido por Computadoras (CADD - Computer Aided Drug Design). 
Pero no hay que perder de vista el hecho de que el CADD depende críticamente de variadas técnicas experimentales, tanto en las etapas de síntesis orgánica, en el empleo de metodologías biológicas asociadas a la evaluación farmacológica de las drogas, y en el uso de técnicas fisicas de cristalización y espectroscopía que proveen los parámetros experimentales a usar en los cálculos. Pero fundamentalmente, tanto el CADD como el Diseño Racional en si, dependen de la sabiduría del químico medicinal para interpretar y utilizar estos resultados.

El Diseño Racional de Drogas ya está dando sus frutos. Esto se debe al constante desarrollo y avance del conocimiento íntimo de los procesos fisiológicos de las enfermedades y las drogas, así como de sus interacciones con los sitios receptores. Sin embargo, hay todavía muchos puntos oscuros, y un amplio espectro de objetivos terapéuticos sobre los cuales trabajar. Un ejemplo claro de esta situación lo constituye el principal desorden neurológico que afecta al ser humano (luego del accidente cerebrovascular o apoplejía): la epilepsia. No se conocen con exactitud los mecanismos bioquímicos que conducen a las descargas eléctricas excesivas que ocurren en las neuronas durante una convulsión epiléptica, aunque sí se sabe de la ocurrencia de varios eventos anormales, como así también de los efectos que producen en la respuesta convulsiva determinadas drogas con mecanismos de acción conocidos.

No sólo el elevado número de personas en el mundo que sufren de epilepsia justifica ampliamente la investigación profunda en esta área. También el hecho de que en un alto porcentaje de pacientes, los tratamientos disponibles actualmente están lejos de resultar óptimos, define una razón indiscutible para la búsqueda intensiva de nuevos fármacos para mitigar este mal. Además, el panorama se ve agravado en países en vías de desarrollo, en donde ciertas enfermedades, complicaciones prenatales y malnutrición, son factores de gran incidencia en la población y que frecuentemente conducen a daño cerebral y epilepsia.

Es dentro de este contexto que surge la idea de estudiar, en forma interdisciplinaria, el problema del descubrimiento de nuevas drogas antiepilépticas. Se utilizan para ello técnicas asociadas al diseño racional de drogas y también metodologías de CADD, con el objeto de lograr un enfoque global. Así, el tema del surgimiento de nuevos fármacos anticonvulsivos o antiepilépticos se aborda desde un punto de vista teórico - experimental, de manera que confluyen en esta investigación resultados derivados de disciplinas tales como: 
$\checkmark$ la química orgánica, a través del empleo de técnicas experimentales para la sintesis, aislamiento, purificación y caracterización de las drogas;

$\checkmark$ la farmacología, mediante la aplicación de ensayos in vivo e in vitro para dilucidar la potencia biológica de las drogas; y

$\checkmark$ la química computacional, en el estudio teórico de las propiedades moleculares de las drogas y el planteo de hipótesis relacionadas al diseño racional.

En este trabajo se detallan los resultados y conclusiones obtenidos mediante la aplicación de las dos últimas disciplinas, vale decir la farmacología experimental y el estudio teórico de las drogas sintetizadas en nuestro Laboratorio de Farmacoquímica de la Facultad de Ciencias Exactas (UNLP), así como también de otras series de fármacos relacionados, con el objeto de sacar conclusiones sobre las características de las estructuras que explican el origen de su actividad biológica.

Así, la esencia del presente trabajo radica no sólo en el aporte de conocimiento sobre las interacciones drogareceptor, fundamentalmente en cuanto al planteo de los requisitos asociados a distintas acciones anticonvulsivas (grupos farmacofóricos), sino también en el diseño racional de potenciales nuevas drogas antiepilépticas en base a la comprensión de estos requerimientos. Las distintas acciones anticonvulsivas analizadas se refieren tanto a la consideración de la potencia in vivo (la habilidad de proteger frente a las convulsiones provocadas por el Electroshock Máximo y por el agente convulsivo Pentilentetrazol), como así también a la capacidad de interaccionar específicamente con determinados sitios receptores, como los canales de sodio neuronales o los receptores metabotrópicos de glutamato. 


\section{\& OBJETIVOS Y DESARROLLO DE ESTA INVESTIGACIÓN}

En los capítulos 1,2 y 3 se analizan cuestiones relacionadas al descubrimiento de nuevos fármacos y a la elección de nuestro objetivo terapéutico, la epilepsia, precisando los problemas relacionados a los tratamientos disponibles actualmente. En los capítulos siguientes se detallan los resultados del trabajo realizado en esta área.

Sobre la base de lo expuesto en la introducción, es posible definir los objetivos del presente trabajo de esta manera:

$\checkmark$ objetivo 1: planteo de una metodologia indirecta de diseño racional y elección de un conjunto inicial de trabajo.

Se elige al ácido valproico como compuesto líder sobre el cual realizar modificaciones tendientes a optimizar su estructura (sección 1 del capítulo 4). Luego se procede a efectuar una intensiva recopilación bibliográfica con el objeto de plantear las variaciones más convenientes (sección 2 del capítulo 4 ), y por último se sintetizan (sección 3 del capítulo 4) y evalúan farmacológicamente estas nuevas estructuras (secciones 4-6 del capítulo 4).

$\checkmark$ objetivo 2: planteo de Relaciones Estructura - Actividad (farmacóforo).

Un perfil farmacológico común, como lo es la acción protectora frente a las convulsiones provocadas por el Electroshock Máximo, define un conjunto de estructuras relacionadas dentro del cual se incluye a la droga de uso clínico fenitoína (sección $6 \mathrm{del}$ capítulo 4), que constituye un análogo rígido. 
El estudio teórico computacional permite definir un farmacóforo relacionado a esta acción farmacológica in vivo (sección 7 del capítulo 4).

objetivo 3: diseño de nuevas estructuras.

En base al conocimiento adquirido, se diseñan nuevas estructuras (sección $8 \mathrm{del}$ capítulo 4). Estas se someten al estudio teórico para definir si cumplen los requisitos necesarios para manifestar actividad biológica, se sintetizan y evalúan farmacológicamente (sección 9 del capítulo 4), a fin de corroborar el diseño planteado.

$\checkmark$ objetivo 4: planteo de Relaciones Estructura - Actividad Cuantitativas.

La obtención de datos cuantitativos (ED50s) para las drogas evaluadas permite el cálculo de relaciones matemáticas que vinculan la actividad biológica con descriptores moleculares (sección 10 del capítulo 4), a partir de las cuales se hacen inferencias sobre las características de la interacción drogareceptor.

objetivo 5: análisis de estructuras que actúan por mecanismos de acción específicos: planteo de una metodología indirecta de diseño racional, elección de un conjunto inicial de trabajo, y planteo de relaciones estructura - actividad (farmacóforo)

Al ser fenitoína el prototipo de las drogas antiepilépticas que actúan específicamente por bloqueo de los canales de sodio neuronales, se enfoca un estudio teórico hacia el planteo de un grupo farmacóforo asociado a esta acción (capitulo 5). 
Dentro del contexto del desarrollo de nuevos fármacos antiepilépticos, se aborda la temática relacionada al decremento de la neurotransmisión excitatoria, orientando el estudio teórico a la determinación de las características relacionadas con una acción antagonista sobre los receptores metabotrópicos de glutamato mGluR1. (capítulo 6). 


\section{$\&$ CAPITULO 1}

\section{DESCUBRIMIENTO DE NUEVAS DROGAS}

Antiguamente los medicamentos consistian principalmente en hierbas y pociones. No fue sino hasta mediados del siglo XIX que surgió el interés por conocer las causas del resultado beneficioso que se obtenía gracias a la administración de estos remedios en forma empírica. Así, comenzaron a realizarse serios esfuerzos por aislar y purificar sus principios activos'. De esta manera, cobraron fundamental importancia y se fueron desarrollando las metodologías asociadas al descubrimiento de nuevas drogas. Los productos naturales derivados de plantas y microorganismos, o aquellos compuestos líderes ${ }^{\star}$ desde un punto de vista bioquímico, o bien los surgidos simplemente por azar, han sido estructuralmente modificados con el fin de obtener análogos con una actividad mejorada y/o menores efectos adversos ${ }^{2}$.

Aunque durante décadas, e inclusive actualmente, las nuevas drogas han surgido sin necesidad de conocer el mecanismo de acción por el cual funcionan, en los últimos años, los paradigmas del descubrimiento de drogas cambiaron significativamente. Nace entonces el Diseño Racional de fármacos, basado en el conocimiento a nivel molecular de los sucesos bioquímicos que median el proceso patológico. Las antiguas estrategias de prueba y error son reemplazadas por otras con fundamentos lógicos. El desarrollo de nuevas tecnologías en diversos campos, tales como la tecnología genética o el CADD (Computer Aided Drug Design*), enriquecieron con sus aportes al Diseño Racional de nuevas drogas ${ }^{2}$.

Así, el mayor aporte de la tecnología genética lo constituye la expresión de proteínas de importancia farmacológica, que pueden ser usadas para sistemas de

\footnotetext{
- se denomina líder a aquella estructura que presenta la mejor actividad biológica dentro de una serie, pero que aún es plausible de optimizarse, ya sea en cuanto a su potencia o en cuanto a la reducción de sus efectos secundarios

* Computer Aided Drug Design: diseño de drogas asistido por computadora
} 
screening ${ }^{\star}$ o bien para la determinación de la estructura 3D por métodos cristalográficos o técnicas NMR.

El CADD constituye uno de los más prominentes desarrollos relacionados con el Diseño Racional de drogas. Mediante la simulación teórica de los eventos bioquímicos se llega a un mayor entendimiento de estos procesos a nivel molecular. Lograda esta comprensión, se procede a la fase experimental de comprobación, con el consiguiente ahorro de tiempo y esfuerzo.

Ya han surgido varias drogas en base a este proceso racional de descubrimiento de estructuras activas. Entre ellas se pueden mencionar a los inhibidores de la enzima convertidora de angiotensina ${ }^{3}$, la cimetidina ${ }^{4}$ y la pralidoxima ${ }^{5}$. Sin embargo, las estrategias clásicas y el azar siguen jugando un papel muy importante. La gran mayoría de las drogas en el mercado fueron desarrolladas mediante una combinación de diseño racional, prueba y error, y buena suerte ${ }^{3}$. Pero fundamentalmente el rol esencial en el descubrimiento de nuevas drogas lo ha tenido y lo seguirá teniendo el quimico medicinal a través del criterio basado en el conocimiento integral del tema, abarcando desde las estrategias de planificación de una síntesis orgánica hasta el uso de programas de química computacional para el estudio teórico de una estructura, pasando por las técnicas de evaluación farmacológica para determinar distintos tipos de actividad biológica.

A continuación se discutirán las distintas estrategias de surgimiento de las nuevas drogas utilizadas actualmente, desde los clásicos métodos de aislamiento de productos naturales y screening farmacológico, hasta las más recientes técnicas relacionadas con el Diseño Racional. Además, se hará hincapié en uno de los puntos más importantes en el proceso del descubrimiento de nuevas drogas: la elección de un ensayo biológico adecuado para la evaluación farmacológica de los compuestos.

\section{Drogas surgidas a partir de productos naturales.}

Los principios activos derivados de plantas han sido la fuente más importante de nuevas drogas ${ }^{6,7,8}$, destacándose por ejemplo el aislamiento de morfina de la amapola, ya en 1806 . Otro importante recurso ha sido el aislamiento de metabolitos secundarios de los microorganismos, como los potentes antibióticos aislados de caldos microbianos y fúngicos. Aunque en menor medida, también las toxinas animales tales

\footnotetext{
- el screening farmacológico es la evaluación de la capacidad de los compuestos de manifestar actividad frente a distintos tests biológicos
} 
Figura 1.1

Taxol,

epibatidina

y artemisina son

algunas de las

tantas drogas

que muestran la

importante

diversidad

estructural

encontrada en

la naturaleza.

como los venenos de serpientes han constituido estructuras líderes para el desarrollo de nuevas drogas.

Sin embargo, el aislamiento de estos principios activos y la subsiguiente elucidación de sus estructuras significa un enorme esfuerzo. Este hecho ha contribuido al gran auge de las técnicas de ensayos bioquímicos rápidas y ultrarrápidas y superminiaturizadas, conocidas como high y ultrahigh throughput screening (HTS y uHTS, respectivamente) ${ }^{\star}$, empleando compuestos provenientes de diversas bibliotecas estructurales. Especialmente esta última técnica de evaluación biológica goza de un gran predicamento en la industria farmacéutica, debido a su simplicidad y rapidez. No obstante, si se considera la diversidad de estructuras químicas encontradas en la naturaleza, en relación a la escasa variación estructural que presenta aún la más importante de las bibliotecas de química combinatoria, no es arriesgado predecir que la naturaleza siempre será la principal fuente de nuevas moléculas ${ }^{2}$. Ejemplos de la real diversidad estructural revelada por los productos naturales lo constituyen las recientemente surgidas drogas líderes, de origen vegetal y animal, taxol (un agente anticancerígeno) $)^{9,10}$, artemisinina (un antimalárico) ${ }^{11,12}$ y epibatidina (un potente analgésico) ${ }^{13,14}$ (Figura 1.1) Anticancerígenos como los alcaloides de vinca (Catbarentbus roseus) y discodermalide, aislado de la esponja del mar

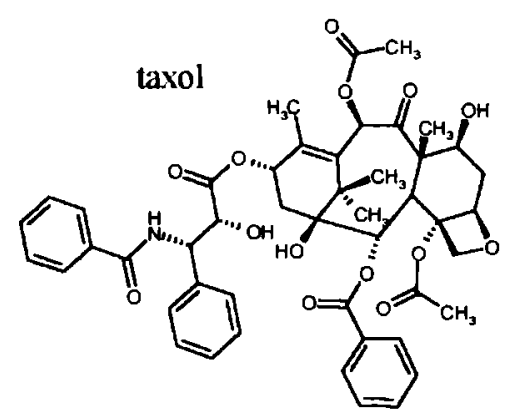

caribe Discodernia disoluta

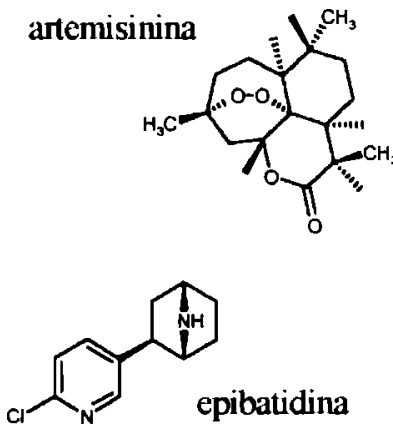

también ilustran esta diversidad $^{15}$.

\section{Hallazgos por azar.}

La suerte siempre jugó un papel importante en el surgimiento de nuevas drogas. Los dos mejores ejemplos de

\footnotetext{
- HTS (high-throughput screening) se refiere a técnicas de testeo in vitro automatizado de grandes cantidades de compuestos simultáneamente, mediante el uso de varios ensayos bioquímicos cuyos efectos son fácilmente detectados y medidos (por ejemplo mediante una reacción enzimática que provoca un cambio de color, o el desplazamiento de ligandos radioactivos) [MC].
} 
descubrimientos azarosos son probablemente la penicilina y el clordiazepóxido ${ }^{2}$.

En el primer caso, Fleming tuvo a su favor la casualidad de que la cepa de Penicillium que infectó su cultivo bacteriano fuera una de las pocas productoras del antibiótico. Por otro lado, se conjugaron condiciones de tiempo y ambientales adecuadas permitiendo el crecimiento simultáneo de ambos organismos y la observación de la acción antibiótica. Pero fundamentalmente, no puede dejar de considerarse el mérito de quien fue capaz de deducir las conclusiones correctas a partir de este experimento no planeado ${ }^{16}$.

En forma semejante, Sternbach trabajó por años en el descubrimiento de un tranquilizante con una nueva estructura, sin lograr su objetivo. Recién cuando se dispuso a dar por finalizados sus esfuerzos, al ordenar su laboratorio, encontró unos cristales y los ensayó en animales aunque sin esperanzas de hallar buenos resultados. Sin embargo, no sólo la actividad fue positiva sino que la estructura del compuesto era distinta del esperado producto de reacción. Se trataba del primer tranquilizante derivado de benzodiazepina, el clordiacepóxido ${ }^{17}$, uno de los raros ejemplos en donde la primer estructura cabeza de serie fue líder y llegó a ser usada en terapéutica.

Muchos otros ejemplos de hallazgos por azar se describen en la literatura ${ }^{16,18,19,20}$, tales como el antipirético fenacetina, el laxante fenolftaleína, el neuroléptico haloperidol, el antidepresivo imipramina, e inclusive el antiepiléptico ácido valproico, cuyas variaciones constituyen uno de los temas centrales de esta Tesis. A pesar de haber sido sintetizado en $1882^{21}$, la actividad anticonvulsiva del ácido valproico no fue descubierta sino hasta 1963, en forma fortuita. Meunier, trabajando en el laboratorio de G. Carraz, usó ácido dipropilacético (ácido valproico) como vehículo para disolver los principios activos destinados al ensayo de actividad anticonvulsiva. Los resultados condujeron a la evaluación del ácido valproico puro y a la confirmación de su capacidad de protección frente a las convulsiones inducidas con el agente convulsivo pentilentetrazol ${ }^{22}$. Los primeros ensayos clínicos se reportaron en $1964^{23}$ y el ácido valproico se comenzó a comercializar en 1967 en Francia y en 1978 en los Estados Unidos, para el tratamiento de la epilepsia ${ }^{24}$.

\section{Screening.}

El screening farmacológico consiste en la búsqueda de un determinado tipo de actividad biológica, mediante el empleo de ensayos especificos para dicha acción, en un conjunto de estructuras químicas. Estas estructuras pueden ser 
tanto compuestos novedosos como sustancias endógenas o drogas empleadas para otras afecciones.

La observación de que algunos pigmentos tenían alta afinidad por microorganismos patógenos, condujo a su ensayo para esclarecer si contaban con algún potencial terapéutico. En 1891, Erlich curó a dos pacientes enfermos de malaria mediante la aplicación de azul de metileno. La primer sulfonamida fue la sulfacrisoidina (el colorante prontosil), la cual representó un adelanto fundamental en la terapia antibacteriana, y se hizo mundialmente famosa tras salvar la vida del hijo del presidente norteamericano Roosevelt quien estaba a punto de morir de una severa infección por estreptococos. Así, el screening en masa comenzó con el cotejo de la actividad antibacteriana de miles de sulfonamidas diferentes.

En las décadas siguientes, muchos programas de descubrimiento de drogas se basaron en el screening masivo de compuestos en diversos modelos farmacológicos. Posteriormente se incorporaron los sistemas in vitro de unión a receptores. Más de 50 nuevas drogas, entre ellas analgésicos, antihistamínicos, neurolépticos y antidepresivos, surgieron a partir de esta estrategia.

Paralelamente al progreso del diseño racional, que incluía metodologías como los análisis QSAR*, el modelado, y el CADD, sobrevino la declinación en el uso del screening clásico. Las estructuras de las potenciales nuevas drogas comenzaron a planificarse más cuidadosamente.

Actualmente las estrategias de screening se han incrementado, ya que la química combinatoria aporta un número considerable de estructuras para ser evaluadas, lo que requiere una alta capacidad de evaluaciones biológicas. Sólo los sistemas HTS y uHTS ${ }^{25}$ pueden aportar soluciones a estos desafios, gracias a su enorme capacidad que permite la evaluación de miles de compuestos o mezclas de ellos por semana. Sin embargo, el proceso de optimización de las estructuras que demostraron una actividad biológica interesante, seguirá dependiendo de las metodologías farmacológicas mas rigurosas y laboriosas, y de la habilidad, experiencia e intuición de los químicos medicinales ${ }^{2}$.

\section{Elección de los ensavos biológicos}

La elección de un ensayo biológico apropiado para la evaluación farmacológica de los compuestos es crucial en el éxito de cualquier programa de desarrollo de drogas.

+ QSAR: Quantitative Structure-Activity Relationships (Relaciones Estructura-Actividad Cuantitativas) 
12 1

Hay varios factores a tener en cuenta en el momento de decidir qué ensayo es el más conveniente. En primer lugar el ensayo debe ser rápido y simple, porque generalmente es necesario evaluar un gran número de compuestos en un periodo de tiempo razonable. Además, debe poseer poder discriminante, es decir que debe ser capaz de diferenciar compuestos promisorios de los que no lo son. Por último, el ensayo adecuado es aquél que presente relevancia clínica, en cuanto a que debe haber una correspondencia entre la medida del efecto biológico y la actividad clínica requerida.

Las evaluaciones biológicas a utilizar en las etapas tempranas del desarrollo de una nueva droga pueden realizarse in vivo $\mathrm{o}$ in vitro. Los ensayos in vivo emplean animales enteros, vivos, y frecuentemente consisten en la inducción de una condición clínica que provoque sintomas observables. Luego el animal se trata con la droga para ver si ésta elimina o reduce los síntomas. Los ensayos in vitro emplean tejidos específicos, células o proteínas. Así, los inhibidores enzimáticos pueden probarse directamente frente a la enzima pura en solución, o bien los agonistas o antagonistas de un dado receptor pueden evaluarse frente a tejidos aislados o células que expresen dicho receptor en su superficie. En general, cuando se utilizan tejidos se mide como respuesta algún efecto fisiológico, mientras que en el caso de la unión a receptores se utilizan ligandos radioactivos para la cuantificación de la respuesta ${ }^{1}$ (ensayos de binding ${ }^{\star}$ ).

Cada tipo de técnica de ensayo farmacológico presenta sus ventajas y desventajas. Por un lado, los ensayos in vivo pueden traer aparejadas ciertas complicaciones, en cuanto a que frente a un resultado negativo no es posible saber si se debe a que la droga falla en la unión al receptor, $o$ si directamente no es capaz de llegar al sitio de acción debido a efectos de $\mathrm{ADME}^{\star}$. Además, es posible que las distintas especies presenten resultados diferentes, y por ende no se puedan extrapolar los datos obtenidos en animales a la eficacia en humanos. Pero por otro lado, los ensayos in vitro frecuentemente presentan desventajas aún más críticas, que surgen del hecho fundamental de que se quiere obtener una droga efectiva, y no sólo un compuesto que se una perfectamente $a$ su receptor. De nada sirve lograr una estructura con una alta afinidad por un dado sitio activo, pero que no pueda sintetizarse o que no sea capaz de llegar a su receptor cuando se administra al ser vivo. El objetivo buscado en el diseño de una droga es que ésta logre sobrevivir el tiempo suficiente como para mostrar el efecto

- binding: reconocimiento

* ADME: Administración, Distribución, Metabolismo y Excreción 
deseado, y que luego se excrete sin haber generado metabolitos tóxicos, una vez logrado este efecto. Otra complicación surge del hecho de que a menudo una determinada enfermedad involucra la participación de varios receptores simultáneamente, y consecuentemente una acción positiva in vitro frente a un receptor específico no necesariamente indica que la droga será eficaz. Por todas estas razones es que muchas de las drogas que mostraron una potencia elevada al ensayarse in vitro, resultaron ser totalmente inactivas in vivo ${ }^{1}$.

\section{Optimización de la estructura líder}

Una vez que una nueva estructura ha sido identificada, se procede a su modificación con el objeto de mejorar sus propiedades farmacológicas.

Pueden postularse varias formas de optimización de una estructura. Las conocidas como metodologías clásicas son procedimientos que consisten en introducir variaciones de sustituyentes, contracciones o expansiones de anillos 0 cadenas, fusiones de anillos, cambios bioisostéricos, simplificación o rigidización de la estructura. Es muy importante que estos cambios no se hagan a ciegas, sino que durante el planteo de las variaciones estructurales se tenga en cuenta la estructura tridimensional de los nuevos compuestos y la distribución espacial de los grupos. Tampoco debe descuidarse la flexibilidad conformacional de los ligandos. Mientras que muchas drogas son compuestos rígidos, muchos neurotransmisores y hormonas peptídicas son muy flexibles, pudiendo adoptar diversas conformaciones y unirse a diferentes receptores y subtipos de receptores. En el primer caso son útiles las estrategias vinculadas por ejemplo a la

Figura 1.2

Estructura de la droga antiepiléptica gabapentin remoción de anillos o disección de la<smiles>NCC1(CC(=O)O)CCCCC1</smiles>

gabapentin molécula como las empleadas para el estudio de la estructura policíclica de la morfina. En el caso de las moléculas flexibles se procede a su rigidización, ejemplo de esto es la inserción de la estructura del GABA (ácido $\gamma$ aminobutírico) en un sistema cíclico ${ }^{26,27,28,29}$ (Figura 1.2).

Al momento de optimizar la estructura del líder deben tenerse en cuenta características fisicoquímicas más allá de las puramente estructurales. Las drogas deben presentar un equilibrio entre sus propiedades hidrofilicas e hidrofóbicas. Las drogas demasiado polares se excretan muy fácilmente por el riñón y no atraviesan fácilmente las barreras lipídicas de las membranas celulares. Por otro lado, las drogas muy lipofilicas 
son poco solubles en agua $\mathrm{y}$ por lo tanto pobremente absorbidas en el tracto gastrointestinal, en donde tienden a coagular en glóbulos lipídicos que no pueden interaccionar con la pared intestinal. Aún cuando pueden llegar al torrente sanguíneo, frecuentemente son removidas y almacenadas en tejidos grasos del cuerpo. Por lo tanto, la hidrofobicidad óptima frecuentemente debe ser una solución de compromiso entre ambos efectos ${ }^{30}$.

En relación al transporte, cobra importancia el desarrollo de prodrogas, con el objeto de evitar algunas de las propiedades no deseadas de las drogas, constituyendo otra forma de optimización. El hecho de desarrollar formas de transporte que favorecen la distribución de la droga en el sitio específico de acción, favorece su localización con la consiguiente disminución de las dosis necesarias para manifestar un mismo efecto, y por lo tanto también de los efectos colaterales.

\section{El impacto de la tecnologla genética en el descubrimiento de drogas}

La tecnología genética agregó nuevos modelos a la investigación en el descubrimiento de drogas, cubriendo distintos aspectos ${ }^{2}$.

Los métodos de ingeniería genética fueron inicialmente usados para la producción de proteínas humanas en forma pura y en cantidades suficientes para su uso terapéutico. El primer ejemplo lo constituyó la insulina humana obtenida de E. Coli en 1982.

La terapia génica ${ }^{31,32}$ en humanos, un objetivo muy atractivo desde el punto de vista teórico, pero también controversial, es una técnica terapéutica en la cual se introduce un gen funcional dentro de células somáticas de un paciente para corregir un gen defectuoso o para introducir una función biológica ausente. La farmacogenomia se refiere a fármacos diseñados de acuerdo al gen del paciente. Consiste en el uso de la información genética para predecir la eficacia, seguridad, y la toxicidad de una droga en un paciente individual o un grupo de pacientes.

Los animales transgénicos ${ }^{33,34}$ constituyen una refinada herramienta para probar el potencial terapéutico de determinados targets $^{*}$ biológicos y para elucidar su rol en ciertos estados fisiopatológicos de una enfermedad. Se han obtenido, por ejemplo, animales que padecen Alzheimer ${ }^{35}$, lo

+ se denomina "target" o "blanco" biológico a la proteína, ya sea enzima, receptor o canal iónico sobre la que se está trabajando 
cual significa una importante contribución al desarrollo de terapias específicas contra esta enfermedad.

Una vez que un target biológico y su relevancia para la terapia humana han sido identificados, la producción de esta proteína para sistemas de screening o para la elucidación de su estructura, es probablemente el aporte más importante de la tecnología genética al descubrimiento de drogas. En rasgos generales, la metodología consiste en el aislamiento inicial del gen que codifica para determinada proteína humana, enzima $o$ receptor, y la determinación de su secuencia. Luego, se construye un vector apropiado para transferir la información genética a células vivas, con el objeto de producir cantidades de proteína suficientes. Mientras que la producción puede resultar relativamente simple y directa para algunas enzimas, ésta se torna complicada en el caso de receptores y otras proteínas complejas. Un correcto folding y glicosilación son los criterios fundamentales para la elección del sistema de expresión. Especialmente el sistema baculovirus / células de insecto proporciona un alto nivel de expresión, inclusive de multisubunidades proteicas activas, mediante la co-expresión de diferentes genes en la misma célula. Una vez construido el vector apropiado y establecido el sistema de expresión adecuado que garanticen una proteina funcional activa, el resto es relativamente rutinario. Generalmente la producción, el aislamiento y la purificación proporciona suficiente cantidad de la proteína para el ensayo biológico y para experimentos de cristalización. Si la cristalización es exitosa, las técnicas de rayos $\mathrm{X}$ permiten la determinación de la estructura tridimensional de la proteína y aún de los complejos con sus ligandos. Las proteínas pequeñas pueden incluso investigarse en solución, mediante técnicas NMR multidimensionales ${ }^{2}$.

\section{\& EL USO DE LA QUÍMICA COMPUTACIONAL EN EL DESCUBRIMIENTO DE DROGAS}

Las computadoras son una herramienta esencial que ha contribuido de manera significativa al desarrollo logrado en muchas áreas del conocimiento científico, pero particularmente han ayudado en la química medicinal moderna y se destaca especialmente la importante contribución realizada en el descubrimiento y el desarrollo de nuevas drogas. Gran parte de los resultados asociados al Diseño Racional pudieron lograrse gracias a la química computacional. Las operaciones llevadas a cabo en el modelado molecular involucran el uso de programas y algoritmos que calculan datos relacionados a la estructura y 
propiedades de las moléculas. Los métodos computacionales que realizan estos cálculos pueden dividirse en dos grandes categorias: métodos de Mecánica Molecular (MM) y métodos Químico Cuánticos (QC).

\section{Métodos de Mecánica Molecular}

Estos métodos emplean ecuaciones que siguen las leyes de la física clásica y se aplican a los núcleos sin consideración de los electrones. En esencia, la molécula es tratada como una serie de esferas (los átomos) conectadas por resortes (los enlaces). Las ecuaciones, derivadas de la mecánica clásica, interpretan las diferentes interacciones y energías como resultantes del alargamiento de enlaces, flexión de ángulos de enlace, energías torsionales, e interacciones lejanas. Estos cálculos requieren el uso de parámetros almacenados dentro de los programas y que describen las interacciones entre distintos tipos de átomos.

Los métodos de $\mathrm{MM}$ son rápidos y no insumen demasiado tiempo computacional en relación a los métodos QC. Claramente, presentan las desventajas de que no pueden usarse para calcular propiedades electrónicas ya que los electrones no se tienen en cuenta en los algoritmos.

\section{Métodos Químico Cuánticos}

Estos métodos se basan en las leyes de la física cuántica $^{36}$ para el cálculo de las propiedades de las moléculas. En la teoría químico cuántica, se buscan soluciones a la ecuación de Schoedinger:

$$
\mathrm{H} \psi=\mathrm{E} \psi
$$

Esta es una ecuación a autovalores, en donde $\mathrm{H}$ es un operador tal que aplicado a una función devuelve la misma función multiplicada por una constante. La función (función de onda) se llama autofunción y la constante (energía del sistema) autovalor. Mediante la resolución de la ecuación de Schoedinger se obtiene no sólo la energía del sistema, sino también una descripción de su estructura electrónica.

Para resolver la ecuación de Schoedinger deben hacerse varias aproximaciones, que condicionan la calidad de los resultados obtenidos. Lo primero que se hace es separar las variables en la función de onda total, factorizando en una función espacial y otra temporal: 


$$
\psi(r, t)=\psi(r) \psi(t)
$$

Como en diseño de fármacos no interesa trabajar con problemas dependientes del tiempo, se resuelve sólo la función espacial:

$$
\mathrm{H} \psi(\mathrm{r})=\mathrm{E} \psi(\mathrm{r})
$$

El operador $\mathrm{H}$ tiene términos de energía cinética $(\mathrm{T})$ y potencial (V), en los núcleos y en los electrones:

$$
\begin{aligned}
H=T+V & =T^{\text {elect }}(r)+T^{n}(R)+V^{n-t}(R, r)+V^{\text {elect }}(r)+V^{n}(R)=\hat{H}^{\text {elect }}+\hat{H}^{n} \\
r & =\text { coordenadas del electrón } \quad R=\text { coordenadas del núcleo }
\end{aligned}
$$

En la aproximación de Born-Oppenheimer los núcleos se consideran fijos, debido a que el movimiento de los electrones es mucho más rápido en comparación. Dejando los núcleos fijos, el $\mathrm{H}$ que nos interesa es:

$$
\frac{\frac{T^{\text {elect }}(r)+V^{n-e}(R, r)+V^{\text {elect }}(r)}{H^{\text {elect }}}+V^{n}(R)}{H^{\text {BO }}}
$$

Como $\mathrm{V}^{\mathrm{n}}(\mathrm{R})$ no depende de las coordenadas del electrón, no actúa explícitamente sobre la función de onda electrónica y el valor se suma como una constante adicional luego del cálculo. Trabajando con el $\mathrm{H}$ electrónico:

$\mathrm{H}^{\text {elect }} \psi^{\text {elect }}(\mathrm{r}, \mathrm{R})=\mathrm{E}^{\text {elect }}(\mathrm{R}) \psi^{\text {elect }}(\mathrm{r}, \mathrm{R})$

$E^{\text {elect }}$ depende paramétricamente de $R$.

$$
\left[T^{n}(R)+V^{n}(R)+E^{\text {elect }}(R)\right] \psi(r, R)=E \psi(r, R)
$$

En la aproximación de núcleos fijos se trabaja entonces con la función de onda electrónica. Pero hay que introducir más aproximaciones para resolver la ecuación de Schoedinger ${ }^{37}$. En la aproximación de Hartree se representa la función de onda molecular como producto de funciones de onda monoelectrónicas, asociando un orbital molecular a cada electrón:

$$
\psi(r)=\varphi_{1}\left(r_{1}\right) \varphi_{2}\left(r_{2}\right) \ldots \varphi_{n}\left(r_{n}\right)
$$

En la aproximación de Fock se exigen condiciones matemáticas a la función (normalización y antisimetrización), 
resultando una función determinantal de Slater ("Slater Type Orbitals", STO):

$$
\psi(\mathrm{r})=(N !)^{-1 / 2}\left|\begin{array}{cccc}
\varphi_{1}(1) & \varphi_{2}(1) & \ldots . & \varphi_{\mathrm{n}}(1) \\
\ldots . & \\
\varphi_{1}(\mathrm{~N}) & \varphi_{2}(\mathrm{~N}) & \ldots . & \varphi_{\mathrm{n}}(\mathrm{N})
\end{array}\right|
$$

Esta función describe la posibilidad de intercambiar electrones entre orbitales. Representa $\mathrm{N}$ electrones ocupando $\mathrm{N}$ orbitales sin especificar cuál en cuál, es decir electrones indistinguibles.

En la aproximación de Rootham se describe la función molecular sobre una base de orbitales atómicos. Expresa los orbitales moleculares como combinación lineal de orbitales atómicos (CLOA) de los átomos que componen la molécula:

$$
\varphi_{\mathrm{i}}=\Sigma_{\mu=1, \mathrm{~N}} \mathrm{C}_{\mu \mathrm{i}} \chi_{\mu}
$$

donde $\chi_{\mu}$ son los $\mathrm{OA}$ o funciones bases, y $\mathrm{C}_{\mu \mathrm{i}}$ es el coeficiente de la función base $\mu$ en el $\mathrm{OM}$ i. El número de OM obtenidos es igual al de OA de partida. La calidad de la función de onda resultante dependerá, entre otros factores, de la calidad y cantidad de bases.

Bajo estas aproximaciones, el método de Hartree Fock Rootham realiza un cálculo variacional. De esta manera, calcular una función de onda consiste en determinar el conjunto de coeficientes $C_{\mu \mathrm{i}}$ que hace mínima la energía de la molécula. Dado que cada electrón se halla bajo el campo eléctrico del resto, cada orbital monoelectrónico $\varphi_{\mathrm{i}}$ dependerá de los demás y la búsqueda del mejor conjunto de coeficientes deberá ser iterativa. Dicha aproximación recibe el nombre de campo autoconsistente ("Self Consistent Field", SCF) de Hartree-Fock (HF).

Los métodos QC se dividen en dos grandes categorías: métodos Ab-initio y métodos Semiempiricos.

\section{Métodos ab-initio.}

Si las aproximaciones anteriores son las únicas que se introducen, se trata de un cálculo ab-initio, cuya calidad dependerá básicamente de la dimensión de la base utilizada para representar cada uno de los átomos de la molécula. Los orbitales STO proporcionan una buena descripción de la densidad electrónica en el entorno de un átomo. Sin embargo, el cálculo de funciones exponenciales es complejo, y por eso se aproximan éstas mediante el uso de varios GTO ("Gaussian Type Orbitals", GTO, o funciones de Gauss) ${ }^{37}$. 
Las bases más simples son las STO-3G, en donde se emplean 3 gaussianas para la aproximación. Las bases 3-21G contienen 3 gaussianas para describir los orbitales internos, 2 gaussianas para describir los orbitales de valencia, y otra gaussiana también para éstos últimos. En un nivel superior de complejidad se agregan a las bases funciones de polarización, que logran modelar la direccionalidad de los orbitales al participar en enlaces. Las bases 6-31G(d) (o 6-31G*) incluye 6 gaussianas para la descripción interna, 3 y 1 gaussianas para las capas de valencia internas $y$ externas respectivamente, y un conjunto de 6 funciones d. Las bases 6$31 \mathrm{G}(\mathrm{d}, \mathrm{p})\left(\mathrm{o} 6-31 \mathrm{G}^{* *}\right)$ poseen, además de los orbitales $\mathrm{d}$ en los átomos no hidrogenoides, un conjunto de funciones $\mathrm{p}$ en cada hidrógeno ${ }^{37}$. Las bases con funciones difusas son importantes en los sistemas donde la densidad electrónica está relativamente alejada del núcleo. Por ejemplo, en los oxígenos negativamente cargados. En tales casos, se adiciona un conjunto de funciones difusas a cada átomo pesado (no al hidrógeno), lo cual se indica con el signo + (por ejemplo 6$31+\mathrm{G}(\mathrm{d}, \mathrm{p})$.

\section{Métodos semiempíricos.}

Además de considerar únicamente los electrones de la capa de valencia, los métodos semiempíricos incorporan aproximaciones en la ecuación a autovalores y emplean parámetros para simplificar el cálculo. Las aproximaciones se centran fundamentalmente en los términos bielectronicos y en el tratamiento del solapamiento orbital.

En este contexto, la reducción más drástica generó el método CNDO (Complet Neglect of Differential Overlap). Este método desprecia todos los términos bielectrónicos, aún entre electrones del mismo átomo. Una mejora a este método la marcó el surgimiento de INDO (Intermediate Neglect of Differential Overlap), donde el solapamiento orbital se suprime solo parcialmente, reteniendo las integrales entre orbitales distintos en el mismo átomo, las cuales se ajustan paramétricamente. Los métodos MINDO/3 (Modified Intermediate Neglect of Differential Overlap) y MNDO (Modified Neglect of Differential Overlap) consideran las integrales bielectrónicas bicéntricas y se diferencian en la forma de calcularlas. Los métodos AM1 y PM3 son básicamente $\mathrm{MNDO}$, pero corrigen la excesiva repulsión a distancias de Van der Waals. Surgen ante la imposibilidad del MNDO de reproducir enlaces de hidrógeno, punto clave para el tratamiento de sistemas biológicos. El nombre PM3 deriva de la $3^{\circ}$ parametrización del MNDO, siendo AM1 la segunda parametrización. Estos métodos surgen como una nueva filosofia, que acompaña el desarrollo del hardware 
computacional. Aprovechan la posibilidad de introducir más parámetros por átomo, resultando competitivos con los métodos a primeros principios para el cálculo de geometrías y calores de formación.

Se han desarrollado muchas otras parametrizaciones, existiendo actualmente gran diversidad de métodos semiempíricos, que prometen el calculo mecano-cuántico de sistemas extensos, como proteínas, en aproximaciones mixtas QC/MM. La tendencia actual trata de reemplazar las metodologías QC/MM por métodos totalmente químico cuánticos $(\mathrm{QM} / \mathrm{QM})$, simulando la macromolécula mediante el uso de técnicas ab-initio en la porción de mayor interés y de metodología semiempírica para el entorno ${ }^{38}$.

Así, los distintos métodos están parametrizados para distintos objetivos, y la elección del método adecuado depende fundamentalmente de la propiedad que se quiere estudiar. Además, no es extraño que los resultados obtenidos mediante el empleo de un método semiempírico apropiado, sean más acertados que los provenientes de metodología abinitio, cuando, en el último caso, las bases no son suficientemente buenas.

\section{Tratamientos post Hartree-Fock.}

En la realidad, los electrones se repelen unos a otros más de lo que puede ser descrito por la función de onda de HF. La diferencia entre la energía ab-initio de una función de onda HF y la energía real del sistema se denomina energía de correlación. Una función de onda que da cuenta de la correlación electrónica provee una energía total menor (y más exacta) ${ }^{37}$. Frecuentemente se emplean dos métodos que tienen en cuenta la correlación electrónica, uno de naturaleza perturbativa y otro de base variacional.

$\checkmark$ La primera aproximación es la teoría perturbativa de Moller-Plesset (MP). Se corrige la función de onda HF por un término perturbativo que da cuenta de la probable ocupación de orbitales de mayor energía. Se emplean correcciones de segundo, tercer y cuarto orden, denominadas MP2, MP3 y MP4, respectivamente. Un tratamiento MP2 puede duplicar los requerimientos de tiempo computacional, mientras que los MP3 y MP4 son aún más costosos ${ }^{37}$.

$\checkmark$ La segunda aproximación es la interacción de configuraciones (CI). En este caso, la función de onda se forma como una combinación lineal de determinantes de Slater, cada uno correspondiendo a una posible configuración 
electrónica. Las configuraciones se construyen promoviendo electrones desde OM ocupados a OM virtuales. La aproximación CI es de gran importancia en el estudio de sistemas en los cuales se forman o rompen enlaces. La CI es mucho más costosa en tiempo computacional que el método $\mathrm{MP}^{37}$.

Métodos basados en la teoría de funcionales de la densidad.

En los últimos años, los métodos basados en la Teoría de Funcionales de la Densidad (DFT) han ganado gran popularidad, debido a que los mejores métodos DFT logran mayor exactitud que los métodos $\mathrm{HF}$, a igualdad de costo computacional. Esta ventaja de los métodos DFT se debe a que involucran algunos de los efectos de la correlación electrónica en forma más simple que los tradicionales métodos correlacionados de $\mathrm{HF}^{39}$.

Estos métodos emplean para el cálculo funciones de la densidad electrónica. Estos funcionales particionan la energía electrónica en varios componentes que se calculan separadamente: la energía cinética, la interacción núcleoelectrones, la repulsión coulómbica, y un término de intercambio-correlación que da cuenta de las interacciones electrón-electrón. Este último término se descompone, en los algoritmos actuales, en dos componentes separados de intercambio y correlación ${ }^{39}$.

Se ha definido una gran variedad de funcionales, que generalmente se distinguen por la forma en que tratan los componentes de intercambio y correlación ${ }^{39}$.

$\checkmark$ Los funcionales locales de intercambio y correlación involucran sólo los valores de las densidades electrónicas de spin. Los más conocidos son los funcionales de intercambio Slater y $\mathrm{X} \alpha$, y el funcional de correlación postulado por Vosko, Wilk y Nusair (VWN).

$\checkmark$ Los funcionales corregidos por gradiente involucran tanto los valores de la densidad electrónica de spin como sus gradientes, y a veces se conocen como funcionales no locales. El funcional de intercambio más conocido es el propuesto por Becke en 1988, mientras que el de correlación más usado es el funcional de Lee, Yang y Parr (LYP). De la combinación de ambos nace el método B-LYP. También Perdew ha propuesto importantes funcionales de este tipo, conocidos como Perdew 86 y Perdew-Wang 91. 
Existen también funcionales hibridos, los cuales definen el funcional de intercambio como una combinación lineal de términos de intercambio de $\mathrm{HF}$, locales y corregidos por gradiente. Este funcional de intercambio se combina luego con un funcional de correlación local y/o corregido por gradiente. La formulación triparamétrica de Becke (B3LYP) es el más conocido de estos funcionales hibridos. Los funcionales de este tipo han demostrado ser superiores a los anteriores.

En base a todo lo expuesto sobre los distintos métodos de cálculo en química computacional, hay que resaltar que en el momento de la elección de un método adecuado se debe tener en cuenta el tamaño del sistema, las capacidades computacionales con que se cuenta y el tipo de estudio que se quiere realizar. Fundamentalmente, no hay que perder de vista el hecho de que siempre se intenta lograr un modelo realista y computacionalmente factible del sistema a estudiar.

\section{Análisis conformacional}

El estudio del espacio conformacional asociado a una estructura es frecuentemente un procedimiento necesario al comenzar el análisis teórico de una molécula. Este estudio implica analizar las características de la hipersuperficie de energía potencial. Esta superficie de energía potencial es una relación matemática entre la estructura molecular y la energía resultante. Para una molécula diatómica, es un gráfico $2 \mathrm{D}$ con la separación internuclear en el eje $X$, y la energía a cada distancia de enlace en el eje $\mathrm{Y}$, generando una curva. Para sistemas más complejos, la hipersuperficie tiene tantas dimensiones como grados de libertad presente la molécula ${ }^{40}$.

Usualmente la superficie de energía potencial se representa mediante la consideración de sólo dos grados de libertad de la molécula, y se grafica la energía sobre el plano definido por éstos. Los mínimos de esta hipersuperficie corresponden a estructuras de equilibrio del sistema, y pueden ser mínimos locales o globales ${ }^{40}$.

Los programas de química computacional proceden realizando cálculos de minimización de la energía del sistema, lo que determina la optimización de la geometría de la molécula. Se calcula la energía de una conformación inicial, luego se varían los parámetros estructurales, trabajando fundamentalmente sobre los ángulos de torsión, creando así una nueva conformación. La energía de esta 
nueva geometría se calcula para conocer si es energéticamente más estable que la anterior. El programa continúa realizando cambios conformacionales y conduciéndose en el sentido de aquéllos que acarrean una estabilización, mediante algoritmos adecuados. Finalmente se encontrará una estructura para la cual todas las variaciones que se le plantean resultan en extremadamente pequeños cambios energéticos y a la vez menos estables. Este será un mínimo energético, y en este punto el programa considerará que se ha llegado a la estructura más estable y detendrá el cálculo en este punto. La optimización es completa cuando ha llegado a convergencia, esencialmente, cuando el gradiente es cero. Pero pueden haber varios criterios de convergencia ${ }^{40}$ :

$\checkmark$ Gradiente o fuerza $=0$

$\checkmark$ La raíz cuadrada media (RMS) de la fuerza $=0$

$\checkmark$ El desplazamiento calculado para el siguiente paso $=0$

$\checkmark \quad$ La raíz cuadrada media del desplazamiento $($ RMSD) $=0$

En realidad, no se requiere estrictamente llegar al valor cero, sino que se consideran valores menores a cierta cota para decretar la convergencia.

La conformación obtenida luego de la minimización de la energía de una dada estructura no necesariamente es la conformación más estable. Esto es porque el proceso de optimización geométrica se detiene apenas alcanza la primer conformación estable, que será aquel mínimo más parecido en su geometría al punto de partida (Figura 1.3) y puede tratarse de un mínimo relativo. Pero si existe otro mínimo de menor energia (un mínimo global), el programa no será capaz de encontrarlo a no ser que parta de una conformación cercana a éste.

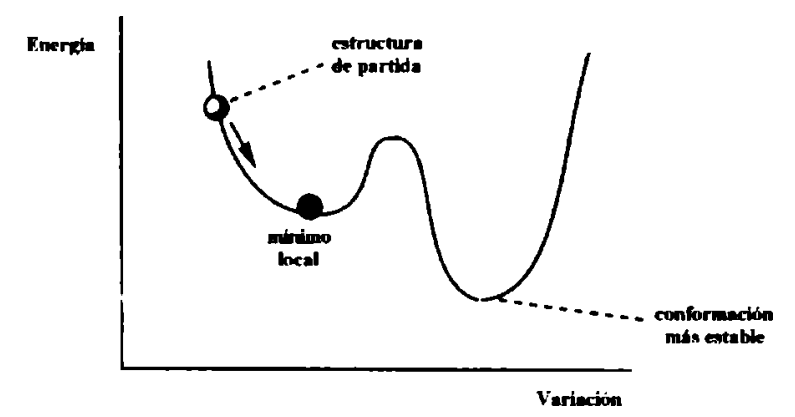

Figura 1.3

Curva de energia potencial

Consecuentemente, para identificar la conformación más estable, es necesario generar diferentes conformaciones de la molécula y comparar sus energías. Existen distintas metodologías para realizar este análisis conformacional, siendo las más empleadas aquellas que hacen uso de una 
dinámica molecular y la técnica de rotación sistemática de enlaces.

\section{Dinámica Molecular.}

Mediante esta técnica se simula un calentamiento del sistema a temperaturas superiores al cero absoluto, lo cual se mantiene durante un tiempo adecuado, del orden de picosegundos. La molécula sufre estiramientos y rotaciones a lo largo del proceso y de esta forma las barreras energéticas entre diferentes conformaciones pueden superarse. Este procedimiento se repite tantas veces como para obtener suficientes conformaciones, que posteriormente se optimizan. Esta metodología de estudio del espacio conformacional es particularmente útil para aquellas moléculas que no pueden analizarse mediante la rotación sistemática, como por ejemplo los sistemas cíclicos, o las estructuras muy extensas con demasiados enlaces rotables.

\section{Rotación sistemática alrededor de enlaces.}

En esta técnica se generan diferentes conformaciones mediante la rotación sistemática alrededor de cada enlace simple en un cierto número de grados. Usualmente no se tienen en cuenta las uniones a átomos de hidrógeno $o$ a grupos metilo debido a que la rotación alrededor de estos enlaces no genera conformaciones significativamente diferentes. Mediante esta técnica, se asegura que podrán identificarse todas las posibles conformaciones de una estructura, de lo cual no existe garantía cuando se utiliza una dinámica molecular.

\section{DISEÑO RACIONAL DE NUEVAS DROGAS}

El Diseño Racional de fármacos se basa en el conocimiento a nivel molecular de los sucesos bioquímicos que median el proceso patológico. Estos eventos involucran macromoléculas biológicas (generalmente estructuras proteicas como receptores o enzimas), y sustancias que interaccionan con sitios específicos de éstas (sitios activos), provocando una respuesta. Sobre esta base, se elige un target u objetivo biológico a través del cual pueda atacarse a la enfermedad.

Una vez seleccionado el target a estudiar, es conveniente, aunque no imprescindible, caracterizar este sitio a nivel atómico. Esta información se puede obtener directamente por caracterización del sitio receptor, o 
indirectamente por inferencias basadas en el conocimiento de las estructuras de ligandos conocidos ${ }^{41}$. Estas dos distintas formas de encarar el problema de la caracterización del sitio activo, es lo que diferencia a las dos metodologías más importantes del Diseño Racional de fármacos (Figura 1.4):

$\checkmark$ las técnicas directas: son aquéllas que parten del conocimiento del receptor, en base al análisis estructural (rayos X, NMR, Modelado, etc.) de la proteína, de porciones proteicas $\mathrm{o}$ inclusive del receptor con el ligando unido al sitio activo; $y$

$\checkmark$ las técnicas indirectas: son aquéllas que, sin conocer al receptor, consideran a los ligandos que se unen al sitio de interés y determinan sus características comunes. Dado un número suficiente de ligandos, se puede incluso construir un modelo del sitio activo en ausencia de evidencia cristalográfica o de NMR del receptor.

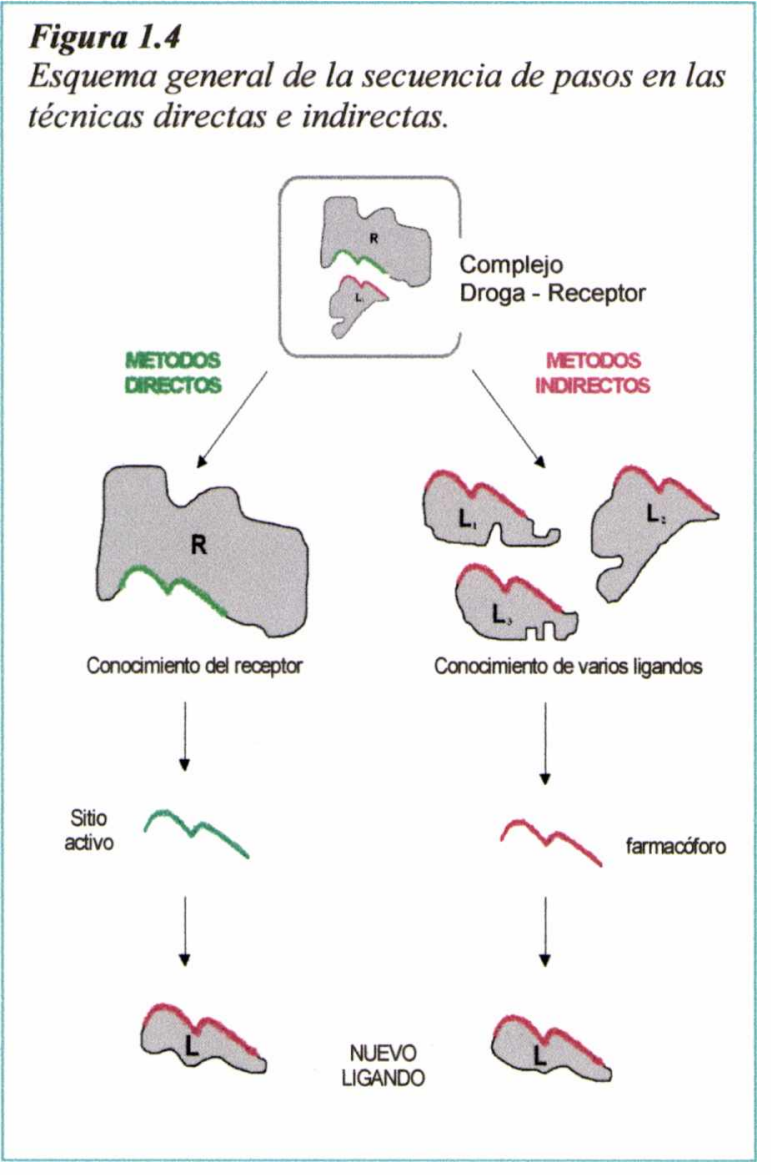

\section{Métodos directos}

La situación más afortunada, aunque no la más común, se presenta cuando la totalidad de la estructura tridimensional del receptor se conoce y se ha determinado la localización del sitio activo, por ejemplo mediante la cocristalización del ligando unido a la macromolécula ${ }^{41}$. Cuando se dan estas condiciones, pueden aplicarse las técnicas descriptas de producción, aislamiento y análisis de estructura proteica (página 15). En el banco de datos Protein Data Bank (PDB) ${ }^{\star}$ se encuentran depositadas las coordenadas 3D de más de 20000 proteínas, complejos ligando-proteína, ácidos nuclei$\cos \mathrm{y}$ otras macromoléculas biológicas.

\footnotetext{
+ sitio web: http://www.rcsb.org/pdb/
} 
En cambio, cuando no se cuenta con datos de rayos $\mathrm{X}$ del receptor ni del sitio activo, generalmente porque la proteína no es fácilmente cristalizable como ocurre con las proteínas de membrana, debe construirse un modelo del receptor. Si se conoce la secuencia aminoacídica de la proteína y la estructura terciaria de una proteína relacionada, puede construirse un modelo del receptor en estudio mediante la técnica de Homology Modeling ${ }^{\star, 42}$. Esta técnica consiste, básicamente, en comparar la secuencia de la proteína en cuestión con las secuencias de otras proteínas con el fin de encontrar alguna que esté estrechamente relacionada. Luego se construye el esqueleto peptídico de la proteína en estudio de manera que concuerde con el de la proteína modelo, y a continuación se agregan las cadenas laterales en conformaciones

energéticamente favorables. Posteriormente se realiza una minimización de la energía y la estructura se refina mediante dinámica molecular, con la finalidad de relajar las tensiones generadas en los puntos de unión. Una vez construido el modelo, se puede evaluar experimentalmente. Por ejemplo, el modelo podría indicar que ciertos aminoácidos

La proteina bacteriorodopsina es uno de los modelos más usados en la técnica de Homology Modeling.

La bacteriorodopsina, la cual ha sido cristalizada y se ha determinado su estructura, constituye un ejemplo de un receptor acoplado a proteína $\mathrm{G}$ con 7 hélices transmembrana. Muchos de los receptores importantes en química medicinal pertenecen a esta familia de proteínas y por lo tanto la estructura de la bacteriorodopsina es de vital importancia en la construcción de modelos de estos receptores de membrana mediante la técnica de Homology Modeling. Mediante la identificación de la secuencia aminoacídica de una proteina dada, y prestando especial importancia a los am inoácidos hidrofóbicos, pueden identificarse los 7 dominios transmembrana y luego usar la bacteriorodopsina como modelo para la construcción de las hélices. Por último se construyen las porciones que conectan para lograr la estructura 3D completa ${ }^{42}$.

son importantes en el sitio activo. Estos pueden mutarse y ver si aparece algún cambio en la capacidad de unión de los ligandos.

Una vez determinada o construida la estructura $3 \mathrm{D}$ del receptor, la atención se centra en el sitio activo. Existen programas que realizan búsquedas en bases de datos para encontrar ligandos que encastren en la cavidad del sitio activo por complementariedad geométrica $\left(\mathrm{DOCK}^{43,44,45}\right)$. El procedimiento de docking consiste en enfrentar los grupos involucrados en la interacción entre la droga y el sitio activo, definiendo así distancias de unión óptimas, y optimizando por último el ligando en el entorno del receptor ${ }^{42}$.

Otros programas comienzan a generar la estructura de un ligando a partir de un segmento inicial capaz de interaccionar con el sitio activo, y van agregando luego

\footnotetext{
- homology modeling: modelado por homología
} 
distintos fragmentos a éste hasta obtener el ligando completo dentro del sitio activo $\left(\mathrm{GROW}^{46,47}\right)$. Un avance significativo sobre estos programas lo constituyeron los programas de diseño "de novo" (LUDI ${ }^{48,49,50,51}$ ), los cuales buscan ligandos totalmente novedosos capaces de interaccionar con el sitio activo.

\section{Métodos indirectos}

En muchas oportunidades se carece totalmente de conocimiento alguno sobre el sitio activo en el receptor, y sólo se cuenta con la información asociada a varias drogas capaces de producir la misma respuesta biológica ${ }^{41}$.

En este caso, la primera etapa será reunir entre éstas, las estructuras que se supone actúan en el mismo sitio de interés, en base a datos farmacológicos. La información de compuestos que son incapaces de actuar en este sitio también puede resultar útil. Para la generación de las estructuras 3D de las moléculas pueden utilizarse métodos computacionales, o bien recurrir a la base de datos de estructuras cristalinas Cambridge Database ${ }^{52}$ en la que se encuentran almacenadas más de 140000 entradas, siendo la mayor parte compuestos orgánicos y productos naturales. Esta base de datos constituye un recurso único de estructuras 3D de compuestos cuyas estructuras cristalinas han sido dilucidadas ${ }^{2}$. Para el paso siguiente de predicción de las múltiples conformaciones de una estructura pueden emplearse las distintas metodologías descriptas de análisis conformacional.

Examinando las estructuras 3D de los compuestos activos, se determina qué características son comunes a todos. Teniendo en cuenta también las características de los compuestos inactivos, es posible deducir los factores que son necesarios para conferir actividad. También puede postularse cuáles grupos la reducen o eliminan ${ }^{41}$, tales como grupos funcionales o volúmenes extra que impiden la unión al sitio activo.

Para este análisis se emplean metodologías de superposición gráfica $\mathrm{o}$ analítica, determinándose así un patrón farmacóforico. Un patrón farmacofórico o farmacóforo está definido por el conjunto de grupos funcionales o porciones de la molécula que son necesarios para la actividad, y su posición relativa en el espacio. No es común que los puntos farmacofóricos coincidan perfectamente en la superposición, por lo tanto el farmacóforo generalmente queda definido por regiones en el espacio asociadas a cada grupo importante ${ }^{42}$. 
Es necesario resaltar que al hablar de similitud y diversidad entre las moléculas, es crítico considerar las estructuras $3 \mathrm{D}$ en términos de propiedades moleculares en el espacio, y no sólo de átomos o grupos funcionales ${ }^{2}$. Aún pequeñas diferencias aparentes, como el mismo átomo de $\mathrm{N}$ en dos análogos, pero en uno actuando como donor y en el otro como aceptor, puede representar una gran diferencia entre la acción vinculada a ambos.

Estas metodologías se tornan complejas debido al hecho de que las moléculas con acción farmacológica muchas veces son muy flexibles. Los compuestos con varios ángulos de torsión, asociados a grados de libertad, son altamente flexibles y pueden presentar varias conformaciones que son energéticamente favorables. La posibilidad de que se logren estas conformaciones depende en general de las características del entorno que rodea la molécula. A pesar de que se puede adquirir una gran cantidad de información, ya sea experimental o por cálculo, es imposible predecir si una estructura experimental 3D en fase gaseosa, en solución, en la estructura cristalina, en una cierta matriz, o una conformación teórica de mínima energía, será idéntica a la estructura tridimensional bioactiva. Se entiende como conformación bioactiva a aquélla que adopta la molécula en el sitio de unión ${ }^{2,41}$. Obviamente, la conformación bioactiva no será una conformación de alta energía, originada en una distorsión estructural desfavorable de la molécula. Pero para las moléculas flexibles con muchos ángulos de torsión, pueden existir muchas geometrías distintas isoenergéticas y estables. Por estas razones, se incluyen compuestos conformacionalmente rígidos o análogos rígidos en los conjuntos de estructuras a superponer. Esto redunda en una mayor precisión en la construcción del modelo del farmacóforo.

Los análogos rigidos son estructuras activas que presentan sólo una conformación posible. Así, las moléculas más flexibles pueden compararse con la rígida para encontrar aquélla conformación que sitúa los puntos farmacofóricos en la misma posición relativa. Si no se cuenta con una estructura totalmente rígida para usar como molde, pueden procurarse diferentes moléculas con cierto grado de rigidez en su esqueleto, de manera que su superposición brinde una estructura rígida. En el caso de que no se cuente con ninguna molécula rígida o semirígida, pueden considerarse todas las conformaciones energéticamente razonables de todos los compuestos activos y luego determinar el volumen o espacios comunes dentro de los cuales se encuentran los puntos farmacofóricos ${ }^{42}$. A veces es factible el diseño y sintesis de un nuevo análogo rígido que, además de ser útil en la 
La rigidificación molecular puede conducir a la creacion de una droga altamente selectiva. Las moleculas flexibles pueden adoptar un gran número de conformaciones posibles. Así, una determinada conformación pueden interactuar con un dado receptor mientras que otra conformación actúa en otro sitio, desencadenando una misma molécula dos respuestas biológicas diferentes. Los neurotransmisores son moléculas altamente flexibles, pero afortunadamente el cuerpo actúa eficientemente al liberarlos cerca de sus receptores e inactivándolos inmediatamente de manera de que no actúen en otros receptores. Sin embargo, ésto no ocurre con las drogas, que interaccionarán con todos los receptores que las acepten a lo largo de su distribución en todo el cuerpo. Cuanto más flexible es una droga, más probable es que interactúe con más de un receptor y produzca más de una respuesta biológica que seguramente será un efecto no deseado ${ }^{42}$. dilucidación de la conformación activa, puede resultar en una droga muy eficaz por su alta selectividad.

Una vez que el

farmacóforo ha sido identificado, se pueden diseñar nuevas estructuras teniendo en cuenta este conocimiento. Pueden analizarse nuevos compuestos con el fin de examinar si son capaces de adoptar una conformación estable que contenga este farmacóforo y por lo tanto ser potenciales compuestos activos ${ }^{42}$.

También, asumiendo que el sitio activo del receptor es complementario al farmacóforo, es posible construir un modelo de este sitio activo. Este modelo aproximado será complementario en forma al compuesto activo más voluminoso, y con cargas localizadas en regiones cercanas a los grupos contrariamente cargados de los ligandos ${ }^{41}$. Contando con esta información, puede luego procederse como en las metodologías directas de diseño racional, proponiendo nuevos compuestos sobre la base del conocimiento de su sitio de acción.

\section{Análisis QSAR}

Las metodologías de investigación indirectas, basadas en el conocimiento de los ligandos, pueden también conducirse bajo la forma de Análisis QSAR (Quantitative Structure Activity Relationships - Relaciones EstructuraActividad Cuantitativas).

En 1964, dos importantes aproximaciones cuantitativas fueron desarrolladas independientemente: el análisis de Hansch y el modelo de Free Wilson ${ }^{2}$.

El modelo extratermodinámico de Hansch $^{53,54,55,56,57}$ describe afinidades de ligandos, constantes de inhibición y otras actividades biológicas en términos de parámetros fisicoquímicos, como lipofilicidad, refractividad molar, términos electrónicos y estéricos. Por lo tanto, el análisis de Hansch en realidad describe relaciones propiedades-actividad.

El análisis de Free Wilson ${ }^{53,58,59,60}$, es un modelo matemático basado estrictamente en el concepto de aditividad 
de las contribuciones de los grupos a la actividad biológica. Es realmente un modelo de relaciones estructura-actividad, porque los factores estructurales se codifican como presentes $o$ ausentes $(1 \quad$ ó 0$)$ y la matriz estructural correspondiente se correlaciona directamente con los valores de actividad biológica.

En sí, el análisis QSAR conduce a relaciones cuantitativas (expresiones matemáticas, derivadas de un análisis estadístico) que vinculan la actividad biológica con parámetros estructurales $\mathrm{y} / \mathrm{o}$ electrónicos, calculados $\mathrm{y} / \mathrm{o}$ determinados experimentalmente, denominados descriptores moleculares. Nos permite así conocer sobre qué propiedad o característica estructural trabajar para modificar la actividad en la forma deseada. Las nuevas estructuras, modificadas por diseño, se sintetizan y se ensayan en su actividad, logrando nuevos fármacos que pueden evaluarse en forma semejante. En sucesivas etapas, nos movemos así en el camino de la optimización o diseño de un fármaco. Este estudio requiere, obviamente, el contar con un conjunto de compuestos análogos de actividad biológica conocida.

Las relaciones QSAR no sólo permiten la identificación de los descriptores capaces de cuantificar los cambios en la actividad biológica, sino también ahondar en la interpretación físicoquímica del origen de la respuesta farmacológica.

Recientemente, los procedimientos de QSAR tridimensionales han ganado importancia en el diseño de nuevas drogas. El método más conocido es el CoMFA (Comparative Molecular Field Analysis). Esta metodología se basa fundamentalmente en la aceptación de que las interacciones droga receptor no son covalentes y que los cambios en la actividad biológica se correlacionan con los cambios en los campos estéricos y/o electrostáticos de las drogas. Para definir estos campos se crea, mediante programas de modelado molecular, la conformación deseada de la molécula, incluida dentro de una grilla. Se sitúa un átomo de prueba (frecuentemente un protón o un carbono con hibridación sp3 y una carga positiva) en cada vértice de la grilla, y se miden las interacciones estéricas y electrostáticas entre el átomo de prueba y la molécula en estudio, en cada vértice de la grilla. De esta manera, es posible definir la forma y propiedades electrostáticas de la molécula en una forma cuantitativa, mediante mapas de contorno que unen puntos de igual valor. El siguiente paso consiste en la relación con la actividad biológica. A diferencia del QSAR $2 \mathrm{D}$, en donde para cada molécula se tiene un valor de cada descriptor, aquí se trabaja con miles de valores para cada 
propiedad, uno de cada vértice de la grilla. Por lo tanto para el análisis estadístico debe emplearse otra técnica, conocida como PLS (partial least squares). Esencialmente, este procedimiento se repite una y otra vez hasta encontrar la mejor fórmula que relaciona la actividad biológica con las distintas variables. Generalmente los resultados se presentan gráficamente en una molécula representativa, mostrando regiones que son importantes para la actividad, tanto en cuanto a los factores estérico como electrónico ${ }^{61}$.

Las características prácticas de los análisis QSAR se discutirán más adelante, en el capítulo 4 .

\footnotetext{
${ }^{1}$ Chapter 8: Drug Discovery and Drug Development En: Patrick, G.L. Medicinal Chemistry, Oxford University Press, New York (2001) pp.142190

${ }^{2}$ Kubinyi, H. Pharmazie (1995) 50: 647-662

${ }^{3}$ Chapter 9: Drug Design and drug-target interactions En: Patrick, G.L. Medicinal Chemistry, Oxford University Press, New York (2001) pp. 191-219

${ }^{4}$ Chapter 18: Cimetidine - A Rational Approach to Drug Design En: Patrick, G.L. Medicinal Chemistry, Oxford University Press, New York (2001) pp. 551-586

${ }^{5}$ Chapter 15: Cholinergic, anticholinergic, and anticholinesterases En: Patrick, G.L. Medicinal Chemistry, Oxford University Press, New York (2001) pp. 432-482

${ }^{6}$ Hylands, P.J.; Nisbet, L.J. Ann. Rep. Med. Chem. (1991) 26: 259

${ }^{7}$ Tempesta, M.S.; King, S.R. Ann. Rep. Med. Chem. (1994) 29: 325

${ }^{8}$ Buss, A.D.; Waigh, R.D. En: Wolf, M.E. (Ed.), Burguer's Medicinal

Chemistry, 5th Ed., vol.1, John Wiley \& Sons, New York (1995) p. 983

${ }^{9}$ Wani, M.C.; Taylor, H.L.; Wall, M.E.; Coggon, P.; McPhail, A.T. J.

Am. Chem. Soc. (1971) 93: 2325

${ }^{10}$ Suffness, M. Ann. Rep. Med. Chem. (1993) 28: 305

${ }^{11}$ Klayman, D.L. Science (1985) 228: 1049

${ }^{12}$ Luo, X.D.; Shen, C.C. Med. Res. Rev. (1987) 7:29

${ }^{13}$ Spande, T.F.; Garraffo, H.M.; Edwards, M.W.; Yeh, H.J.C.; Pannell, L.; Daly, J.W. J. Am. Chem. Soc. (1992) 114: 3475

${ }^{14}$ Badio, B.; Garraffo, H.M.; Spande, T.F.; Daly, J.W. Med. Chem. Res. (1994) $4: 440$

${ }^{15}$ Kavallaris, M.; Verrillis, N.M.; Hill, B.T. Drug Resistance Update (2001) 4: 392-401

${ }^{16}$ Burguer, A. A Guide to the Chemical Basis of Drug Design, John Wiley \& Sons, New York (1983)

${ }^{17}$ Sternbach, L.H. Prog. Drug Res. (1978) 22: 229

${ }^{18}$ Stevens, G.D. Progr. Drug Res. (1986) 30: 189

${ }^{19}$ Roberts, R.R. Serendipity. Accidental Discoveries in Science, Wiley Science Editions, John Wiley \& Sons, New York (1989)

${ }^{20}$ Sneader, W. En: Kennewell, P.D. (Ed.) General Principles, Vol.1 of Hansch, C. (Ed.) Comprenhensive Medicinal Chemistry. The Rational Design, Mechanistic Study \& Therapeutic Application of Chemical Compounds, Pergamon Press, Oxford (1990), p. 7
} 
${ }^{21}$ Chan, S.C. Clin. Chem. (1980) 26: 1528-30

${ }^{22}$ Meunier, H.; Carraz, G.; Meunier, Y.; Eymard, P.; Aimard, M. Thérapie (1963) 18: 435-8

${ }^{23}$ Cook, N.J.; Jowett, D.A. J. Chromatog. (1983) 272: 181-6

${ }^{24}$ Fariello, R.; Smith, M.C. Chapter 39: Valproate En: Levy, R.; Mattson, R.; Meldrum, B.; Penry, J.K.; Dreifuss, F.E. (Eds.) Antiepileptic Drugs, $3^{\text {rd }}$ Ed., Raven Press, Ltd., New York (1989) pp.567-582

${ }^{25}$ Sweetnam, P.M.; Price, C.H.; Ferkany, J.W. En: Wolf, M.E. (Ed.),

Burguer's Medicinal Chemistry, 5th Ed., vol.1, John Wiley \& Sons, New York (1995) p. 697

${ }^{26}$ Ganellin, C.R.; Roberts, S.M. (Eds.) Medicinal Chemistry. The Role of Organic Chemistry in Drug Research, Academic Press, London (1993)

${ }^{27}$ Taylor, J.B.; Kennewell, P.D. Modern Medicinal Chemistry, Ellis Horwood, New York (1993)

${ }^{28}$ King, F.D. (Ed.) Medicinal Chemistry: Principles and Practice, The Royal Society of Chemistry, Cambridge (1994)

${ }^{29}$ Dean, M.; Jolles, G.; Newton, C.G. (Eds.) New Perspectives in Drug Design, Academic Press, London (1995)

${ }^{30}$ Chapter 10: Pharmacokinetics En: Patrick, G.L. Medicinal Chemistry, Oxford University Press, New York (2001) pp. 220-257

${ }^{31}$ Nabel, G.J.; Nabel, E.G. Ann. Rep. Med. Chem. (1991) 26: 315

${ }^{32}$ McGarrity, G.J.; Chiang, Y. Ann. Rep. Med. Chem. (1993) 28: 267

${ }^{33}$ Coombes, J.D.; Evans, M. Ann. Rep. Med. Chem. (1989) 24: 207

${ }^{34}$ Swanson, M.E.; Grass, D.S. Ann. Rep. Med. Chem. (1994) 29: 265

${ }^{35}$ Games, D. Nature (1995) 373: 523

${ }^{36}$ Szabo, A.; Ostlund, N.S. Modern Quantum Chemistry, $I^{s t} E d$., Mc Graw-Hill Publishing Company, New York (1989)

${ }^{37}$ Boyd, D.B. Chapter 9: Aspects of Molecular Modeling En: Lipkowitz, K.B.; Boyd, D.B. (Eds.) Reviews in Computational Chemistry, Vol.1, VCH Publishers, Inc., New York (1990) pp.321-354

${ }^{38}$ Chapter 3: Methods of Applications of Combined Quantum Mechanical and Molecular Mechanical Potentials En: Lipkowitz, K.B.; Boyd, D.B.

(Eds.) Reviews in Computational Chemistry, Vol.7, VCH Publishers, Inc., New York (1996) pp.119-186

${ }^{39}$ Chapter 6: Selecting an Appropriate Theoretical Method. En:

Foresman, J.B.; Frisch, A. Exploring Chemistry with Electronic Structure Methods $2^{\text {nd }} E d$. Gaussian Inc., Pittsburgh PA (1996) pp. 111-140

${ }^{40}$ Chapter 3: Geometry Optimizations. En: Foresman, J.B.; Frisch, A. Exploring Chemistry with Electronic Structure Methods $2^{\text {nd }}$ Ed. Gaussian Inc., Pittsburgh PA (1996) pp. 39-60

${ }^{41}$ Balbes, L.M.; Mascarella, S.W.; Boyd, D.B. Chapter 7: A Perspective of Modern Methods in Computer Aided Drug Design En: Lipkowitz, K.B.; Boyd, D.B. (Eds.) Reviews in Computational Chemistry, Vol.5, VCH Publishers, Inc., New York (1994) pp.337-379

${ }^{42}$ Chapter 13: Computers in Medicinal Chemistry En: Patrick, G.L. Medicinal Chemistry, Oxford University Press, New York (2001) pp. 319-374

${ }^{43}$ Shoichet, B.K.; Stroud, R.M.; Santi, D.V.; Kuntz, I.D.; Perry, K.M. Science (1993) 259: 1445

${ }^{44}$ DesJarlais, R.L.; Sheridan, R.P.; Seibel, G.L.; Dixon, J.S.; Kuntz, I.D.; Venkataraghavan, R. J. Med. Chem. (1988) 31: 722

${ }^{45}$ Kuntz, I.D. Science (1992) 257: 1078

${ }^{46}$ Moon, J.B.; Howe, W.J. Tetrahedron Comput. Methodol. (1990) 3: 681

${ }^{47}$ Moon, J.B.; Howe, W.J. Proteins (1991) 11: 314 


\footnotetext{
${ }^{48}$ Bohm, H.J. En: Kubinyi, H. (Ed.) $3 D$ QSAR in Drug Design. Theory, Methods and Applications, ESCOM Science Publishers B. V., Leiden (1993) p. 386

${ }^{49}$ Bohm, H.J. J. Comput. Aided Mol. Design (1992) $\underline{6}: 61$

${ }^{50}$ Bohm, H.J. J. Comput. Aided Mol. Design (1992) $6: 593$

${ }^{51}$ Bohm, H.J. J. Comput. Aided Mol. Design (1994) $\underline{8}: 243$

${ }^{52}$ Allen, F.H.; Davies, J.E.; Galloy, J.J.; Jonson, O.; Kennard, O.; Macrae, C.F.; Mitchell, E.M.; Mitchell, G.F.; Smith, J.M.; Watson, D.G. J. Chem. Inf. Comput. Sci. (1991) 31: 187

${ }^{53}$ Kubinyi, H. QSAR: Hansch Analysis and Related Approaches, VCH, Weinheim (1993)

${ }^{54}$ Hansch, C.; Leo, A. Exploring QSAR. Fundamentals and Applications in Chemistry and Biology, American Chemical Society, Washington (1995)

${ }^{55}$ Hansch, C.; Fujita, T. J. Am. Chem. Soc. (1964) 86: 1616

${ }^{56}$ Fujita, T. En: Ramsden, C.A. (Ed.) Quantitative Drug Design, Vol.4 of Hansch, C. (Ed.) Comprenhensive Medicinal Chemistry. The Rational Design, Mechanistic Study \& Therapeutic Application of Chemical Compounds, Pergamon Press, Oxford (1990) p. 497

${ }^{57}$ Kubinyi, H. En: Wolf, M.E. (Ed.), Burguer's Medicinal Chemistry, 5th Ed., vol.1, John Wiley \& Sons, New York (1995) p. 497

${ }^{58}$ Free Jr., S.M.; Wilson, J.W. J. Med. Chem. (1964) 7: 395

${ }^{59}$ Fujita, T.; Ban, T. J. Med. Chem. (1971) 14: 148

${ }^{60}$ Kubinyi, H. En: Ramsden, C.A. (Ed.) Quantitative Drug Design, Vol.4 of Hansch, C. (Ed.) Comprenhensive Medicinal Chemistry. The Rational Design, Mechanistic Study \& Therapeutic Application of Chemical Compounds, Pergamon Press, Oxford (1990) p. 589

${ }^{61}$ Chapter 11: Quantitative Structure-Activity Relationships En: Patrick, G.L. Medicinal Chemistry, Oxford University Press, New York (2001) pp. 258-288
} 


\section{$\propto$ CAPITULO $2 \propto$}

\section{EPILEPSIA}

Pocas experiencias son tan dramáticas como lo es una crisis convulsiva. Una persona que está sufriendo una crisis severa puede gritar, caer al piso inconsciente, realizar movimientos descontrolados, babear, y hasta perder el control de la vejiga. En pocos minutos, el ataque finaliza y la persona recobra el conocimiento, pero está agotada y aturdida. Esta es la imagen que la mayoría de la gente tiene cuando escucha la palabra epilepsia. Sin embargo, este tipo de crisis convulsiva (convulsión tónico-clónica generalizada) constituye sólo una clase de epilepsia ${ }^{1}$. Hay muchas otras clases, cada una con un conjunto distinto de síntomas que la caracteriza.

La epilepsia fue uno de los primeros desórdenes cerebrales en ser descriptos. Fue mencionado en la antigua Babilonia hace más de 3000 años. El comportamiento extraño causado por algunas convulsiones ha contribuido a través de los años a muchas supersticiones y prejuicios. Se pensaba que los que sufrían de epilepsia eran visitados por dioses o por demonios. Sin embargo, hacia el año $400 \mathrm{AC}$, el médico Hipócrates ya sugirió que la epilepsia era un desorden originado en el cerebro. La ciencia, a través de los años, le ha dado la razón'.

\section{Qué es la epilepsia?}

La epilepsia es uno de los desórdenes del sistema nervioso central más frecuentes en la población mundial.

En la epilepsia, el patrón normal de actividad neuronal se torna desequilibrado, causando sensaciones, emociones, y conductas extrañas, o a veces convulsiones, espasmos musculares, y pérdida de conocimiento ${ }^{1}$.

Las crisis convulsivas que surgen periódicamente en los pacientes epilépticos, se refieren a trastornos transitorios de la conducta, provocados por la activación desordenada, sincrónica y rítmica de grandes poblaciones de neuronas cerebrales.

Aunque hasta un 5 por ciento de las personas pueden manifestar una convulsión en algún momento de sus vidas, el diagnóstico de epilepsia se reserva para aquéllos con 
convulsiones recurrentes, al menos dos convulsiones no provocadas.

Durante una convulsión, las neuronas pueden dispararse tanto como 500 veces por segundo, mucho más rápido que en condiciones normales en que lo hacen aproximadamente 80 veces por segundo. En algunos pacientes, esto ocurre sólo de vez en cuando, pero para otros, puede pasar hasta cientos de veces en un día'.

En condiciones normales, el flujo de información a través del $\mathrm{SNC}^{*}$ se mantiene gracias a un delicado equilibrio entre actividad excitatoria $e$ inhibitoria dentro de los circuitos neuronales. Cualquier evento que altere este balance entre excitación e inhibición puede producir una convulsión ó descarga epiléptica. Por lo tanto, disminuyendo la inhibición ó aumentando la excitación se pueden inducir convulsiones. Hay muchas formas de que esto suceda. Casi cualquier perturbación de un canal iónico ó de un receptor puede cambiar la excitabilidad de manera tal de producir una convulsión. Sin embargo, una vez que la descarga ocurre, existen en la corteza algunos mecanismos comunes que amortiguan la excitabilidad y previenen la propagación de la descarga epiléptica desde un área localizada a otras áreas, ya sean cercanas ó distantes. Si estos mecanismos se anulan, ocurre una convulsión generalizada ${ }^{2}$.

Aproximadamente 50 millones de personas en el mundo padecen de epilepsia ${ }^{3}$, siendo la incidencia mayor en países en vías de desarrollo ${ }^{4}$, debido a que existe una mayor probabilidad de experimentar condiciones que conduzcan a daño cerebral permanente (ciertas enfermedades, complicaciones prenatales, malnutrición, etc.). Las convulsiones pueden ser controladas con tratamientos farmacológicos o mediante técnicas quirúrgicas en aproximadamente el 80 por ciento de los pacientes. Sin embargo, el 20 por ciento restante seguirá sufriendo convulsiones hasta con el mejor tratamiento disponible. Esto es lo que se conoce como epilepsia intratable ${ }^{1}$.

\section{Causas de la epilepsia.}

La epilepsia es un desorden con muchas causas posibles. Cualquier factor que perturbe el patrón normal de actividad de la neurona puede conducir a convulsiones. La epilepsia puede desarrollarse debido a una anormalidad en el desarrollo de cerebro, un desequilibrio de neurotransmisores, o una combinación de estos factores ${ }^{1}$.

\footnotetext{
* SNC: Sistema Nervioso Central
} 


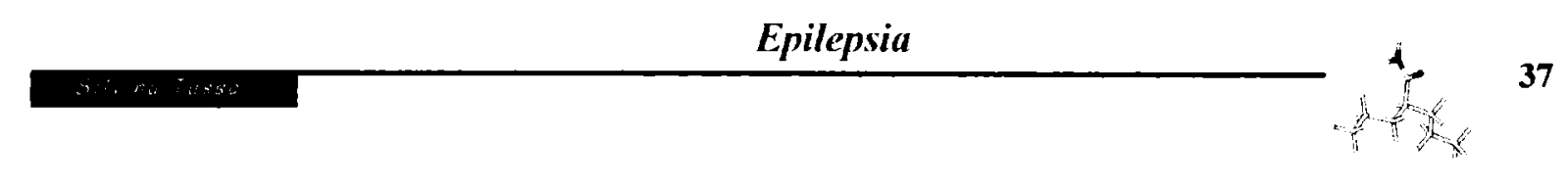

Aproximadamente la mitad de todos las convulsiones son idiopáticas, es decir, no tienen ninguna causa conocida. Sin embargo, en otros casos, las convulsiones claramente se asocian a infección, trauma, $u$ otros problemas identificables ${ }^{1}$.

$\mathrm{La}$ investigación sugiere que las anormalidades genéticas pueden ser algunos de los factores más importantes que contribuyen a la epilepsia. Algunos tipos de epilepsia han sido vinculados a una anormalidad en un gen específico. Se estima que más de 500 genes podrían jugar un rol en este desorden. Sin embargo, es cada vez más claro que para muchas formas de epilepsia, las anormalidades genéticas cumplen sólo un rol parcial, quizás aumentando la sensibilidad de una persona a las convulsiones que son provocadas por un factor ambiental.

En muchos casos, la epilepsia se desarrolla como consecuencia del daño cerebral por otros desórdenes. Por ejemplo, los tumores cerebrales, el alcoholismo, y la enfermedad de Alzheimer con frecuencia conducen a trastornos epilépticos porque cambian los funcionamientos normales del cerebro. Las condiciones que privan al cerebro de oxígeno también pueden causar epilepsia en algunos casos. Este es a menudo el caso de la gente anciana que desarrolla epilepsia, en donde en aproximadamente el 32 por ciento de los pacientes las causas son las enfermedades cerebrovasculares, que reducen el suministro de oxígeno a las células cerebrales. La meningitis, el SIDA, encefalitis viral, y otras enfermedades infecciosas pueden conducir también a epilepsia, así como la condición de hidrocefalia (exceso de fluido en el cerebro). La epilepsia también puede ser resultado de la enfermedad celíaca, o de una infección parasitaria del cerebro llamada neurocisticercosis. En estos casos, las convulsiones pueden cesar una vez que estos desórdenes son tratados satisfactoriamente. Sin embargo, las probabilidades de que esto ocurra son inciertas y varían según el tipo de desorden, la región cerebral que esté afectada, y cuánto daño cerebral haya ocurrido antes del tratamiento.

$\mathrm{Al}$ igual que las enfermedades, las lesiones en la cabeza originadas en accidentes pueden conducir a convulsiones o a epilepsia.

Las lesiones prenatales y problemas del desarrollo constituyen otra causa de epilepsia. Se ha observado que algunos casos de epilepsia que ocurren sin causa obvia pueden ser asociados con áreas de displasia en el cerebro que probablemente se desarrollan antes del nacimiento. El cerebro en desarrollo es susceptible a muchas clases de lesiones. Las infecciones durante el embarazo, una nutrición pobre, y carencias de oxígeno son solamente algunas 
condiciones que pueden afectar al cerebro de un bebé que se está desarrollando. Estas condiciones pueden conducir a parálisis cerebral, que a menudo provoca epilepsia.

Condiciones ambientales, tales como la exposición a plomo, monóxido de carbono, y muchas otras sustancias tóxicas pueden también ocasionar convulsiones. Estas pueden también ser el resultado de la exposición a drogas de abuso y de las sobredosis de antidepresivos y otros fármacos.

Existen disparadores de convulsiones que no causan epilepsia, pero pueden provocar primeras convulsiones o causar convulsiones en las personas que de otra manera experimentan buen control con una medicación adecuada. La carencia de sueño en particular es un disparador universal y poderoso de convulsiones. También lo son el stress fisico o emocional, y los cambios hormonales asociados con el ciclo menstrual. Para algunas personas, la luz que destella en una cierta velocidad o el parpadeo de un monitor puede provocar una convulsión, lo que se conoce como epilepsia fotosensible ${ }^{l}$.

\section{Tipos de convulsiones}

Se considera que las convulsiones se originan en la corteza cerebral. Más aún, la manifestación del episodio convulsivo depende de las funciones normales que ejerza el sitio de la corteza afectado. Por ejemplo, se producirían sacudidas del brazo derecho si la corteza motora relacionada a este brazo representa el sitio de la corteza en donde se origina la convulsión.

Las convulsiones epilépticas se han clasificado en dos grupos: convulsiones parciales, que se inician de manera focal en un sitio cortical, y convulsiones generalizadas, que abarcan con amplitud ambos hemisferios desde un principio. En humanos, las convulsiones parciales representan la forma predominante ( 68 por ciento) ${ }^{5}$.

A los efectos del tratamiento médico, muchas veces se diagnostica un determinado síndrome epiléptico más que una determinada convulsión en particular, ya que el síndrome epiléptico se refiere a un conjunto de síntomas asociados que describen el trastorno en su totalidad. Estos factores incluyen, además del tipo de convulsión epiléptica, su causa, edad de inicio, y síntomas electroencefalográficos, por ejemplo. Sin embargo, en la elección definitiva del tratamiento a utilizar prevalece la importancia del tipo de convulsión que presenta el paciente epiléptico. 


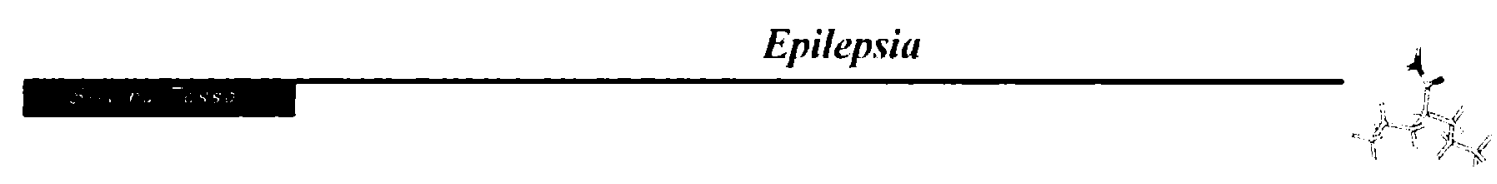

La Liga Internacional contra la Epilepsia (International League Against Epilepsy) $^{6}$ ha propuesto clasificaciones que son a las que más se hace referencia cuando se habla de distintos tipos de convulsiones epilépticas $^{7}$ o de síndromes epilépticos ${ }^{6}$. Esta última clasificación comprende también una diferenciación entre trastornos parciales y generalizados, incluyendo además síndromes muy característicos tales como el síndrome West o el síndrome Lennox-Gastaut.

Se presentan a continuación las características más sobresalientes de cada tipo de convulsión epiléptica.

\section{Convulsiones generalizadas.}

Las convulsiones generalizadas involucran desde su origen a ambos hemisferios cerebrales. Se conocen seis tipos principales.

$\checkmark$ Crisis de ausencia: son breves lapsos de pérdida del conocimiento, de entre 3 y 30 segundos. Comienzan y terminan abruptamente y ocurren desde unas pocas hasta varios cientos de veces al día. Se caracterizan porque el paciente de repente interrumpe sus movimientos o muestra conducta automatizada (mirada fija, leve parpadeo, se frota la nariz, mastica o traga) y luego rápidamente recupera la conciencia. Estas crisis son las que antiguamente se conocían como petit mal.

$\checkmark$ Convulsiones mioclónicas: son contracciones musculares breves (de aproximadamente 1 segundo).

$\checkmark$ Convulsiones clónicas: se producen sacudidas en ambos lados del cuerpo.

$\checkmark$ Convulsiones tónicas: contracción tónica severa de los músculos de duración corta, generalmente de la espalda, brazos y piernas. El paciente mantiene la postura y no siempre pierde la conciencia.

$\checkmark$ Convulsiones tónico-clónicas: se caracterizan por pérdida de conciencia y caída. Mientras el paciente cae, el cuerpo se pone tieso debido a la contracción tónica generalizada de los músculos de los miembros. Durante esta fase tónica, que dura menos de 1 minuto, la respiración se detiene y puede observarse cianosis. Luego de la fase tónica, siguen los movimientos clónicos, con periodos alternados de contracción y relajación de los músculos de las extremidades, por menos de 1 minuto. El paciente puede morderse la lengua, y ocasionalmente se observa espuma en la boca. También puede haber incontinencia urinaria. Sigue un periodo de 
inconsciencia más relajado, que dura alrededor de 1 minuto. Luego de esa fase, el individuo está confuso, adormecido, e incapaz relacionarse con el medio por varios minutos, antes de recuperarse totalmente. El paciente invariablemente no recuerda haber sufrido una convulsión. Estas convulsiones constituyen lo que antes se denominaba grand mal.

$\checkmark$ Convulsiones atónicas: se caracterizan por la pérdida abrupta del tono muscular, que frecuentemente causa injuria. Usualmente comienzan en la niñez y duran hasta la adultez. Generalmente se presentan asociadas a retardo mental.

\section{Convulsiones parciales.}

Este tipo de convulsiones se origina en un sitio específico del cerebro, aunque luego la propagación pueda afectar a toda la corteza. De hecho, más de la mitad de los pacientes que padecen epilepsias parciales presentan tanto convulsiones parciales, simples y/o complejas, así como también convulsiones parciales que evolucionan a tónicoclónicas generalizadas. De acuerdo a datos epidemiológicos en poblaciones europeas y de los Estados Unidos, el tipo más frecuente es la convulsión parcial compleja ${ }^{8}$.

$\checkmark$ Convulsiones parciales simples: se caracterizan fundamentalmente por la conservación de la conciencia. Tienen una duración de aproximadamente 20 a 60 segundos. Los sintomas observados reflejan la región en donde se originó la convulsión, pudiendo incluir síntomas motores, somatosensoriales (tales como entumecimiento, hormigueo), sensoriales (visuales, auditivos, olfatorios, gustatorios), autonómicos (dolor de cabeza, vértigo, náuseas, dolor abdominal, disnea, transpiración).

$\checkmark$ Convulsiones parciales complejas: hay pérdida del conocimiento que dura de 30 segundos a 2 minutos. Se caracterizan por automatismos (conductas repetitivas), tales como tragado, masticado, movimientos aleatorios de los ojos. Durante el automatismo, el individuo mantiene el control de la postura y tono muscular pero realiza movimientos sin darse cuenta de lo que hace.

$\checkmark$ Convulsiones parciales que evolucionan secundariamente a tónico-clónicas generalizadas: aquí la convulsión parcial, simple ó compleja, evoluciona hasta convertirse en una convulsión 
generalizada tónico-clónica, con las características ya descriptas. Se detectan cuando la observación clínica y el EEG indican que la convulsión ocurre desde un foco unilateral, y no se observa una implicancia simultánea bilateral desde el comienzo de la convulsión, como ocurre en las convulsiones tónico-clónicas secundarias.

\section{Diagnóstico}

Existen varias pruebas diferentes para determinar si una persona sufre epilepsia y, si es así, qué tipo de convulsiones tiene. En algunos casos, la persona puede tener síntomas que se parecen muchísimo a una crisis convulsiva, pero de hecho son acontecimientos no epilépticos causados por otros desórdenes. A veces es muy difícil apreciar la diferencia entre estos desórdenes y la epilepsia sin la observación cercana y el empleo de pruebas intensivas.

\section{Monitoreo por EEG}

El EEG (electroencefalograma) es la prueba de diagnóstico más común para la epilepsia y puede descubrir anormalidades en la actividad eléctrica del cerebro. Los pacientes con epilepsia con frecuencia tienen cambios en su patrón normal de ondas cerebrales, aún cuando no están experimentando una convulsión. Pero aunque este tipo de prueba puede ser muy útil en el diagnóstico de la epilepsia, no es infalible. Algunas personas siguen mostrando el patrón de ondas cerebrales normal aún después de que han experimentado una convulsión. En otros casos, las ondas cerebrales inusuales se generan profundamente en el cerebro, donde el EEG es incapaz de descubrirlas. Muchas personas que no padecen epilepsia también muestran alguna actividad cerebral inusual en un EEG. Siempre que sea posible, el EEG debería ser realizado dentro de 24 horas de la primera convulsión de un paciente. Idealmente, el EEG debería ser realizado mientras el paciente duerme además de cuando está despierto, porque la actividad cerebral durante el sueño es a menudo bastante diferente.

E1 MEG (magnetoencefalograma) permite supervisar la actividad cerebral en puntos diferentes con el tiempo, revelando funciones cerebrales diferentes. Mientras el MEG es similar en el concepto al EEG, no requiere electrodos y puede descubrir señales más profundas en el cerebro que un EEG.

\section{Exploraciones Cerebrales}

Uno de los modos más importantes de diagnosticar la epilepsia es por el empleo de exploraciones cerebrales. La CT 
(tomografia computada) y la MRI (imagen de resonancia magnética) revelan la estructura del cerebro, siendo útiles para identificar tumores cerebrales, quistes, y otras anormalidades estructurales. La PET (tomografía de emisión de positrones) y una clase adaptada de MRI llamada MRI funcional (fMRI) pueden ser usadas para supervisar la actividad del cerebro y descubrir anormalidades en su funcionamiento. La SPECT (tomografia computada de emisión de fotón simple) es una clase relativamente nueva de exploración cerebral que a veces es usada para localizar focos de convulsión en el cerebro. También se está experimentando con exploraciones cerebrales de espectroscopia de resonancia magnética (MRS) que pueden descubrir anormalidades en los procesos bioquímicos del cerebro, y con espectroscopia de infrarrojo cercano, una técnica que puede descubrir niveles de oxígeno en el tejido cerebral.

\section{Historia Clínica}

El análisis de una historia clínica detallada, incluyendo síntomas y duración de las convulsiones, es todavía un método valioso para determinar si una persona tiene epilepsia y qué tipo de convulsiones tiene. Ya que la persona que ha sufrido una convulsión a menudo no recuerda qué pasó, la narración de quien presenció la convulsión es vital para esta evaluación.

\section{Análisis de sangre}

A menudo se examinan en busca de desórdenes metabólicos o genéticos, o bien para comprobar problemas subyacentes como infecciones, envenenamiento por plomo, anemia, y diabetes que pueden estar provocando las convulsiones.

\section{Tratamiento}

El diagnóstico exacto del tipo de epilepsia es crucial para encontrar un tratamiento eficaz.

Hay muchos modos diferentes de tratar la epilepsia. Los tratamientos actualmente disponibles pueden controlar las convulsiones, al menos durante un periodo de tiempo, en aproximadamente el 80 por ciento de las personas con epilepsia. Sin embargo, el otro 20 por ciento tiene convulsiones intratables. Esta estadística pone en claro la gran necesidad de nuevos tratamientos que existe aún hoy en día.

Una vez que la epilepsia es diagnosticada, es importante comenzar el tratamiento cuanto antes, para evitar que las convulsiones causen consecuencias no deseadas. 
Tratamiento farmacológico.

El tratamiento más corriente de la epilepsia lo constituye la prescripción de drogas antiepilépticas. Este punto se tratará en detalle en el próximo capítulo.

Cirugía.

Se recomienda que la persona sea evaluada para la cirugía sólo después de que los pacientes han intentado dos o tres medicaciones diferentes sin éxito, o si hay una lesión cerebral identificable que se cree que causa los convulsiones.

Para decidir si una persona puede beneficiarse de la cirugía, se considera el tipo de convulsión que presenta, la región cerebral involucrada y la importancia que esa región tiene para el comportamiento diario. En general se evita operar en las áreas del cerebro que son necesarias para el discurso, la lengua, el oído, u otras capacidades importantes. Se supervisa al paciente de manera intensiva antes de la cirugía para señalar la posición exacta en el cerebro donde comienzan las convulsiones.

Así como la cirugía puede reducir considerablemente o inclusive acabar con las convulsiones, es importante recordar que cualquier clase de cirugía conlleva cierto riesgo. La cirugía para la epilepsia no siempre reduce satisfactoriamente las convulsiones y puede resultar en cambios cognoscitivos o de personalidad, aún en aquellos pacientes que son excelentes candidatos para la cirugía.

Luego de una cirugía, es importante seguir tomando la medicación durante algún tiempo para dar tiempo al cerebro para adaptarse de nuevo. Generalmente se recomienda seguir con el tratamiento farmacológico durante 2 años después de una operación exitosa para evitar nuevas convulsiones.

Los tipos de cirugía que actualmente se practican se comentan a continuación.

Cirugía para tratar condiciones subyacentes, como un tumor cerebral o la hidrocefalia.

Cirugía para quitar foco convulsivo, apropiada sólo para convulsiones parciales las cuales provienen de un área del cerebro. Las lobectomías tienen una tasa de éxito del 5570 por ciento cuando el tipo de epilepsia y el foco están bien definidos, siendo la más común la sección del lóbulo temporal.

Transección múltiple subpial. Cuando las convulsiones se originan en una parte del cerebro que no puede ser quitada, se practican una serie de cortes que impiden que la convulsión se extienda a otras partes del cerebro. 
Callosotomía corpus. Implica el corte de la red de conexiones nerviosas entre las mitades derecha e izquierda del cerebro, se realiza principalmente a niños con convulsiones severas que comienzan en un hemisferio y se extienden al otro. El procedimiento no evita las convulsiones que se parten del lado del cerebro originalmente dañado, inclusive estas convulsiones parciales pueden aumentar después de la cirugía.

Hemisferectomía. Este procedimiento, que quita la mitad de la corteza cerebral, es usada sólo en niños con encefalitis de Rasmussen u otro daño severo a un hemisferio cerebral. A pesar de que este tipo de cirugía es muy radical y es realizado sólo como una última instancia, los niños a menudo se recuperan muy bien del procedimiento, y por lo general se reducen enormemente sus convulsiones. Con rehabilitación intensa, a menudo recuperan capacidades casi normales. Ya que la posibilidad de una buena recuperación sólo es posible a corta edad, la hemisferectomía casi nunca se realiza en niños de más de 13 años.

\section{Dispositivos.}

El estimulador del nervio vago fue aprobado por la Administración de Drogas y Alimentos estadounidense (FDA) en 1997 para el empleo en pacientes con convulsiones que no son bien controladas por la medicación. El estimulador del nervio vago es un dispositivo a pilas que se implanta quirúrgicamente bajo la piel del pecho, como un marcapasos, y se liga al nervio vago. Este dispositivo entrega paquetes de energía eléctrica al cerebro vía nervio vago. Por regla general, esta estimulación reduce las convulsiones en un 20-40 por ciento. Los pacientes por lo general no pueden dejar de tomar la medicación, pero a menudo experimentan menos convulsiones y pueden ser capaces de reducir la dosis de su medicación. Los efectos colaterales del estimulador del nervio vago son generalmente suaves, pero pueden incluir dolor de oído, dolor de garganta, o náuseas. El ajuste de la cantidad de estimulación por lo general puede eliminar estos efectos colaterales. Las pilas en el estimulador del nervio vago tienen que ser substituidas alrededor de una vez cada 5 años, lo cual requiere de una operación menor.

Otros varios dispositivos nuevos se están actualmente estudiando y pueden estar disponibles en el futuro. La estimulación transcranial magnética es un procedimiento que usa un fuerte imán sostenido fuera de la cabeza para influir en la actividad cerebral y reducir convulsiones. También se están desarrollando dispositivos implantables que pueden entregar drogas a partes específicas del cerebro. 
Dieta.

Se ha demostrado que, en algunos casos, los niños experimentan menos convulsiones si mantienen una estricta dieta cetogénica, rica en grasas y baja en carbohidratos. Esta dieta propicia la combustión de grasas en lugar de carbohidratos provocando un estado de cetosis, en donde la formación de $\beta$-hidroxibutirato como subproducto probablemente inhiba las convulsiones. La dieta cetogénica no es fácil de mantener, ya que requiere la adhesión estricta a una gama limitada de alimentos. Pero además de esta incomodidad, existen efectos colaterales importantes, como el crecimiento retardado debido a la deficiencia alimenticia, y una acumulación de ácido úrico en la sangre, que puede conducir a cálculos renales.

A pesar de que durante los últimos 30 años ha habido un gran incremento del entendimiento de los fenómenos neurobiológicos básicos y de algunos de los mecanismos moleculares y celulares involucrados en los fenómenos epilépticos, aún es necesario indagar mucho más en el conocimiento de estos procesos fisiopatológicos ${ }^{2}$. La investigación actual se basa fundamentalmente en la premisa de que un mayor entendimiento de los mecanismos de la epilepsia facilita el desarrollo de nuevos medicamentos para el tratamiento de las convulsiones ${ }^{2}$.

Por lo tanto, la investigación en esta área está en constante desarrollo, y es primordial contar con un panorama permanentemente actualizado de los avances logrados, para así contribuir también a este incesante progreso.

\footnotetext{
${ }^{1}$ Hope Through Research: Seizures and Epilepsy. NIH Publication N ${ }^{\circ} 00$ $156(2000)$

${ }^{2}$ Dichter, M.A. Emerging Insight into Mechanisms of Epilepsy:

Implications for New Antiepileptic Drug Development En: Epilepsia

Vol.35, Raven Press Ltd., New York (1994) pp. 51-7

${ }^{3}$ White, H.S. Epilepsia (1999) 40(5): 2-10

${ }^{4}$ Epilepsy: Epidemiology, Etiology and Prognosis. WHO Fact Sheet

No165 (2001). Sitio web: www. who.int/inf. Is/en/fact 165.html

${ }^{5}$ Edafiogho, I.; Scott, K. Cap.39: Anticonvulsants. En: Wolff, M. (Eds.), Burger's Medicinal Chemistry and Drug Discovery $5^{\text {th }}$ Edición Vol.3.

Therapeutic Agents, John Wiley \& Sons Inc. (1996) pp. 175-254
} 
${ }^{6}$ Commission on Classification and Terminology of the International League Against Epilepsy. Proposal for revised classification of epilepsies and epileptic syndromes. Epilepsia (1989) 30: 389-99

${ }^{7}$ Commission on Classification and Terminology of the International League Against Epilepsy. Proposal for revised clinical and electroencephalographic classification of epileptic seizures. Epilepsia (1981) 22: 489-501

${ }^{8}$ Loscher, W.; Schmidt, D. Epilepsy Research (1994) 17: 95-134 


\section{CAPÍtUlO 3}

\section{DROGAS ANTIEPILÉPTICAS}

Al ser la epilepsia un síndrome caracterizado por descargas neuronales excesivas, es de esperar que los mecanismos de acción por los cuales las drogas antiepilépticas (DAEs) manifiestan sus respuestas se relacionen con un efecto inhibitorio en el SNC, opuesto a la enorme excitación propia del fenómeno convulsivo.

Efectivamente, la mayoría de las drogas antiepilépticas en uso, ya sean aquéllas clínicamente establecidas o las surgidas recientemente, manejan el control de la convulsión incrementando la actividad inhibitoria o decreciendo la actividad excitatoria del SNC. Esta modulación se logra, a nivel molecular, mediante un efecto sobre canales iónicos, receptores, $\mathrm{o}$ bien sobre el metabolismo de los neurotransmisores.

Las distintas drogas actualmente en uso han surgido de varias maneras. Entre las DAEs clásicas se destaca la fenitoína, cuya actividad se descubrió mediante el empleo de modelos animales de convulsión. Posteriormente se descubrió que ésta actúa mediante una acción sobre los canales de sodio neuronales. Por otro lado, drogas como tiagabina surgen gracias al empleo de un método mecanístico basado en el conocimiento de los procesos involucrados en la prevención de los fenómenos convulsivos. Específicamente el uso de ensayos farmacológicos in vitro permitió encontrar este compuesto inhibidor de la retoma sináptica de GABA ${ }^{1}$.

A diferencia de lo que ocurrió históricamente en relación al surgimiento de las DAEs clásicas, en donde prevalecían las estrategias de screening farmacológico, variación estructural e inclusive el azar, actualmente se tiende a seguir un proceso mucho más racional, en donde entran en juego los conocimientos adquiridos a través de los años sobre los sistemas fisiopatológicos y los modos de acción de las drogas.

A continuación se describirán las diferentes formas en que las DAEs han sido descubiertas, y en la sección siguiente se detallarán los distintos mecanismos de acción por los que actúan, conocimiento gracias al cual pueden emplearse las técnicas actuales del Diseño Racional al desarrollo de nuevas DAEs. 


\title{
PANORAMA HISTÓRICO
}

\section{Surgimiento de las drogas antiepilépticas clásicas}

Las primeras drogas usadas para el tratamiento de la epilepsia fueron bromuros, introducidos hacia mediados del siglo XIX para el tratamiento de convulsiones ${ }^{2}$. Los bromuros fueron la única terapia útil durante aproximadamente 60 años, momento a partir del cual puede considerarse que comienza la historia moderna de las drogas antiepilépticas con la comercialización en los Estados Unidos, en 1912, del fenobarbital ${ }^{3}$ (Tabla 3.1). El fenobarbital rápidamente se convirtió en la droga de elección, por ser más efectivo y menos tóxico que el bromuro de potasio. Además, al ser la molécula del ácido barbitúrico fácilmente modificable, se sintetizaron muchos análogos del fenobarbital, entre los cuales se destacó el mefobarbital con buena capacidad antiepiléptica.

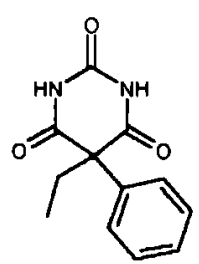

Fenobarbital<smiles>CCC1(c2ccccc2)C(=O)NC(=O)N(C)C1=O</smiles>

Mefobarbital

\begin{tabular}{cllc}
$\begin{array}{c}\text { Año } \\
\text { introducida } \\
\text { en el mercado }\end{array}$ & Droga & $\begin{array}{c}\text { Nombre } \\
\text { comercial }\end{array}$ & $\begin{array}{c}\text { Compañía } \\
\text { farmacéutica }\end{array}$ \\
\hline 1912 & Fenobarbital & Luminal & WINTHROP \\
1935 & Mefobarbital & Mebaral & WINTHROP \\
1938 & Fenitoina & Dilantin & PARKE-DAVIS \\
1946 & Trimetadiona & Tridione & ABBOTT \\
1947 & Mefenitoína & Mesantoin & SANDOZ \\
1949 & Parametadiona & Paradione & ABBOTT \\
1950 & Fentenilato & Thiantoin & LILLY \\
1951 & Fenacemida & Phenurone & ABBOTT \\
1952 & Metharbital & Gemonil & ABBOTT \\
1952 & Benzoclorpropamida & Hibicon & LEDERLE \\
1953 & Fensuximida & Milontin & PARKE-DAVIS \\
1954 & Primidona & Mysoline & AYERST \\
1957 & Methsuximida & Celontin & PARKE-DAVIS \\
1957 & Etotoína & Peganone & ABBOTT \\
1960 & Aminoglutetimida & Elipten & CIBA \\
1960 & Etosuximida & Zarontin & PARKE-DAVIS \\
1968 & Diazepam & Valium & ROCHE \\
1974 & Carbamazepina & Tegretol & GEIGY \\
1975 & Clonazepam & Clonopin & ROCHE \\
1978 & Ácido valproico & Depakene & ABBOTT \\
1981 & Clorazepato dipotásico & Tranxene & ABBOTT \\
& & &
\end{tabular}

\author{
Tabla 3.1 \\ Drogas \\ antiepilépti- \\ cas comercia- \\ lizadas en los \\ Estados \\ Unidos hasta \\ fin de los \\ años 70 . \\ (tomado de \\ Portery \\ col." )
}

\footnotetext{
* retirada del mercado.
}

- aprobada como droga auxiliar para el tratamiento de la epilepsia. 


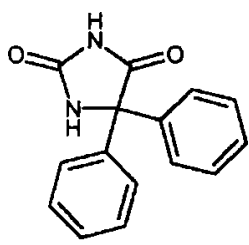

Fenitoina<smiles>CN1C(=O)OC(C)(C)C1=O</smiles>

Trimetadiona

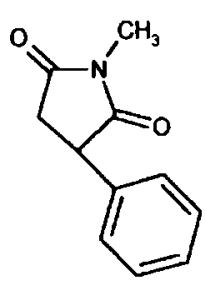

Fensuximida

El efecto anticonvulsivo del bromuro y del fenobarbital se descubrió por azar, ya que no existía en aquel momento una metodología científica que usara modelos experimentales de convulsiones para probar la capacidad anticonvulsiva. El año 1937 marcó el comienzo de la evaluación experimental de las drogas en una etapa previa a su uso clínico.

Las propiedades anticonvulsivas de la fenitoina se descubrieron mediante la evaluación de una serie de nuevos compuestos suministrados por Parke-Davis, ${ }^{4,5}$, utilizando un modelo de convulsiones basado en una técnica de electroshock para animales ${ }^{6}$. Esta droga se sometió a los ensayos clínicos en 1938 y se comercializó ese mismo año, debido fundamentalmente a su gran capacidad de protección sumada a la falta de efectos sedantes. Por otro lado, en aquella época, la introducción de nuevas drogas en los Estados Unidos sólo requería una calificación adecuada sin ser necesarias pruebas de seguridad o eficacia ${ }^{7}$.

El método de electroshock ${ }^{*, 4}$ ofrecía las ventajas de su confiabilidad y capacidad cuantitativa para la evaluación de nuevos compuestos en animales. Se evitaba así el ensayo directo en humanos, que resultaba más costoso e insumía más<smiles>CCC1(C)OC(=O)N(C)C1=O</smiles>
tiempo, además de constituir en sí mismo un procedimiento riesgoso. La colaboración academia-industria en los Estados Unidos generó una relación floreciente durante los siguientes 20 años, en donde muchas compañías farmacéuticas comenzaron Parametadiona proyectos de modificación molecular mientras que los investigadores exploraban métodos nuevos y mejorados para la inducción de convulsiones.

En 1944 se demostró la capacidad anticonvulsiva de la trimetadiona, que luego se convertiría en la primer droga anti-ausencias, evitando las convulsiones provocadas por el<smiles>CN1C(=O)CC(C)(c2ccccc2)C1=O</smiles>

Methstaximida<smiles>CCC1(C)CC(=O)NC1=O</smiles>

Etoswoximida compuesto convulsivo pentilentetrazol (PTZ)* en modelos animales. En 1951 se investigó la actividad anticonvulsiva de aproximadamente 65 fenilsuccinimidas $^{8}$ y se encontró que entre los compuestos anti-PTZ más potentes figuraban fensuximida y methsuximida, los cuales fueron luego aprobados para el tratamiento de ausencias (en 1953 y 1957 respectivamente).

+ más adelante, en las secciones 4 y 5 del capítulo 4, se describirán en detalle las técnicas de evaluación anticonvulsiva en animales 
Una tercer succinimida (etosuximida) se introdujo en 1960 con el mismo propósito.

Durante el mismo período (19381960) se comercializaron en Estados Unidos dos análogos de fenitoína (mefenitoína y etotoína), dos de fenobarbital (metharbital y primidona), y uno de trimetadiona (parametadiona),<smiles>CCC1(c2ccccc2)NC(=O)N(C)C1=O</smiles>

Mefenitoina

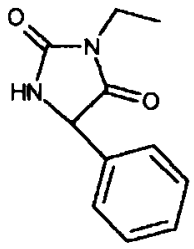

Etotoína cada uno con un espectro de actividad comparable al de su<smiles>CCC1(CC)C(=O)NC(=O)N(C)C1=O</smiles>

Metharbital<smiles>CCC1(c2ccccc2)C(=O)NCNC1=O</smiles>

Primidona compuesto padre $\mathrm{y}$ comercializado para uso similar.

Notablemente, todas las drogas antiepilépticas desarrolladas desde 1912 a 1960 se basaron en una

estructura heterocíclica simple (Figura 3.1). Durante este período, no se crearon estructuras genuinamente novedosas sino que la atención se centró en las hidantoinas, barbituratos, oxazolidinodionas, succinimidas y acetilureas.

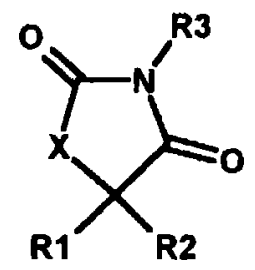

Figura 3.1

Estructura general de las $D A E s . R 1, R 2$ y $R 3$ indican distintas cadenas laterales. $X=-N H$ - en hidantoínas, $X=-C O-N H$ - en barbitúricos, $X=-O$ - en oxazolidinodionas, $\mathrm{X}=-\mathrm{CH}_{2}$ en succinimidas, $\mathrm{X}=-\mathrm{NH}_{2}$ - en acetilureas.

\section{El ocaso del desarrollo de nuevos antiepilépticos}

A la era altamente productiva de las drogas antiepilépticas de los años 40 y 50 siguió un período inerte de más de 10 años (entre 1961 y 1973), durante el cual la única droga de interés que surgió fue el diazepam, de relativa importancia para el tratamiento de las convulsiones. A pesar de que muchos pacientes no respondían a los tratamientos y otros sufrían los efectos colaterales, existieron varias razones que contribuyeron a esta etapa infructífera. Muchos médicos consideraban que las mejoras en los tratamientos dependían exclusivamente de un mejor uso de las drogas ya<smiles>CN1C(=O)CN=C(c2ccccc2)c2cc(Cl)ccc21</smiles>

Diazepam existentes, sumado al relativamente alto número de drogas antiepilépticas disponibles y al interés que comenzá a despertar en las industrias farmacéuticas otro tipo de drogas de acción en el SNC, como los tranquilizantes y sedantes- 
hipnóticos, por su mayor rédito. Esto condujo al cuestionamiento por parte de las compañías farmacéuticas de las posibilidades de que una nueva droga pueda capturar un mercado suficientemente grande como para justificar el costo de su desarrollo. El desarrollo de nuevas drogas se vio además notoriamente afectado en los Estados Unidos cuando, en 1962, se aprobó una legislación ${ }^{9}$ que exigía establecer la eficacia de la droga previa a su comercialización. Esta legislación restringió además las condiciones de las evaluaciones, lo cual tuvo un serio impacto en el surgimiento de nuevos fármacos, no sólo para el tratamiento de la epilepsia sino también de otras enfermedades que afectaban a un número limitado de la población.

En 1967, un informe reveló que la mayoría de las firmas farmacéuticas ${ }^{10}$ no contaban con desarrollos de nuevas

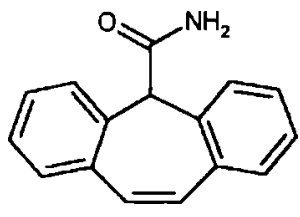

Carbamazepina drogas antiepilépticas debido a que los costos eran prohibitivos. Por otro lado, varias drogas no habían sido aprobadas por la FDA* debido a que no contaban con pruebas de eficacia adecuadas. Al mismo tiempo, un informe académico elevado por químicos medicinales reveló que no era posible acceder a las evaluaciones farmacológicas adecuadas para la evaluación de los potenciales agentes anticonvulsivos ${ }^{11}$. En un intento de revertir esta situación, la Epilepsy Branch del National Institute of Neurological and Communicative Disorders and Stroke dependiente del NIH ${ }^{\star}$ (Estados Unidos), condujo los ensayos clínicos de siete drogas que<smiles>O=C1CN=C(c2ccccc2Cl)c2cc([N+](=O)[O-])ccc2N1</smiles>

Clonazepam<smiles>O=C(O)C1N=C(c2ccccc2)c2cc(Cl)ccc2NC1=O</smiles>

Clorazepato dipotásico<smiles>CCCC(CCC)C(=O)O</smiles>

Ácido valproico necesitaban ser sometidas a pruebas de eficacia para poder ser comercializadas. Entre ellas se encontraban compuestos estructuralmente diversos, como la carbamazepina, cu-

ya capacidad anticonvulsiva había sido descubierta mediante un estudio de relaciones estructura-actividad llevado a cabo a fines de los años 50 en los laboratorios Geigy, y el ácido

\footnotetext{
+ FDA (Food and Drug Administration): organismo estadounidense encargado del control de alimentos y drogas

- Epilepsy Branch del National Institute of Neurological and Communicative Disorders and Stroke dependiente del NIH: Sección Epilepsia del Instituto Nacional de Desórdenes Neurológicos y Comunicativos y Accidente Cerebrovascular dependiente del Instituto Nacional de Salud (Estados Unidos)
} 
valproico, descubierto al azar a principios de los años 60 en Francia. Como resultado de este emprendimiento, se logró la comercialización de cuatro nuevas drogas: carbamazepina, ácido valproico, clonazepam y clorazepato dipotásico. Pronto quedó en evidencia la necesidad de implementar también un programa de ensayo preclínico para el desarrollo de nuevas drogas. Así, la Epilepsy Branch (NINCDS - NIH, Estados Unidos), creó en 1975 el Antiepileptic Drug Development Program (Programa ADD), que incluye las fases de evaluación preclínica agrupadas dentro del Anticonvulsant Screening Project ${ }^{\star}$ (ASP) ${ }^{11,12}$. Gracias al funcionamiento de este Proyecto, en los Estados Unidos, se reciben nuevas estructuras con potencial actividad, provenientes tanto de entidades académicas como de industrias, y se evalúan sus capacidades anticonvulsivas a nivel preclínico. Además, este Programa sirve como modelo, a nivel mundial, de los lineamientos a seguir durante la evaluación anticonvulsiva temprana de una nueva droga. Actualmente sólo un pequeño número de compuestos progresa desde las fases iniciales de identificación de la actividad hasta los procedimientos más avanzados de evaluación ${ }^{12}$.

\section{Resurgimiento del interés por el descubrimiento de nuevos agentes antiepilépticos}

Entre las drogas desarrolladas antes de 1978, varias de ellas siguen siendo las más ampliamente prescriptas: fenitoína ${ }^{1,13,14}$ carbamazepina ${ }^{1,13,14}$, valproato ${ }^{1,13,14}$, etosuximida $^{13,14}$, primidona ${ }^{13}$, fenobarbital ${ }^{1,14}$ y ciertas benzodiazepinas $^{13,14}$ (Tabla 3.2).

Aunque estas drogas prototipo son de considerable uso en clínica actualmente, cerca del 30 por ciento de los pacientes no logran un adecuado control de sus convulsiones, a pesar del uso óptimo de las drogas disponibles (refractariedad) ${ }^{15}$. Otros que sí lo logran lo hacen $a$ expensas de severos efectos colaterales ${ }^{12,14}$. Los problemas asociados a la administración de estas DAEs pueden ser leves pero muchas veces tienen serias implicancias. Entre los más comunes se encuentran: ataxia, diplopía, embotamiento, erupciones cutáneas, discrasias sanguíneas, y

\footnotetext{
- Antiepileptic Drug Development Program: Programa de Desarrollo de Drogas Antiepilépticas

- Anticonvulsant Screening Project: Proyecto de Screening

Anticonvulsivo
} 
hepatotoxicidad ${ }^{1}$, los cuales se ven agravados por el hecho de ser estos medicamentos de uso prolongado.

Por lo tanto, existe una gran necesidad de mejorar los tratamientos farmacológicos. El programa ADD, así como varios otros programas de desarrollo de drogas comerciales, han contribuido en gran manera a estimular el surgimiento de nuevos antiepilépticos ${ }^{1,12}$.

Tabla 3.2 Drogas de uso primario en clinica, según el tipo de convulsión.

(tomado de McNamara, J.O. ${ }^{27}$ )

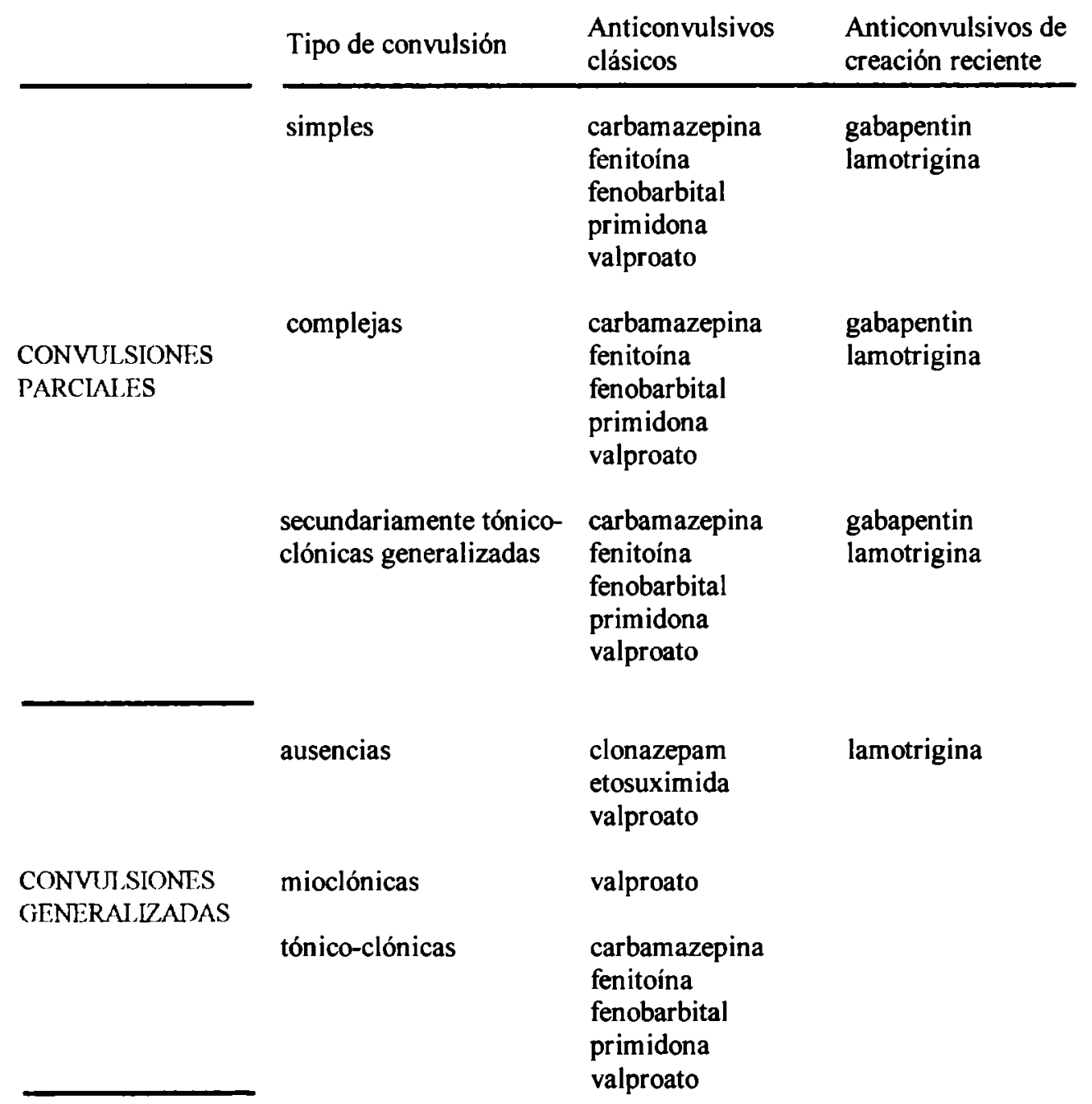

Mientras que entre 1978 y 1993, no se aprobó ninguna nueva droga en los Estados Unidos, a partir de 1993 cinco nuevos agentes han sido aprobados y comercializados: felbamato, gabapentin, lamotrigina, topiramato y tiagabina, y muchas otros están disponibles en otros países $^{1,13}$ (Tabla 3.3). 
Felbamato, gabapentin, lamotrigina, topiramato y tiagabina se encuentran aprobados como tratamientos auxiliares de convulsiones parciales refractarias a otros anticonvulsivos en terapia con una sola droga. Felbamato y lamotrigina también lo están en terapia con una única droga . Sin embargo, felbamato se usa sólo en casos complicados, debido al riesgo de anemia aplástica fatal o hepatotoxicidad que ha resultado de su uso crónico en algunos pacientes ${ }^{16}$.<smiles>NC(=O)OCC(COC(N)=O)c1ccccc1</smiles>

Felbamato<smiles>NCC1(CC(=O)O)CCCCC1</smiles>

Gabapentin<smiles>Nc1nnc(-c2cccc(Cl)c2Cl)c(N)n1</smiles>

Lamotrigina

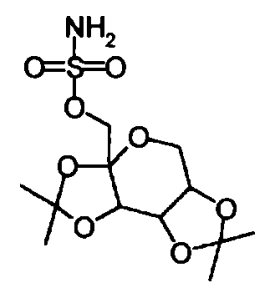

Topiramato

Vigabatrin y zonisamida están en proceso de ser aprobados en los Estados Unidos y se encuentran disponibles comercialmente desde hace varios años en Europa y Japón respectivamente'. Otras drogas se encuentran en etapas tempranas del desarrollo (Tabla 3.3).<smiles>Cc1ccsc1C(=CCCN1CCCC(C(=O)O)C1)c1sccc1C</smiles>

Tiagabina<smiles>O=C(O)C1CCCNC1</smiles><smiles>NS(=O)(=O)Cc1noc2ccccc12</smiles>

Zonisamida<smiles>NCCCC(=O)O</smiles><smiles>C=CC(N)CCC(=O)O</smiles>

Vigabatrin

Resulta evidente que la década de los años 90 ha instaurado grandes avances en el desarrollo de DAEs, constituyendo una era apasionante para los médicos, que ahora pueden tratar pacientes con desórdenes convulsivos refractarios $^{14}$ (Tabla 3.2). Gran parte de esta importante evolución se debe al conocimiento y exploración de nuevos mecanismos de acción.

En la tabla 3.3 se listan las nuevas drogas surgidas en esta etapa. Hay que remarcar que todas presentan estructuras novedosas (Figura 3.2), ninguna deriva de la variación de una droga ya existente ${ }^{1}$. La singularidad de estas estructuras sugiere que los mecanismos celulares y moleculares pueden ser distintos.

Tabla 3.3 (pdgina siguiente).

Nuevas drogas antiepilépticas, comercializadas a partir de los años 90, y en desarrollo. (tomado de Taylor, Ch.P.') 


$\begin{array}{cccccc}\text { Droga } & \begin{array}{c}\text { Año } \\ \text { 1ra. } \\ \text { publ.* }\end{array} & \begin{array}{c}\text { Año } \\ \text { introducida en } \\ \text { el mercado }\end{array} & \begin{array}{c}\text { Compañía } \\ \text { farmacéutica }\end{array} & \begin{array}{c}\text { Estudios } \\ \text { clínicos }\end{array} & \begin{array}{c}\text { Mecanismo de } \\ \text { acción propuesto }\end{array}\end{array}$

\begin{tabular}{|c|c|c|c|c|c|}
\hline Gabapentin & $1975^{4}$ & $\begin{array}{l}1992 \text { (UK) } \\
1993 \text { (US) }\end{array}$ & $\begin{array}{c}\text { PARKE-DAVIS } \\
\text { (WARNER-LAMBERT) }\end{array}$ & $\begin{array}{l}\text { Fase } 3 \\
\text { completa }\end{array}$ & $\uparrow$ sintesis de GABA (?) \\
\hline Vigabatrin & $1977^{77}$ & 1990 (UK) & $\begin{array}{l}\text { MARRION-MERRLL- } \\
\text { DOW }\end{array}$ & $\begin{array}{l}\text { Fase } 3 \\
\text { completa }\end{array}$ & inhibición de GABA-T \\
\hline Zonisamida & $\underset{154}{1979}$ & 1995 (Japón) & DAINIPPON & $\begin{array}{l}\text { Fase } 3 \\
\text { completa }\end{array}$ & $\begin{array}{c}\text { canal } \mathrm{Na}^{+} \\
\text {(canal } \mathrm{Ca}^{++} \text {tipo } \mathrm{T} \text { ) }\end{array}$ \\
\hline $\begin{array}{l}\text { Oxcarbaze- } \\
\text { pina }\end{array}$ & $\underset{155}{1981}$ & 1990 (Europa) & NOVARTIS & $\begin{array}{l}\text { Fase } 3 \\
\text { completa }\end{array}$ & canal $\mathrm{Na}^{+}$ \\
\hline Felbamato & 1984 & $\begin{array}{c}1993 \text { (US) } \\
1995 \text { (Europa) }\end{array}$ & CARTER-WALLACE & $\begin{array}{l}\text { Fase } 3 \\
\text { completa }\end{array}$ & $\begin{array}{c}\text { canal } \mathrm{Na}^{+} \\
\text {(antagonista sitio de } \\
\text { glicina NMDA) } \\
\text { (modulador GABA) }\end{array}$ \\
\hline Lamotrigina & 1984 & $\begin{array}{l}1991 \text { (UK) } \\
1996 \text { (US) }\end{array}$ & GLAXO-WELLCOME & $\begin{array}{l}\text { Fase } 3 \\
\text { completa }\end{array}$ & $\underset{\left(\text { canal } \mathrm{Ca}^{++}\right)}{\text {cana } \mathrm{Na}^{+}}$ \\
\hline Topiramato & 1987 & $\begin{array}{l}1996 \text { (UK) } \\
1997 \text { (US) }\end{array}$ & $\begin{array}{c}\text { MCNEIL } \\
\text { (JOHNSON\&JOHNSON) }\end{array}$ & $\begin{array}{l}\text { Fase } 3 \\
\text { completa }\end{array}$ & $\begin{array}{c}\text { canal } \mathrm{Na}^{+} \\
\text {(antagonista AMPA) } \\
\text { (modulador GABA) }\end{array}$ \\
\hline Tiagabina & 1987 & $\begin{array}{c}1997 \text { (US) } \\
1996-98 \\
\text { (Europa) }\end{array}$ & $\begin{array}{l}\text { NOVO NORDISK, } \\
\text { ABBOTT }\end{array}$ & $\begin{array}{c}\text { Fase } 3 \\
\text { completa }\end{array}$ & $\begin{array}{l}\text { inhibidor retoma de } \\
\text { GABA }\end{array}$ \\
\hline $\begin{array}{l}\text { Remacemi- } \\
\qquad \mathrm{da}\end{array}$ & 1990 & & ASTRA-ZENECA & Fase 3 & $\begin{array}{c}\text { canal } \mathrm{Na}^{+} \\
\text {(antagonista NMDA) }\end{array}$ \\
\hline Losigamona & $\begin{array}{c}1990 \\
156\end{array}$ & & $\begin{array}{l}\text { SCHWABE } \\
\text { (GERMANY) }\end{array}$ & Fase 3 & $\begin{array}{l}\text { canal } \mathrm{Na}^{+}(?) \\
\text { canal } \mathrm{Ca}^{++}(?)\end{array}$ \\
\hline Acea 1021 & $\begin{array}{c}1994 \\
157\end{array}$ & & COSENSYS & Fase 1 & $\begin{array}{l}\text { antagonista sitio de } \\
\text { glicina NMDA } \\
\text { (bloqueo de AMPA) }\end{array}$ \\
\hline LY 300164 & & & LILLY & Fase 2 & $\begin{array}{l}\text { antagonista no } \\
\text { competitivo AMPA }\end{array}$ \\
\hline D 23129 & 1994 & & $\begin{array}{l}\text { ASTA MEDICA } \\
\text { (GERMANY) }\end{array}$ & Fase 1 & $\begin{array}{c}\uparrow \text { sintesis de GABA } \\
\text { antagonista kainato } \\
\text { apertura canal } \mathrm{K}^{+}\end{array}$ \\
\hline GP3269 & 1996 & & GENSIA-SICOR & Fase 1 & $\begin{array}{l}\text { inhibidor adenosina } \\
\text { quinasa }\end{array}$ \\
\hline 534U87 & 1996 & & GLAXO-WELLCOME & $\begin{array}{c}\text { Fase } 1 \\
\text { (discont.") }\end{array}$ & canal $\mathrm{Na}^{+}$ \\
\hline $\begin{array}{l}\text { NNC14- } \\
0185\end{array}$ & & & NOVO NORDISK & $\begin{array}{c}\text { Fase } \\
\text { preclínica }\end{array}$ & $\begin{array}{l}\text { agonista parcial } \\
\text { benzodiazepinas }\end{array}$ \\
\hline Rufinamida & & & NOVARTIS & Fase 3 & canal $\mathrm{Na}^{+}$ \\
\hline Ganaloxona & & & COSENSYS & Fase 2 & $\begin{array}{c}\text { modulación alostérica } \\
\text { GABA }_{\mathrm{A}}\end{array}$ \\
\hline
\end{tabular}

año en que fue publicada por primera vez.

- Fase de los estudios clínicos en que se encuentra: Fase 1 comprende estudios en voluntarios sanos para determinar tolerancia y farmacocinética, Fase 2 denota estudios preliminares de eficacia en 


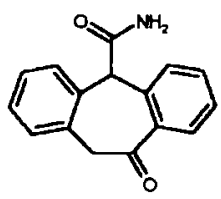

Oxcarbazepina<smiles>O=c1[nH]c2cc(Cl)c(Cl)c([N+](=O)[O-])c2[nH]c1=O</smiles>

ACEA102I<smiles>OC1COC(n2cc(-c3ccccc3)c3c(Nc4ccc(F)cc4)ncnc32)C1O</smiles>
GP3269<smiles>NC(=O)c1cn(Cc2c(F)cccc2F)nn1</smiles>

Rufinamida

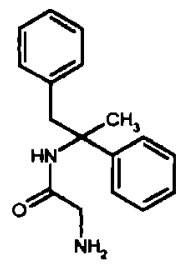

Remacemida<smiles>CC(=O)N1N=C(c2ccc(N)cc2)c2cc3c(cc2CC1C)OCO3</smiles>

LY 300164

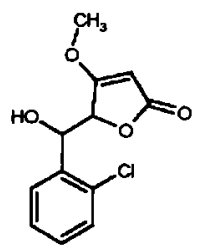

Losigamona

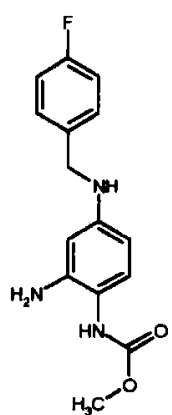

D23129<smiles>Nc1nccc2c1nnn2Cc1c(F)cccc1F</smiles>

$534 U 87$<smiles>C=C(C)C1CCC2C3CCC4CC(C)(O)CCC4(C)C3CCC12C</smiles>

Ganaloxona
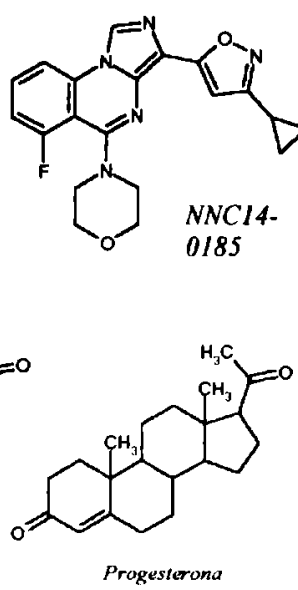

Figura 3.2

Estructuras

de las nuevas

DAEs.

Salvo algunas excepciones sus estructuras no se asemejan entre sí. Mientras que gabapentin y vigabatrin derivan de la estructura del $G A B A y$ tiagabina se relaciona con el ácido nipecótico (ver esquemas anteriores), GP3269 es estructuralmente similar a la adenosina $y$ ganaloxona $a$ la

progesterona

El progreso en el descubrimiento de nuevas DAEs se describe claramente en la serie de reportes sobre las Conferencias que se vienen realizando en Eilat (Israel) desde principios de los años $90^{17,18,19,20}$, en donde se dan a conocer los últimos avances mundiales en el desarrollo de DAEs y se plantean los posibles mecanismos de acción asociados a cada nuevo fármaco.

pacientes epilépticos, Fase 3 indica estudios doble-ciego, controlados por placebo en pacientes epilépticos.

- en la siguiente sección se describirán en detalle cada uno de estos mecanismos por los que actúan las DAEs.

recientemente discontinuada. 


\section{MECANISMOS DE ACCION DE LAS DROGAS ANTIEPILEPTICAS}

La clasificación de las DAEs de acuerdo a su mecanismo de acción es generalmente complicada debido a que muchas drogas poseen más de un mecanismo responsable de la acción anticonvulsiva, estando bajo estudio cuál es el mecanismo primario de cada una'. Este último está en estrecha relación con el perfil farmacológico que exhiben las drogas en su evaluación preclínica en modelos animales, que a la vez es indicativo de la eficacia frente a determinado tipo de convulsión en humanos. El tema en particular de la relación que existe entre el perfil preclínico en animales y la eficacia clínica en humanos se tratará más adelante (sección 4 del capítulo 4), en referencia al empleo de los distintos ensayos de evaluación preclínica.

Durante la evaluación preclínica de las drogas, se utilizó en muchos casos (lamotrigina, zonisamida, felbamato, topiramato y varias otras) la técnica de electroshock (ver más adelante, secciones 4 y 5 del capítulo 4) para la determinación de la capacidad anticonvulsiva. La respuesta positiva en este modelo animal se relaciona con un probable mecanismo de acción por bloqueo de los canales de $\mathrm{Na}^{+}$ neuronales'. Otras drogas fueron seleccionadas sobre otras bases, como los inhibidores selectivos de la enzima GABAtransaminasa (vigabatrin), los inhibidores selectivos de la retoma sináptica de GABA (tiagabina), y varios moduladores alostéricos de los receptores $\mathrm{GABA}_{\mathrm{A}}$. La evaluación inicial con ensayos farmacológicos in vitro relacionados con un sistema específico permitió asignarles un determinado mecanismo de acción. Gabapentin es una de las tantas estructuras análogas de GABA diseñadas químicamente para imitar su acción en el cerebro ${ }^{21}$, que logra cruzar las barreras mucho más fácilmente que éste. Sin embargo, contrariamente a lo supuesto, resultó no ser un agonista de GABA ${ }^{22}$. Otras drogas, como el inhibidor de la adenosina quinasa GP3269, fue diseñado racionalmente para actuar mediante un nuevo mecanismo que todavía no había sido ensayado clínicamente.

En base a lo expuesto, se ve claramente que la tendencia actual se enfoca hacia un desarrollo racional de nuevas DAEs, en donde prevalece la comprensión de los mecanismos de acción asociados a una respuesta anticonvulsiva, dejando en segundo plano los métodos 
clásicos de screening al azar o de variación estructural de compuestos conocidos.

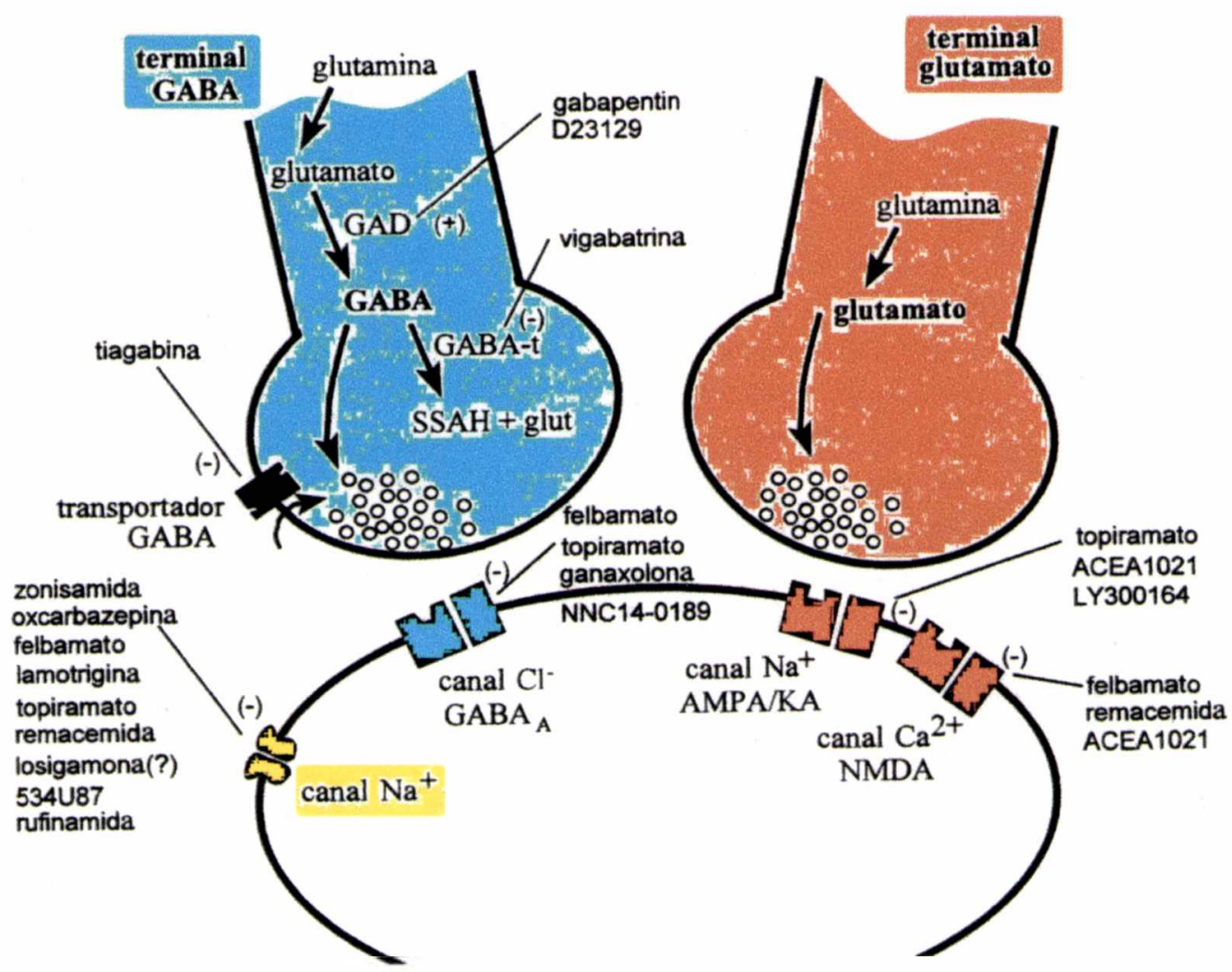

\section{Figura 3.3}

Sitios de acción de las nuevas DAEs.

Las lineas finas indican las drogas que inhiben (-) o incrementan (+) las acciones celulares en los distintos sitios de la terminales nerviosas gabaérgicas o glutamatérgicas y en la membrana postsináptica. Obsérvese que algunas drogas están citadas varias veces debido a que actúan por más de un mecanismo simultáneamente.

en naranja: vía glutamatérgica.

en turquesa: via gabaérgica.

en amarillo: modulación directa de corrientes iónicas.

GAD: glutamato decarboxilasa, GABA: ácido raminobutírico, GABA-t: GABA transaminasa, SSAH: semialdehído succínico, $G A B A_{A}$ : receptor $G A B A_{A}, A M P A / K A$ : receptor AMPA (ácido a-amino-3-hidroxi-5-metil-4-isoxazolpropiónico) o receptor kainato, NMDA: receptor NMDA (N-metil-D-aspartato)

(tomado de Taylor, Ch.P.')

El conocimiento logrado a nivel molecular permite centrarse en los mecanismos más importantes por los que las DAEs manifiestan sus acciones, los cuales pueden recapitularse de la siguiente manera: 


\section{$\checkmark$ aumento de la inhibición neuronal mediada por GABA, \\ $\checkmark$ disminución de la neurotransmisión excitatoria mediada por glutamato, $y$ \\ $\checkmark$ modulación de los canales iónicos.}

Estos mecanismos generales constituyen las principales estrategias a seguir en el desarrollo de nuevas DAEs.

En la figura 3.3 se representan esquemáticamente estas tres vías de acción en forma conjunta, y las nuevas DAEs capaces de interactuar en cada punto de estos procesos.

En el caso de muchos antiepilépticos clásicos e incluso de algunos nuevos, son varios los procesos que se encuentran implicados simultáneamente en la respuesta biológica (Tabla 3.4 y figura 3.3).

\begin{tabular}{|c|c|c|c|}
\hline $\begin{array}{l}\text { Tabla } 3.4 \\
\text { Perfil } \\
\text { mecanístico } \\
\text { de las } \\
\text { DAEs } \\
\text { clásicas y } \\
\text { nuevas. }\end{array}$ & $\begin{array}{l}\text { Mecanismo de acción } \\
\text { propuesto }\end{array}$ & $\begin{array}{l}\text { Anticonvulsivos } \\
\text { clásicos }\end{array}$ & $\begin{array}{l}\text { Anticonvulsivos de } \\
\text { creación reciente }\end{array}$ \\
\hline \multirow[t]{4}{*}{$\begin{array}{l}\text { (tomado de } \\
\text { White, } \\
\text { H.S. }{ }^{14} \text { ) }\end{array}$} & $\begin{array}{l}\text { Bloqueo de los canales de } \\
\mathrm{Na}^{+} \text {voltaje-dependientes }\end{array}$ & $\begin{array}{l}\text { fenitoína } \\
\text { carbamazepina } \\
\text { valproato }\end{array}$ & $\begin{array}{l}\text { felbamato } \\
\text { gabapentin } \\
\text { lamotrigina } \\
\text { topiramato } \\
\text { oxcarbazepina } \\
\text { zonisamida } \\
\text { remacemida }^{1} \\
\text { rufinamida }^{1} \\
\text { ralitolina }^{18} \\
\text { dezinamida }^{18} \\
\text { Vinpocetina }^{54}\end{array}$ \\
\hline & $\begin{array}{l}\text { Incremento de la inhibición } \\
\text { mediada por GABA }\end{array}$ & $\begin{array}{l}\text { benzodiazepinas } \\
\text { fenobarbital } \\
\text { valproato (?) }\end{array}$ & $\begin{array}{l}\text { vigabatrin } \\
\text { tiagabina } \\
\text { gabapentin } \\
\text { felbamato } \\
\text { topiramato } \\
\text { zonisamida }\end{array}$ \\
\hline & $\begin{array}{l}\text { Bloqueo de los canales de } \\
\mathrm{Ca}^{++} \text {voltaje-dependientes }\end{array}$ & $\begin{array}{l}\text { etosuximida } \\
\text { valproato (?) }\end{array}$ & $\begin{array}{l}\text { gabapentin } \\
\text { zonisamida } \\
\text { felbamato } \\
\text { lamotrigina } \\
\text { oxcarbazepina }\end{array}$ \\
\hline & $\begin{array}{l}\text { Disminución de la excitación } \\
\text { mediada por glutamato }\end{array}$ & & $\begin{array}{l}\text { felbamato } \\
\text { topiramato }\end{array}$ \\
\hline
\end{tabular}

A continuación se describirán brevemente cada uno de estos mecanismos de acción generales, haciendo hincapié no sólo en la forma en que cada uno de ellos se manipula farmacológicamente para lograr la prevención de la excesiva excitación convulsiva, sino también en los sitios específicos 
en donde hoy se conoce que actúan algunas de las ampliamente utilizadas DAEs clásicas.

\section{Modulación directa de los canales iónicos}

El ambiente iónico es vital para la excitabilidad de las neuronas. Todas las drogas en última instancia manifiestan sus acciones a nivel iónico en las sinapsis y membranas, ya sea actuando directa $\mathrm{o}$ indirectamente sobre las conductancias iónicas ${ }^{23}$. Una acción directa sobre la conductancia iónica de la membrana neuronal afecta la tendencia al disparo de los potenciales de acción. Sin embargo, la posibilidad de desarrollar drogas que modulen selectivamente la regulación iónica de la excitabilidad neuronal no fue posible sino hasta el descubrimiento y caracterización de los canales iónicos ${ }^{24}$. Los canales catiónicos regulados por voltaje son una importante superfamilia de proteínas de membrana excitables, siendo de gran importancia los canales de $\mathrm{Na}^{+}$, como también los de $\mathrm{Ca}^{++}$y los de $\mathrm{K}^{+}{ }^{15}$. Distintas drogas pueden modular el funcionamiento de estos canales catiónicos mediante la unión a sitios receptores ubicados en algunas de sus subunidades ${ }^{24}$.

\section{Canales de sodio.}

Los canales de $\mathrm{Na}^{+}$dependientes del voltaje son responsables de la propagación de los potenciales de acción en las fibras mielinizadas y no mielinizadas. Son capaces de adoptar 3 estados conformacionales: abierto, de reposo e inactivado $^{25}$. Cada estado permite una determinada permeabilidad al $\mathrm{Na}^{+}{ }^{26}$. Luego de que la membrana se despolariza, la permeabilidad al $\mathrm{Na}^{+}$aumenta y éste entra en la célula, siguiendo luego un retorno al estado normal ${ }^{25}$ (Figura 3.4).

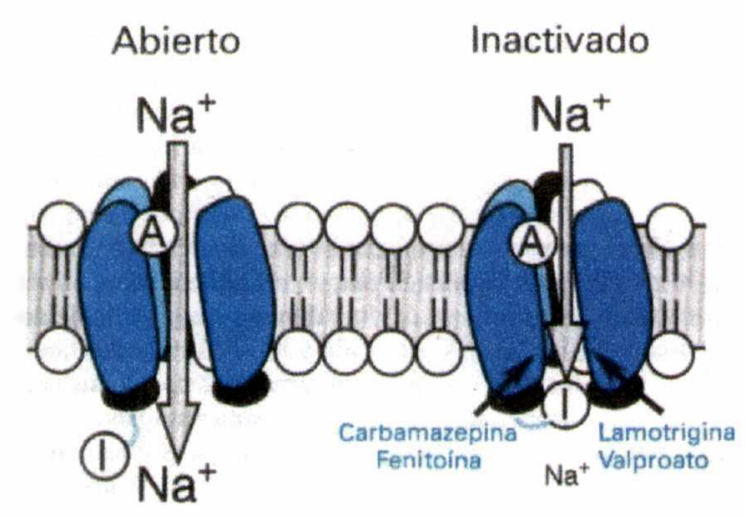

Figura 3.4

Inactivación del canal de $\mathrm{Na}^{+}$, intensificada por el fármaco anticonvulsivo, que reduce la capacidad de las neuronas para efectuar activación a frecuencias altas.

A: compuerta de activación. I: compuerta de inactivación. (tomado de McNamara, $J . .^{27}$ )

Durante una convulsión, se observa que las neuronas presentan despolarización y potenciales de acción de 
activación a frecuencias altas. Este patrón de activación neuronal es característico de las convulsiones, y es infrecuente durante la actividad neuronal fisiológica ${ }^{27}$. Carbamazepina, lamotrigina, fenitoína y ácido valproico inhiben esta activación de alta frecuencia en neuronas del foco epiléptico ( $\sin$ afectar la generación de potenciales por parte de neuronas centrales normales) ${ }^{28}$, lo cual se considera que está mediado por la disminución en la capacidad de los canales de $\mathrm{Na}^{+}$de recuperarse de dicha activación ${ }^{27}$. Esto es, se requiere la apertura desencadenada por la despolarización de los canales de $\mathrm{Na}^{+}$en la membrana axoniana de una neurona, para que se produzca un potencial de acción. Después de su apertura, los canales se cierran de manera espontánea, proceso que se denomina inactivación. Se piensa que esta inactivación da origen al período refractario, lapso breve después de un potencial de acción durante el cual es imposible evocar otro potencial. Al recuperarse de la inactivación, los canales de $\mathrm{Na}^{+}$quedan de nuevo preparados para participar en otro potencial de acción. Como la activación a una velocidad baja da un tiempo suficiente para que los canales se recuperen de la inactivación, ésta tiene poco o ningún efecto en la estimulación de baja frecuencia. Sin embargo, el decremento en la velocidad de recuperación de los canales limitaría la capacidad de una neurona para activar a frecuencias altas, efecto que quizás sea por el que actúan carbamazepina, lamotrigina, fenitoína y ácido valproico ${ }^{27}$.

Se postula que el sitio de acción de los anticonvulsivos se encuentra en el lado intracelular del canal $^{25}$ (Figura 3.4), y al activarse se produce una inhibición alostérica del sitio 2 de neurotoxinas ${ }^{29}$ (ver más adelante, capítulo 5).

Canales de calcio.

Los canales de $\mathrm{Ca}^{++}$juegan un rol fundamental en la función neuronal ${ }^{15}$. Se clasifican en cuatro tipos principales $(T$, $\mathrm{N}$, L y P) encontrándose todos ellos en neuronas.

Las descargas de potenciales de acción de las neuronas talámicas son mediadas por la activación de los canales de $\mathrm{Ca}^{++}$tipo T regulados por voltaje ${ }^{27}$ (Figura 3.5). El mecanismo principal por medio del cual parece actuar la mayor parte de los fármacos en las crisis de ausencia (etosuximida, ácido valproico, trimetadiona) es la inhibición de la corriente $\mathrm{T}^{30}$. 


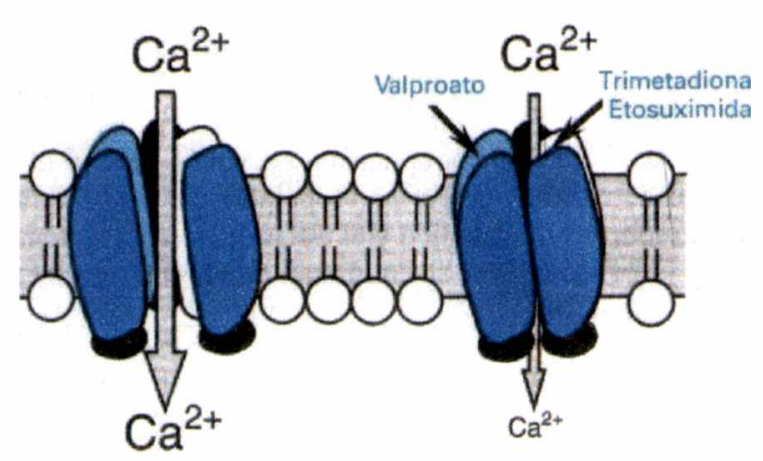

Figura 3.5

Reducción de la corriente por los canales de $\mathrm{Ca}^{++}$del tipo $T$, inducida por los fármacos anticonvulsivos.

(tomado de McNamara, J.O. ${ }^{27}$ )

\section{Canales de potasio.}

La conductancia al $\boldsymbol{K}^{+}$está involucrada en el control de la excitabilidad neuronal ${ }^{24}$. La activación de los canales de $\mathrm{K}^{+}$se piensa que hiperpolariza las neuronas y por lo tanto las inhibe. Se han desarrollado drogas selectivas para estos canales, pero aún no se han logrado análogos capaces de penetrar la barrera hemato-encefálica $(\mathrm{BHE})^{31}$.

\section{Disminución de la excitación mediada por glutamato}

Los aminoácidos glutamato y aspartato son los principales neurotransmisores excitatorios del sistema nervioso central de los mamíferos.

Existe cada vez más evidencia de que una anormalidad en la neurotransmisión mediada por glutamato puede contribuir al fenómeno epiléptico ${ }^{32,33,34,35,36}$. Los receptores de aminoácidos excitatorios consisten en al menos tres tipos ionotrópicos y un tipo metabotrópico, pudiendo este último clasificarse en ocho subtipos diferentes (como se verá con mayor detalle en el capítulo 6). Los receptores ionotrópicos son canales iónicos regulados por ligando y son los más extensamente estudiados ${ }^{25}$, mientras que los del tipo metabotrópico están acoplados a proteínas $\mathrm{G}$ y su activación desencadena una respuesta metabólica. Los primeros están acoplados a un canal catiónico que se abre en respuesta a la unión de agonistas, lo cual despolariza a la célula, y se clasifican de acuerdo a los agonistas selectivos para cada uno. Los principales son: NMDA (N-metil-D-aspartato), AMPA (ácido $\alpha$-amino-3-hidroxi-5-metil-4-isoxazolpropiónico) y kainato ${ }^{25}$.

El hecho de que los antagonistas del receptor NMDA, tanto competitivos como no competitivos, han demostrado ser efectivos como anticonvulsivos en varios modelos animales de 
epilepsia ${ }^{37}$ fomentó en gran medida esta línea de investigación.

El receptor NMDA consta de un sitio de unión de glutamato y un sitio para el co-agonista glicina, debiendo estar ambos sitios ocupados para que se produzca la apertura del canal, permitiendo el pasaje de $\mathrm{Ca}^{+}$y Na$^{+}$hacia el interior de la célula y de $\mathrm{K}^{+}$hacia el exterior ${ }^{15}$. Drogas clásicas, como fenitoína, carbamazepina y ácido valproico bloquean en cierta medida las respuestas mediadas por el $\mathrm{NMDA}^{38,39}$. Sin embargo, a pesar de que el desarrollo de antagonistas selectivos del receptor NMDA aparecía como una prometedora estrategia para el diseño racional de nuevas DAEs no ha dado resultados tan beneficiosos como se esperaba, en el sentido de que prácticamente todos los antagonistas produjeron importantes efectos adversos psicotomiméticos, como confusión ${ }^{15}$. A este problema se sumó el hecho de que en algunos tipos de epilepsia, los pacientes están más predispuestos a la psicopatología ${ }^{40}$ que las personas sanas.

Otras estrategias alternativas para la disminución de la neurotransmisión glutamatérgica consisten en el uso de drogas que actúan en el sitio de glicina del receptor NMDA, antagonistas de los receptores ionotrópicos AMPA y kainato, ligandos del receptor metabotrópico, y drogas que inhiban la liberación de glutamato ${ }^{33,34,36,41,42}$.

\section{Incremento de la inhibición gabaérgica}

El GABA es el principal neurotransmisor inhibitorio en el cerebro ${ }^{25}$. El incremento de la inhibición sináptica mediada por el GABA reduce la excitabilidad neuronal y eleva el umbral convulsivo ${ }^{27}$. Hay gran evidencia que demuestra que éste es el mecanismo de acción de varias DAEs clásicas usadas en clínica, particularmente barbituratos, benzodiazepinas y ácido valproico ${ }^{43}$. También diversos fármacos de la nueva generación bloquean las convulsiones al fomentar la inhibición sináptica mediada por GABA a través de una actividad en distintos sitios de la sinapsis gabaérgica (Figura 3.3). En medio fisiológico, el GABA se encuentra casi exclusivamente en su forma zwitteriónica, siendo prácticamente incapaz de penetrar la BHE, por lo tanto una condición que deben cumplir los nuevos análogos es contar con una mayor capacidad de atravesarla ${ }^{25}$.

El GABA se sintetiza en las neuronas gabaérgicas a partir de glutamato, gracias a la enzima glutamato decarboxilasa $(\mathrm{GAD})^{25}$. Se sabe que una de las acciones del ácido valproico es la de aumentar los niveles de GABA mediante el incremento de la actividad de la enzima $\mathrm{GAD}^{44}$. 
La metabolización del GABA se lleva a cabo tanto en las neuronas como en la glia, mediante su conversión a semialdehído succínico catalizada por la enzima GABA transaminasa (GABA-t). La inactivación de esta enzima conduce a la acumulación de GABA en el cerebro ${ }^{25}$.

Una vez liberado en la hendidura sináptica, el GABA puede actuar en alguno de sus receptores, o bien ser recaptado a las terminales nerviosas o a las células gliales ${ }^{45}$. Una acción para disminuir este efecto es el desarrollo de agentes inhibidores de esta retoma como el ácido nipecótico, un análogo de GABA, que bloquea este proceso pero no es capaz de penetrar la $\mathrm{BHE}^{25}$.

El principal receptor postsináptico es el receptor ionotrópico $\mathrm{GABA}_{\mathrm{A}}$, aunque también existen los receptores $\mathrm{GABA}_{\mathrm{B}}$, que están acoplados a través de proteínas $\mathrm{G}$ con canales de $\mathrm{K}^{+}$y Ca ${ }^{++}$neuronales ${ }^{46}$ y han sido implicados en la modulación presináptica de la liberación de GABA, aunque su función es limitada ${ }^{46}$.

La activación del receptor $\mathrm{GABA}_{\mathrm{A}}$ inhibe a la célula postsináptica, al incrementar el flujo de iones $\mathrm{Cl}^{-}$hacia el interior de la célula, lo cual tiende a hiperpolarizar a la neurona ${ }^{27}$ (Figura 3.6). Las benzodiazepinas y los barbitúricos actúan facilitando la inhibición gabaérgica mediante la unión a sitios moduladores en el receptor $\mathrm{GABA}_{\mathrm{A}}{ }^{15,25,27}$. El sitio de

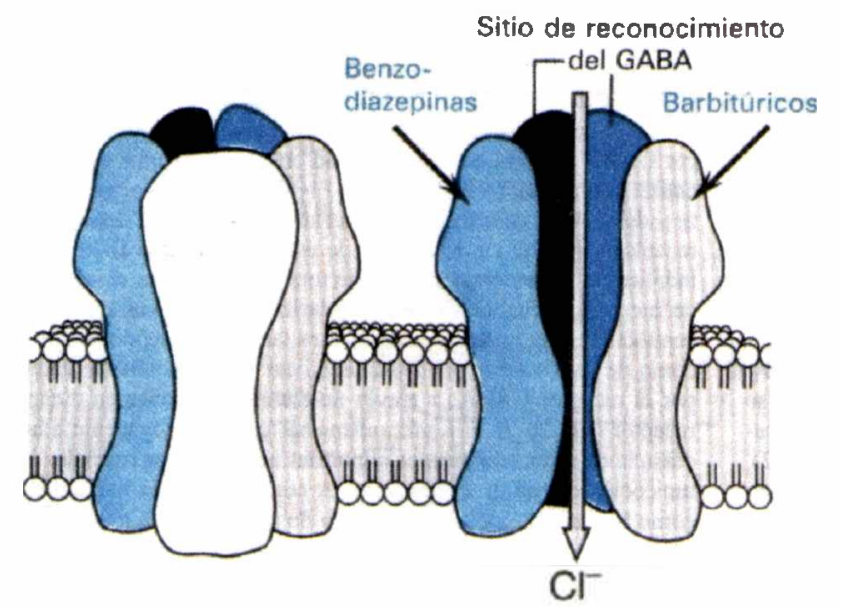
Figura 3.6
En presencia de $G A B A$, el receptor $G A B A_{A}$ se abre, lo que permite la entrada de $\mathrm{Cl}$, que a su vez incrementa la polarización de la membrana Algunos fármacos anticonvulsivos favorecen la entrada de $\mathrm{Cl}$.
(tomado de McNamara, $J . \mathrm{O}^{27}$

unión a benzodiazepinas es un sitio alostérico que interactúa con el sitio de reconocimiento de $\mathrm{GABA}^{47}$ y el efecto es aumentar el número de canales de $\mathrm{Cl}^{-}$abiertos por una cierta concentración de $\mathrm{GABA}^{48}$. Los barbitúricos, en cambio, incrementan el tiempo promedio de apertura del canal ${ }^{15}$.

Además del sitio de agonistas y de los sitios moduladores de benzodiazepinas y barbitúricos, el receptor $\mathrm{GABA}_{\mathbf{A}}$ comprende también varios otros sitios de unión a drogas mediante los cuales puede modularse farmacológicamente el efecto del GABA en la conductancia al $\mathrm{Cl}^{-}$. Ciertos esteroides muestran el mismo efecto que los 
barbitúricos, pero gracias a la unión a un sitio distinto. Varios compuestos convulsivos, como picrotoxina, PTZ y TBPS ( $t$ butilbiciclofosforotionato) se unen a otro sitio mediante lo cual reducen a través de un impedimento estérico el pasaje de $\mathrm{Cl}$ por el canal ${ }^{15}$.

Los receptores $\mathrm{GABA}_{\mathbf{A}}$ muestran una heterogeneidad estructural llamativa en el cerebro, comprendiendo cinco clases de subunidades diferentes $(\alpha, \beta, \gamma, \delta, \rho)$ las cuales consisten de varias variantes (existen, por ejemplo, al menos 6 clases distintas de subunidades $\alpha)^{49}$. Asumiendo que el receptor $\mathrm{GABA}_{\mathbf{A}}$ tiene una estructura pentamérica compuesta de dos subunidades $\alpha$ y dos $\beta$, junto con una $\gamma$ o una $\delta$, el número teórico de variantes posibles excede las $500^{50}$.

No todos los sitios de unión descriptos están presentes en cada subtipo de receptor $\mathrm{GABA}_{\mathrm{A}}$. El sitio de benzodiazepinas se encuentra en la subunidad $\alpha$, mientras que el sitio de GABA está localizado en la subunidad $\beta$, siendo necesarias las subunidades $\gamma_{2}$ y $\gamma_{3}$ para la funcionalidad de estos sitios $^{50,51}$. Además, la farmacología de los sitios alostéricos y del sitio de GABA mismo es dependiente de la composición de las subunidades ${ }^{52}$.

En vista de la heterogeneidad de receptores $\mathrm{GABA}_{\mathrm{A}}$ y la potencial diversidad de funciones ${ }^{49,50,52}$, pueden surgir nuevos conceptos de desarrollo de drogas en el sentido de que ligandos selectivos de los subreceptores $\mathrm{GABA}_{\mathrm{A}}$ pueden presentar ventajas como DAEs, comparados con los agonistas tradicionales no selectivos ${ }^{15}$.

\section{Mono y politerapia con fármacos antiepilépticos}

El concepto futuro en cuanto al tratamiento de la epilepsia está orientado a la monoterapia o a la politerapia racional. El concepto de monoterapia esta restringido a la manipulación de un único mecanismo farmacológico, y no a la administración de una única droga (pseudomonoterapia) que puede tener varios modos de acción, no todos necesariamente deseados. La politerapia enfoca el tratamiento mediante más de un mecanismo de acción, empleando una droga para cada mecanismo ${ }^{53}$.

Por un lado, drogas como ETH con un espectro de acción reducido (Tabla 3.2) probablemente debido a su acción mediada por un único mecanismo (Tabla 3.4), son útiles para ciertos tipos de convulsiones. Pero en muchos casos, cuando el tipo de epilepsia a tratar está asociado a un conjunto de mecanismos fisiopatológicos, lo ideal sería el tratamiento con una droga que intervenga en varios mecanismos simultáneamente, tal como el ácido valproico. 
En este caso también sería eficaz la politerapia racional, recurriendo al empleo de varias drogas con mecanismos de acción únicos, pero que en suma no produzcan más efectos secundarios que si se usara una sola droga múltiple.

La tendencia al uso de drogas con mecanismos puros depende del progreso en el conocimiento íntimo de la epileptogénesis y del desarrollo de nuevos fármacos en base a este conocimiento. Probablemente en un futuro nos encontraremos frente a una elección mucho más racional de los tratamientos farmacológicos, implicando tanto el uso de drogas nuevas con mecanismos puros, como así también drogas clásicas con mecanismos múltiples.

\footnotetext{
${ }^{1}$ Taylor, Ch.P. Cap.69: Mechanisms of New Antiepileptic Drugs. En: Delgado-Escueta, A.V.; Wilson, W.A.; Olsen, R.W.; Porter, R.J. (Eds.), Jasper's Basic Mechanisms of the Epilepsis, $3^{\text {rd }}$ Ed.: Advances in Neurology, Vol.79, Lippincott Williams \& Wilkins, Philadelphia (1999) pp. $1011-1026$

${ }_{2}^{2}$ Locock C.; Sieveking, E.H. Lancet (1857) 1:527

${ }^{3}$ Hauptmann, A. Munch Med Wochenschr (1912) 59: 1907-9

${ }^{4}$ Merrit, H.H.; Putnam, T.J. Arch Neurol Psychiatry (1938) 39: 1003-15

${ }^{5}$ Merrit, H.H.; Putnam, T.J. JAMA (1938) 111: 1068-73

${ }^{6}$ Spiegel, E.A. J. Lab. Clin. Med. (1937) 22: 1274-6

${ }^{7}$ Federal Food and Drugs Act of 1906. Public Law 384, $59^{\text {th }}$ Congress

${ }^{8}$ Chen, G.; Portman, R.; Ensor, C.R.; Bratton, A.C.Jr. J. Pharmacol. Exp. Ther. (1951) 103: 54-61

${ }^{9}$ Drug Amendments Act of 1962. Public Law 87-781, 21 USC 355

${ }^{10}$ Public Health Service Advisory Committee on the Epilepsies. Minutes of meeting, February 9, 1967. Bethesda, Md.: National Institutes of Health (1967)

${ }^{11}$ Porter, R.J.; Cereghino, J.J.; Gladding, G.D.; Hessie, B.J.; Kupferberg, H.J.; Scoville, B.; White, B.G. Clev. Clin. Q. (1984) 51: 293-305

${ }^{12}$ Stables, J.P.; Kupferberg, H.J. Cap.16: The NIH Anticonvulsant Drug Development (ADD) Program: preclinical anticonvulsant screening project. En: Avanzini, G.; Regesta, G.; Tanganelli, P.; Avoli, M. (Eds.), Molecular and cellular targets for anti-epileptic drugs John Libbey \& Company Ltd. (1997) pp. 191-8

${ }^{13}$ Bazil, C.W.; Pedley, T.A. Annu. Rev. Med. (1998) 49: 135-62

${ }^{14}$ White, H.S. Epilepsia (1999) 40(5): S2-S10

${ }^{15}$ Loscher, W.; Schmidt, D. Epilepsy Research (1994) 17: 95-134

${ }^{16}$ Bebin, E.M.; Sofia, R.D.; Dreifuss, F.E. Felbamate: Toxicity. En: Levy, R.H.; Mattson, R.H.; Meldrum, B.S. (Eds.) Antiepileptic Drugs. Raven Press, New York (1995) pp. 823-7

${ }^{17}$ Stables, J.P.; Bialer, M.; Johannessen, S.I.; Kupferberg, H.J.; Levy, R.H.; Loiseau, P.; Perucca, E. Epilepsy Res. (1995) 22(3): 235-46

${ }^{18}$ Bialer, M.; Johannessen, S.I.; Kupferberg, H.J.; Levy, R.H.; Loiseau, P.; Perucca, E. Epilepsy Res. (1996) 25(3): 299-319
} 
${ }^{19}$ Bialer, M.; Johannessen, S.I.; Kupferberg, H.J.; Levy, R.H.; Loiseau, P.; Perucca, E. Epilepsy Res. (1999) 34(1): 1-41

${ }^{20}$ Bialer, M.; Johannessen, S.I.; Kupferberg, H.J.; Levy, R.H.; Loiseau, P.; Perucca, E. Epilepsy Res. (2001) 43(1):11-58

${ }^{21}$ Satzinger, G. Drug Res. (1994) 44: 261-6

${ }^{22}$ Taylor, C.P. Gabapentin: Mechanisms of Action. En: Levy, R.H.; Mattson, R.H.; Meldrum, B.S. (Eds.) Antiepileptic Drugs. Raven Press, New York (1995) pp. 829-41

${ }^{23}$ Porter, R.J. Epilepsia (1989) 30: 29-34

${ }^{24}$ Faingold, C.L. Overview of ion channels, antiepileptic drugs, and seizures. En: Faingold, C.L.; Fromm, G.H. (Eds.) Drugs for Control of Epilepsy: Actions on Neuronal Networks Involved in Seizure Disorders. CRC Press, Boca Ratón, Florida (1992) pp. 57-68

${ }^{25}$ Edafiogho, I.; Scott, K. Cap. 39: Anticonvulsants. En: Wolff, M. (Eds.), Burger's Medicinal Chemistry and Drug Discovery $5^{\text {th }}$ Ed. Vol.3:

Therapeutic Agents, John Wiley \& Sons Inc. (1996) pp. 175-254

${ }^{26}$ Catterall, W.A. Trends Pharmacol. Sci. (1987) 8: 57-65

${ }^{27}$ McNamara, J.O. Cap.20: Fármacos Eficaces para el Tratamiento de las Epilepsias En: Hardman, J.G.; Limbird, L.E.; Molinoff, P.B.; Ruddon, R.W.; Goodman Gilman, A. (Eds.) Las Bases Farmacológicas de la Terapéutica, 9na Ed., Vol.I McGraw-Hill InterAmericana, México (1996) pp. $491-519$

${ }^{28}$ Catterall,W.A. Trends Pharmacol. Ther. (1987) 8: 57-65

${ }^{29}$ Foster, A.C.; Fagg, G.E. Brain Res. Rev. (1984) 7: 103-164

${ }^{30}$ MacDonald, R.L.; Kelly, K.M. Epilepsia (1993) 34(Suppl.5): SI-S8

${ }^{31}$ Porter, R.J.; Rogawski, M.A. Epilepsia (1992) 33: S1-S6

${ }^{32}$ Dingledine, R.; McBain, C.J.;McNamara, J.O. Trends Pharmacol. Sci. (1990) 11: 334-8

${ }^{33}$ Loscher, W. Curr. Opin. Neurol. Neurosurg. (1993) 6: 223-32

${ }^{34}$ Meldrum, B.S. Epilepsy Res. (1992) 12: 189-96

${ }^{35}$ Mutani, R.; Cantello, R.; Gianelli, M.; Bettucci, D. Rational Basis for the Development of New Antiepileptic Drugs. En: Pisane, F.; Perucca, E.; Avanzini, G.; Richens, A. (Eds.) New Antiepileptic Drugs. Epilepsy Res. Suppl. 3 Elsevier, Amsterdam (1991) pp. 23-8

${ }^{36}$ Rogawski, M.A.; Porter, R.J. Pharmacol. Rev. (1990) 42: 223-85

${ }^{37}$ Meldrum, B.S. En: Hicks, T.P.; Lodge, D.; McLennan, H. (Eds.)

Excitatory Amino Acid Transmission, Neurology and Neurobiology, Vol.24. Alan R. Liss, Inc., New York (1987) pp. $189-96$

${ }^{38}$ McLean, M.J. Pol. J. Pharmacol. Pharm. (1992) 44: 46-7

${ }^{39}$ Wamil, A.W.; McLean, M.J. J. Pharmacol. Exp. Ther. (1993) 267(1): 218-27

${ }^{40}$ Trimble, M.R. Epilepsy Res. (1991) 10: $71-9$

${ }^{41}$ Carter, A.J. Drugs Future (1992) 17: 595-613

${ }^{42}$ Rogawski, M.A. Drugs (1992) 44: $279-92$

${ }^{43}$ Loscher, W. GABA and the Epilepsies. Experimental and Clinical Considerations. En: Bowery, N.G.; Nisticó, G. (Eds.) GABA. Basic Research and Cellular Applications. Pythagora Press, Rome (1989) pp. 260-300

${ }^{44}$ Loscher, W. Neurochem. Res. (1993) 18: 485-502

${ }^{45}$ Woodruff, G.N.; Foster, A.C.; Gill, R.; Kemp, J.A.; Wong, E.F.H.; Iversen, L.L. Neuropharmacology (1987) 26: 903-9

${ }^{46}$ Bowery, N.G.; Pratt, G.D. Arzneim.-Forsch. (Drug Res.) (1992) 42 215-23

${ }^{47}$ Meldrum, B.S.; Chapman, A.G. Epilepsia (1986) 27(Suppl.1): S3-S13

${ }^{48}$ Taft, W.C.; DeLorenzo, R.J. Proc. Natl. Acad. Sci. USA (1984) 81: 3118-22

${ }^{49}$ Mohler, H. Arzneim.-Forsch. (Drug Res.) (1992) 42: 211-4 


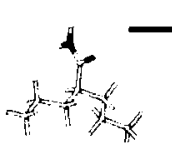

${ }^{50}$ Luddens, H.; Wisden, W. Trends Pharmacol. Ther. (1991) 12: 49-51

${ }^{31}$ Doble, A.; Martín, I.L. Trends Pharmacol. Sci. (1992) 13: 76-81

${ }^{52}$ Sieghart, W. Trends Pharmacol. Ther. (1992) 13: 446-50

${ }^{53}$ Gram, L. Epilepsia (1995) 36(6): S22-S24

${ }^{54}$ Molnar, P.; Erdo, S.L. Eur. J. Pharmacol. (1995) 273: 303 


\section{$\infty$ CAPITULO $4 \propto$}

\section{DESCUBRIMIENTO DE NUEVAS DROGAS CON ACCION ANTICONVULSIVA}

El fin principal de la investigación expuesta en este trabajo de Tesis es el descubrimiento de nuevas drogas para el tratamiento de la epilepsia. Puntualmente el aporte a este conocimiento consiste en la búsqueda de los requisitos mínimos que debe presentar una estructura para manifestar actividad anticonvulsiva. Se plantean para ello metodologías indirectas de Diseño Racional. El punto de partida es la elección de un compuesto líder sobre el cual se proponen variaciones químicas tendientes a su optimización, tanto en el incremento de su potencia como en la disminución de efectos colaterales. El paso siguiente es la síntesis y evaluación biológica de los derivados planteados. Contando así con seis estructuras análogas e incluyendo además otros siete compuestos con un mismo perfil farmacológico, se identifica un farmacóforo para la acción protectora frente a las convulsiones provocadas por el Electroshock Máximo (más adelante, en las secciones 4 y 5 del capítulo 4 , se describirán en detalle las técnicas de evaluación anticonvulsiva en animales). Basándose en el conocimiento adquirido, se procede luego al Diseño de nuevas estructuras, y por último se realiza un análisis QSAR incluyendo a todos los derivados estudiados.

A lo largo de este capítulo se describirán estas etapas, precisando en cada caso la justificación de la metodología elegida, los resultados obtenidos, las discusiones y conclusiones alcanzadas. 


\section{ELECCIÓN DEL COMPUESTO LIDER Y PLANTEO DE LAS METODOLOGÍAS DE OPTIMIZACION}

Según se discutió en el capítulo 3 (ítem "Resurgimiento del interés por el descubrimiento de nuevos agentes antiepilépticos"), todo antiepiléptico clásico es factible de ser mejorado, debido fundamentalmente a que todos poseen efectos adversos asociados, además de la alta refractariedad observada en los tratamientos actuales. A pesar de los grandes avances logrados en los años 90 en el desarrollo de nuevos fármacos antiepilépticos, aún sigue existiendo una gran demanda de nuevos y mejores tratamientos ${ }^{1}$.

El ácido valproico ( $\mathrm{Vpa}$ ) es el compuesto líder seleccionado en la presente investigación como estructura básica sobre la cual trabajar. Existen varias razones para esta elección.

En primer lugar, el Vpa es una droga de primera opción en la fase clínica. En el momento de la indicación médica, tiene gran importancia el hecho de ser la droga antiepiléptica con mayor espectro de acción, efectiva tanto frente a las convulsiones parciales como a las generalizadas (ver tabla 3.2 del capítulo 3$)^{2}$.

No se conocen con precisión las bases moleculares de la acción anticonvulsiva del $\mathrm{Vpa}$, aunque se postulan tres mecanismos posibles:

$\checkmark$ interacción con los canales de sodio voltaje dependientes ${ }^{3}$,

$\checkmark$ reducción de la corriente de canales $T$ de calcio ${ }^{4}$,

$\checkmark$ elevación de la concentración en cerebro de ácido $\gamma$-aminobutírico (GABA) y potenciación de sus respuestas ${ }^{5}$.

La convulsión epiléptica puede deberse a múltiples factores. Por ello, las drogas antiepilépticas con varios mecanismos de acción, tales como el $\mathrm{Vpa}$, tienen claras ventajas en su eficacia antiepiléptica clínica respecto a las drogas de efecto selectivo. Por otro lado, al existir varios mecanismos de acción implicados en la manifestación de su acción, es muy probable que las modificaciones realizadas en su estructura permitan obtener nuevos compuestos que conserven al menos alguno de estos mecanismos.

Además, este compuesto líder posee una ventaja adicional desde el punto de vista químico-medicinal. A 
diferencia de la complejidad molecular asociada a los anillos heterocíclicos de la mayoría de los antiepilépticos de uso clínico, el $\mathrm{Vpa}$ es estructuralmente una molécula alifătica simple (ácido dipropilacético). Esto brinda la posibilidad de obtener información relevante a partir de un número discreto de modificaciones moleculares, ya que pueden proponerse dos únicas opciones de modificación estructural: trabajar sobre el grupo funcional carboxilato o sobre las calenas hidrocarbonadas alifáticas.

\footnotetext{
'Taylor, Ch.P. Cap.69: Mechanisms of New Antiepileptic Drugs. En: Delgado-Escueta, A.V.; Wilson, W.A.; Olsen, R.W.; Porter, R.J. (Eds.), Jasper's Basic Mechanisms of the Epilepsis, $3^{\text {rd }}$ Ed: Advances in Neurology, Vol.79, Lippincott Williams \& Wilkins, Philadelphia (1999) pp. 1011-1026

${ }_{2}^{2}$ McNamara, J.O. Cap.20: Fármacos Eficaces para el Tratamiento de las Epilepsias En: Hardman, J.G.; Limbird, L.E.; Molinoff, P.B.; Ruddon, R.W.; Goodman Gilman, A. (Eds.) Las Bases Farmacológicas de la Terapéutica, 9ma Ed., Vol.I McGraw-Hill InterAmericana, México (1996) pp. 491-519

${ }^{3}$ White, HS. Mechanisms of antiepileptic drugs. En: Porter, R;

Chadwick, D. (Eds.), Epilepsies 11, Butterworth-Heinemann, Boston (1997) pp. 1-30

${ }^{4}$ Kelly, K.M.; Gross, RA.; Macdonald, R.L. Newrosci. Lett. (1990) 116 : 233-8

${ }^{5}$ Rogawski, M.A.; Porter, R.J. Pharmacol. Rev. (1990) 42: 223-86
} 


\section{NUEVOS COMPUESTOS OBTENIDOS POR VARIACIÓN ESTRUCTURAL \\ DEL ACIDO VALPROICO}

Ya se ha presentado, en la sección anterior, la justificación de la elección del Vpa como estructura de partida sobre la cual realizar modificaciones. Se analizarán a continuación las variaciones que se pueden plantear a la estructura de esta droga, considerando las ventajas y desventajas asociadas a cada modificación.

Desde el punto de vista químico medicinal pueden postularse varias posibles modificaciones a la estructura original del ácido dipropilacético, a saber:

$\checkmark$ modificaciones sobre las cadenas n-propílicas: cambio en la longitud de las cadenas alquilicas, introducción de insaturaciones, ciclación, ramificaciones,

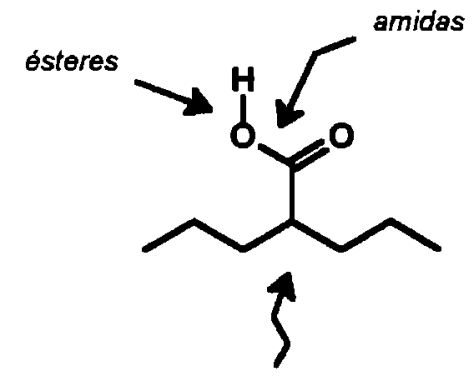

$\checkmark$ derivatización a ésteres,

$\checkmark$ derivatización a amidas: mono- y análogos, metabolitos di-sustituídas.

\section{Estado de la investipación en el tema}

Desde el descubrimiento azaroso de la capacidad anticonvulsiva del $\mathrm{Vpa}$, comenzaron a estudiarse numerosos compuestos similares a éste, con el objeto de encontrar nuevas estructuras que sean aún más potentes y que posean menor neurotoxicidad que el Vpa.

Los compuestos resultantes de esta investigación pueden clasificarse según:

$\checkmark$ ácidos carboxílicos análogos del Vpa

$\checkmark$ metabolitos del Vpa

$\checkmark$ derivados amídicos de $V$ pa y ácidos relacionados

$\checkmark$ prodrogas del Vpa 


\section{Acidos carboxílicos análogos de ácido valproico.}

Con la idea de investigar los resultados de las modificaciones sobre las cadenas propílicas originales del Vpa, varios autores sintetizaron y evaluaron gran cantidad de ácidos monocarboxilicos análogos del ácido valproico. Se plantearon cambios en la longitud, saturación y ramificación de las

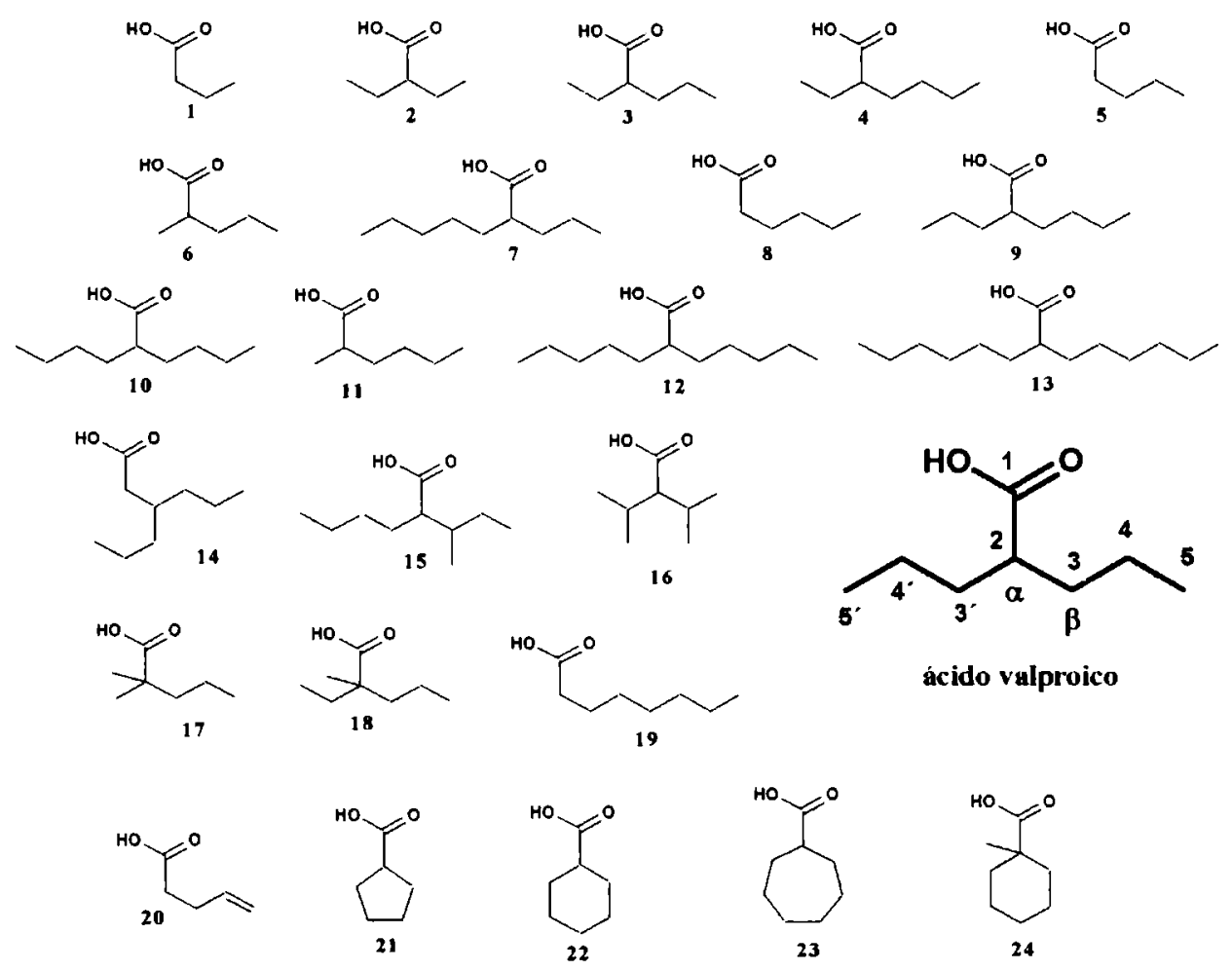

cadenas hidrocarbonadas unidas al grupo ácido, resultando incluso en la generación de compuestos cíclicos. En 1983, Keane' encontró una correlación significativa entre la longitud de las cadenas laterales y la potencia anticonvulsiva de 10 análogos del Vpa (1-10). Sin embargo, paralelamente al aumento de la longitud, aparecen fenómenos sedativos $y$
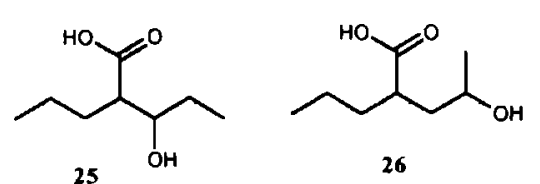

26<smiles>CCCC(CCCO)C(=O)O</smiles>

27<smiles>CCCC(C(=O)O)C(=O)CC</smiles><smiles>C=CCC(CCC)C(=O)O</smiles>

29<smiles>C=CC/C(=C/CC)C(=O)O</smiles>

33<smiles>C/C=C/C(CCC)C(=O)O</smiles>

30<smiles>C=CCC(CC=C)C(=O)O</smiles>

3<smiles>CC/C=C(/CCC)C(=O)O</smiles>

31<smiles>CCCC(CCC(=O)O)C(=O)O</smiles><smiles>CC/C=C(\CCC)C(=O)O</smiles>

32 
tóxicos. Los 3 derivados no ramificados (1, 5 y 8) no presentaron actividad'. Posteriormente, Loscher ${ }^{2}$ ensayó 32 análogos (2-4,6,9-24) y metabolitos (25-35) del Vpa, comprobando que tanto la disminución de la longitud de las cadenas laterales, así como la obtención de derivados no ramificados o compuestos cíclicos, conducían a actividad débil o nula, mientras que la elongación de las cadenas originaba compuestos con mayor actividad pero también mayores efectos colaterales. $\mathrm{Abbott}^{3}$ ensayó también una serie de ácidos monocarboxílicos estructuralmente relacionados al Vpa $(10,24,31,36-42)$ sin lograr una mejora significativa en la<smiles>C=C(O)C(C)C</smiles>

36<smiles>O=C(O)CC1CCCCC1</smiles>

$\$ 0$<smiles>CC(C)(C)C(=O)O</smiles>

37<smiles>CCC(C)(C)C(=O)O</smiles>

38<smiles>CCC(CC)CC(=O)O</smiles>

39

potencia. A partir de un análisis QSAR, estos autores sugirieron que existen otros factores, distintos del $\log P$ y el pKa, que influyen en la actividad. A modo de ejemplo puede mencionarse el efecto estérico, vinculado a la naturaleza de los sustituyentes alquilo ${ }^{3}$.

En relación a las cadenas laterales, la afirmación de que el ácido valproico posee la estructura química óptima con respecto al margen entre su actividad anticonvulsiva y sus efectos colaterales sedativos e hipnóticos, quedó entonces demostrada ${ }^{1,2,3,4}$.

Sin embargo, los efectos adversos centrales no son los únicos asociados al uso del Vpa. Originalmente considerado de baja toxicidad, desafortunadamente el Vpa demostró tener un considerable potencial teratogénico en humanos. Actualmente se sabe que su uso durante el embarazo lleva a la aparición de malformaciones ${ }^{5,6,7,8,9,10}$, siendo el efecto más aparente y severo la espina bífida ${ }^{6}$. En animales de experimentación (ratones) se ha encontrado exencefalia ${ }^{11,12,13}$ cuando el Vpa se administra al día 8 de gestación y espina bífida ${ }^{11,12,14}$ cuando se administra el día 9.

Desde que comenzaron a manifestarse estas consecuencias tóxicas severas del uso del Vpa durante el embarazo, la búsqueda de nuevas estructuras alternativas se orientó a la supresión de estos efectos colaterales, cuidando de no perder la eficacia antiepiléptica de la droga. 
Con ese objetivo, $\mathrm{Nau}^{15}$ estudió una serie de
metabolitos $\mathrm{y}$ compuestos relacionados al Vpa $(2,3,9,10,17,19,24,29-31,34,35,43-45)$ observando que la capacidad teratogénica (en términos de exencefalia) sigue en cierta medida una tendencia inversa a la descripta anteriormente para el aumento de la acción anticonvulsiva y la disminución de los efectos secundarios centrales. La estructura del Vpa como tal es justamente la que posee un mayor efecto teratogénico ${ }^{18}$. Compuestos homólogos al $\mathrm{Vpa}$ con cadenas tanto mayores como menores son menos teratogénicos ${ }^{18}$. Más aún, aquéllos no ramificados, como el ácido octanoico (19), no son teratogénicos. Por otro lado, la ausencia de un $\mathrm{H} \alpha$ evita la teratogenicidad, ya que compuestos doblemente sustituidos en posición $2(17,24,43)$ no producen exencefalia. El efecto de la inclusión de dobles enlaces en la estructura del Vpa es ambiguo: un doble enlace en 4 mantiene la teratogenicidad (metabolito 4-en-vpa,29), pero ésta se evita por doble insaturación en 4 (metabolito 4,4'-dien-vpa,34) o por insaturación sencilla en 3 o en 2 (metabolitos 3-en-vpa, 30 y 2en-vpa,31, respectivamente).

Por otro lado, valpramida (Vpd, 45), la amida primaria del $\mathrm{Vpa}$, carece de efectos teratogénicos ${ }^{18}$, lo cual levó a asociar la presencia de un grupo carboxilico con la aparición de teratogenicidad.

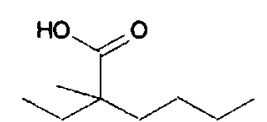

43<smiles>C=CCC(C(=O)O)C(=O)CC</smiles>

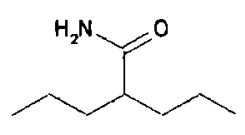

45, Valpramida

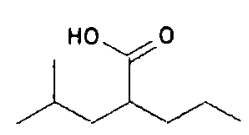

46

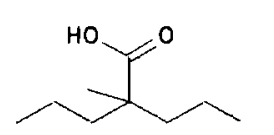

47

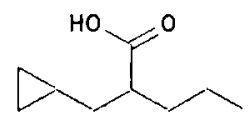

48

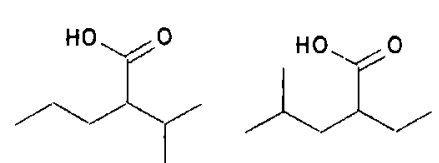

49

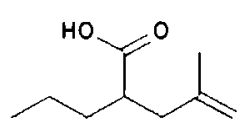

51

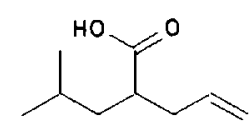

52

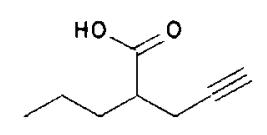

$\mathbf{5 3}$

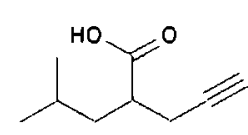

54

$\mathrm{La}$ adición de grupos $-\mathrm{CH}_{3}$ en $\mathrm{C}_{2}, \mathrm{C}_{3}$ o $\mathrm{C}_{4}$ reduce también en gran medida la teratogenicidad del $\mathrm{Vpa} y$ compuestos relacionados $(3,29$ y 53), dando lugar a las especies $46-52$ y $54^{16}$.

\section{Metabolitos del ácido valproico.}

El estudio de los metabolitos del ácido valproico cobró importancia al tratarse, en algunos casos, de compuestos no teratogénicos. 
El Vpa se elimina principalmente por metabolismo, en varias especies animales, incluyendo el hombre. Los metabolitos identificados indican 4 principales rutas metabólicas ${ }^{17}$ :

$\checkmark \quad$ pa es conjugado con ácido glucurónico.

$\checkmark$ Vpa es metabolizado vía $\beta$-oxidación en 3ceto-vpa (28), con 2-en-vpa (31) y 3-hidroxivpa (25) como intermedios en esta vía.

$\checkmark$ Vpa es transformado vía $\omega 1$-oxidación dando ácido 2-n-propilglutárico (35), con 4-en-vpa (29) y 5-hidroxi-vpa (27) como intermediarios.

$\checkmark$ Vpa se metaboliza vía $\omega 2$-oxidación formando 3-en-vpa (30) y 4-hidroxi-vpa (26).

Todos los metabolitos del Vpa son activos pero menos que éste. Los metabolitos 2-en-vpa (31) y 4-en-vpa (29) son los más activos mostrando 50 y 90 por ciento de la potencia del Vpa. Considerando las distintas potencias, el Vpa es

insaturación hidroxilacion oxidación adicional<smiles>CCCC(CCC)C(=O)OC(=O)C(CCC)C(=O)O</smiles><smiles>C/C=C/C(CCC)C(=O)O</smiles><smiles>CCCCC(CCCO)C(=O)O</smiles>

responsable de más del 80 por ciento del efecto antiepiléptico manifestado durante el tratamiento crónico en el hombre ${ }^{20}$.

Solo el 2-en-vpa (31) se ha encontrado en cerebro ${ }^{18}$. La terapia con Vpa presenta una pobre relación farmacocinéticafarmacodinamia ${ }^{19,20}$, lo cual puede deberse a la existencia de este metabolito activo. Mientras que los efectos tempranos del Vpa pueden deberse a su rápida entrada al cerebro, los efectos 
tardíos pueden deberse a la persistencia de este metabolito en cerebro.

Son varios los modelos animales en los que el 2-en-vpa mostró efectos anticonvulsivos ${ }^{21}$, siendo tan efectivo como el $\mathrm{Vpa}$ en cuatro sistemas experimentales, aunque también se ha observado mayor neurotoxicidad ${ }^{22}$. Como se describe más adelante, otro efecto colateral severo asociado al uso del Vpa es la hepatotoxicidad. El 2-en-vpa presenta la ventaja de no ser hepatotóxico, y sólo pequeñas cantidades se transfieren al hígado por su alta unión a proteínas plasmáticas ${ }^{19,20,23,24}$. Además, el 2-en-vpa presenta menor embriotoxicidad que el $\mathrm{Vpa}, \mathrm{y}$ no es teratogénico en ratones $\mathrm{s}^{25,26}$.

Todas estas características hicieron del 2-en-vpa, especialmente el isómero trans, una alternativa ventajosa respecto al $\mathrm{Vpa}^{26,27,28,29,30,31,32,33,34}$. Sin embargo, estudios clínicos preliminares mostraron que 2-en-vpa es parcialmente convertido a $\mathrm{Vpa}^{35}$ y que es posible que se biotransforme a un metabolito con una doble ligadura en posición $4^{36}$.

El metabolito 4-en-vpa (29), también es efectivo en cuanto a actividad anticonvulsiva, pero además de no haberse comprobado su capacidad de localizarse en cerebro, es tan teratogénico como el $\mathrm{Vpa}^{15}$. Su principal desventaja es que la hepatotoxicidad del Vpa ha sido asociada a la formación de este metabolito ${ }^{33,37}$. Por lo tanto, los análogos del Vpa con una doble ligadura en posición 4 pueden originar fenómenos hepatotóxicos ${ }^{33,38}$.

\section{Derivados amídicos.}

En 1985, Loscher ${ }^{2}$ observó que la valpramida (Vpd, 45) era el compuesto más potente de toda una serie de análogos del Vpa (2-4,6,9-24-35,45), tanto en el ensayo MES como en el ensayo PTZ* (2-5 veces mas activa que el Vpa). La Vpd (45) se ha seguido estudiando desde entonces y ha sido usada en clínica como antiepiléptico y antipsicótico en varios países europeos ${ }^{39,40,41,42,43}$.

Al no poseer el grupo carboxilico libre característico del $\mathrm{Vpa}$, la Vpd es menos teratogénica que éste $\mathrm{e}^{15,44,45,46}$. Sin embargo, las ventajas de Vpd sobre Vpa no suponen grandes implicancias clínicas, ya que en humanos, a diferencia de lo que ocurre en animales, Vpd se biotransforma a $\mathrm{Vpa}^{43,47}$. Se ha reportado que se metaboliza en un 77-81 por ciento al ácido ${ }^{47}$, es decir, actúa como prodroga o forma de liberación retardada de Vpa. En cambio, en perros la biotransformación es parcial (30-40 por ciento $)^{48,49}$, en ratas es menor ${ }^{50}$, y en ratones es despreciable ${ }^{51,52}$. Estudios farmacocinéticos en rata ${ }^{50}$ muestran

- el ensayo MES y el ensayo PTZ son los ensayos más utilizados para la evaluación anticonvulsiva, ver mas adelante "Elección de los Ensayos Biológicos". 
que Vpd sigue metabolización hepática a Vpa. El cerebro no es sitio de biotransformación Vpd-Vpa (ver Figuras 4.2.1 y 4.2.2, más adelante).

Se han invertido muchos esfuerzos en el descubrimiento de nuevas amidas estables, es decir, que no se biotransformen a sus respectivos ácidos. M. Bialer, quien trabajó extensamente en el tema ${ }^{4,36,50,53,54}$, destaca la dependencia de la actividad con la farmacocinética, monitoreada mediante el dosaje de las drogas en sangre y orina de perros o en distintos tejidos de ratas, mediante el empleo de cromatografia gaseosa ${ }^{55,56}$ o de HPLC ${ }^{57}$.

Haj-Yehia y col..$^{53}$, mediante el análisis de una serie de amidas análogas a Vpd (55-60), concluyen que las amidas como tales son más activas que sus respectivos ácidos $(61,16$, $62,63,34$ y 19 , respectivamente), y plantean el requerimiento de una sustitución en posición $\beta$ para evitar la biotransformación a ácido, según lo demuestran 55 (Valnoctamida, Vcd) y 56 que son resistentes a la hidrólisis y<smiles>CCC(C)C(CC)C(N)=O</smiles><smiles>CC(C)C(C(N)=O)C(C)C</smiles>

s6<smiles>CCC(C)CC(CC)C(N)=O</smiles>

s.<smiles>CC(C)(C)C</smiles><smiles>CCC(C)C(CC)C(=O)O</smiles>

61
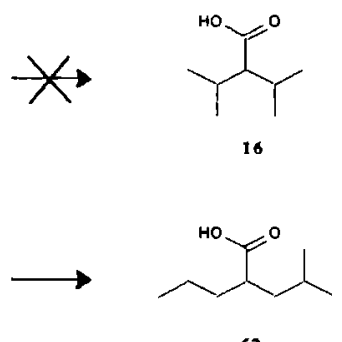

62

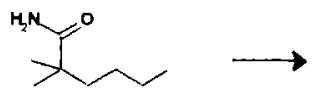

58
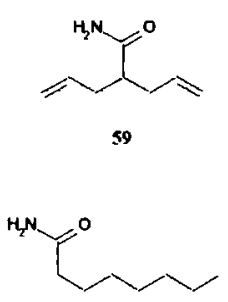

60

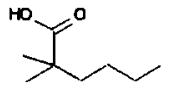

$\mathbf{6}$
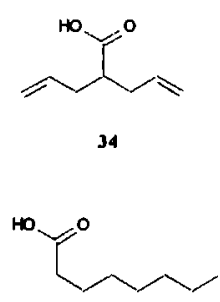

por lo tanto más potentes. Este concepto fue corregido posteriormente ${ }^{4}$ gracias al estudio de más análogos de $\mathrm{Vpd}$ (64-68). La resistencia a la biotransformación requiere dos sustituciones (ambas en $\beta$ o bien una en $\alpha$ y otra en $\beta$ ), según lo demuestra 67 , monosustituida en $\beta$, que también se hidroliza, y 64 , doblemente sustituida en $\beta$, que muestra resistencia. Teniendo en cuenta estos resultados, los mismos autores ${ }^{54}$ sintetizaron luego análogos tetrametilciclopropano de Vpd $(69,70)$, incorporando también derivados $\mathrm{N}$-sustituidos. Se encontró que la $\mathrm{N}$-sustitución aumenta la potencia, ya que el derivado 70 es el que muestra el mejor perfil anticonvulsivo, a pesar de metabolizarse parcialmente ( 32 por ciento) a $69^{58}$. Ninguno de los 2 se biotransforma al ácido correspondiente (ácido 2,2,3,3-tetrametil ciclopropanoico) ${ }^{58}$. 


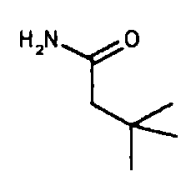

64

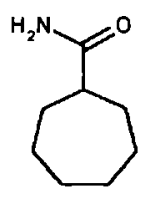

65<smiles>CC1(C(N)=O)CCCCC1</smiles>

66<smiles>CCC(CC)CC(N)=O</smiles>

67<smiles>CC(CC(C)(C)C)C(N)=O</smiles>

68

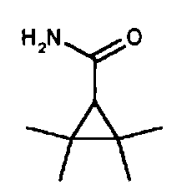

69

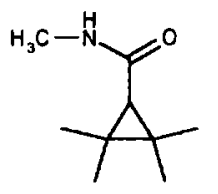

70

Valnoctamida (Vcd, 55), a diferencia de Vpd, no sufre biotransformación a ácido valnóctico, menos activo (61). Es estable en perros $^{59}$ y en humanos ${ }^{53,59,60,61}$. Se elimina por biotransformación a metabolitos no identificados ${ }^{50}$. No presenta teratogenicidad en ratones (sólo un $1 \%$ de exencefalia contra un $53 \%$ provocada por Vpa, y un $6 \%$ por $\mathrm{Vpd})^{44}$. Vcd no presenta un efecto selectivo, ha sido usada como ansiolítico ${ }^{62}$ y como antiepiléptico ${ }^{60,61,63,64}$.

La investigación farmacocinética de Vpd, Vcd y Vpa en ratas ${ }^{50}$, basada en el monitoreo de los niveles en cerebro,
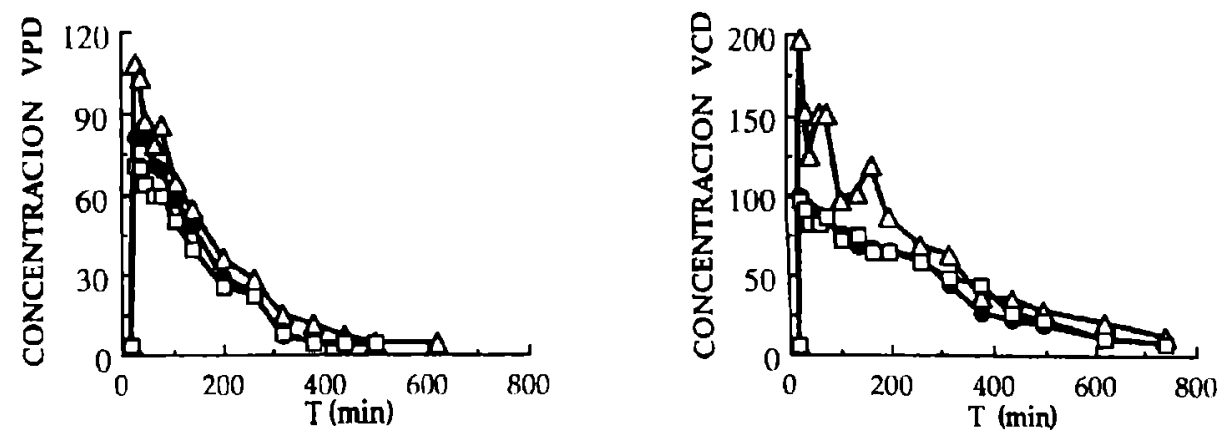

Figura 4.2.1 Concentraciones en plasma (•, $\mathrm{mg} / \mathrm{l})$, cerebro $(\square, \mathrm{mg} / \mathrm{kg})$, e hígado $(\Delta$, $\mathrm{mg} / \mathrm{kg}$ ), obtenidas luego de la administración iv en ratas de $20 \mathrm{mg}$ de Vpd y Vcd.

(Tomado de Blotnik, S. y col. ${ }^{s 0}$ )

hígado, plasma y orina mostró (Figuras 4.2.1 y 4.2.2) que Vcd, al igual que Vpd, se distribuye mejor que el Vpa en el cerebro, hecho que puede contribuir a su mejor actividad anticonvulsiva ${ }^{50}$.

La biotransformación de las amidas a ácidos tiene singular importancia, por dos razones fundamentales ${ }^{36}$ :

$\checkmark$ Las amidas, actuando como tales, tienen una mayor actividad intrínseca, y además, al ser compuestos neutros, que no se unen en gran 
medida a proteínas plasmáticas, pueden atravesar mejor la BHE. La hidrólisis de una amida a su respectivo ácido, disminuye la eficacia de su acción.
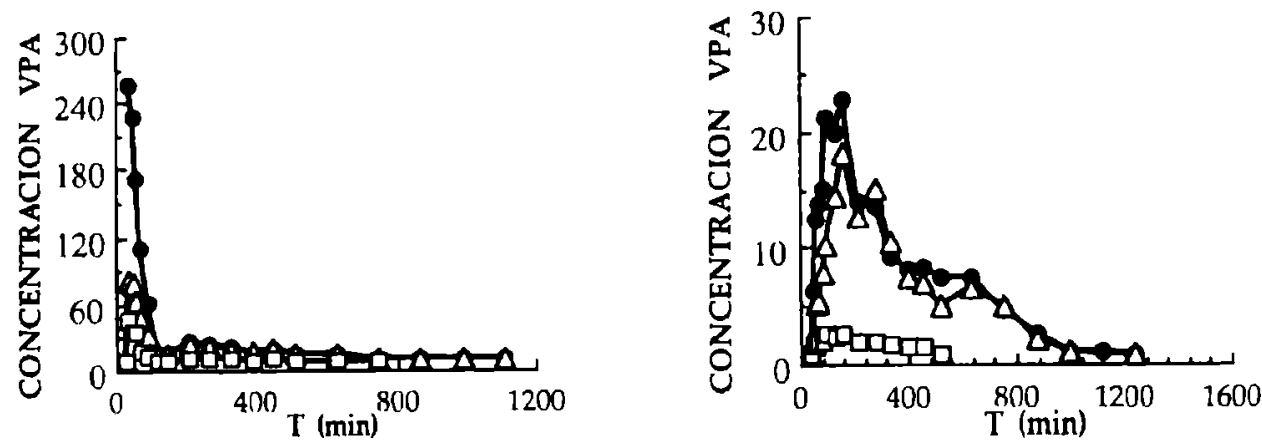

Figura 4.2.2 Concentraciones de Vpa en plasma (•, mg/l), cerebro ( $\square, \mathrm{mg} / \mathrm{kg})$, e hígado $(\Delta, \mathrm{mg} / \mathrm{kg}$ ), obtenidas luego de la administración iv en ratas de $20 \mathrm{mg}$ de Vpa y Vpd, respectivamente.

(Tomado de Blotnik, S. y col. ${ }^{50}$ )

Los ácidos pueden presentar complicaciones como la potencial teratogenicidad, ya que $l a$ función carboxilica es crucial para la manifestación de efectos teratogénicos ${ }^{45,46}$.

En base a todos los datos recopilados a partir del uso clínico, y de las investigaciones desarrolladas sobre el Vpa, Vpd y Vcd, y sobre todo los estudios sobre análogos y derivados de éstos, el desarrollo de nuevas drogas derivadas del Vpa se ha dirigido, durante el transcurso de la década del 90, hacia el diseño de nuevas estructuras derivadas de amidas, con el objeto de lograr mayor potencia y menor teratogenicidad, logrando así favorecer la selectividad de acción antiepiléptica, con eliminación de efectos adversos.

Estudios posteriores ${ }^{4,53,54}$ indican que la biotransformación a ácidos no sólo está condicionada por la sustitución en las cadenas laterales. La (N-valproil)glicinamida (71), valpramida monosustituida en el $\mathrm{N}$, no se metaboliza a Vpa a pesar de no satisfacer los requisitos de ramificaciones antes descriptos ${ }^{57}$. La existencia de muchas otras valpramidas $\mathrm{N}$-sustituidas resistentes a la hidrólisis a Vpa resulta indicativo de una dependencia de la tendencia a la biotransformación a Vpa con la sustitución en el $\mathrm{N}$, y no sólo con la sustitución en las cadenas laterales. Se han estudiado derivados mono- y disustituidos de $\mathrm{Vpd}^{65,66,67}$ cuyas propiedades 
farmacocinéticas, analizadas en perros, demostraron que ninguno de ellos actuaba como prodroga o sistema de liberación de Vpa. Hadad ${ }^{67}$ estudió derivados de Vpd resultantes de la combinación de Vpa con GABA y glicina (71-74). Entre los compuestos preparados, (Nvalproil)glicinamida (71) resultó ser el más potente, caracterizado además por un mejor margen de seguridad que Vpa. Ninguno actuó como sistema de liberación de glicina, GABA o Vpa, sino como drogas por sí mismas. (Nvalproil)glicinamida (71) y (N-valproil)gabamida (73) se metabolizan parcialmente a (N-valproil)glicina (72) y $(\mathrm{N}$ valproil)GABA (74) respectivamente, los cuales se excretan parcialmente intactos por orina. El mismo grupo de investigación $^{65}$ estudió luego compuestos resultantes de la combinación de Vpa con ácido nipecótico (inhibidor de la<smiles>CCCC(CCC)C(=O)NCC(N)=O</smiles><smiles>CCCC(CCC)C(=O)NCCCC(N)=O</smiles>

73<smiles>CCCC(CCC)C(=O)NO</smiles><smiles>CCCC(CCC)C(=O)NCC(=O)O</smiles><smiles>CCCC(CCC)C(=O)NCCCC(=O)O</smiles><smiles>CCCC(CCC)C(=O)NCCO</smiles>

78<smiles>CCCC(CCC)C(=O)N1CCCC(C(N)=O)C1</smiles><smiles>CCCC(CCC)C(=O)N1CCCC(C(=O)O)C1</smiles>

retoma de GABA) $(75,76)$, encontrando nuevamente que ninguno de los compuestos actúa como sistema de liberación de ácido nipecótico o Vpa. Otros compuestos sintetizados posteriormente $(77,78)^{66}$, aunque mostraron menor potencia anticonvulsiva que $\mathrm{Vpd}$, también actuaron conservando su identidad, y contribuyeron a afianzar la idea central de estos estudios: la sustitución del $N$ amídico previene la hidrólisis a ácido valproico, de la misma manera que la ramificación de las cadenas laterales de las amidas libres ${ }^{4,36,53,54}$.

Además de las ya descriptas, se han sintetizado otras Vpd N-sustituidas ${ }^{68}(79,80)$, llegando en algunos casos a compuestos muy promisorios, como es el caso de $\mathrm{vpu}^{69}(81)$, mas activa y menos tóxica que el Vpa, con un PI de 9.5, y activa por vía oral. 


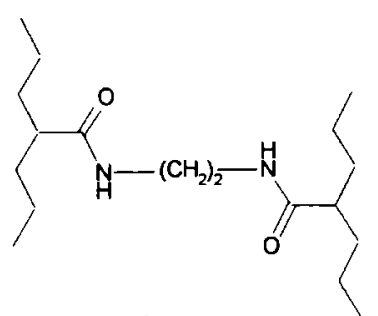

79

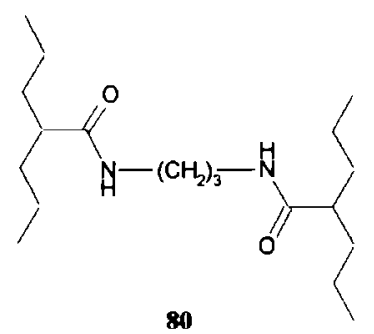

80

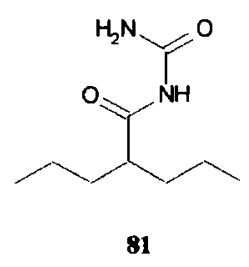

$\mathbf{8 1}$

Debido al excelente perfil del derivado (Nvalproil)glicinamida $(71)^{70}$, se ha trabajado en compuestos que combinan los análogos y metabolitos de Vpd mas aventajados con el grupo glicinamida. Así, N-(2-en-valproil)glicinamida $(82)^{65}, \quad$ (N-valnoctil)glicinamida (83) y $\quad(\mathrm{N}$ diisopropilacetil)glicinamida $(84)^{71}$ mostraron actividades y márgenes de seguridad similares a aquéllos de (Nvalproil)glicinamida. No operan como sistemas de liberación de glicina, 2-en-vpa, ácido valnóctico o diisopropil acético,<smiles>CC/C=C(/CCC)C(=O)NCC(N)=O</smiles>

82<smiles>CCCCCCCC(=O)NCC(N)=O</smiles>

85<smiles>CCC(C)C(CC)C(=O)NCC(N)=O</smiles>

83<smiles>CCCCC(=O)NCC(N)=O</smiles>

86<smiles>CC(C)C(C(=O)NCC(N)=O)C(C)C</smiles>

84<smiles>CCCCCNCC(N)=O</smiles>

87, milacemida

sino que se biotransforman parcialmente a sus respectivos metabolitos de glicina, los cuales se excretan en orina, al igual que lo que ocurre con ( $\mathrm{N}$-valproil)glicinamida. Los isómeros de ( $\mathrm{N}$-valproil)glicinamida no ramificados que se estudiaron $\left((\mathrm{N}-o c t a n o i l) g l i c i n a m i d a, 85\right.$ y $(\mathrm{N} \text {-valeroil)glicinamida, 86 })^{71}$ no presentaron actividad anticonvulsiva. A pesar de la similitud estructural, (N-valeroil)glicinamida (86) no es activa, a diferencia de la droga antiepiléptica milacemida (87), que es activa debido a que actúa como sistema de liberación de glicina.

Recientemente ha surgido un nuevo efecto adverso relacionado al uso de derivados y análogos de $\mathrm{Vpa}$ : la 
inhibición de la epóxido hidrolasa microsomal (mEH). La inhibición in vivo de esta enzima tiene importantes implicancias toxicológicas ${ }^{72}$, ya que es una de las enzimas más importantes en la detoxificación de intermediarios epóxidos reactivos formados en el metabolismo oxidativo de xenobióticos ${ }^{72,73,74}$.

$\mathrm{La}$ interacción medicamentosa que existe entre Vpd y carbamazepina ${ }^{75,76,77,78,79,80}$, se debe a la inhibición de la $\mathrm{mEH}$ por parte de la Vpd, e hizo que su uso, como una alternativa al uso de Vpa, sea considerado sólo en monoterapia ${ }^{36}$. Es probable que exista esta misma interacción entre Vcd y carbamazepina, ya que Vcd es también un potente inhibidor de la $\mathrm{mEH}^{61,81}$.

Además de Vpd y Vcd, Vpa también es capaz de inhibir esta enzima, y lo hacen a concentraciones plasmáticas clínicamente relevantes ${ }^{82,83,84}$. Estas drogas representan una nueva clase de inhibidores competitivos de la $\mathrm{mEH}$, ya que hasta el momento sólo se conocían inhibidores que contienen un grupo epóxido y actúan como sustratos alternativos ${ }^{72,73,74,85}$.

Con el objeto de estudiar las características estructurales asociadas a la aparición de este efecto colateral, se ha estudiado recientemente la acción de derivados y análogos del $\mathrm{Vpa}$ en relación a la inhibición de la $\mathrm{mEH}^{86}$. Treinta análogos, isómeros y derivados de Vpd, entre los que se encuentran derivados amídicos ramificados $(56,58,59)$, no ramificados (60), y derivados sustituidos en el $\mathrm{N}$ $(70,71,72,77,78)$, así como también Vpa y 4 isómeros de $\mathrm{Vpa}$, han sido evaluados en su capacidad inhibitoria. Se observó que una gran variedad de amidas no sustituidas (Vpd, Vcd, $56,58,59,60)$ son potentes inhibidores de la enzima, mientras que la sustitución del $N$ amídico de la valpramida en general reduce o elimina la potencia inhibitoria, como lo demuestran los derivados de Vpd analizados $(71,72,77,78)$. Lo mismo parece ocurrir con los análogos de Vpd, ya que la sustitución del $\mathrm{N}$ en el caso de 69 originando 70 , conduce a una notable disminución de la potencia inhibitoria ${ }^{86}$.

\section{Prodrogas del ácido valproico.}

Las prodrogas actúan como transportadores, liberando la droga activa en el sitio específico de acción. Esto permite un efecto doblemente beneficioso: disminución de las dosis a administrar, y minimización de los efectos no deseados originados por la interacción en otros sitios.

El planteo de prodrogas del ácido valproico ha sido un tema de investigación promisorio. La localización del Vpa en el sitio en que ejerce su acción anticonvulsiva, el cerebro, es un objetivo codiciado. Desde el punto de vista farmacoquímico, estos sistemas de liberación de Vpa pueden lograrse mediante 
la síntesis de amidas o ésteres del Vpa. La prodroga administrada se libera en el organismo gracias a reacciones metabólicas, donde intervienen procesos de hidrólisis química (medio ácido o alcalino) o enzimática (amidasas, esterasas), que dan lugar a la generación de la especie activa, Vpa, y los grupos transportadores (alcoholes o aminas).

Según se comentó antes, Vpd constituye un ejemplo de prodroga amídica de $\mathrm{Vpa}$ en humanos, aunque no en otras especies animales. No rige lo mismo para drogas derivadas de ésta, como las mencionadas previamente en este capítulo.

Entre las prodrogas ésteres conocidas pueden mencionarse ésteres de $\mathrm{Vpa}$ con fenitoína ${ }^{87}$, con aminoácidos $^{88}$, con manitol ${ }^{89}$ y con un transportador fosfolipídico (88), encontrándose este último próximo a entrar<smiles>CCCC(CCC)C(=O)OC(COC(=O)CC)COP(=O)([O-])OCN</smiles><smiles>CCCCC(CCC)C(=O)OC(=O)C(CCCC)CCCC</smiles>

89

88, DP-VPA

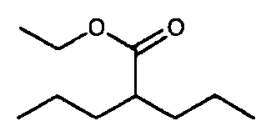

90

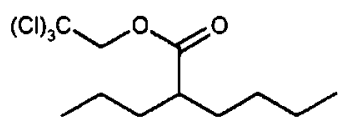

91<smiles>CCCC(CCC)C(=O)OCC(C)C</smiles>

94<smiles>CCCCCCOC(=O)C(CCC)CCC</smiles>

95<smiles>CCCCOC(=O)C(CCC)CCC</smiles>

93<smiles>CCCC(CCC)C(=O)OCCC(C)C</smiles>

96

a los estudios clínicos de Fase $\mathrm{II}^{90,91}$. También se han estudiado ésteres simples del Vpa como 89-96 ${ }^{92,93}$. Entre los 8 ésteres analizados, sólo el propilvalproato (90) mostró efecto anticonvulsivo, aunque con potencia menor que Vpa y Vpd, pero también menor neurotoxicidad y mejor PI que éstos. El seguimiento farmacocinético en perros ${ }^{92,93}$ indica, por otro lado, que los 8 ésteres se biotransforman rápidamente, en forma parcial $(89,94,96)$ o total $(90,91,92,93,95)$, a Vpa. El etil éster (90) ha sido recientemente estudiado por Redecker ${ }^{89}$ empleando un ensayo electrofisiológico en donde se observa la 


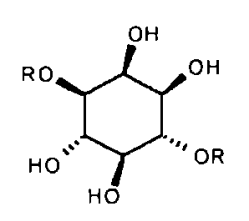

97

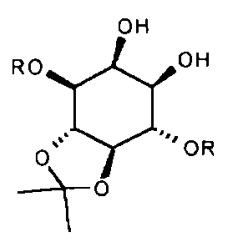

99

disminución de la actividad epileptiforme generada por la aplicación del convulsivo PTZ, informándose una actividad comparable a la del Vpa y su probable acción como prodroga de Vpa.

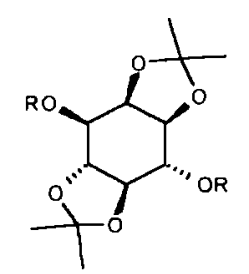

98

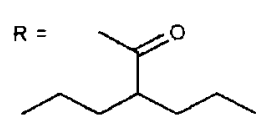

anticonvulsiva a 4 horas.
En el Laboratorio de Farmacoquímica se han diseñado, sintetizado y evaluado farmacológicamente otras prodrogas del Vpa (97-99), empleando el myo-inositol, componente del segundo mensajero IP3 (inositol trifosfato), como transportador de dos moléculas de $\mathrm{Vpa}^{94}$. Así, el derivado 97 resultó ser más de 5 veces más potente que el Vpa, presentando su máxima acción

\section{Planteo de nuevos derivados}

La situación actual, en donde el Vpa como tal se continúa utilizando como droga de primera opción en el tratamiento de muchos tipos de epilepsia, representa la más clara prueba de que no se ha logrado aún una droga que justifique su reemplazo. Esto no defiende, sin embargo, la finalización de la búsqueda. Los efectos secundarios del Vpa, previamente discutidos en este capítulo, justifican el esfuerzo. Se ha avanzado muchísimo en el tema, pero aún queda mucho camino por recorrer hasta que se descubra una nueva droga capaz de tener la eficacia del Vpa y carecer de sus efectos secundarios, presentando, en suma, suficientes ventajas que justifiquen el cambio.

En el momento de diseñar nuevas estructuras derivadas del Vpa es sumamente necesario tener presente toda la experiencia ganada y el conocimiento adquirido en este tema. Se ha descrito brevemente en el inciso anterior todo este conocimiento, recabado durante años de investigación, desde el descubrimiento del Vpa como droga anticonvulsiva hasta ahora.

Como hemos visto, se han planteado numerosas modificaciones a la estructura original del Vpa con el objeto de encontrar nuevos compuestos que manifiesten mayor potencia como antiepilépticos, pero que a la vez no posean los efectos adversos asociados al éste: teratogénesis, sedación y ataxia, hepatotoxicidad, e inhibición de la mEH. 
Las modificaciones sobre las cadenas laterales del $\mathrm{Vpa}$, que dan lugar a nuevos ácidos monocarboxílicos, han permitido concluir que el Vpa posee la estructura química óptima con respecto al margen entre su actividad anticonvulsiva y sus efectos colaterales centrales. Pero su estructura está lejos de ser la óptima si consideramos los efectos teratogénicos asociados a su uso. Teniendo en cuenta estos efectos indeseables, las alternativas posibles se reducen a: i- inclusión de dobles enlaces a la estructura del $\mathrm{Vpa}$, iiinclusión de ramificaciones en determinado número y posición, iii- generación de estructuras que carezcan del grupo carboxílico libre. La última alternativa se presenta indudablemente como la más ventajosa. Entre las diversas opciones de modificación funcional, se destaca la $\mathrm{Vpd}$, con mayor potencia anticonvulsiva y ausencia de teratogenicidad. Aunque la acción de $\mathrm{Vpd}$ en humanos está mediada por una reacción de hidrólisis generando Vpa como especie activa, ésto no establece una condición para nuevas amidas derivadas de Vpd, que se muestran más potentes y menos teratogénicas que los ácidos.

Tomando Vpd como droga líder, se pueden postular nuevamente modificaciones sobre las cadenas laterales, o Nsustituciones. Esta última sustitución tiende a evitar la biotransformación a ácidos. Por otro lado, los derivados $\mathrm{N}$ sustituidos de Vpd serán probablemente inhibidores pobres 0 nulos de la enzima epóxido hidrolasa microsomal, y por lo tanto tendrán menor tendencia a provocar efectos tóxicos que sus compuestos padres Vpa y Vpd.

Los derivados amídicos han demostrado avanzar más allá de las ventajas que surgen de la evaluación preclínica inicial, como es el caso de la Vpd.

Conforme al progreso de las investigaciones en este tema, se encuentra actualmente que, entre la gran cantidad de estructuras estudiadas, sólo algunos compuestos surgidos a partir de la estructura básica del Vpa han llegado a etapas clínicas e inclusive a comercializarse ${ }^{90}$. Estos son:

$$
\begin{aligned}
& \text { Valpramida, usada como } \\
& \text { antiepiléptico y antipsicótico } \\
& \checkmark \text { Valnoctamida, usada como } \\
& \text { ansiolítico y antiepiléptico } \\
& \checkmark \begin{array}{l}
\text { Valrocemida } \\
\text { valproilglicinamida): actualmente }
\end{array}
\end{aligned}
$$


está entrando en la fase IIb de los ensayos clínicos.

$\checkmark$ DP-VPA, próximo a entrar a los estudios clínicos de fase II.

El surgimiento reciente de estos dos últimos derivados ilustra claramente las dos principales y más convenientes estrategias para el diseño de nuevos antiepilépticos generados a partir del Vpa: la generación de derivados amídicos y de prodrogas del ácido valproico.

Ya se discutió la conveniencia de los derivados amidicos $\mathrm{N}$-sustituidos:

$\checkmark$ presentan mayor potencia que los ácidos,

$\checkmark$ manifiestan menos teratogenicidad por carecer del grupo carboxilato libre,

$\checkmark$ son pobres o nulos inhibidores de la $\mathrm{mEH}$.

Por otro lado, el uso de prodrogas del ácido valproico constituye también una alternativa ventajosa ya que, al distribuirse preferencialmente en cerebro, las dosis necesarias de Vpa son menores, con la consiguiente disminución de efectos colaterales.

La investigación aquí presentada se basa en la elección de la primera de estas estrategias: síntesis, evaluación biológica y estudio teórico de valpramidas mono y disustituidas. Considerando los compuestos ya estudiados hasta el momento, el trabajo enfoca el estudio de amidas del ácido valproico simples, pero a la vez novedosas. Dentro de esta perspectiva, se plantearon inicialmente varios derivados amidicos de Vpa, de los cuales se reportan aquí aquéllos para los cuales se ha podido efectuar la evaluación de la actividad biológica. No se reportan aquéllos en que, al no lograrse la solubilización de las drogas, resulta imposible la posterior administración en los animales de experimentación. Se muestran en la figura 4.2.3 los compuestos sintetizados y ensayados derivados de valpramida mono- $y$ di-sustituidos en el $N$, incluyendo un compuesto nuevo combinando PABA (ácido p-aminobenzoico, una sustancia fisiológica necesaria para la formación de ácido fólico, implicado en la biosíntesis de las purinas), y Vpa (CpVpd).

La revisión bibliográfica indica que estos compuestos no habían sido previamente estudiados en esta acción. Algunos compuestos ( $\mathrm{CpVpd}$ ) son noveles. 
La síntesis y acción farmacológica han sido solamente discutidas por Benoit en el año 1965, donde plantea la síntesis de algunos derivados amídicos del $\mathrm{Vpa}^{95}$, y posteriormente, hacia 1968 considera también la acción<smiles>CCCC(CCC)C(N)=O</smiles>

VPD

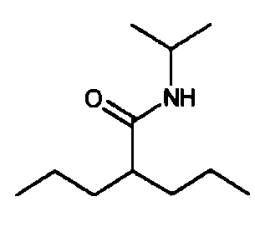

IPVPD<smiles>CCCCNC(=O)C(CCC)CCC</smiles>

BUVPD<smiles>CCCC(CCC)C(=O)NC1CCCCC1</smiles>

CHVPD<smiles>CCCC(CCC)C(=O)N1CCOCC1</smiles>

MOVPD<smiles>CCCC(CCC)C(=O)Nc1ccc(C(=O)O)cc1</smiles>

CPVPD

farmacológica de estos compuestos ${ }^{96}$, estudiándose las acciones sobre el SNC (anticonvulsiva, convulsivante, hipnótica y tranquilizante) y antiespasmódicas. Sin embargo, en aquella oportunidad no se reporta en detalle la metodología empleada para la determinación de las actividades y se indica que ninguno de los compuestos

Figura

4.2.3

Nuevos derivados de Vpd estudiados alcanza la actividad del Vpa, e inclusive se encuentran compuestos proconvulsivos.

Por lo tanto, es totalmente válido el estudio de estos derivados en cuanto a su potencia anticonvulsiva, de acuerdo a las técnicas modernas de desarrollo de drogas antiepilépticas.

\footnotetext{
${ }^{1}$ Keane, P.E.; Simiand, J.; Mendes, E.; Santucci, V. Neuropharmacology (1983) 22: 875-9

${ }^{2}$ Loscher, W.; Nau, H. Neuropharmacology (1985) 24(5): 427-35

${ }^{3}$ Abbott, F.S.; Acheampong, A.A. Neuropharmacology (1988) 27(3): 287-

94

${ }^{4}$ Haj-Yehia, A.; Hadad, S.; Bialer, M. Pharmaceutical Research (1992)

9(8): 1058-63

${ }^{5}$ Lindhout, D.; Meinardi, H. Lancet (1984) II: 396

${ }^{6}$ Robert, E.; Rosa, F. Lancet (1983) II: 1142
} 


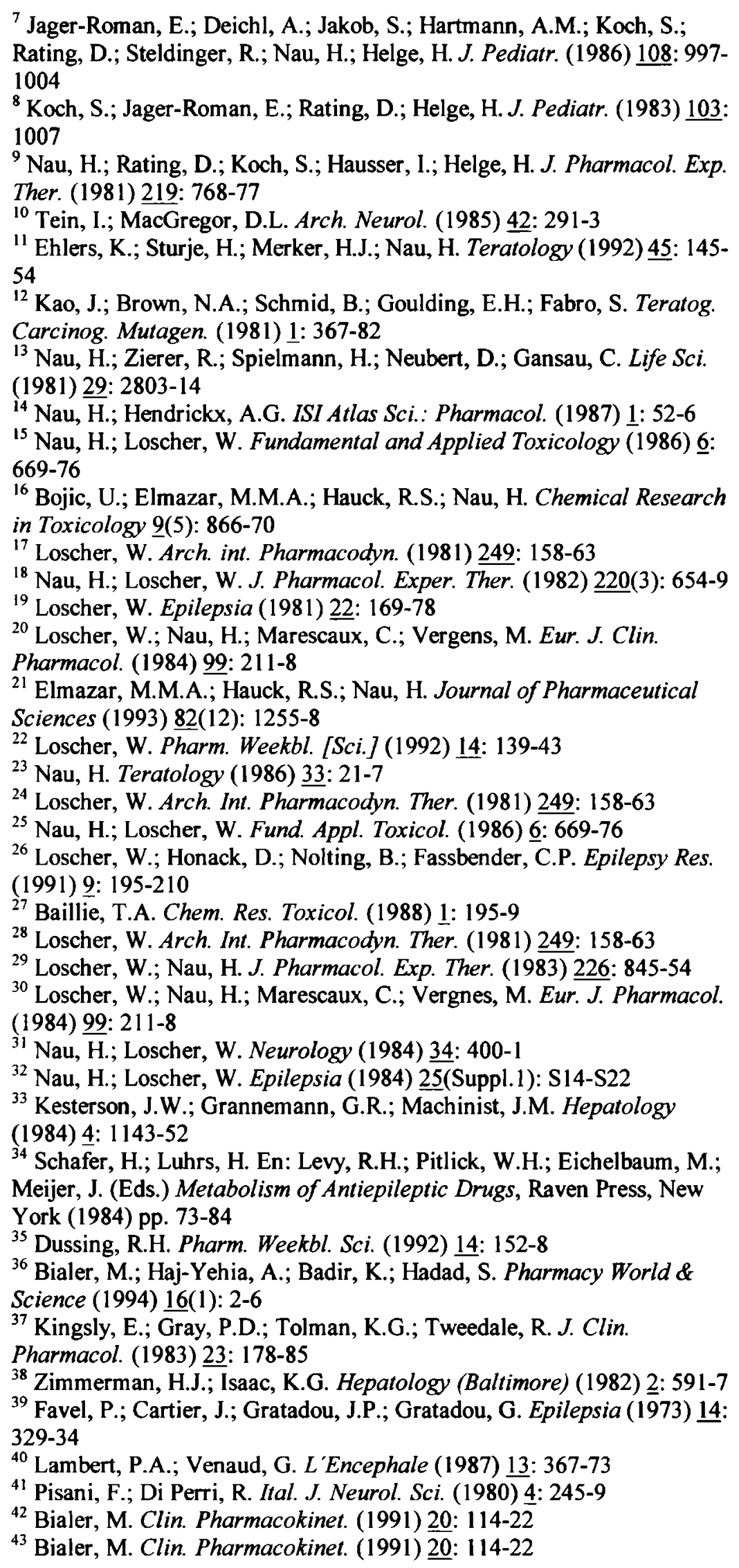


${ }^{44}$ Radatz, M.; Ehlers, K.; Yagen, B.; Bialer, M.; Nau, H. Epilepsy Research (1998) 30: 41-8

${ }^{45}$ Nau, H.; Hendrickx, A.G. ISI Atlas Sci.: Pharmacol. (1987) 1: 52-6

${ }^{46}$ Nau, H.; Hauck, R.S.; Ehlers, K. Pharmacol. Toxicol. (1991) 69: 31021

${ }^{47}$ Bialer, M.; Rubinstein, A.; Dubrovsky, J.; Raz, I.; Abramsky, O. Int. J. Pharm. (1985) 23: 25-33

${ }^{48}$ Bialer, M.; Rubinstein, A. J. Pharm. Pharmacol. (1983) 35: 607-9

${ }^{49}$ Bialer, M.; Rubinstein, A. Biopharm. Drug Dispos. (1984) $\underline{5}$ : 177-83

${ }^{50}$ Blotnik, S.; Bergman, F.; Bialer, M. Drug Metabolism and Disposition (1996) 24(5): 560-4

${ }^{51}$ Nau, H.; Scott, W.J. Nature (London) (1986) 323: 276-8

${ }^{52}$ Nau, H.; Scott, W.J. Arch. Toxicol. (1987) 11: 128-39

${ }^{53}$ Haj-Yehia, A.; Bialer, M. Journal of Pharmaceutical Sciences (1990) 79(8): 719-24

${ }^{54}$ Bialer, M.; Hadad, S.; Kadry, B.; Abdul-Hai, A.; Haj-Yehia, A.;

Sterling, J.; Herzig, Y.; Yagen, B. Pharmaceutical Research (1996)

$\frac{13}{55}(2): 284-9$

${ }^{55}$ Bialer, M.; Friedman, M.; Rubinstein, A. J. Pharm. Sci. (1984) 73: 991-3

${ }^{56}$ Bialer, M.; Hoch, B. J. Chromatogr. Biomed. Appl. (1985) 337: 408-11

${ }^{57}$ Blotnik, S.; Bergman, F.; Bialer, M. Pharmaceutical Research (1997) 14(7): 873-8

${ }^{58}$ Blotnik, S.; Bergman, F.; Bialer, M. European Journal of Pharmaceutical Sciences (1998) 6: 93-8

${ }^{59}$ Haj-Yehia, A.; Bialer, M. J. Pharm. Sci. (1988) 77: 831-4

${ }^{60}$ Bialer, M.; Haj-Yehia, A.; Barzaghi, N.; Pisani, F.; Perucca, E. Eur. J. Clin. Pharmacol. (1990) 38: 289-91

${ }^{61}$ Pisani, F.; Haj-Yehia, A.; Fazio, F.; Artesi, C.; Oteri, G.; Perucca, E.; Kroetz, D.L.; Levy, R.H.; Bialer, M. Epilepsia (1993) 34: 945-9

${ }^{62}$ Stephansky, W. Curr. Ther. Res. (1960) 2: 144-9

${ }^{63}$ Chambon, J.P.; Peiro, A. Neurosci. Lett. Suppl. (1980) S327

${ }^{64}$ Haj-Yehia, A.; Bialer, M. Pharm. Res. (1989) 6: 682-9

${ }^{65}$ Bialer, M.; Kadry, B.; Abdul-Hai, A.; Haj-Yehia, A.; Sterling, J.; Herzig, Y.; Shirvan, M. Biopharmaceutics \& Drug Disposition (1996) 17: 565-75

${ }^{66}$ Levi, M.; Yagen, B.; Bialer, M. Pharmaceutical Research (1997) 14(2): 213-7

${ }^{67}$ Hadad, S.; Bialer, M. Pharmaceutical Research (1995) 12(6): 905-10

${ }^{68}$ Bechar, E.; Astroug, H. Arch. Pharm. Pharm. Med. Chem. (1997) 330: 273-6

${ }^{69}$ Tantisira, B.; Tantisira, M. H.; Patarapanich, C.; Sooksawate, T.; Chunngam, T. Research Communications in Molecular Pathology and Pharmacology (1997) 97(2): 151-64

${ }^{70}$ Isoherranen, N.; Woodhead, J.H.; White, H.S.; Bialer, M. Epilepsia (2001) 42(7),831-6

${ }^{71}$ Hadad, S.; Bialer, M. Biopharmaceutics \& Drug Disposition (1997) 18(7): 557-66

${ }_{72}$ Oesch, F. Prog. Clin. Biol. Res. (1983) 135: 81-105

${ }^{73}$ Siedegard, J.; DePierre, J.W. Biochim. Biophys. Acta (1983) 695: 25170

${ }^{74}$ Siedegard, J.; Ekstrom, G. Environ. Health Perspect. (1997) 105(4):791-9

${ }^{75}$ Kerr, B.M.; Rettie, A.E.; Eddy, A.C., Loiseau, P.; Guyod, M.;

Wilensky, A.J. Clin. Pharmacol. Ther. (1989) 46: 82-93

${ }^{76}$ Meijer, J.W.A.; Binnie, C.D.; Debets, R.M.C.; Van Parys, J.A.P.; De

Beer-Pawlikowski, N.K.B. Lancet (1984) i, 802 


\footnotetext{
${ }^{77}$ Pacifici, G.M.; Tomson, T.; Bertilsson, L.; Rane, A. Lancet (1985) ii, 397-8

${ }^{78}$ Pisani, F.; Fazio, A.; Oteri, G.; Ruello, G.; Gitto, C.; Russo, F.; Perucca, E. Epilepsia (1986) 27: 548-52

${ }^{79}$ Pacifici, G.M.; Rane, A. Pharmacol. Toxicol. (1987) 60: 237-8

${ }^{80}$ Pisani, F.; Fazio, A.; Oteri, G.; Spina, E.; Perucca, E.; Bertilsson, L. Br. J. Clin. Pharmacol. (1988) 25: 611-3

${ }^{81}$ Pisani, F.; Fazio, A.; Aresi, C.; Oteri, G.; Spina, E.; Tomson, T. Eur. J. Clin. Pharmacol. (1992) 34: 85-7

${ }^{82}$ Kerr, B.M.; Rettie, A.E.; Hedí, A.C.; Loiseau, P.; Guyot, M.; Wilensky, A.J.; Levy, R.H. Clin. Pharmacol. Ther. (1989) 46: 82-93

${ }^{83}$ Pisani, F.; Haj-Yehia, A.; Fazio, F.; Artesi, C.; Oteri, G.; Perucca, E.; Kroetz, D.L.; Levy, R.H.; Bialer, M. Epilepsia (1993) 34: 954-9

${ }^{84}$ Kerr, B.M.; Levy, R.H. Drug Metab. Dispos. (1990) 15: 540-2

${ }^{85}$ Dent, J.G.; Schnell, S.R. Biochem. Pharmacol. (1981) 30: 1712-4

${ }^{86}$ Spiegelstein, O.; Kroetz, D.L.; Levy, R.H.; Yagen, B.; Hurst, S.I.; Levi, M.; Haj-Yehia, A.; Bialer, M. Pharmaceutical Research (2000) 17(2): 216-21

${ }^{87}$ Scriba, G.K.E. Arch. Pharm. Pharm. Med. Chem. (1996) 329: 554-5

${ }^{88}$ Giannola, L.I.; Lamartina, L.; de Caro, V. Pharmazie (1998) 53(12): 829-34

${ }^{89}$ Redecker, C.; Altrup, U.; Hoppe, D.; Dusing, R.; Speckmann, E. J. Neuropharmacology (2000) 39: 254-66

${ }^{90}$ Bialer, M.; Johannessen, S.I.; Kupferberg, H.J.; Levy, R.H.; Loiseau, P.; Perucca, E. Epilepsy Res. (2001) 43(1):11-58

91 Jain, K.K. Exp Opin Invest Drugs (2000) 9(4): 829-40

92 Badir, K.; Haj-Yehia, A.; Vree, T.B.; van der Kleijn, E.; Bialer, M. Pharmaceutical Research (1991) 8(6): 750-3

${ }^{93}$ Hadad, S.; Vree, T.B.; van der Kleijn, E.; Bialer, M. Journal of Pharmaceutical Sciences (1992) 81(10): 1047-50

${ }^{94}$ Bodor, N.; Moon, S.; Bruno-Blanch, L.Pharmazie (2000) 55: 184-6

${ }_{95}$ Benoit-Guyod, J.L.; Boucherle, A.; Carraz, G. Bull. Soc. Chim. (1965) $1660-1$

${ }^{96}$ Benoit-Guyod, J.L.; Boucherle, A.; Benoit-Guyod, M.; Dardas, A.; Rupp, R.; Eymard, P.; Carraz, G.; Boitard, M.; Lebreton, S.; Beriel, H.; Meunier, H. Chimie Therapeutique (1968) 3 (5): 336-42
} 


\section{SÍNTESIS DE DERIVADOS DE VALPRAMIDA}

La síntesis de los derivados estudiados ha sido realizada por otro miembro del grupo de investigación en la Cátedra de Farmacoquímica, el Lic. Sung Chin Moon.

El procedimiento general involucra una reacción de amidación entre un haluro de ácido y una amina, en condiciones anhidras (Figura 4.3.1).

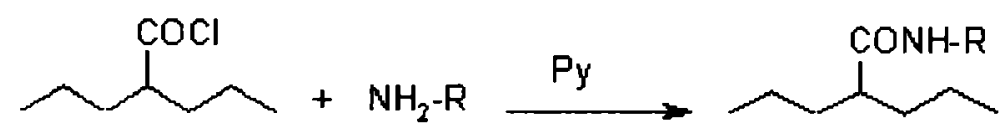

Figura 4.3.1

Reacción general de sintesis de los derivados de Vpd.

Específicamente, se hizo reaccionar el cloruro de valproílo con las distintas aminas: isopropilamina, n-butilamina, ciclohexilamina, morfolina y ácido p-aminobenzoico para dar lugar a las respectivas amidas: $\mathrm{N}$-isopropilvalpramida, $\mathrm{N}$ butilvalpramida, $\mathrm{N}$-ciclohexilvalpramida, $\mathrm{N}$-valproilmorfolina y N-(4-carboxifenil)valpramida. El cloruro de valproílo se hizo reaccionar con $\mathrm{NH}_{3}$ para generar la valpramida sin sustituir. Como medio de reacción se utilizó un solvente orgánico anhidro (benceno o acetona), y piridina como catalizador. El progreso de la reacción se controló mediante TLC.

Los compuestos fueron aislados y purificados de acuerdo a normas habituales, de acuerdo al estado de agregación de compuesto (cristalización, destilación, cromatografia, sublimación). Los compuestos fueron caracterizados y/o identificados por: punto de fusión, RMN ${ }^{1} \mathrm{H}{ }^{13} \mathrm{C}$, mono y bidimensional, espectros de masa (FAB), análisis elemental.

Detalles adicionales de la síntesis, aislamiento, purificación y caracterización de los productos figuran en referencia ${ }^{1}$.

El ácido valproico usado en los ensayos farmacológicos fue la sal monosódica, o el divalproato monosódico, ambos productos comerciales. 
${ }^{1}$ Tasso, S.M.; Moon, S.Ch.; Bruno Blanch, L.E.; Estiú, G.L. J. Med. Chem., manuscrito enviado para publicación. 


\section{ELECCIÓN DE LOS ENSAYOS BIOLÓGICOS PARA LA EVALUACIÓN ANTICONVULSIVA Y NEUROTOXICA

El paso más importante en el descubrimiento de nuevas drogas es la elección de un modelo biológico apropiado para la evaluación inicial de los compuestos.

El ensayo biológico debe detectar la acción anticonvulsiva provocando convulsiones experimentales en animales de laboratorio similares a las manifestaciones clínicas en humanos. En la etapa preclínica, los ensayos deben ser predictivos no sólo de la eficacia antiepiléptica sino también de los efectos adversos a las dosis anticonvulsivas. El lograr ésto evita seguir adelante con el estudio de compuestos que no muestran una ventana terapéutica aceptable.

Existe gran variedad de ensayos destinados a la evaluación de los distintos tipos de actividad anticonvulsiva ${ }^{!}$. La correcta elección del ensayo es de fundamental importancia, ya que el uso de modelos inapropiados significa tiempo, dinero y vidas animales malgastados, proporcionando resultados no relevantes y confusos.

Un modelo "ideal" de epilepsia es aquél capaz de manifestar convulsiones en el animal de experimentación en total correspondencia con las convulsiones en humanos, tanto en el tipo de convulsión, en las manifestaciones observadas en el EEG, en la frecuencia de las convulsiones, e incluso en la farmacocinética de las drogas utilizadas. No existe actualmente un modelo biológico que reúna todos los criterios nombrados. En contrapartida, se han desarrollado modelos genéticos de epilepsia. Se trata de animales de laboratorio con epilepsia congénita, que semejan la epilepsia idiopática en humanos mucho mejor que cualquier otro modelo experimental ${ }^{2}$. Sin embargo, el empleo de estos modelos en etapas tempranas de la evaluación preclínica, implica costos que en muchos casos no justifican su uso.

Por razones prácticas, los ensayos más ampliamente usados no son modelos de epilepsia crónica, sino aquéllos en los que se inducen convulsiones simples por medios eléctricos ó químicos. La inducción eléctrica (Maximal Electroshock Seizure test o ensayo MES) y la inducción química por administración de pentilentetrazol ó PTZ (ensayo PTZ o Met) $)^{2}$ han permitido descubrir la actividad de muchas de las drogas en uso en la actualidad, como se comentó en la sección "Panorama histórico" del capítulo 3. De hecho, 
todos los antiepilépticos clínicos son capaces de proteger frente a por lo menos uno de estos dos ensayos ${ }^{3}$. Resulta por tanto adecuado y muy útil evaluar si cada nueva droga presenta ventajas sobre las clásicas basándose en la comparación de sus potencias frente a estos ensayos.

La elección del ensayo es además importante en el estudio del perfil farmacológico de las drogas anticonvulsivas, ya que los resultados obtenidos frente a los modelos animales sirven como indicadores de potencial actividad frente a las distintas crisis convulsivas en humanos (Tabla 4.4.1). Así, el ensayo MES es un modelo de convulsiones generalizadas tónico-clónicas tanto primarias como secundarias ${ }^{1}$ mientras que la protección frente al ensayo PTZ es indicativa de eficacia contra ausencias generalizadas $\mathrm{y} / \mathrm{o}$ convulsiones mioclónicas en humanos. Ejemplo de esto se encuentra en drogas como fenitoína,

\begin{tabular}{|c|c|c|c|c|c|c|c|c|c|c|c|}
\hline & & & & \multicolumn{8}{|c|}{ Eplepsiahme } \\
\hline & \multicolumn{3}{|c|}{ Mtahequintral } & \multicolumn{3}{|c|}{ ammisiors priciales } & \multicolumn{3}{|c|}{ armukioes gorealizads } & \multirow[b]{2}{*}{$\begin{array}{l}\text { sindure } \\
\text { Lernox } \\
\text { Chetart }\end{array}$} & \multirow[b]{2}{*}{$\begin{array}{l}\text { sindume } \\
\text { West }\end{array}$} \\
\hline & $\begin{array}{l}\text { Gxwo } \\
\text { ME }\end{array}$ & $\begin{array}{l}\text { ERIyO } \\
\text { PLZ }\end{array}$ & $\begin{array}{l}\text { andido } \\
\text { de } \\
\text { anigdla }\end{array}$ & simpls & amplejs & $\begin{array}{l}\text { general. } \\
\text { seund }\end{array}$ & $\begin{array}{l}\text { tớio } \\
\text { dónicas } \\
\text { (grandma) }\end{array}$ & $\begin{array}{l}\text { assicis } \\
\text { (patit mil) }\end{array}$ & miodénicas & & \\
\hline Cathmbapin & $H$ & $\mathbf{N E}$ & $H$ & $H$ & $+H$ & $H$ & $H$ & NE & $\mathbf{N E}$ & $\mathbf{N E}$ & $\mathbf{N E}$ \\
\hline Feriture & $H$ & $\mathbf{N E}$ & + & $+H$ & $+H$ & $H$ & $H$ & $\mathbf{N E}$ & $\mathbf{N E}$ & $\mathrm{NE}$ & $\mathbf{N E}$ \\
\hline Fentatita & $H$ & $H$ & $H$ & $H$ & $H$ & $H$ & $H$ & $\mathbf{N E}$ & + & $\mathbf{N E}$ & $\mathbf{N E}$ \\
\hline Pimidna & $H$ & $H$ & $H$ & $+H$ & $+1+$ & $H$ & $H$ & $\mathbf{N E}$ & $H$ & $\mathbf{N E}$ & $\mathbf{N E}$ \\
\hline Valpoin & + & $H+$ & $H$ & + & + & $H$ & $+H$ & $+1+$ & $H$ & + & + \\
\hline Elosuminich & $\mathbf{N E}$ & $H$ & $\mathbf{N E}$ & $\mathrm{NE}$ & $\mathbf{N E}$ & $\mathbf{N E}$ & $\mathbf{N E}$ & $H$ & $H$ & $N E$ & $\mathbf{N E}$ \\
\hline Benationites & + & $H+$ & + & + & ++ & $H$ & + & + & + & $H$ & + \\
\hline $\begin{array}{l}\text { Ithidues de } \\
\text { GABAt (uggharin) }\end{array}$ & $\mathbf{N E}$ & + & $H$ & $H$ & $+H$ & $H$ & $?$ & $\mathbf{N E}$ & $\mathbf{N E}$ & $?$ & + \\
\hline $\begin{array}{l}\text { Aragrists MMA } \\
\text { (MK-801, DCPPex) }\end{array}$ & + & + & $\mathbf{N E}$ & $\mathbf{N E}$ & $\mathbf{N E}$ & $\mathbf{N E}$ & $?$ & $?$ & $?$ & $\mathbf{N E}$ & $?$ \\
\hline
\end{tabular}

Tabla 4.4.1

Comparación de las respuestas frente a modelos experimentales y eficacia clínica en humanos.

"general. secund." se refiere a las convulsiones que evolucionan secundariamente a tónico clónicas generalizadas.

(Tomado de Loscher, W. $y$ col. $^{2}$ )

activa frente al ensayo MES, que también lo es para las convulsiones tónicas y/o clónicas (grand mal) en humanos. Trimetadiona y etosuximida protegen de las convulsiones clónicas provocadas por el PTZ, y son efectivas para el tratamiento de las convulsiones mioclónicas y ausencias en 
humanos. Muchos otros ejemplos pueden encontrarse en la literatura ${ }^{2}$.

Las crisis epilépticas parciales no son fácilmente asociables a un modelo animal. La eficacia del ensayo MES contra estas convulsiones fue refutada por estudios recientes en modelos experimentales y clínicos con nuevas drogas antiepilépticas, tales como vigabatrin (inhibidor de GABA-T) y antagonistas de glutamato. Los encendidos de hipocampo o amígdala ("hippocampal / amigdala kindling") se presentan actualmente como modelos más adecuados para probar específicamente la eficacia contra crisis epilépticas parciales (Tabla 4.4.1).

Resulta claro que en vista de los diversos tipos de convulsiones epilépticas, debe usarse más de un modelo biológico para el análisis del perfil farmacológico de las nuevas drogas antiepilépticas.

En cuanto a los efectos adversos habitualmente presentes en drogas de acción central, se considera en la evaluación preclínica la posible capacidad neurotóxica. Esta toxicidad se evalúa generalmente mediante la respuesta frente al ensayo RotoRod.

En el ítem "Resurgimiento del interés por el descubrimiento de nuevos agentes antiepilépticos" del capítulo 3, se ha hecho mención al programa ADD (NINCDS - NIH) ${ }^{3,4}$, el cual a través del ASP ha fomentado el desarrollo de nuevos compuestos para el tratamiento de la epilepsia. Este proyecto plantea las metodologías a seguir para la evaluación preclínica, mediante el uso de modelos animales, de nuevas drogas con sospechada acción anticonvulsiva. En la actualidad, prácticamente todos los laboratorios en el ámbito mundial siguen las directivas planteadas en este proyecto, en el momento de determinar si sus nuevas estructuras poseen características de actividad prometedoras.

El ASP del programa ADD consta de siete fases, cada una de las cuales utiliza diferentes ensayos y aporta datos sobre distintos aspectos de la acción de las drogas, desde la existencia de actividad anticonvulsiva hasta la presencia de tolerancia luego de la administración repetida de la droga, incluyendo perfiles de actividad anticonvulsiva, neurotoxicidad, índices terapéuticos, duración de la acción, comparación de la actividad según la vía de administración y según la especie animal, etc. (Tabla 4.4.2).

Tabla 4.4.2 (página siguiente)

Programa $A D D$

Descripción de las fases y la batería de ensayos empleados en cada una.

(tomado de Porter, R.J. y col. ${ }^{4}$ ) 
descripción de las acciones

FASE 1 Identificación de acción anticonvulsiva y neurotóxica, para determinar el nivel de actividad

$$
\begin{array}{ll}
\checkmark & \text { ensayo MES } \\
\checkmark & \text { ensayo PTZ } \\
\checkmark & \text { ensayo RotoRod }
\end{array}
$$

FASE 2 Cuantificación de la acción anticonvulsiva y neurotóxica, mediante la determinación de ED50, TD50 y PI

$\checkmark$ ensayo MES

$\checkmark$ ensayo PTZ

$\checkmark$ ensayo RotoRod

FASE 3 Perfil de toxicidad

$\checkmark$ dosis letal media (LD50)

$\checkmark$ dosis hipnótica media (HD50)

FASE 4 Cuantificación de la acción anticonvulsiva por vía oral, para determinar las características de absorción y metabolismo
$\checkmark$ ensayo MES
$\checkmark$ ensayo PTZ
$\checkmark$ ensayo RotoRod

FASE 5 Comparación con drogas antiepilépticas conocidas y diferenciación del posible mecanismo de acción

$\checkmark$ ensayo de umbral convulsivo por PTZ

$\checkmark$ ensayo de umbral convulsivo por picrotoxina

$\checkmark$ ensayo de umbral convulsivo por bicuculina

$\checkmark$ ensayo de umbral convulsivo por estricnina

$\checkmark$ estudios in vitro de unión a receptores

FASE 6 Cuantificación de la acción anticonvulsiva y neurotóxica en otras especies, mediante la determinación de ED50, TD50 y PI
$\checkmark$ ensayo MES
$\checkmark$ ensayo PTZ
$\checkmark$ ensayo de sentido posicional
$\checkmark$ ensayo de marcha y postura

FASE 7 Estimación de la dosis letal mínima (LD3) y de los efectos de la administración prolongada (tolerancia)

$\checkmark$ determinación de la LD3 luego de la administración diaria durante 3 días

$\checkmark$ administración durante 5 días

$\checkmark$ ensayo de duración del sueño por hexobarbital

$\checkmark$ estudios in vitro de enzima microsomal

$\begin{array}{cc}\begin{array}{c}\text { especie } \\ \text { animal } \\ \text { ratones }\end{array} & \begin{array}{c}\text { vía de } \\ \text { adm.* }\end{array} \\ \text { i.p. }\end{array}$
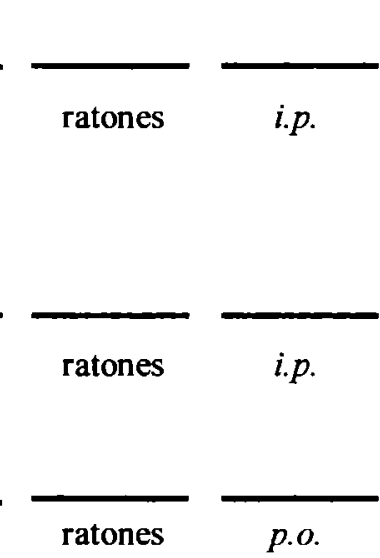

ratones

i.p.

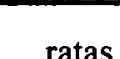

p.o.

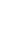


La Fase 1 del ASP del programa ADD involucra la identificación de la acción anticonvulsiva (Tabla 4.4.2), mediante la prueba a cuatro niveles de dosis distintas (30, 100,300 y $600 \mathrm{mg} / \mathrm{kg}$ ). La clasificación de las estructuras ensayadas en cuatro categorías permite decidir cuáles serán capaces de continuar dentro del proyecto, y cuáles se descartan. De esta forma, aquéllas que no son activas o lo son recién a $600 \mathrm{mg} / \mathrm{kg}$ (categoría 3) se descartan, las que son activas a dosis de hasta $100 \mathrm{mg} / \mathrm{kg}$ (categoría 1) pasan a Fase 2 , mientras que las que lo son a $300 \mathrm{mg} / \mathrm{kg}$ (categoría 2) pueden o no considerarse dependiendo de lo novedoso de su estructura. Aquellas estructuras que presentan actividad pero también efectos neurotóxicos a $30 \mathrm{mg} / \mathrm{kg}$ (categoría 4 ), se re evalúan a dosis menores (Handbook85).

La fase 2 de programa es la más importante en el momento de cuantificar la actividad anticonvulsiva y neurotóxica de una droga. Los valores de ED50 frente a los ensayos MES y PTZ son los parámetros más ampliamente usados para describir la potencia de los nuevos compuestos con acción anticonvulsiva. Constituyen la primera indicación preclínica de potencial capacidad antiepiléptica para determinado tipo de convulsión humana, además de permitir una comparación válida entre potencias anticonvulsivas con distintas drogas antiepilépticas ya establecidas.

\footnotetext{
${ }^{1}$ Fisher, R.S. Brain Research Reviews (1989) 14: 245-78

${ }^{2}$ Loscher, W.; Schmidt, D. Epilepsy Research (1994) 17: 95-134

${ }^{3}$ Stables, J.P.; Kupferberg, H.J. Cap. 16: The NIH Anticonvulsant Drug Development (ADD) Program: preclinical anticonvulsant screening project. En: Avanzini, G.; Regesta, G.; Tanganelli, P.; Avoli, M. (Eds.), Molecular and cellular targets for anti-epileptic drugs, John Libbey \& Company Ltd. (1997) pp. 191-198

${ }^{4}$ Porter, R.J.; Cereghino, J.J.; Gladding, G.D.; Hessie, B.J.; Kupferberg, H.J.; Scoville, B.; White, B.G. Clev. Clin. Q. (1984) s1: 293-305
} 


\section{DESCRIPCIÓN DE LA METODOLOGÍA DE EVALUACIÓN ANTICONVULSIVA Y NEUROTÓXICA}

Los ensayos realizados para la evaluación de la capacidad anticonvulsiva y neurotóxica de los derivados $\mathrm{N}$ sustituidos de Vpd planteados siguen los lineamientos descriptos en el ASP del programa $\mathrm{ADD}^{1}$. Se efectúa, específicamente, la fase 2 de dicho programa, cuyo objetivo principal es la determinación cuantitativa de la actividad anticonvulsiva y neurotóxica en ratones inyectados por vía intraperitoneal.

Inicialmente, se determina de un tiempo de efecto máximo ( $\left.\mathrm{TPE}^{\star}\right)$, el cual surge de la evaluación de la droga a distintos tiempos (usualmente 30, 60, 120 y 240 minutos, ó hasta

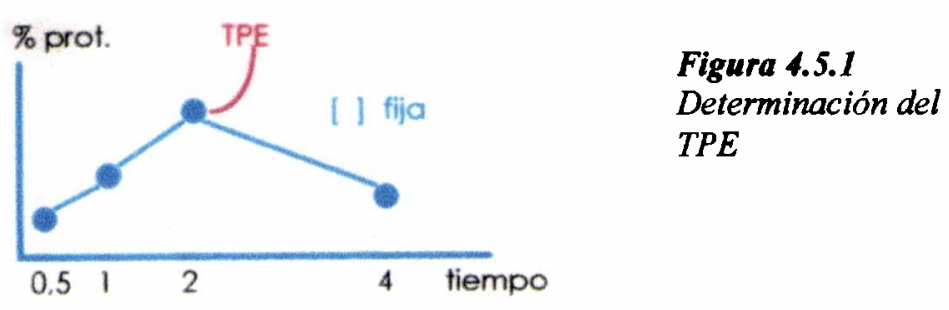

que el tiempo de mayor actividad o neurotoxicidad haya pasado), empleando 3-5 animales por tiempo. Los porcentajes de protección o neurotoxicidad se grafican en función del tiempo y se determina el TPE por inspección visual de la curva obtenida (Figura 4.5.1).

Posteriormente, se procede a calcular las ED50

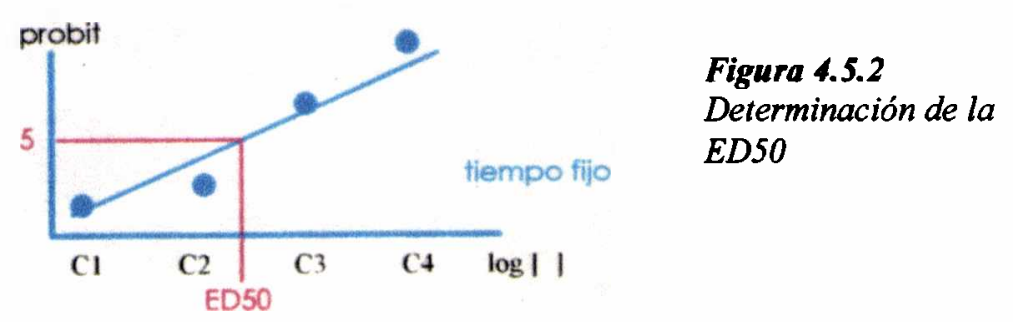

(empleando el ensayo MES y el ensayo PTZ) y la TD50 (empleando el ensayo RotoRod). Grupos de aproximadamente 8 animales por dosis son evaluados al TPE determinado previamente. Se continúa la evaluación hasta tener al menos 4 dosis distintas comprendidas entre aquélla que no induce protección $(0 \%)$ y la que provoca protección total $(100 \%)$. Los porcentajes de protección a cada dosis,

+ TPE: time of peak effect (tiempo de efecto máximo) 
convertidos a probits ${ }^{2}$, se grafican en función del logaritmo de la dosis (Figura 4.5.2). Mediante el método estadístico descripto más adelante (en el ítem "Tratamiento estadístico de los datos" de esta misma sección), se elige la recta más adecuada, para luego extrapolar, a probit 5 , el valor de la ED50.

Las ED50s se calculan al TPE determinado por el ensayo MES, excepto cuando una evaluación preliminar indica que la máxima actividad frente al ensayo PTZ ocurre a un tiempo diferente'.

\section{Animales}

Para la evaluación de las drogas frente a los ensayos descriptos se utilizan ratones albinos adultos de 25-31 grs. de peso $^{3,4,5,6}$ (Figura 4.5.3) al
momento del ensayo
biológico.
Los animales son
mantenidos en el Bioterio
del Área Diseño de
Fármacos de la Facultad
de Ciencias Exactas
(UNLP), en una

Figura 4.5.3 Ratón albino, especie empleada en los ensayos biológicos

habitación exclusiva para la cría de ratones, distinta a la sala de Ensayos Biológicos. Se mantienen en jaulas colectivas de hasta 12 animales (Figura 4.5.4), con alimento balanceado y agua ad libitum, y bajo un régimen de ciclos día-noche de 12
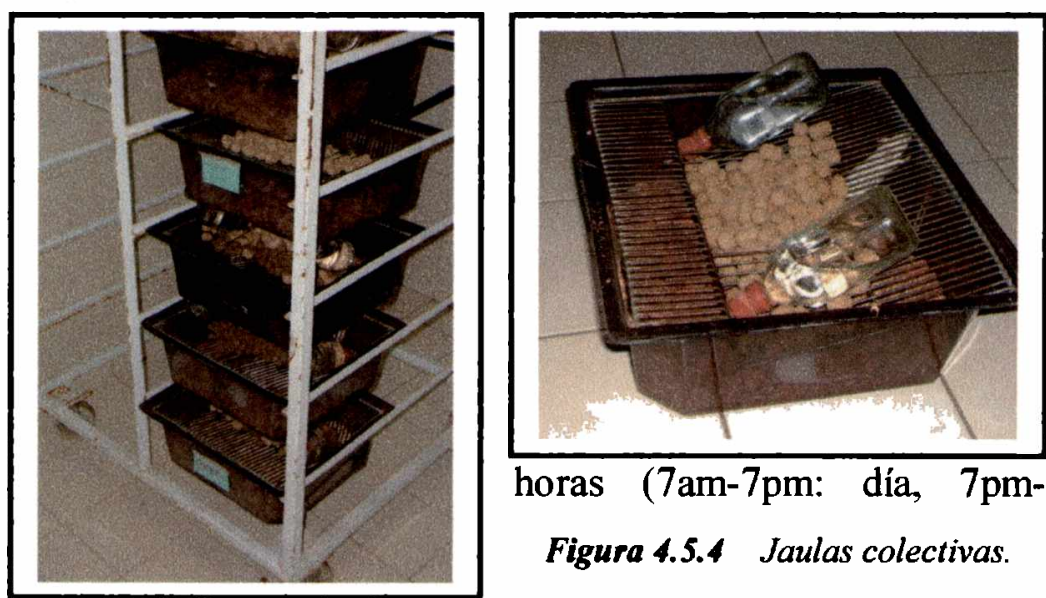

Figura 4.5.4 Jaulas colectivas.

7am: noche). Se separan

por sexo y por etapas del crecimiento (hembras preñadas, crías en amamantamiento, animales jóvenes, adultos, animales en reproducción, etc.).

A los animales recién recibidos en el Bioterio se les permite estabilizarse durante por lo menos 48 horas antes de 
Figura 4.5.5 Casilleros individuales para la realización de los ensayos biológicos destinarlos a algún ensayo, para compensar las restricciones de agua y alimento y el estrés que sufren durante los traslados. Este accionar es fundamental ya que la inanición incrementa la severidad de las convulsiones provocadas por el Electroshock.

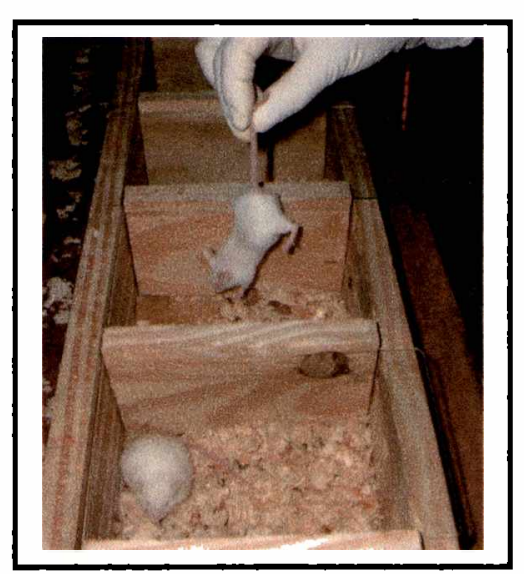

En el momento de someterlos a los ensayos, los ratones se colocan en compartimientos individuales (Figura 4.5.5) hasta finalizadas las evaluaciones, las cuales se realizan en la sala de Ensayos Biológicos. Luego los animales se vuelven a las jaulas colectivas y cada lote de ratones correspondiente a un ensayo se mantiene en observación por separado durante 72 horas, para detectar posibles efectos tóxicos a largo plazo que puedan llevar a la muerte de los animales.

\section{Predaración v administración de las drogas a ensavar}

Los derivados de Vpd estudiados, al igual que todas las drogas de acción en el SNC, deben presentar la suficiente lipofilicidad como para ser capaces de atravesar la BHE, pero por otro lado es conveniente, para una correcta evaluación farmacológica, que las drogas sean solubles en agua o bien puedan ser administradas en forma de suspensión o emulsión homogéneas. En el programa ADD se admite el empleo de solución fisiológica, metilcelulosa y polietilenglicol 400 $(\mathrm{PEG} 400)^{7}$ para la preparación de soluciones, suspensiones o emulsiones.

Las drogas estudiadas no son solubles en agua, por lo tanto no es posible administrarlas en solución fisiológica. Se utiliza entonces PEG 400, solvente que no afecta los resultados biológicos ${ }^{1,8,9}$. Se recomienda que los solventes a ser usados en investigaciones farmacológicas y toxicológicas no superen en concentración un cuarto del valor de la LD50 correspondiente ${ }^{9}$. Por tal razón, siendo $12.9 \mathrm{ml} / \mathrm{kg}$ la LD50 del PEG 400 en ratones inyectados por vía intraperitoneal ${ }^{9}$, éste se emplea en concentraciones no mayores a $3 \mathrm{ml} / \mathrm{kg}$, solo o en proporciones que llegan a $30 \%$ PEG 400 y $70 \%$ agua. En este último caso, el volumen total a administrar se eleva a $10 \mathrm{ml} / \mathrm{kg}$. Proporciones intermedias de PEG $400 /$ agua dan lugar a volúmenes de administración que varían entre 3 y 10 $\mathrm{ml} / \mathrm{kg}$. 
Cuando la droga es sólida, se morterea y solubiliza en PEG 400. Se somete a ultrasonido para favorecer la disolución, y si no se logra solución límpida, se calienta a $37^{\circ} \mathrm{C}$ la preparación. Luego se agrega agua y se repite el sonicado y calentamiento si es necesario.

Cuando la droga es líquida, se solubiliza con PEG 400 , y si no se logra disolución, se calienta a $37^{\circ} \mathrm{C}$. Luego se incorpora el agua y repite la operación si es necesario.

Al momento de la administración, las preparaciones son soluciones límpidas, suspensiones homogéneas 0 emulsiones finas, en PEG 400 o en PEG 400 / agua.

Según las proporciones de PEG 400 y agua utilizados, y el peso de cada animal, los volúmenes de administración varían desde 0,08 hasta $0,31 \mathrm{ml}$. Se utilizan jeringas graduadas al $0,01 \mathrm{ml}$.

Las vías de administración de las drogas son (Figuras 4.5.6 y 4.5.7):

$\checkmark$ vía i.p. (intraperitoneal): la inyección se realiza en el abdomen del animal, formando un ángulo de $30^{\circ}$ con el plano del cuerpo, utilizando agujas $27 \mathrm{G} 1 / 2$ cuando se inyectan soluciones y $25 \mathrm{G}$ $5 / 8$ cuando se trata de suspensiones o emulsiones. Al retirar la aguja se presiona suavemente con un trozo de algodón para verificar posibles pérdidas de volumen de administración.

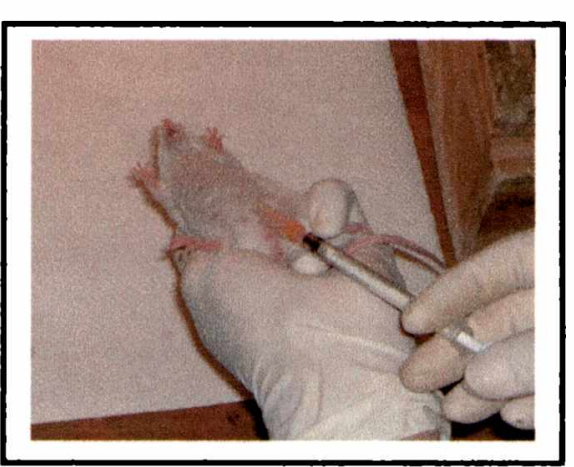

Figura 4.5.6 (arriba) Via i.p. Fieura 4.5.7 (abaio) Via s.c.

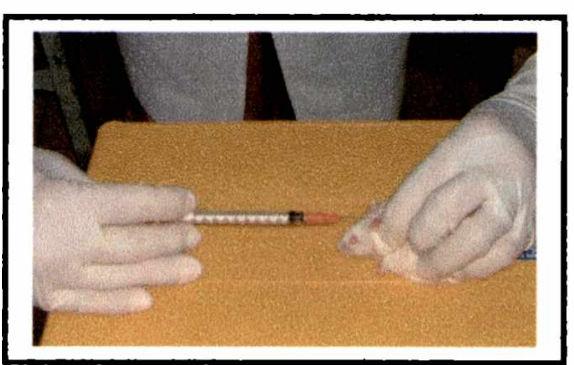

La vía de administración s.c. se utiliza para la aplicación de los agentes convulsivos, mientras que la vía i.p. se utiliza tanto para la inyección de las drogas anticonvulsivas como convulsivas. Es importante seleccionar juiciosamente las vías de inyección de las distintas sustancias, fundamentalmente para evitar falsos positivos inducidos por drogas vasoconstrictoras que retardan la absorción del agente convulsivo. En tal caso, es preciso utilizar vías distintas, o bien aplicar las inyecciones en sitios alejados entre $\mathbf{s i}^{\mathbf{7}}$. 


\section{Ensavo MES}

Este ensayo consiste básicamente en la aplicación de una descarga eléctrica controlada a animales de experimentación (ratas $o$ ratones) con el objeto de provocarles un episodio convulsivo. Se mide la capacidad que tiene un fármaco, administrado previamente, de prevenir la convulsión.

Este modelo identifica compuestos que previenen la propagación de la descarga convulsiva.

Aparato utilizado: los equipos utilizados para la generación del estímulo eléctrico que provoca la convulsión en ratas y ratones, responden en líneas generales al diseño original propuesto por Woodbury y Davenport ${ }^{10}$. En el Laboratorio de Farmacoquímica se cuenta con un generador de pulsos de corriente constante, diseñado y construido en la Facultad de Ingeniería de la UNLP. Este equipo fue diseñado para cubrir específicamente las necesidades relativas a este tipo de ensayo, y se desarrolló a semejanza de la unidad ECT $^{*}$ (Ugo Basile - Biological Research Apparatus, Varese, Italia), uno de los modelos de aparatos de electroshock más nuevos usados actualmente en las pruebas de convulsión. En este aparato se pueden fijar:

$\checkmark$ la corriente a aplicar, entre 10 y $100 \mathrm{~mA}$, ya que la corriente necesaria para provocar una convulsión varía según las distintas especies animales,

$\checkmark$ la frecuencia (f) del estímulo (o sea la cantidad de pulsos por segundo), entre 1 y $250 \mathrm{~Hz}$, segundos, $\mathrm{y}$

$\checkmark$ la duración total de la descarga, entre 0.1 y 9.9 9.9 milisegundos.

$\checkmark$ el ancho del pulso (AP) de corriente, entre $0.1 \mathrm{y}$

Para el ensayo en ratones, se emplean los parámetros típicos de estimulación para lograr una convulsión máxima ${ }^{11}$, es decir, una corriente de $50 \mathrm{~mA}$, con una frecuencia de 60 $\mathrm{Hz}$, y un ancho de pulso de 2.8 milisegundos, aplicando el estímulo durante 0.2 segundos.

Con los parámetros descriptos "seteados" de esta forma se logra obtener un tren de ondas rectangulares de esta forma:

\footnotetext{
+ ECT: Electro Convulsive Treatment, Unidad de tratamiento electroconvulsivo
} 


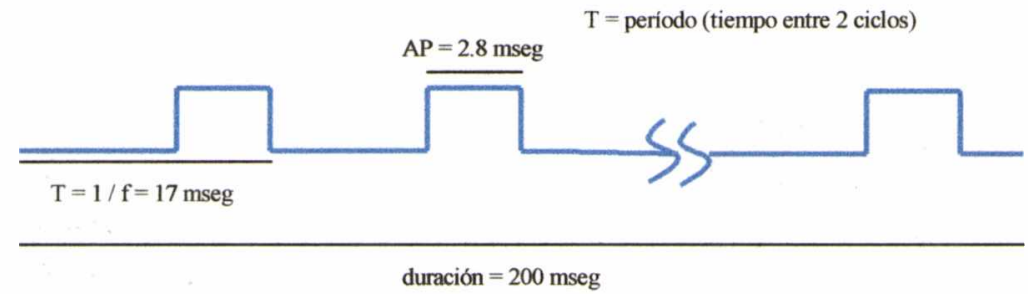

logrando así una respuesta convulsiva máxima, ya que el estímulo aplicado corresponde a 4-5 veces el necesario para llegar al umbral de convulsión.

Hay que destacar en este punto la diferencia entre convulsión mínima o umbral convulsivo y convulsión máxima.

Una convulsión mínima se caracteriza por una reacción de aturdimiento y movimientos clónicos de la cara y miembros anteriores. En cambio, las convulsiones máximas comprenden un período corto de flexión tónica seguido de un período más largo de extensión tónica de los miembros posteriores, y finalmente se observa un episodio clónico" (ver figura 4.5.8).

La supresión de la fase de extensión tónica de los miembros posteriores (Figura 4.5.8 $b$ ) en las convulsiones por electroshock máximo es lo que determina si el animal se encuentra protegido o no.

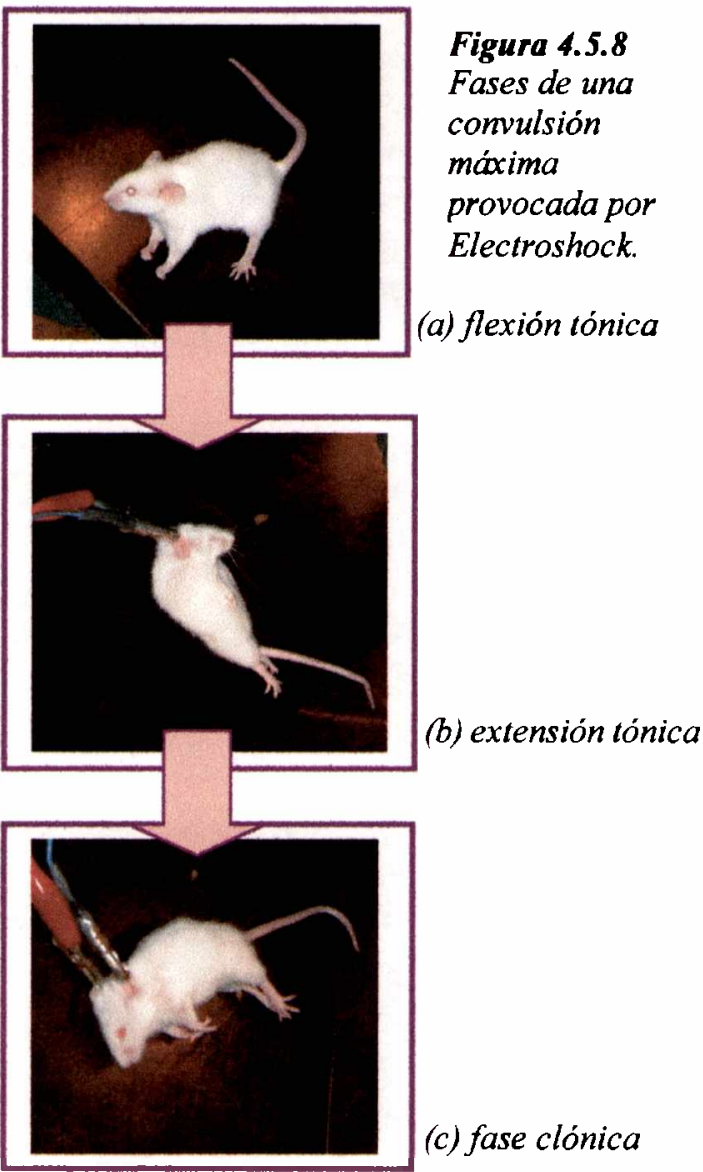

Como resultado de cada ensayo frente al ensayo MES se obtiene el porcentaje de protección de la droga:

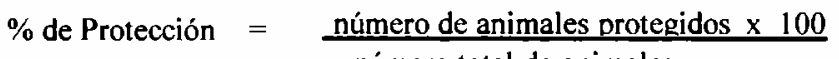

Existen distintos tipos de electrodos que se conectan al equipo y permiten entregar el paquete de descarga eléctrica deseado al animal. Los corneales y los de orejas son los más 
ampliamente usados y en el Laboratorio de Farmacoquímica se cuenta con ambos tipos (Figura 4.5.9).

Figura 4.5.9

Electrodos

corneales

(izquierda) y

de oreja

(derecha).
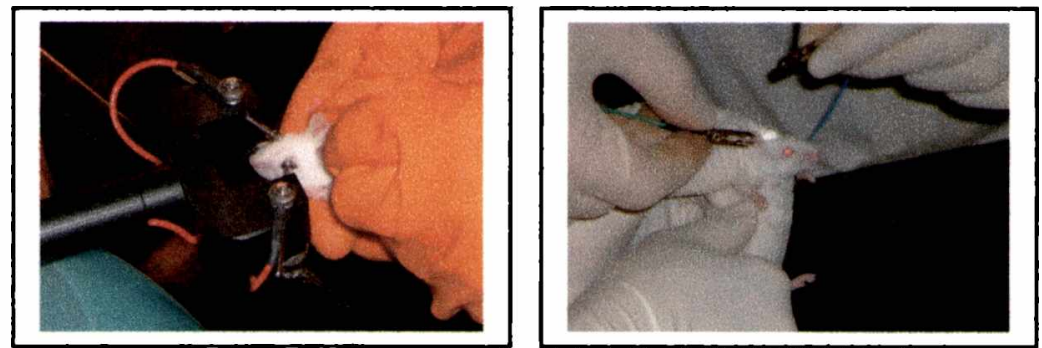

Los resultados de protección frente al ensayo MES presentados en este trabajo de Tesis se obtuvieron con electrodos de orejas en todos los casos. Los electrodos son humedecidos con solución fisiológica en el momento de la aplicación en las orejas del animal, con el objeto de asegurar el contacto y favorecer la conducción de la corriente eléctrica.

\section{Ensavo PTZ}

En este ensayo se inducen los episodios convulsivos por medio de un agente convulsivo: pentilentetrazol (PTZ) o metrazol. Aquí también se analiza la capacidad de un fármaco, administrado previamente, de prevenir la convulsión.

Este modelo identifica compuestos que elevan el umbral convulsivo.

La solución de PTZ $(1.7 \%$ en $0.9 \%$ de solución salina) a utilizar se prepara momentos antes de la inyección en frasco opaco para evitar la fotodegradación. El PTZ se administra a razón de $5 \mathrm{ml} / \mathrm{kg}$, ya que se observa que utilizando volúmenes de inyección mayores se aumentan las probabilidades de derramamiento por el punto de inyección al retirar la aguja. La cantidad de PTZ administrada $(85 \mathrm{mg} / \mathrm{kg})$ corresponde a la CD97 en ratones, es decir aquélla que es capaz de inducir convulsiones en el 97 por ciento de los animales ${ }^{7,11}$.

El PTZ puede administrarse por varias vías. La vía s.c. es la más utilizada aunque también puede utilizarse la vía i.p. a dosis $50-75 \mathrm{mg} / \mathrm{kg}^{12}$ o la $i . v$. (intravenosa) a $50 \mathrm{mg} / \mathrm{kg}^{13}$. Los resultados de protección frente al ensayo PTZ presentados en este trabajo corresponden al uso de la vía s.c., salvo en el caso de Vpa y CpVpd para los cuales se empleó también la administración i.p. Una vez inyectados con PTZ, los animales son observados durante 30 minutos para determinar si se produce alguna convulsión.

El PTZ provoca inicialmente sacudidas clónicas, que luego se hacen más sostenidas, y pueden conducir a un episodio tónico clónico. Como criterio para decidir 
protección o no frente a la convulsión, se toma la aparición de al menos un episodio clónico continuo de más de 5 segundos de duración.

Como resultado de cada ensayo frente al ensayo PTZ se obtiene el porcentaje de protección de la droga:

$$
\% \text { de Protección }=\frac{\text { número de animales protegidos } \times 100}{\text { número total de animales }}
$$

\section{Ensavo RotoRod}

Este ensayo mide el efecto neurotóxico, manifestado como sedación o ataxia, que puede provocar una droga anticonvulsiva.

Un ratón normal es capaz de mantener el equilibrio sobre un cilindro giratorio por largos períodos de tiempo. La inhabilidad de un ratón de mantener la caminata sobre el cilindro en cada uno de 3 ensayos sucesivos, se considera como signo de sedación o ataxia.

Aparato utilizado: se utiliza un equipo construido en la Facultad de Ingeniería de la UNLP (Figura 4.5.10), en base al diseñado inicialmente por Dunham y Miya ${ }^{14}$ y a semejanza del Rota-Rod tredmill for mice (Ugo Basile - Biological Research Apparatus, Varese, Italia). Este aparato consiste en un cilindro estriado de $3 \mathrm{~cm}$ de diámetro que gira a $15 \mathrm{rpm}^{15}$, sobre el cual se ubican los animales, separados unos de otros por paneles circulares. Los animales que

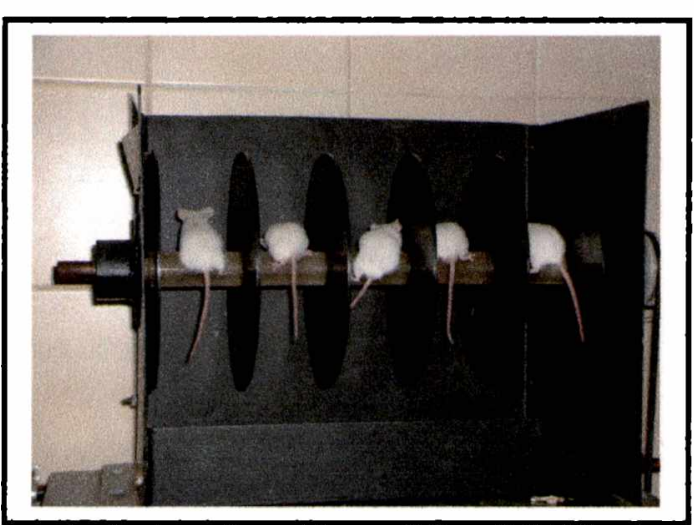

Figura 4.5.10 Aparato de RotoRod.

caen, lo hacen sobre una bandeja situada debajo del cilindro. $\mathrm{La}$ velocidad de rotación puede graduarse en forma continua.

Como resultado de cada ensayo frente al ensayo RotoRod se obtiene el porcentaje de toxicidad de la droga:

$$
\% \text { de toxicidad }=\frac{\text { número de animales que caen } \times 100}{\text { número total de animales }}
$$




\section{Tratamiento estadístico de los datos}

Es importante la elección del método estadístico a utilizar para el tratamiento de los datos recogidos. El método de Litchfield y Wilcoxon ${ }^{16}$ es el más usado para este tipo de análisis ya que es el que mejor se adapta a la solución de los experimentos biológicos dosis-efecto.

De la aplicación del método se obtienen:

$\checkmark$ el dato de ED50 ó TD50

$\checkmark$ los intervalos de confianza de esta dosis

$\checkmark$ la función pendiente de la recta (S)

$\checkmark$ los intervalos de confianza de esta función

Se analizan los datos obtenidos, volcados en formato Excel, para cada uno de los compuestos cuya evaluación biológica fue satisfactoria, es decir que se pudo lograr llegar a un mínimo de cuatro dosis con actividades biológicas distintas del 0 ó $100 \%$.

A modo de ejemplo se presenta aquí la evaluación estadística del experimento con el derivado N,Ndimetilvalpramida* en el ensayo MES (Tabla 4.5.1). Los datos se ingresan en una tabla creada para facilitar el cálculo de los distintos parámetros y factores que es necesario obtener a lo largo del análisis por el método de Litchfield y Wilcoxon (Tabla 4.5.1).

\begin{tabular}{|c|c|c|c|c|c|c|c|c|c|c|}
\hline dose & $\log$ dose & n react & $n$ test & \%eff obs & correct & probit obs & probit exp & $\%$ eff exp & diff oe & Chi 2 \\
\hline 200 & 2,30103 & 1 & 4 & 25 & & 4,33 & 4,0133 & & 25 & 0,001 \\
\hline 300 & 2,477121 & 4 & 8 & 50 & & 5 & 4,7405 & & 50 & 0,016 \\
\hline 400 & 2,60206 & 3 & 6 & 50 & & 5 & 5,2565 & & 50 & 0,03 \\
\hline 500 & 2,69897 & 4 & 7 & 57,14286 & & 5,18286 & 5,6567 & & 57,143 & 0,08 \\
\hline 600 & 2,778151 & 7 & 8 & 87,5 & & 6,155 & 5,9838 & & 87,5 & 0,039 \\
\hline
\end{tabular}

\begin{tabular}{|c|c|}
\hline Tdari2 & 0,16 \\
\hline Noses & \\
\hline AveNan & \\
\hline Qri 2 line & 1,0966 \\
\hline Degfree & \\
\hline Ci2 12 & 7,8 \\
\hline $\mathrm{Ne}^{\top 16-84}$ & 3 \\
\hline sope & 4,1 \\
\hline & -5 \\
\hline I & 0,80 \\
\hline
\end{tabular}

\begin{tabular}{|c|c|}
\hline$B D 16=$ & 199,6375 \\
\hline$E D 0=$ & 346,6982 \\
\hline$B 084=$ & 602,0894 \\
\hline$S=$ & 1,736039 \\
$R=3$ \\
$A=1,38$
\end{tabular}

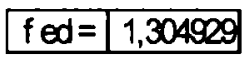 \\ $\mathrm{fs}=1,566025$}

Tabla 4.5.1 Tratamiento estadístico de los datos obtenidos a partir de la evaluación del derivado $N, N$ dimetilvalpramida frente al ensayo MES. œirf lim I 205,6837

conf $\lim$ S 452,4164 26,93015

corf lim 1 1,100047

conf $\lim$ S 2719619 46,37325

\footnotetext{
- más adelante, en la sección 9 de este capítulo, se describen los resultados de la evaluación biológica de este compuesto.
} 
Los datos de entrada son: las dosis usadas (dose), el número de animales protegidos ( $n$ react), el número total de animales ( $n$ test), y los porcentajes de protección (\%eff obs). Los datos de actividad se convierten a probits (probit obs). Este mismo método puede usarse de forma equivalente para la cuantificación de los efectos neurotóxicos (TD50).

Posteriormente se grafica el logaritmo de las dosis (log dose) en función de los probits correspondientes (probit $o b s)$ y se traza la recta que interprete bien los puntos, particularmente aquéllos situados entre el $40 \%$ y el $60 \%$ de protección. Los puntos de nula actividad ó aquéllos con 100 $\%$ de actividad son corregidos (correct) en base al valor esperado para cada uno de ellos (\%eff exp). El peso estadístico de la línea propuesta se evalúa obteniendo un valor de $(\mathrm{Chi})^{2}$ de la recta (Tot Chi 2), en base a las diferencias entre valores esperados y observados (ó corregidos) (diff o-e) para cada dosis y al número promedio de animales por dosis (Ave $N$ ani). Se considera que los datos no son significativamente heterogéneos, de manera que la línea trazada es aceptable, cuando el valor de $(\mathrm{Chi})^{2}$ no supera un cierto valor límite (Chi 2 T2) estipulado para distintos grados de libertad (Deg Free).

Los datos de ED50 surgen directamente de la recta, mientras que el valor de la función pendiente surge de la expresión:

$$
\mathrm{S}=(\mathrm{ED} 84 / \mathrm{ED} 50+\mathrm{ED} 50 / \mathrm{ED} 16) / 2
$$

Los factores $f e d$ y $f s$ tienen en cuenta el número de dosis usadas ( $N$ doses), el número de animales involucrados en los puntos que caen dentro de los valores de probit 4-6 de actividad esperada ( $N$ e/16-84), la función pendiente $(S)$ y el valor $A$ que depende de las dosis más alta y baja empleadas (cuyo cociente es $R$ ). Estos factores son los que permiten calcular los intervalos de confianza para la ED50 y la $S$ respectivamente.

En el ejemplo de la tabla 4.5.1 aparecen grisados la ED50 y la S, así como los intervalos de confianza superiores (conf $\lim S$ ) e inferiores (conf lim $I$ ) de estos parámetros.

\footnotetext{
' Porter, R.J.; Cereghino, J.J.; Gladding, G.D.; Hessie, B.J.; Kupferberg, H.J.; Scoville, B.; White, B.G. Clev. Clin. Q. (1984) 51: 293-305

${ }^{2}$ Goldstein, A.; Aronow, L.; Kalman, S. Principles of drug Action: The Basis of Pharmacology 2nd Ed. J. Wiley \& Sons, New York (1974) pp. 449-70
} 


\footnotetext{
${ }^{3}$ Shek, E.; Murakami, T.; Nath, Ch.; Pop, E.; Bodor, N. J. Pharm. Res. (1989) 78(10): 837-43

${ }^{4}$ Loscher, W.; Esenwein, H. Drug Res. (1978) 28(I) 782-7

${ }^{5}$ Loscher, W. Arch. int. Pharmacodyn. (1981) 249: 158-63

${ }^{6}$ Loscher, W.; Nau, H. Neuropharmacology (1985) 24(5): 427-35

${ }^{7}$ Swinyard, E.A.; Woodhead, J.H.; White, H.S.; Franklin, M.R. Cap. 5: Experimental Selection, Quantification, and Evaluation of Anticonvulsant En: Levy, R.; Mattson, R.; Meldrum, B.; Penry, J.K.; Dreifuss, F.E. (Eds.) Antiepileptic Drugs, $3^{\text {rd }}$ Ed., Raven Press, Ltd., New York (1989) pp. 85102

${ }^{8}$ Gladding, G.D.; Kupferberg, H.J.; Swinyard, E.A. Apéndice Cap.12: Antiepileptic Drug Development Program En: Handbook Exp. Pharm. Vol.74 Antiepileptic Drugs (1985) pp. 341-347

${ }^{9}$ Bartsch, W.; Sponer, G.; Dietmann, K.; Fuchs, G. Arzneimittel Forschung (Drug Research) (1976) 26(8): 1581-3

${ }^{10}$ Woodbury, L.A.; Davenport, V.D. Arch. Int. Pharmacodyn. (1952) XCII(1): 97-107

"Fisher, R.S. Brain Research Reviews (1989) 14: 245-78

${ }^{12}$ Stone, W.E. Pharmacology (1970) $3: 367-70$

${ }^{13}$ Little, H.J.; Nutt, D.J.; Taylor, S.C. Br. J. Pharmacol. (1986) 88: 326

${ }^{14}$ Dunham, N.W.; Miya, T.S. J. Am. Pharmaceut. Assoc. (1957) 46: 3

${ }^{15}$ Elmazar, M.M.A.; Hauck, R.S.; Nau, H. Journal of Pharmaceutical Sciences (1993) 82(12): 1255-8

${ }^{16}$ Litchfield, J.T.; Wilcoxon, F. J. Pharm. Exp. Ther. (1949) 96: 99-113
} 


\section{RESULTADOS DE LA EVALUACIÓN ANTICONVULSIVA Y NEUROTÓXICA}

Se presentan a continuación los resultados obtenidos a partir de la evaluación biológica de los derivados estudiados, siguiendo los lineamientos metodológicos del ASP del programa $\mathrm{ADD}$, descriptos en la sección 5 del presente capítulo.

Al ser el Vpa el compuesto padre a partir del cual surgen todos los derivados ensayados, se lo utiliza como referencia al analizar comparativamente los resultados de los nuevos compuestos, sometiéndolo a los mismos ensayos que para el resto de los derivados. Además, la obtención de resultados propios, en el Laboratorio de Farmacoquímica, nos asegura reproducibilidad de los datos, ya que al ser comparables los resultados propios a los ya reportados en bibliografia para las mismas técnicas, se logra confirmar la validez de nuestro trabajo.

Debido al comportamiento farmacológico particular que presenta la fenitoína, ésta constituye un compuesto de referencia en el estudio teórico de las Vpds, y será tenida en cuenta más adelante (sección 7) en relación a consideraciones conformacionales en el momento de la definición de un patrón farmacofórico. Por esta razón, también se la evalúa farmacológicamente en el Laboratorio de Farmacoquímica, y se comparan asimismo los resultados propios con los anteriormente reportados por otros autores.

Al tratarse de antiepilépticos clásicos de amplio uso en clínica, existen, para Vpa y fenitoína, varios datos referentes a su evaluación preclínica mediante el empleo de las técnicas del programa ADD. En el caso de Vpd, también se han podido recopilar algunas referencias bibliográficas en donde figura su evaluación preclínica. Para el resto de los compuestos estudiados, los resultados farmacológicos son novedosos, ya que, como ya se mencionó en la sección 2 del presente capítulo, ninguno de ellos había sido sometido a este tipo de ensayos con anterioridad.

Se han presentado, en mayor o menor medida, problemas de solubilidad en la preparación de las drogas estudiadas. Como ya se describió en la sección 4, todos los derivados son insolubles en solución fisiológica, por lo tanto la forma de solubilizarlos es mediante el empleo de PEG 400 / agua como vehículo. Pero de todas formas no fue posible lograr suspensiones o emulsiones homogéneas cuando la concentración de la droga es relativamente alta. Por tal razón, 
el cálculo de las TD50s no pudo completarse en esos casos, consignándose en su reemplazo los porcentajes de neurotoxicidad encontrados a las dosis más altas ensayadas.

Comparando las dosis que muestran acción de los distintos compuestos, con las ED50 o TD50 de Vpa, sólo se continúa investigando aquellas estructuras que representen ventajas en comparación con éste, tanto en cuanto a actividad como a efectos neurotóxicos. Para éstos, las dosis sucesivas serán más o menos concentradas que la anterior en base al resultado obtenido para la última, aunque en algunos casos la elección depende de cuestiones prácticas, como la disponibilidad de droga, el límite de solubilidad que se puede alcanzar, etc. Para el cálculo de las ED50s, se continúa este proceso hasta completar la evaluación de 4 dosis distintas como mínimo.

Como se ha detallado en la sección 4 , la determinación de los TPEs* surge del ensayo mediante el ensayo MES y/o el ensayo PTZ para el caso de TPE anticonvulsivo" y mediante el empleo del ensayo RotoRod para la determinación del TPE neurotóxico, aunque generalmente los picos máximos de ambas acciones se alcanzan simultáneamente.

Con respecto al ensayo PTZ, en el Laboratorio de Farmacoquímica se puso a punto primeramente la técnica de administración i.p. del PTZ, y posteriormente la administración por vía s.c. . Por tal razón, las drogas Vpa y $\mathrm{CpVpd}$, que fueron las primeras en ensayarse farmacológicamente, se evaluaron inicialmente utilizando la vía i.p. y luego se confirmaron los resultados empleando también la vía s.c. para administrar el PTZ.

\section{Acido valproico (Vpa)}

El Vpa presenta su mayor actividad anticonvulsiva en ratones 15 minutos después de la inyección intraperitoneal ${ }^{1,2,3,4}$.

La determinación de los TPEs

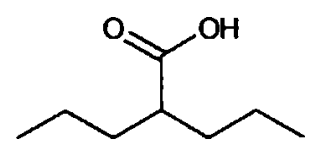

y la evaluación anticonvulsiva y neurotóxica se realizó en el Laboratorio de Farmacoquímica con fines comparativos. La determinación de la mayor acción arrojó un TPE de 15 minutos, empleando el ensayo PTZ, en concordancia con los datos publicados.

\footnotetext{
* TPE (time of peak effect)= tiempo de efecto máximo, ya explicado en la sección 5 del presente capitulo.

- para la determinación del TPE anticonvulsivo, puede utilizarse cualquiera de los dos ensayos, 0 ambos.
} 


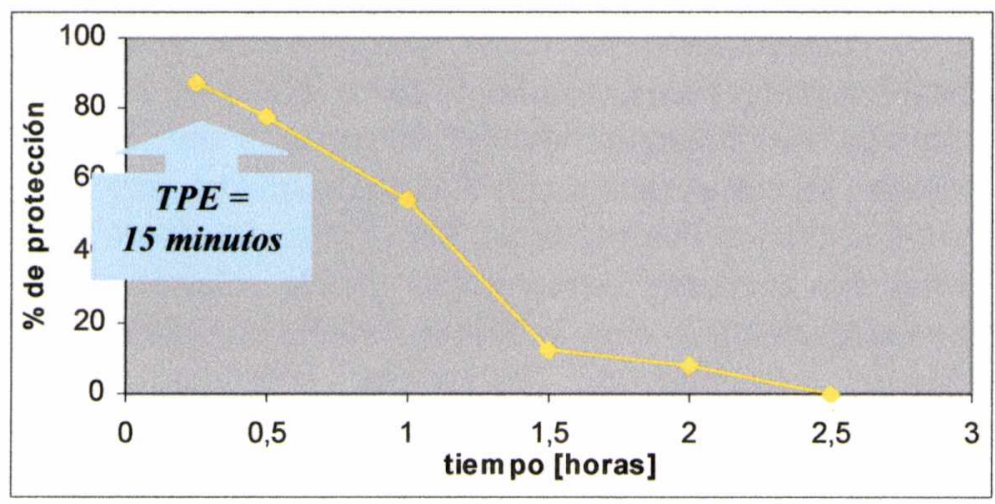

Figura

4.6.1

Estimación del TPE

para Vpa

La curva de protección en función del tiempo (Figura 4.6.1) muestra que la actividad, que parte de un máximo a los 15 minutos, va decayendo hasta llegar a un $0 \%$ de protección luego de 2 y $1 / 2$ horas.

La cuantificación de la potencia anticonvulsiva frente al ensayo MES se evaluó midiendo el porcentaje de protección obtenido a cada una de seis dosis distintas (Tabla 4.6.1).

\begin{tabular}{|c|c|c|c|c|}
\hline MES & $\begin{array}{c}\text { dosis } \\
{[\mu \mathrm{mol} / \mathrm{kg}]}\end{array}$ & $\begin{array}{l}\text { tiempo } \\
\text { [horas] }\end{array}$ & $\begin{array}{c}\% \text { de } \\
\text { protección }\end{array}$ & $\begin{array}{c}\mathrm{N}^{*} \text { protegidos } \\
\mathrm{N}_{\text {total }}\end{array}$ \\
\hline & 200 & 0.25 & 22,2 & $2 / 9$ \\
\hline & 375 & 0.25 & 40 & $2 / 5$ \\
\hline & 400 & 0.25 & 50 & $3 / 6$ \\
\hline & 550 & 0.25 & 54,5 & $6 / 11$ \\
\hline & 620 & 0.25 & 85,7 & $6 / 7$ \\
\hline & 850 & 0.25 & 100 & $10 / 10$ \\
\hline
\end{tabular}

Tabla 4.6.1 Actividad anticorvulsiva del Vpa en el ensayo MES

Del análisis estadístico surge una ED50 $=1008 \mu \mathrm{mol} / \mathrm{kg}(792-$ 1282) y $S=1.7$ (1.3-2.2).

En etapas posteriores se realizaron otras determinaciones, generalmente como control en la evaluación de otras drogas. Puede apreciarse en la figura 4.6.2 que existe concordancia entre ambos conjuntos de datos.

\footnotetext{
- las dosis están expresadas como $\mu \mathrm{mol} / \mathrm{kg}$ de divalproato sódico, que es la especie usada en los experimentos. Un mol de divalproato sódico equivale a dos moles de ácido valproico ( $\mathrm{Vpa}$ ).

- $\mathrm{N}=$ número de animales.
} 
Figura 4.6.2

Actividad del

Vpa frente al

ensayo MES.

En rojo: puntos utilizados para el cálculo de la ED50.

En verde:

controles

posteriores

Tabla 4.6.2 Actividad anticonvulsiva del

Vpa en el ensayo PTZ

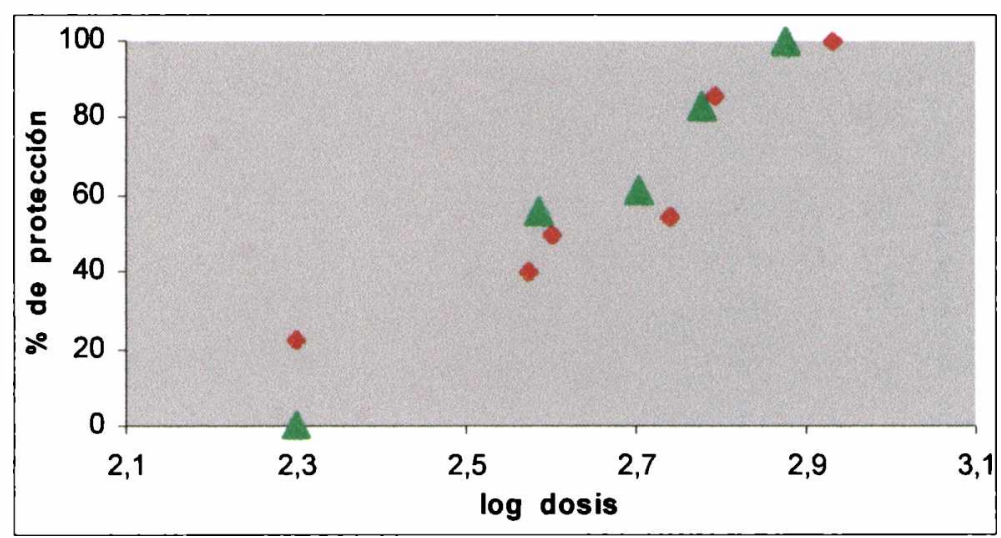

La actividad manifestada por el Vpa frente al ensayo PTZ se cuantifica en base a los datos obtenidos de la evaluación a 6 dosis distintas (Tabla 4.6.2).

\begin{tabular}{|c|c|c|c|c|}
\hline$P T Z$ & $\begin{array}{c}\text { dosis } \\
{[\mu \mathrm{mol} / \mathrm{kg}]}\end{array}$ & $\begin{array}{l}\text { tiempo } \\
\text { [horas] }\end{array}$ & $\begin{array}{c}\% \text { de } \\
\text { protección }\end{array}$ & $\begin{array}{c}N_{\text {protegidos }} / \\
N_{\text {total }}\end{array}$ \\
\hline & 250 & 0.25 & 0 & $0 / 8$ \\
\hline & 500 & 0.25 & 12.5 & $1 / 8$ \\
\hline & 590 & 0.25 & 12.5 & $1 / 8$ \\
\hline & 625 & 0.25 & 50 & $4 / 8$ \\
\hline & 670 & 0.25 & 75 & $6 / 8$ \\
\hline & 750 & 0.25 & 87.5 & $7 / 8$ \\
\hline
\end{tabular}

Se obtiene una ED50 $=1261 \mu \mathrm{mol} / \mathrm{kg}(1155-1377)$ con $\mathrm{S}=1.2(1.0-1.3)$.

En el caso del ensayo PTZ también se realizaron evaluaciones posteriores, pero utilizando en estos casos la vía s.c. en lugar de la i.p. para la administración del PTZ, por las razones explicadas al comienzo de esta sección. En la figura 4.6.3 se observan todos los datos en conjunto. Puede apreciarse que la vía de administración del PTZ no influye en la capacidad de protección de la droga.

El máximo efecto neurotóxico $\left(\mathrm{TPE}_{\mathrm{N}}{ }^{*}\right)$ manifestado en el ensayo RotoRod es, al igual que la máxima actividad anticonvulsiva, de 15 minutos ${ }^{1,2,3,4}$, como surge también de nuestras evaluaciones (Figura 4.6.4).

- expresadas como $\mu \mathrm{mol} / \mathrm{kg}$ de divalproato sódico.

- $\mathrm{TPE}_{\mathrm{N}}=$ tiempo de efecto neurotóxico máximo. 


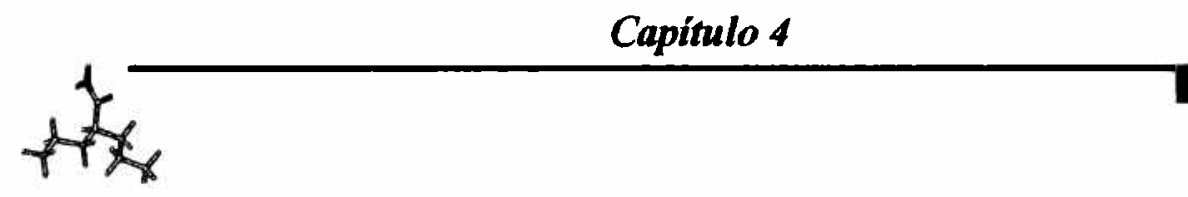

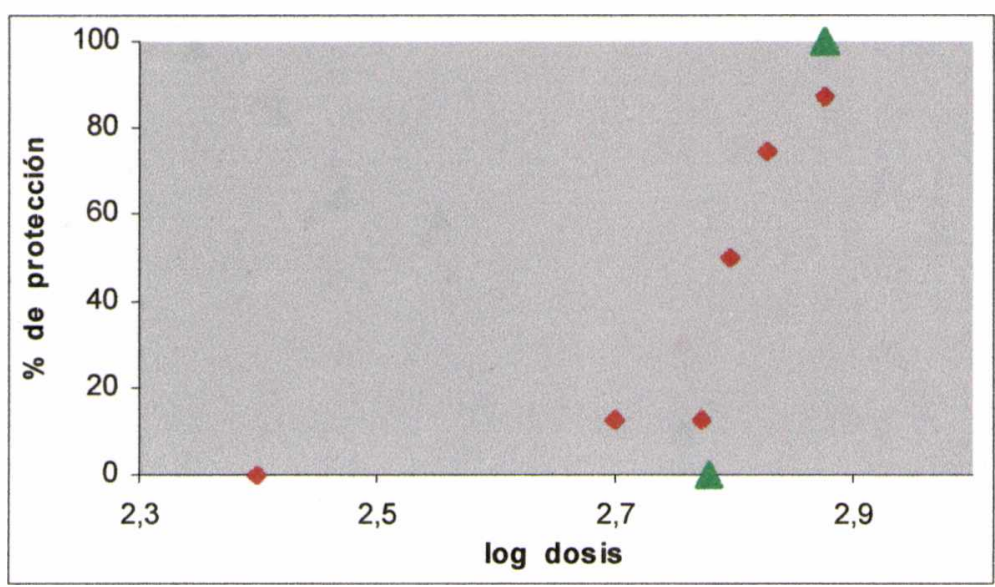

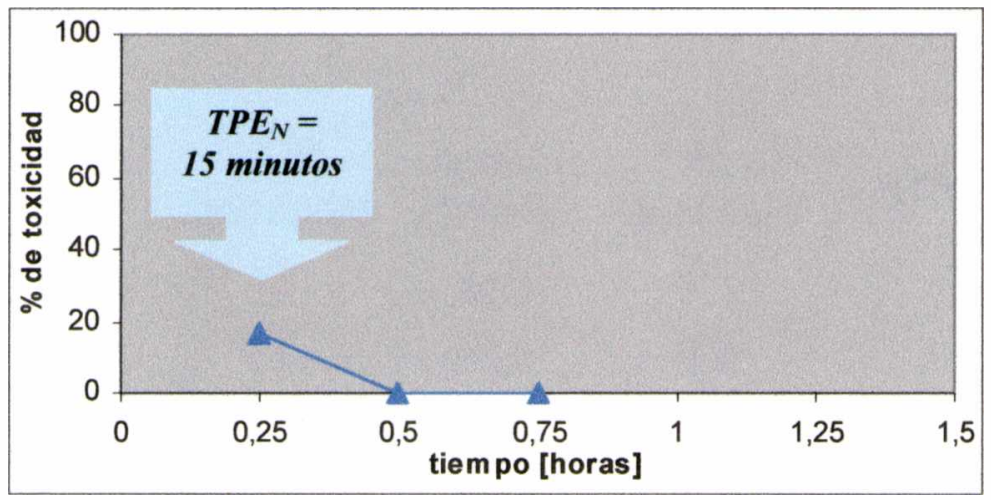

El Vpa mostró leves efectos neurotóxicos recién a 1700 $\mu \mathrm{mol} / \mathrm{kg}$ (Tabla 4.6.3).

\begin{tabular}{|c|c|c|c|c|}
\hline Rowallod & $\begin{array}{c}\text { dosis }^{\star} \\
{[\mu \mathrm{mol} / \mathrm{kg}]}\end{array}$ & $\begin{array}{l}\text { tiempo } \\
\text { [horas] }\end{array}$ & $\begin{array}{c}\% \text { de } \\
\text { toxicidad }\end{array}$ & $\begin{array}{c}\mathrm{N}_{\text {afectados }} \\
\mathrm{N}_{\text {total }}\end{array}$ \\
\hline & 200 & 0.25 & 0 & $0 / 10$ \\
\hline & 386 & 0.25 & 6.7 & $1 / 15$ \\
\hline & 504 & 0.25 & 0 & $0 / 17$ \\
\hline & 750 & 0.25 & 0 & $0 / 3$ \\
\hline & 850 & 0.25 & 16.7 & $1 / 6$ \\
\hline
\end{tabular}

- expresadas como $\mu \mathrm{mol} / \mathrm{kg}$ de divalproato sódico.

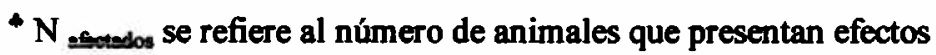
neurotóxicos en el RotoRod test, es decir que se caen las 3 veces que se los coloca sobre el cilindro rotante.
Figura 4.6.3

Actividad del Vpa frente al ensayo

$P T Z$.

En rojo: ensayos utilizados para el cálculo de la ED50, empleando via i.p.

En verde: controles posteriores, por via s.c.

\section{Figure 4.6.4}

Estimación del

TPE neurotóxico para el Vpa
Tabla 4.6.3 Neurotoxicidad del Vpa manifestada en el ensayo RotoRod 
La evaluación farmacológica del Vpa realizada en el Laboratorio de Farmacoquímica permitió comparar los resultados propios con los ya reportados en bibliografía para estudios similares, lo cual brinda validez a nuestro trabajo, ya que los datos obtenidos se encuentran dentro de valores aceptables. Teniendo en cuenta la naturaleza variable de los ensayos biológicos, sobre todo aquéllos en los que intervienen animales vivos, no es llamativo que los valores de ED50s y TD50s reportados por distintos grupos sean relativamente dispares, a pesar de emplear la misma metodología experimental (Tabla 4.6.4).

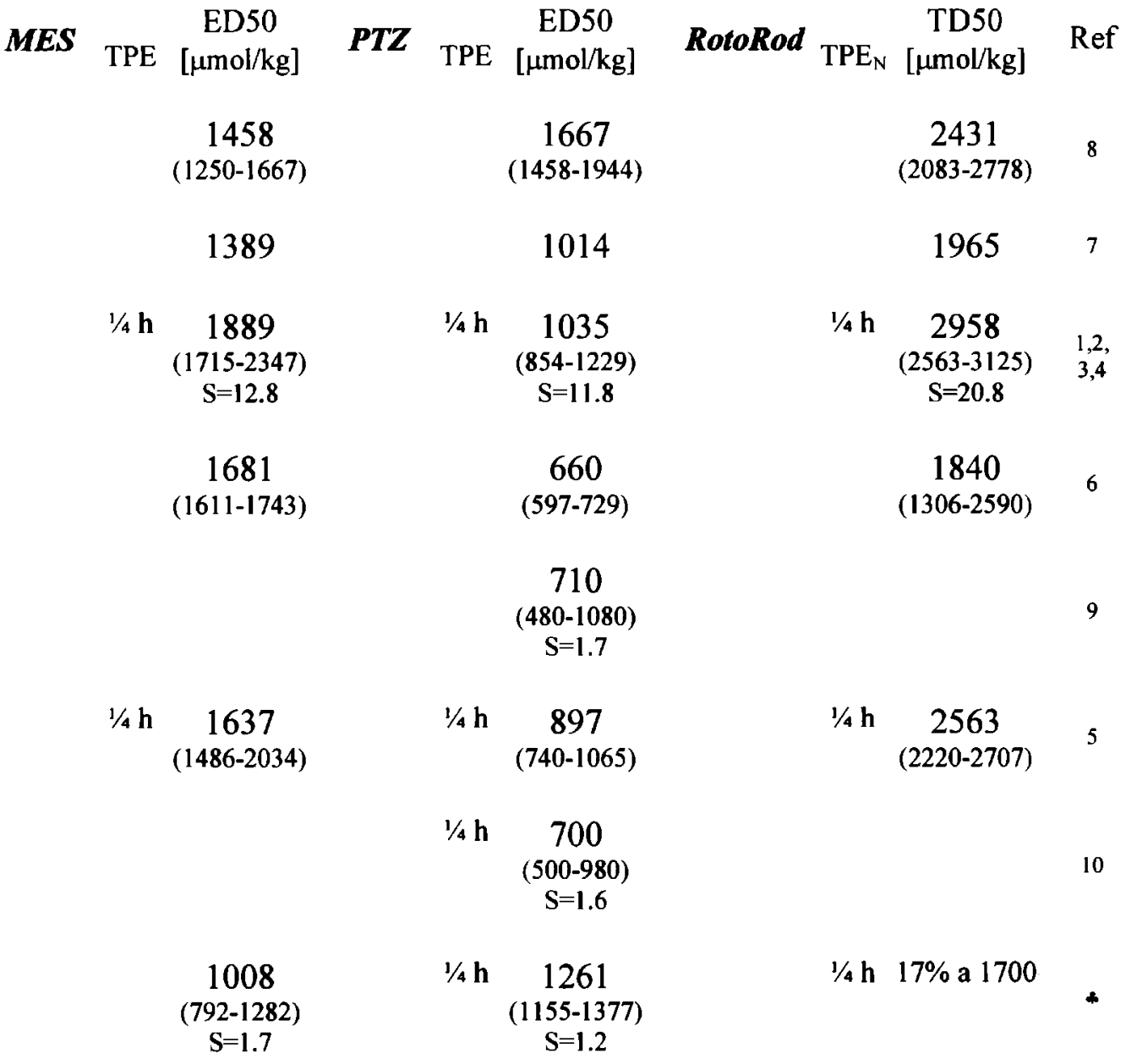

Tabla 4.6.4 Datos experimentales de actividad anticonvulsiva y neurotoxidad de Vpa, obtenidos por otros autores

+ resultados propios. 


\section{Fenitoina (PHE)}

La fenitoína es un potente anticonvulsivo frente a las convulsiones provocadas por el electroshock máximo, pero es inactiva frente al ensayo PTZ $Z^{1,2,3,4}$.

La actividad anticonvulsiva de

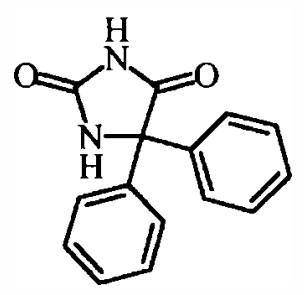

la fenitoína se evaluó mediante el ensayo MES, considerando tiempos de efecto máximo anticonvulsivo y neurotóxico de $\mathbf{2}$ horas $^{1,2,3,4}$.

Los resultados de su actividad anticonvulsiva, luego del ensayo a cinco concentraciones distintas, se presentan en la tabla 4.6.5.

\begin{tabular}{|c|c|c|c|c|c|}
\hline \multirow[t]{6}{*}{ MES } & $\begin{array}{c}\text { dosis } \\
{[\mu \mathrm{mol} / \mathrm{kg}]}\end{array}$ & $\begin{array}{l}\text { tiempo } \\
\text { [horas] }\end{array}$ & $\begin{array}{c}\% \text { de } \\
\text { protección }\end{array}$ & $\begin{array}{c}\mathrm{N}_{\text {protegidos }} / \\
\mathrm{N}_{\text {total }}\end{array}$ & \multirow{6}{*}{$\begin{array}{l}\text { Tabla } 4.6 .5 \\
\text { Actividad } \\
\text { anticonvul- } \\
\text { siva de } \\
\text { PHE en el } \\
\text { ensayo } \\
\text { MES }\end{array}$} \\
\hline & 10 & 2 & 20 & $1 / 5$ & \\
\hline & 20 & 2 & 66.7 & $4 / 6$ & \\
\hline & 30 & 2 & 66.7 & $6 / 9$ & \\
\hline & 38 & 2 & 77.8 & $7 / 9$ & \\
\hline & 50 & 2 & 100 & $8 / 8$ & \\
\hline
\end{tabular}

El análisis de estos datos, graficados en la figura 4.6.5, permite la obtención de la ED50 $=22 \mu \mathrm{mol} / \mathrm{kg}(16-32)$ y de la $\mathrm{S}=2.2(1.3-3.9)$.

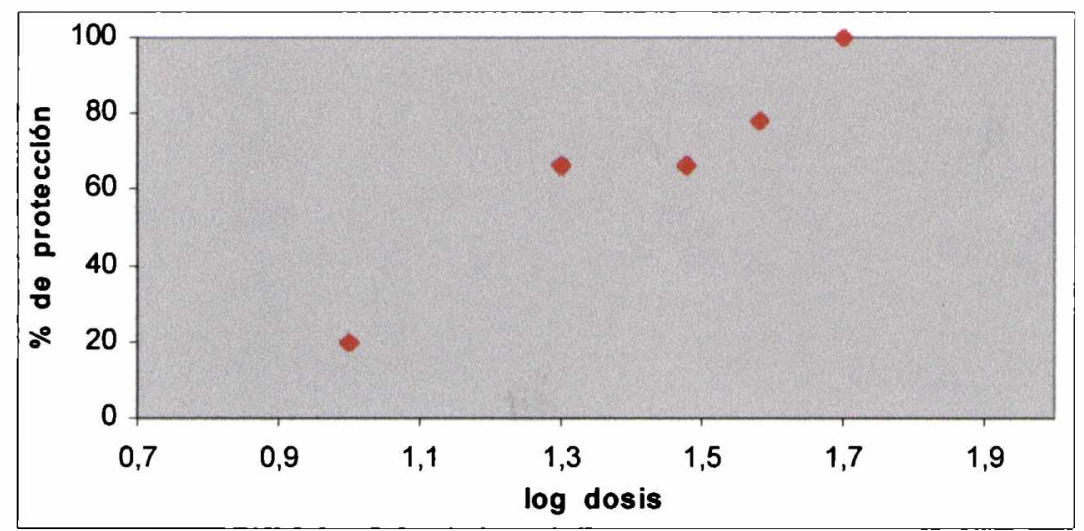

Figura 4.6.5

Actividad de

PHE frente al ensayo MES

La incapacidad de PHE de proteger las convulsiones causadas por el PTZ se verificó mediante un ensayo a 30 $\mu \mathrm{mol} / \mathrm{kg}$ (Tabla 4.6.6). 
Tabla 4.6.6

Actividad

anticonvulsi-

va de PHE en

el ensayo

$P T Z$

$\begin{array}{ccccc}\boldsymbol{P T Z} & \begin{array}{c}\text { dosis } \\ {[\mu \mathrm{mol} / \mathrm{kg}]}\end{array} & \begin{array}{c}\text { tiempo } \\ {[\text { horas] }}\end{array} & \begin{array}{c}\% \text { de } \\ \text { protección }\end{array} & \begin{array}{c}\mathrm{N}_{\text {protegidos }} / \\ \mathrm{N}_{\text {total }}\end{array} \\ 30 & 2 & 0 & 0 / 4\end{array}$

La evaluación de los efectos neurotóxicos manifestados en el ensayo RotoRod muestra que PHE no es tóxica a concentraciones anticonvulsivas (hasta $50 \mu \mathrm{mol} / \mathrm{kg}$ ) (Tabla 4.6.7).

$\begin{array}{ccccc}\text { RotoRod } & \begin{array}{c}\text { dosis } \\ {[\mu \mathrm{mol} / \mathrm{kg}]}\end{array} & \begin{array}{c}\text { tiempo } \\ {[\text { horas] }}\end{array} & \begin{array}{c}\% \text { de } \\ \text { toxicidad }\end{array} & \begin{array}{c}\mathrm{N}_{\text {afectados }} / \\ \mathrm{N}_{\text {total }}\end{array} \\ 10 & 2 & 0 & 0 / 5 \\ 38 & 2 & 0 & 0 / 9 \\ 50 & 2 & 0 & 0 / 3\end{array}$

Como puede apreciarse en la tabla 4.6.8, los resultados propios son coincidentes con los de otros autores, lo que nuevamente valida la técnica de evaluación en el Laboratorio de Farmacoquímica.
Tabla 4.6.7 Neurotoxicidad de PHE manifestada en el ensayo RotoRod

\begin{tabular}{|c|c|c|c|c|c|c|c|c|c|}
\hline MES & TPE & $\begin{array}{c}\text { ED50 } \\
{[\mu \mathrm{mol} / \mathrm{kg}]}\end{array}$ & $P T Z$ & TPE & $\begin{array}{c}\text { ED50 } \\
{[\mu \mathrm{mol} / \mathrm{kg}]}\end{array}$ & RotoRod & $\mathrm{TPE}_{\mathrm{N}}$ & $\begin{array}{c}\text { TD50 } \\
{[\mu \mathrm{mol} / \mathrm{kg}]}\end{array}$ & Ref \\
\hline & $2 \mathrm{~h}$ & $\begin{array}{c}37.7 \\
(32.1-41.3) \\
S=13.7\end{array}$ & & & $\mathrm{NE}^{\star}$ & & $2 \mathrm{~h}$ & $\begin{array}{c}260 \\
(208-286) \\
\mathrm{S}=15.2\end{array}$ & $\begin{array}{l}1,2 \\
3,4\end{array}$ \\
\hline & & 23.9 & & & & & & & 11 \\
\hline & $1 \mathrm{~h}$ & $\begin{array}{c}25.8 \\
(22.6-28.6)\end{array}$ & & $1 \mathrm{~h}$ & $>198$ & & $1 / 2 h$ & $\begin{array}{c}170 \\
(144-188)\end{array}$ & 12 \\
\hline & & $\begin{array}{c}22 \\
(16-32) \\
S=2.2\end{array}$ & & & $>30$ & & & $0 \%$ a 50 & 4 \\
\hline
\end{tabular}

\section{Tabla 4.6.8}

Datos experimentales de actividad anticonvulsiva y neurotoxidad de PHE, obtenidos por otros autores

\footnotetext{
- NE = no efectivo

- resultados propios.
} 


\section{$\underline{\text { Valoramida }\left(V_{D d}\right)}$}

La determinación del tiempo de efecto máximo indicó que se llega a la mayor potencia anticonvulsiva, tanto frente a las convulsiones provocadas por el electroshock máximo como a las debidas al PTZ, luego de 1 hora de haber inyectado i.p. la droga, como puede observarse en la figura 4.6.6.

\section{$T P E=1$ hora}

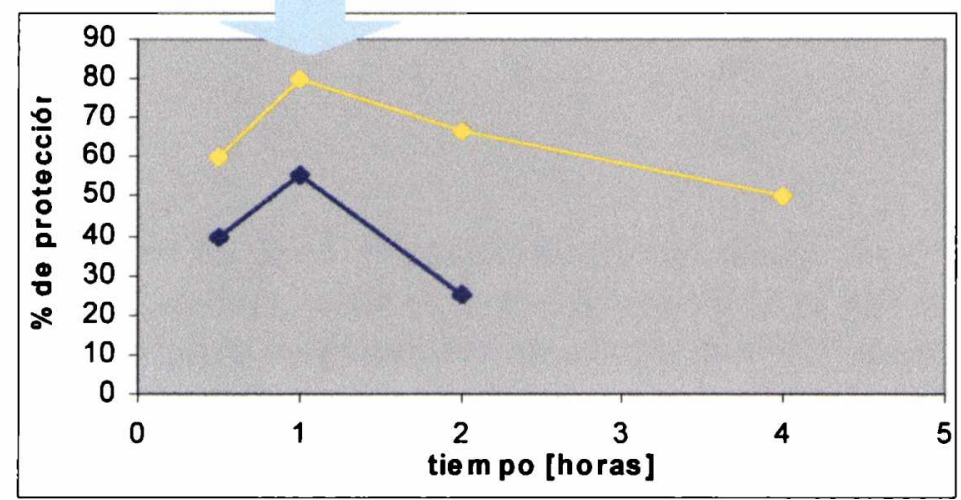

\section{Figura 4.6.6}

Estimación del TPE para Vpd, mediante el ensayo MES (azul) $y$ el ensayo PTZ (amarillo)

La evaluación de la acción frente al ensayo MES a cuatro dosis distintas, entre el 0 y el $100 \%$ de protección, permitió cuantificar la actividad (Figura 4.6.7 y tabla 4.6.9).

\begin{tabular}{|c|c|c|c|c|c|}
\hline \multirow[t]{4}{*}{ MES } & $\begin{array}{c}\text { dosis } \\
{[\mu \mathrm{mol} / \mathrm{kg}]}\end{array}$ & $\begin{array}{l}\text { tiempo } \\
\text { [horas] }\end{array}$ & $\begin{array}{c}\% \text { de } \\
\text { protección }\end{array}$ & $\begin{array}{c}\mathrm{N}_{\text {protegidos }} / \\
\mathrm{N}_{\text {total }}\end{array}$ & \multirow{5}{*}{$\begin{array}{l}\text { Tabla } 4.6 .9 \\
\text { Actividad } \\
\text { anticonvulsi- } \\
\text { va de Vpd en } \\
\text { el ensayo } \\
\text { MES }\end{array}$} \\
\hline & 200 & 1 & 37.5 & $3 / 8$ & \\
\hline & 300 & 1 & 50 & $4 / 8$ & \\
\hline & 400 & 1 & 55.6 & $5 / 9$ & \\
\hline & 500 & 1 & 57.1 & $4 / 7$ & \\
\hline
\end{tabular}




\section{Figura 4.6.7} Actividad de Vpd frente al ensayo MES

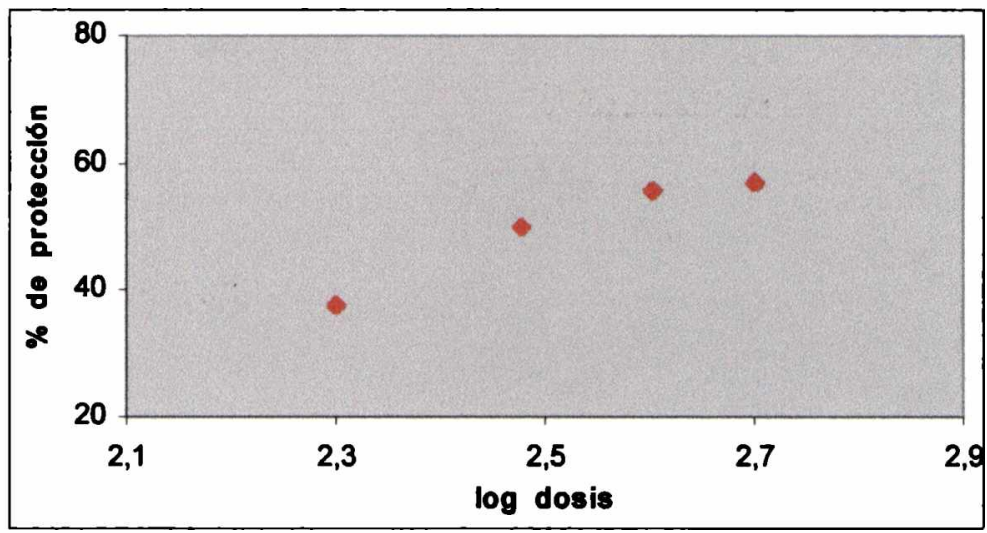

De esta evaluación resulta una ED50 $=353 \mu \mathrm{mol} / \mathrm{kg}$ (267-466), y una $S=1.8$ (1.1-2.9).

La evaluación con el ensayo PTZ, también ensayando cuatro dosis entre el 0 y el $100 \%$ (Figura 4.6.8), brindó los resultados mostrados en tabla 4.6.10.

Tabla 4.6.10
Actividad
anticonvulsi-
va de Vpd en
el ensayo
PTZ

PIX

\begin{tabular}{|c|c|c|c|}
\hline $\begin{array}{c}\text { dosis } \\
{[\mu \mathrm{mol} / \mathrm{kg}]}\end{array}$ & $\begin{array}{l}\text { tiempo } \\
\text { [horas] }\end{array}$ & $\begin{array}{c}\% \text { de } \\
\text { protección }\end{array}$ & $\begin{array}{c}\mathbf{N}_{\text {protegidos }} / \\
\mathbf{N}_{\text {total }}\end{array}$ \\
\hline 400 & 1 & 28.6 & $2 / 7$ \\
\hline 500 & 1 & 30.8 & $4 / 13$ \\
\hline 550 & 1 & 53.8 & $7 / 13$ \\
\hline 600 & 1 & 80 & $4 / 5$ \\
\hline
\end{tabular}

Figura 4.6.8

Actividad de Vpd frente al ensayo PTZ

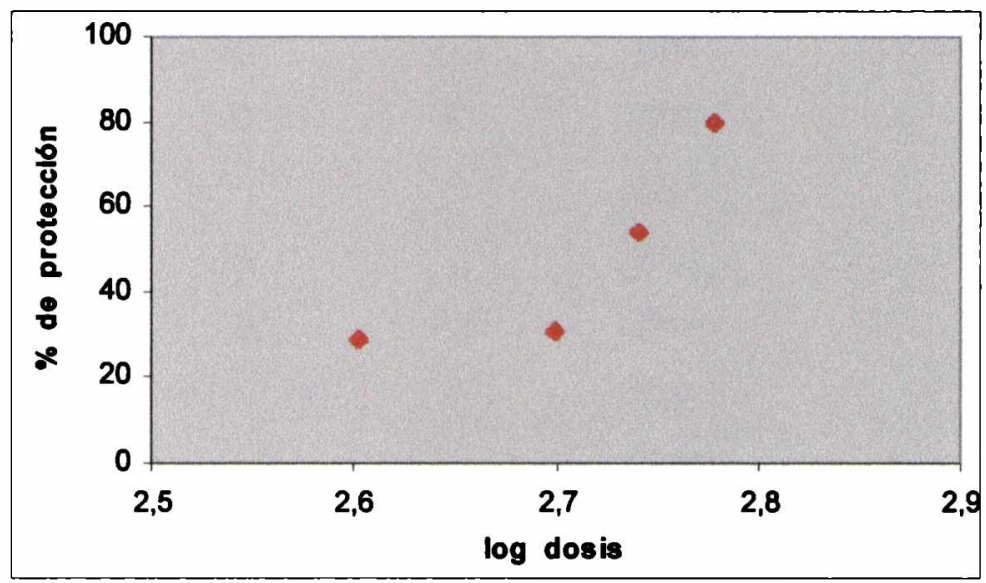

El análisis estadístico permitió calcular una ED50 = $490 \mu \mathrm{mol} / \mathrm{kg}(447-537)$ y una $S=1.2(1.1-1.4)$. 
Los efectos tóxicos de la Vpd comienzan a evidenciarse 2 horas después de la inyección i.p. (Figura 4.6.9).

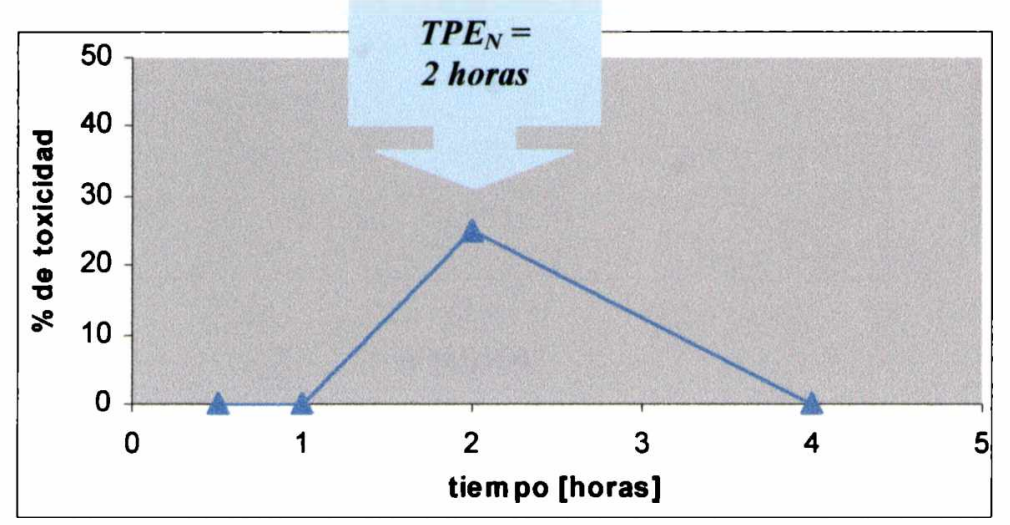

Figura 4.6.9

Estimación del

TPE neurotóxico

para $V p d$

Sin embargo, como se muestra en la tabla 4.6.11, la Vpd presenta leves efectos neurotóxicos recién a $600 \mu \mathrm{mol} / \mathrm{kg}$.

\begin{tabular}{|c|c|c|c|c|c|}
\hline \multirow[t]{15}{*}{ RotoRod } & $\begin{array}{c}\text { Dosis } \\
{[\mu \mathrm{mol} / \mathrm{kg}]}\end{array}$ & $\begin{array}{l}\text { tiempo } \\
\text { [horas] }\end{array}$ & $\begin{array}{c}\% \text { de } \\
\text { toxicidad }\end{array}$ & $\begin{array}{c}\mathrm{N}_{\text {afectados }} / \\
\mathrm{N}_{\text {total }}\end{array}$ & \multirow{15}{*}{$\begin{array}{l}\text { Tabla } \\
\text { 4.6.11 } \\
\text { Neurotoxi } \\
\text { cidad de } \\
\text { Vpd } \\
\text { manifesta- } \\
\text { da en el } \\
\text { ensayo } \\
\text { RotoRod }\end{array}$} \\
\hline & 100 & 1 & 0 & $0 / 8$ & \\
\hline & 200 & 1 & 0 & $0 / 8$ & \\
\hline & 300 & 1 & 0 & $0 / 8$ & \\
\hline & 400 & 0.5 & 0 & $0 / 4$ & \\
\hline & 400 & 1 & 0 & $0 / 15$ & \\
\hline & 400 & 2 & 0 & $0 / 3$ & \\
\hline & 500 & 0.5 & 0 & $0 / 4$ & \\
\hline & 500 & 1 & 0 & $0 / 17$ & \\
\hline & 500 & 2 & 0 & $0 / 4$ & \\
\hline & 550 & 1 & 0 & $0 / 13$ & \\
\hline & 600 & 0.5 & 0 & $0 / 4$ & \\
\hline & 600 & 1 & 0 & $0 / 12$ & \\
\hline & 600 & 2 & 25 & $1 / 4$ & \\
\hline & 600 & 4 & 0 & $0 / 4$ & \\
\hline
\end{tabular}

Los valores obtenidos en el Laboratorio de Farmacoquímica para la evaluación de la Vpd, al igual que en el caso del Vpa, son comparables a los encontrados por otros grupos de investigación empleando las mismas técnicas, como puede observarse en la tabla 4.6.12. 


\begin{tabular}{|c|c|c|c|c|c|c|c|c|c|}
\hline \multirow[t]{5}{*}{ MES } & TPE & $\begin{array}{c}\text { ED50 } \\
{[\mu \mathrm{mol} / \mathrm{kg}]}\end{array}$ & $P T Z$ & TPE & $\begin{array}{c}\text { ED50 } \\
{[\mu \mathrm{mol} / \mathrm{kg}]}\end{array}$ & RotoRod & $\mathrm{TPE}_{\mathrm{N}}$ & $\begin{array}{c}\text { TD50 } \\
{[\mu \mathrm{mol} / \mathrm{kg}]}\end{array}$ & Ref \\
\hline & & $\begin{array}{c}699 \\
(559-909)\end{array}$ & & & $\begin{array}{c}839 \\
(769-909)\end{array}$ & & & $\begin{array}{c}909 \\
(839-1049)\end{array}$ & 8 \\
\hline & & 392 & & & 385 & & & 566 & 7 \\
\hline & & & & & 340 & & & & 13 \\
\hline & $1 \mathrm{~h}$ & $\begin{array}{c}353 \\
(267-466) \\
S=1.8\end{array}$ & & $1 \mathrm{~h}$ & $\begin{array}{c}490 \\
(447-537) \\
S=1.2\end{array}$ & & $2 \mathrm{~h}$ & $25 \%$ a 600 & 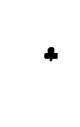 \\
\hline
\end{tabular}

\section{Tabla 4.6.12}

Datos experimentales de actividad anticonvulsiva y neurotoxidad de Vpd, obtenidos por otros autores

\section{$\underline{N \text {-isopropilvalpramida (lpVpd) }}$}

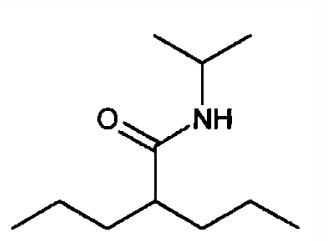

El TPE frente al ensayo MES resultó ser de 1 hora (Figura 4.6.10), aunque no hubo una diferencia significativa de protección entre $1 / 2,1$ y 4 horas. Por tal razón, se repitió el ensayo a la hora con el fin de confirmar un máximo efecto a ese tiempo. La evaluación final a 1 hora se realizó sobre 9 animales, confirmándose la máxima actividad a este tiempo (78 \% de protección) (Figura 4.6.10).

Estimación del TPE para la Ipvpd, mediante el MES test (en azul) y el PTZ test (en amarillo)

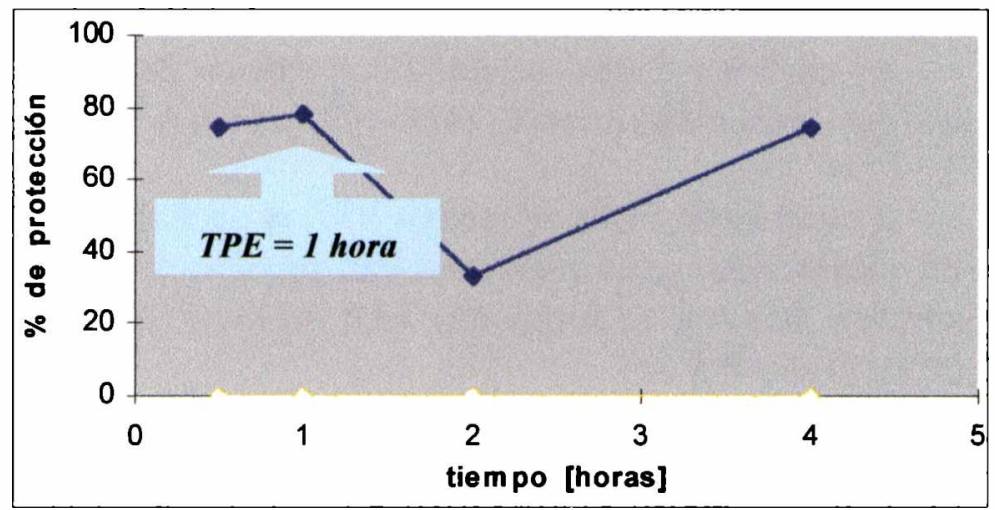

* resultados propios. 
Se descartó que la acción observada a las 4 horas (Figura 4.6.10, en azul) se deba a Vpa liberado, ya que el ensayo en las mismas condiciones pero utilizando PTZ como agente convulsivo, presentó nula protección a todos los tiempos (Figura 4.6.10, en amarillo).

La cuantificación de la acción anticonvulsiva a 1 hora frente al ensayo MES se realizó mediante el ensayo a cuatro concentraciones, entre 0 y $100 \%$ de protección (Figura 4.6.11 y tabla 4.6.13).

\begin{tabular}{|c|c|c|c|c|c|}
\hline \multirow[t]{4}{*}{ MES } & $\begin{array}{c}\text { dosis } \\
{[\mu \mathrm{mol} / \mathrm{kg}]}\end{array}$ & $\begin{array}{l}\text { tiempo } \\
\text { [horas] }\end{array}$ & $\begin{array}{c}\% \text { de } \\
\text { protección }\end{array}$ & $\begin{array}{c}\mathrm{N}_{\text {protegidos }} / \\
\mathrm{N}_{\text {total }}\end{array}$ & \multirow{5}{*}{$\begin{array}{l}\text { Tabla } \\
4.6 .13 \\
\text { Actividad } \\
\text { anticonvul- } \\
\text { siva de } \\
\text { IpVpd en el } \\
\text { ensayo } \\
\text { MES }\end{array}$} \\
\hline & 232 & 1 & 12.5 & $1 / 8$ & \\
\hline & 300 & 1 & 22.2 & $2 / 9$ & \\
\hline & 375 & 1 & 25 & $2 / 8$ & \\
\hline & 450 & 1 & 28.6 & $2 / 7$ & \\
\hline
\end{tabular}

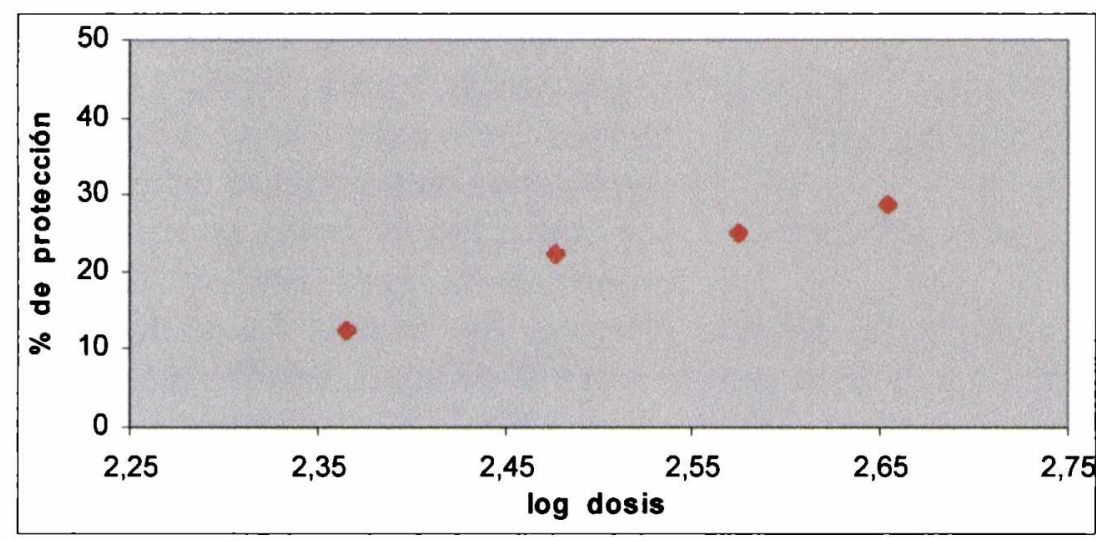

Figura 4.6.11 Actividad de Ipvpd frente al ensayo MES.

El análisis estadístico permitió el cálculo de la ED50, siendo ésta igual a $384 \mu \mathrm{mol} / \mathrm{kg}(300-492)$ y de la $S=1.7(1.0-$ 2.7).

Los ensayos frente al ensayo PTZ se realizaron a dos dosis, observándose que mientras a $250 \mu \mathrm{mol} / \mathrm{kg}$ la IpVpd es totalmente inactiva, se logra una leve acción recién a $\mathbf{4 5 0}$ $\mu \mathrm{mol} / \mathrm{kg}$ (Tabla 4.6.14).

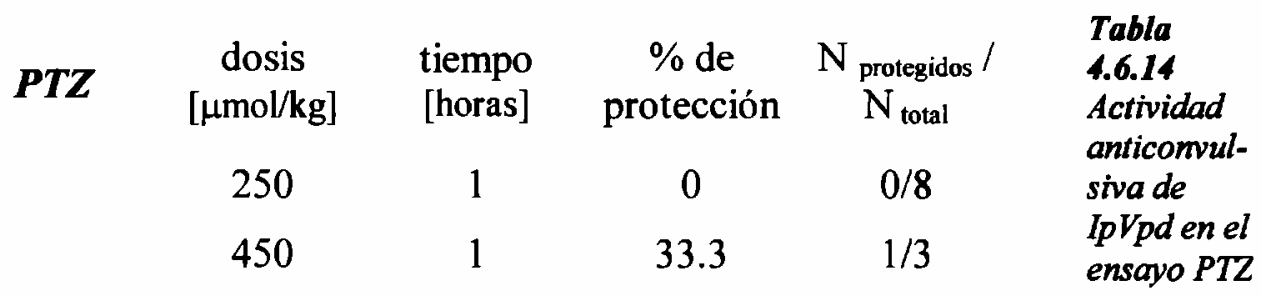


La IpVpd no presentó efectos neurotóxicos a ninguna de las dosis evaluadas (Tabla 4.6.15).

Tabla
4.6.15
Neurotoxi-
cidad de
IpVpd
manifesta-
da en el
ensayo
RotoRod

\begin{tabular}{|c|c|c|c|c|}
\hline RotoRod & $\begin{array}{c}\text { dosis } \\
{[\mu \mathrm{mol} / \mathrm{kg}]}\end{array}$ & $\begin{array}{l}\text { tiempo } \\
\text { [horas] }\end{array}$ & $\begin{array}{c}\% \text { de } \\
\text { toxicidad }\end{array}$ & $\begin{array}{c}\mathrm{N}_{\text {afectados }} \\
\mathrm{N}_{\text {total }}\end{array}$ \\
\hline & 175 & 1 & 0 & $0 / 8$ \\
\hline & 232 & 1 & 0 & $0 / 8$ \\
\hline & 250 & 1 & 0 & $0 / 8$ \\
\hline & 300 & 1 & 0 & $0 / 7$ \\
\hline & 450 & 0.5 & 0 & $0 / 4$ \\
\hline & 450 & 1 & 0 & $0 / 9$ \\
\hline & 450 & 2 & 0 & $0 / 3$ \\
\hline & 450 & 4 & 0 & $0 / 3$ \\
\hline
\end{tabular}

Como se aprecia en la tabla 4.6.15 y en la figura 4.6.12, el intento por determinar un $\mathrm{TPE}_{\mathrm{N}}$ mostró nula actividad a todos los tiempos, empleando la mayor concentración (450 $\mu \mathrm{mol} / \mathrm{kg}$ ) para la cual se logró solubilizar el material para su administración en PEG 400 / agua.

Figura 4.6.12

Estimación del TPE neurotóxico para Ipvpd

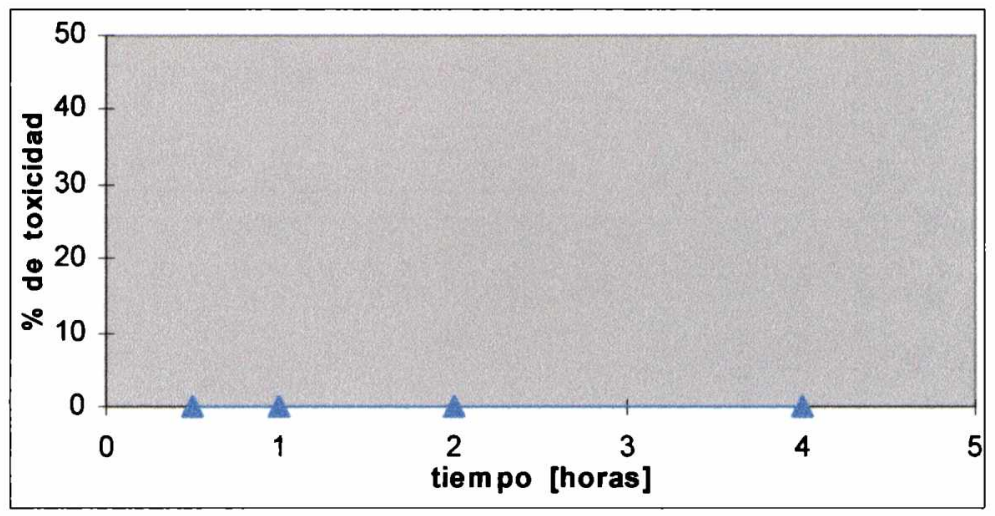

\section{$\underline{\text { N-butilvalpramida (BuVpd) }}$}

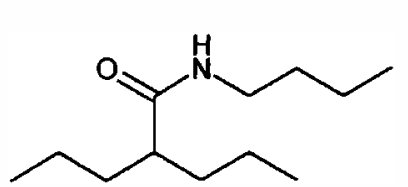

La actividad frente al ensayo MES es máxima 1 hora después de la administración i.p. de la droga, y luego va disminuyendo (Figura 4.6.13, curva en azul). En cambio, la droga no es activa frente al ensayo PTZ (Figura 4.6.13, curva en amarillo). 


\section{Capitulo 4}

124
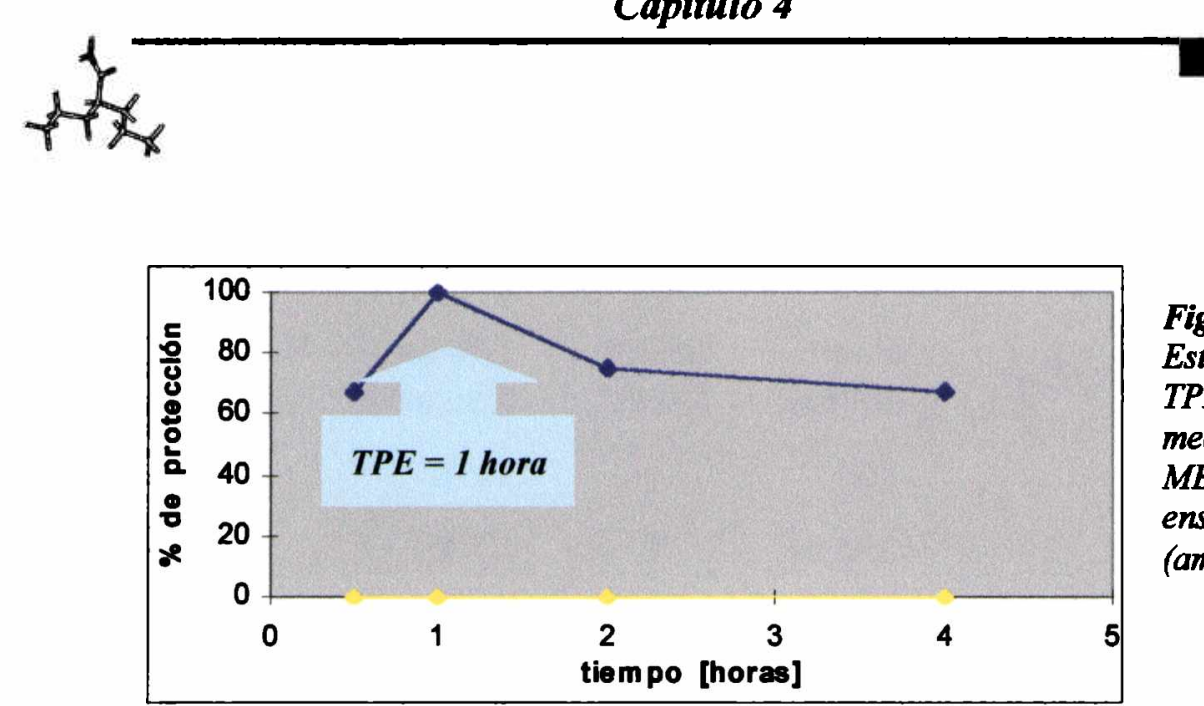

Figura 4.6.13

Estimación del TPE para Buvpd, mediante el ensayo MES (azul) y el ensayo PTZ (amarillo)

La evaluación a 1 hora de cuatro dosis distintas entre el 0 y el $100 \%$ de protección frente al ensayo MES (Figura 4.6.14 y tabla 4.6.16) permitió obtener una $\mathbf{E D 5 0}=487$ $\mu \mathrm{mol} / \mathrm{kg}(412-576)$ y una $\mathrm{S}=1.3(1.1-1.6)$.

\begin{tabular}{|c|c|c|c|c|}
\hline$M E S$ & $\begin{array}{c}\text { dosis } \\
{[\mu \mathrm{mol} / \mathrm{kg}]}\end{array}$ & $\begin{array}{l}\text { tiempo } \\
\text { [horas] }\end{array}$ & $\begin{array}{c}\% \text { de } \\
\text { protección }\end{array}$ & $\mathrm{N}_{\text {protegidos }}$ \\
\hline & 300 & 1 & 12.5 & $1 / 8$ \\
\hline & 400 & 1 & 37.5 & $3 / 8$ \\
\hline & 500 & 1 & 42.9 & $3 / 7$ \\
\hline & 600 & 1 & 57.1 & $4 / 7$ \\
\hline
\end{tabular}

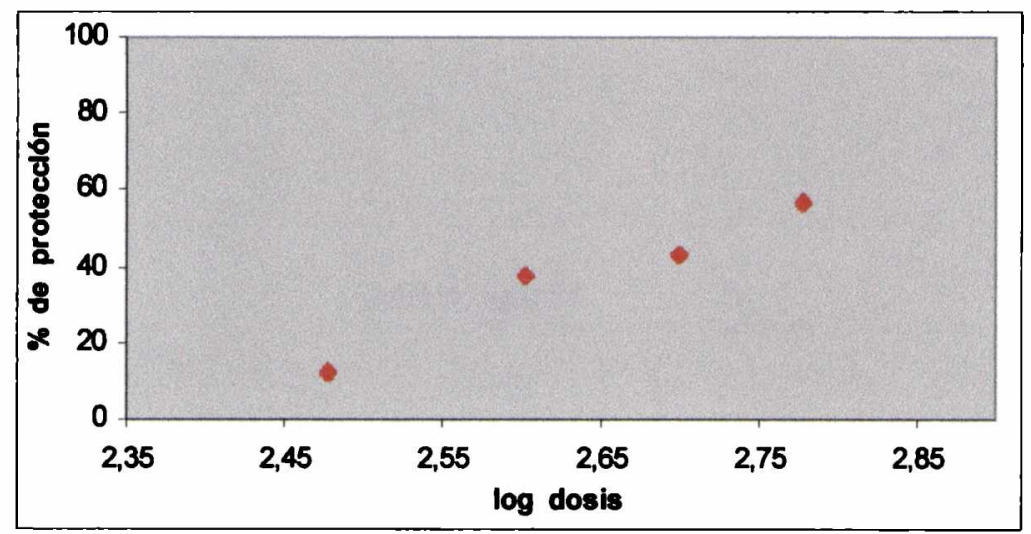

Figura 4.6.14

Actividad de Buvpd frente al ensayo MES

La evaluación frente al PTZ se realizó a la mayor concentración soluble $(600 \mu \mathrm{mol} / \mathrm{kg})$, no percibiéndose acción protectora (Tabla 4.6.17). 


\section{Tabla}

4.6.17 Actividad anticonvulsiva de BuYpd en el ensayo $P T Z$

\begin{tabular}{|c|c|c|c|c|}
\hline$P T Z$ & $\begin{array}{c}\text { dosis } \\
{[\mu \mathrm{mol} / \mathrm{kg}]}\end{array}$ & $\begin{array}{l}\text { tiempo } \\
\text { [horas] }\end{array}$ & $\begin{array}{c}\% \text { de } \\
\text { protección }\end{array}$ & $\begin{array}{c}N_{\text {protegidos }} \\
N_{\text {total }}\end{array}$ \\
\hline & 600 & 1 & 0 & $0 / 4$ \\
\hline
\end{tabular}

La droga presentó efectos neurotóxicos en el ensayo RotoRod a $600 \mu \mathrm{mol} / \mathrm{kg}$, observándose un TPE neurotóxico de 30 minutos (Figura 4.6.15 y tabla 4.6.18).

\begin{tabular}{|c|c|c|c|c|c|}
\hline \multirow{9}{*}{$\begin{array}{l}\text { Tabla } \\
\text { 4.6.18 } \\
\text { Neurotoxi- } \\
\text { cidad de } \\
\text { BuVpd } \\
\text { manifesta- } \\
\text { da en el } \\
\text { ensayo } \\
\text { RotoRod }\end{array}$} & \multirow[t]{9}{*}{ RotoRod } & $\begin{array}{c}\text { dosis } \\
{[\mu \mathrm{mol} / \mathrm{kg}]}\end{array}$ & $\begin{array}{l}\text { tiempo } \\
\text { [horas] }\end{array}$ & $\begin{array}{c}\% \text { de } \\
\text { toxicidad }\end{array}$ & $\begin{array}{c}N_{\text {afectados }} / \\
N_{\text {total }}\end{array}$ \\
\hline & & 200 & 1 & 0 & $0 / 7$ \\
\hline & & 300 & 1 & 0 & $0 / 8$ \\
\hline & & 400 & 1 & 0 & $0 / 8$ \\
\hline & & 500 & 1 & 0 & $0 / 6$ \\
\hline & & 600 & 0.5 & 40 & $2 / 5$ \\
\hline & & 600 & 1 & 10 & $1 / 10$ \\
\hline & & 600 & 2 & 0 & $0 / 3$ \\
\hline & & 600 & 4 & 0 & $0 / 3$ \\
\hline
\end{tabular}

Figura 4.6.15

Estimación del TPE neurotóxico para Buvpd

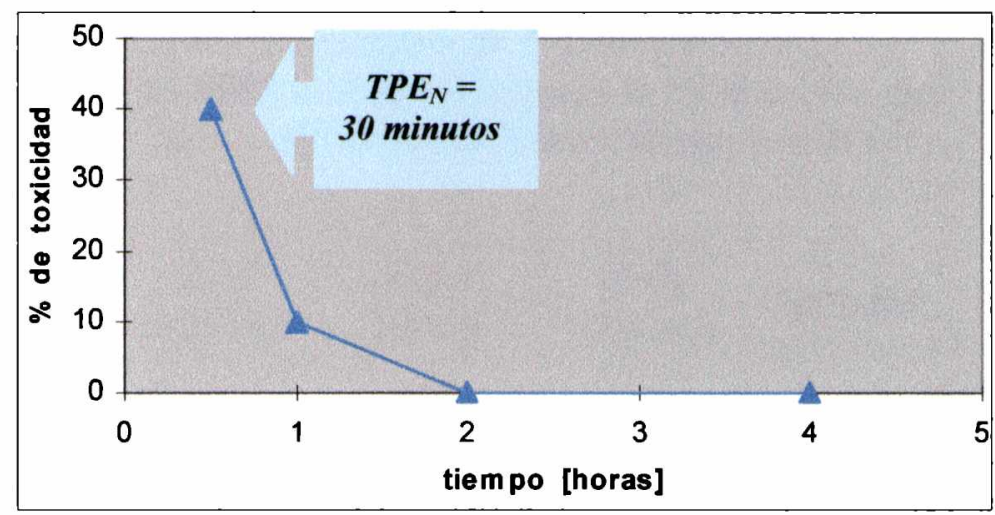<smiles>CCCC(CCC)C(=O)N1CCOCC1</smiles>

\section{$\underline{N \text {-valproilmorfolina (MoVpd) }}$}

A diferencia del resto de las Vpds estudiadas, esta droga no presentó actividad frente a ninguno de los ensayos para anticonvulsivos (Figura 4.6.16). Se evaluó a dosis altas $(\mathbf{1 5 0 0} \mu \mathrm{mol} / \mathrm{kg}$ tanto en 


\section{Capitulo 4}

126

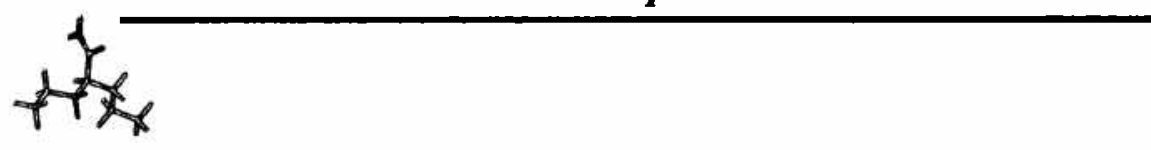

el ensayo MES como en el ensayo PTZ) pero aún así no mostró acción a ninguno de los tiempos ensayados (Figura 4.6.16).

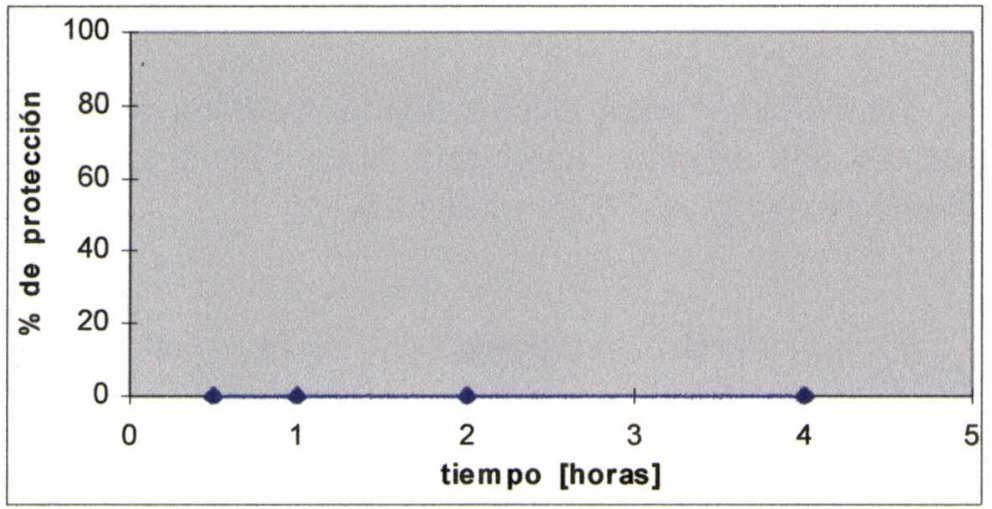

Figura 4.6.16

Evaluación de la acción de Movpd a distintos tiempos, mediante el ensayo MES (arriba) y el ensayo PTZ (abajo)

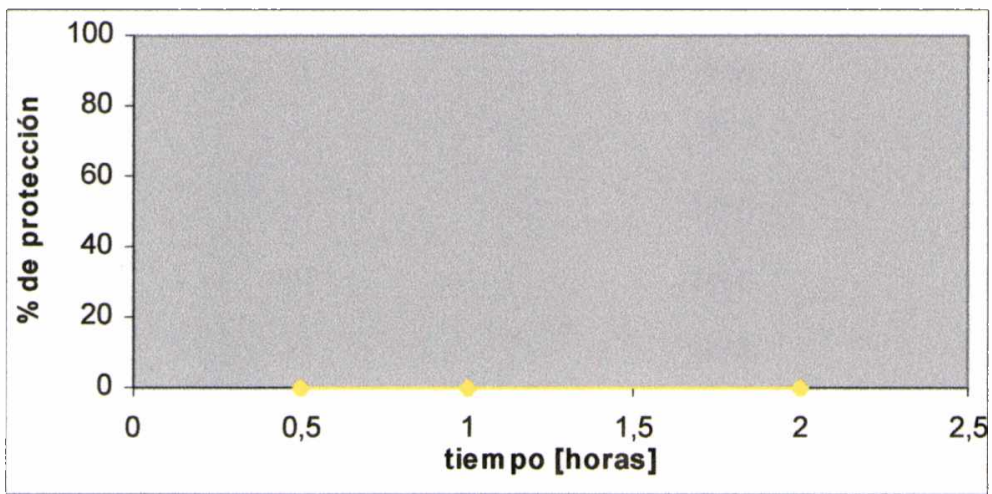

Tampoco presentó importantes efectos neurotóxicos ya que, evaluada en el ensayo RotoRod a $1500 \mu \mathrm{mol} / \mathrm{kg}$, recién comienzan a manifestarse (Tabla 4.6.19).

\begin{tabular}{|c|c|c|c|c|c|}
\hline \multirow[t]{8}{*}{ Roworod } & $\begin{array}{c}\text { dosis } \\
{[\mu \mathrm{mol} / \mathrm{kg}]}\end{array}$ & $\begin{array}{l}\text { tiempo } \\
\text { [horas] }\end{array}$ & $\begin{array}{c}\% \text { de } \\
\text { toxicidad }\end{array}$ & $\begin{array}{c}\mathrm{N}_{\text {affoctados }} ! \\
\mathrm{N}_{\text {total }}\end{array}$ & \multirow{5}{*}{$\begin{array}{l}\text { Tabla } \\
4.6 .19 \\
\text { Neurotoxi- } \\
\text { cidad de } \\
\text { MoVpd } \\
\text { manifesta- } \\
\text { da en el } \\
\text { ensayo } \\
\text { RotoRod }\end{array}$} \\
\hline & 1000 & 0.5 & 0 & $0 / 3$ & \\
\hline & 1000 & 1 & 0 & $0 / 4$ & \\
\hline & 1000 & 2 & 0 & $0 / 4$ & \\
\hline & 1500 & 0.5 & 25 & $1 / 4$ & \\
\hline & 1500 & 1 & 0 & $0 / 4$ & \\
\hline & 1500 & 2 & 25 & $1 / 4$ & \\
\hline & 1500 & 4 & 0 & $0 / 4$ & \\
\hline
\end{tabular}




\section{$\underline{\text { N-ciclohexilvalpramida (ChVpd) }}$}

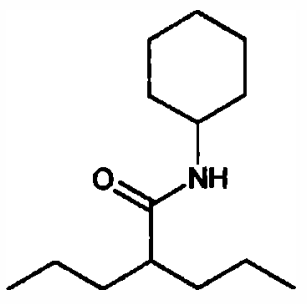

Esta droga mostró un TPE anticonvulsivo frente al ensayo MES más tardío que el del resto de los derivados ( 2 horas), mientras que no reveló actividad frente al ensayo PTZ, a ninguno de los aprecia en la figura 4.6.17. tiempos ensayados, como se

Figura 4.6.17

Estimación del TPE para Chvpd, mediante el ensayo MES

(en azul) y el ensayo PTZ (en amarillo)

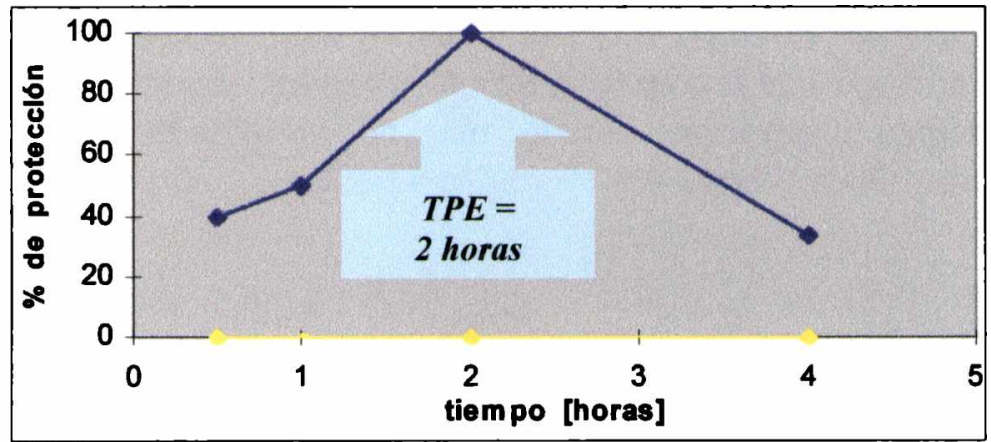

La actividad anticonvulsiva frente al ensayo MES se evaluó mediante el ensayo a cuatro concentraciones distintas (Figura 4.6.18 y tabla 4.6.20).

Tabla
4.6 .20
Actividad
anticonvul-
siva de
ChVpd en
el ensayo
MES

MES

\begin{tabular}{|c|c|c|c|}
\hline $\begin{array}{c}\text { dosis } \\
{[\mu \mathrm{mo} / \mathrm{kg}]}\end{array}$ & $\begin{array}{l}\text { tiempo } \\
\text { [horas] }\end{array}$ & $\begin{array}{c}\% \text { de } \\
\text { protección }\end{array}$ & $\begin{array}{c}N_{\text {protegidos }} / \\
N_{\text {total }}\end{array}$ \\
\hline 20 & 2 & 14.3 & $1 / 7$ \\
\hline 35 & 2 & 20 & $1 / 5$ \\
\hline 50 & 2 & 25 & $2 / 8$ \\
\hline 65 & 2 & 33 & $3 / 9$ \\
\hline
\end{tabular}

Figura 4.6.18

Actividad de Chvpd frente al ensayo MES

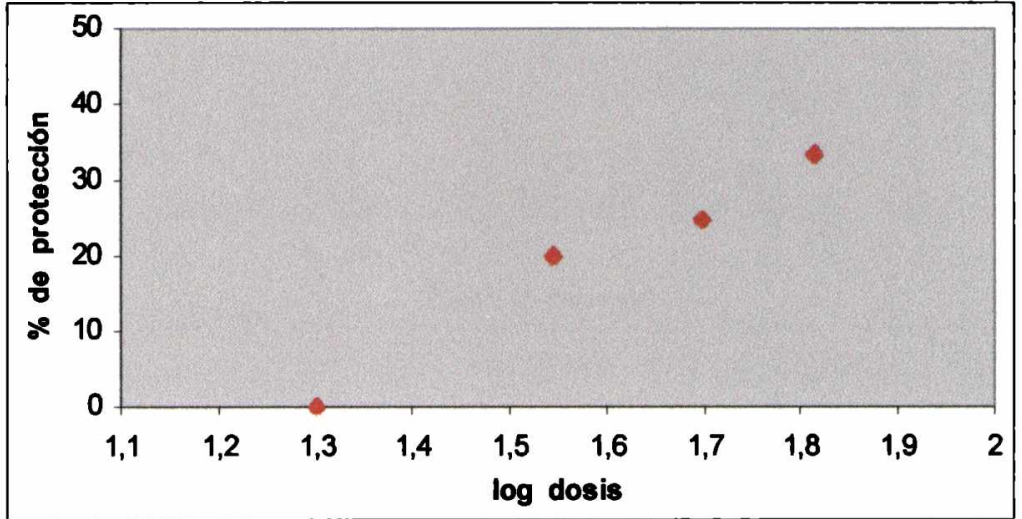


Del análisis estadístico surge una ED50 $=61 \mu \mathrm{mol} / \mathrm{kg}$ (44-85) con $\mathrm{S}=1.7$ (1.1-2.7).

La mayor concentración que fue posible solubilizar fue de $65 \mu \mathrm{mol} / \mathrm{kg}$, pero la droga se mostró inactiva a esta dosis frente al ensayo PTZ (Tabla 4.6.21).

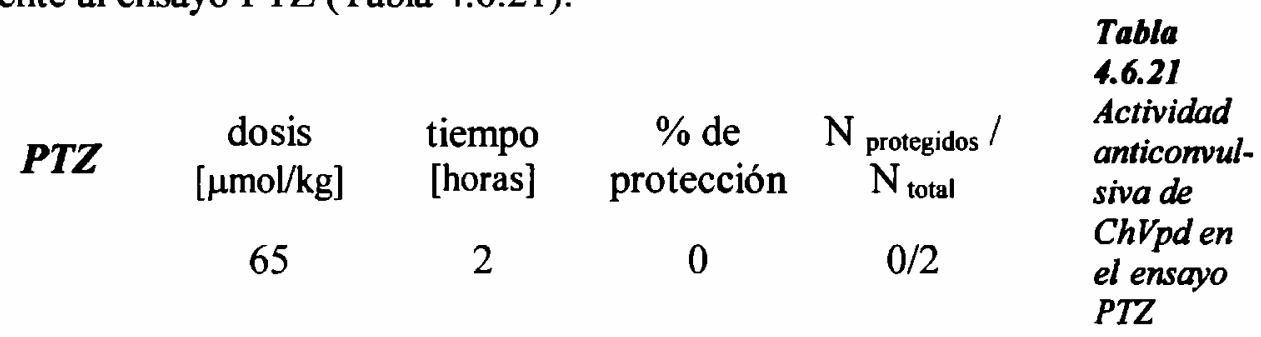

La droga no presenta efectos tóxicos frente al ensayo RotoRod hasta la concentración $65 \mu \mathrm{mol} / \mathrm{kg}$, a ninguno de los tiempos ensayados, por lo que no se obtuvo un TPE neurotóxico (Figura 4.6.19 y tabla 4.6.22).

$\begin{array}{cccccl}\text { RotoRod } & \begin{array}{c}\text { dosis } \\ {[\mu \mathrm{mol} / \mathrm{kg}]}\end{array} & \begin{array}{c}\text { tiempo } \\ {[\text { horas }]}\end{array} & \begin{array}{c}\% \text { de } \\ \text { toxicidad }\end{array} & \begin{array}{c}\mathrm{N}_{\text {afectados }} / \\ \mathrm{N}_{\text {total }}\end{array} & \begin{array}{l}\text { Tabla } \\ \mathbf{4 . 6 . 2 2} \\ \text { Neurotoxi- } \\ \text { cidad de }\end{array} \\ 20 & 2 & 0 & 0 / 7 & \begin{array}{l}\text { ChVpd } \\ \text { manifesta- } \\ \text { da en } \text { el } \\ \text { ensayo }\end{array} \\ 35 & 2 & 0 & 0 / 5 & 0 / 8 & \text { RotoRod } \\ 50 & 2 & 0 & 0 / 4 & \\ 65 & 0.5 & 0 & 0 / 13 & \\ 65 & 2 & 0 & 0 / 3 & \\ 65 & 4 & 0 & & & \end{array}$

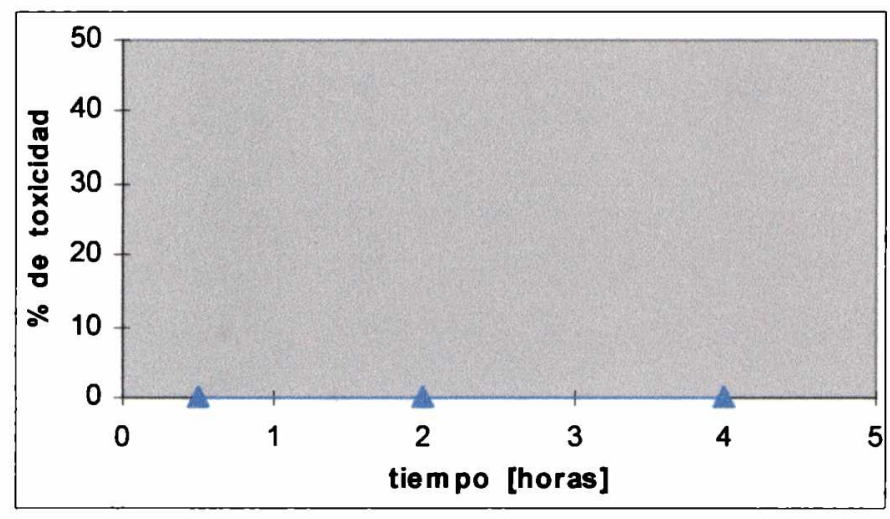

Figura 4.6.19

Estimación del TPE neurotóxico para Chvpd 


\section{Ácido 4-(valproilamido)benzoico (CDVDd)}

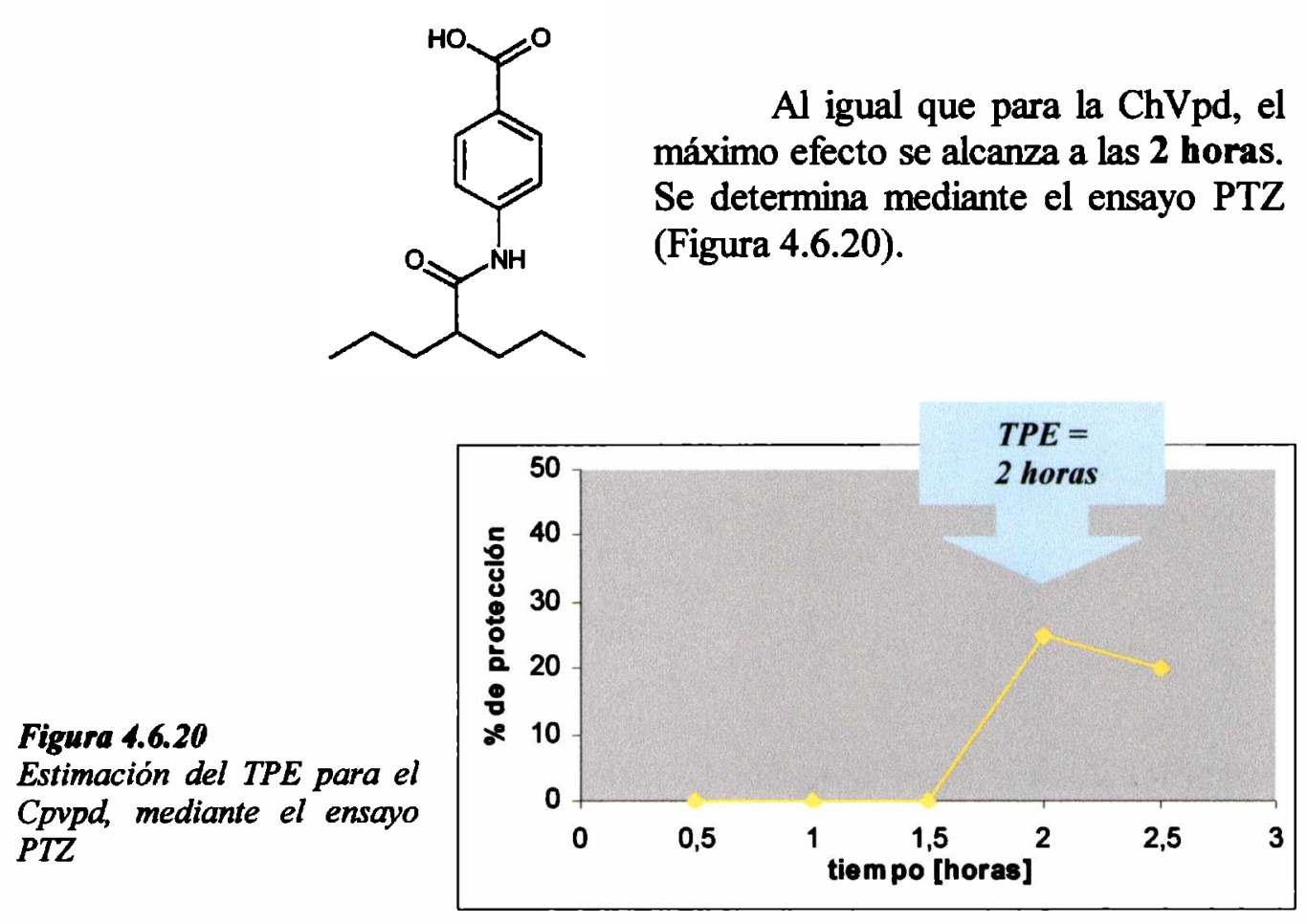

A este tiempo se evaluaron cuatro dosis distintas frente al ensayo MES (Figura 4.6.21 y tabla 4.6.23).

Tabla
4.6.23
Actividad
anticonvul-
siva de
CpVpd en
el ensayo
MES

\begin{tabular}{|c|c|c|c|c|}
\hline MES & $\begin{array}{c}\text { dosis } \\
{[\mu \mathrm{mol} / \mathrm{kg}]}\end{array}$ & $\begin{array}{l}\text { tiempo } \\
\text { [horas] }\end{array}$ & $\begin{array}{c}\% \text { de } \\
\text { protección }\end{array}$ & $\begin{array}{c}N_{\text {protegidos }} \\
N_{\text {total }}\end{array}$ \\
\hline & 1000 & 2 & 37.5 & $3 / 8$ \\
\hline & 1200 & 2 & 50 & $4 / 8$ \\
\hline & 1250 & 2 & 50 & $4 / 8$ \\
\hline & 1500 & 2 & 85.7 & $6 / 7$ \\
\hline
\end{tabular}

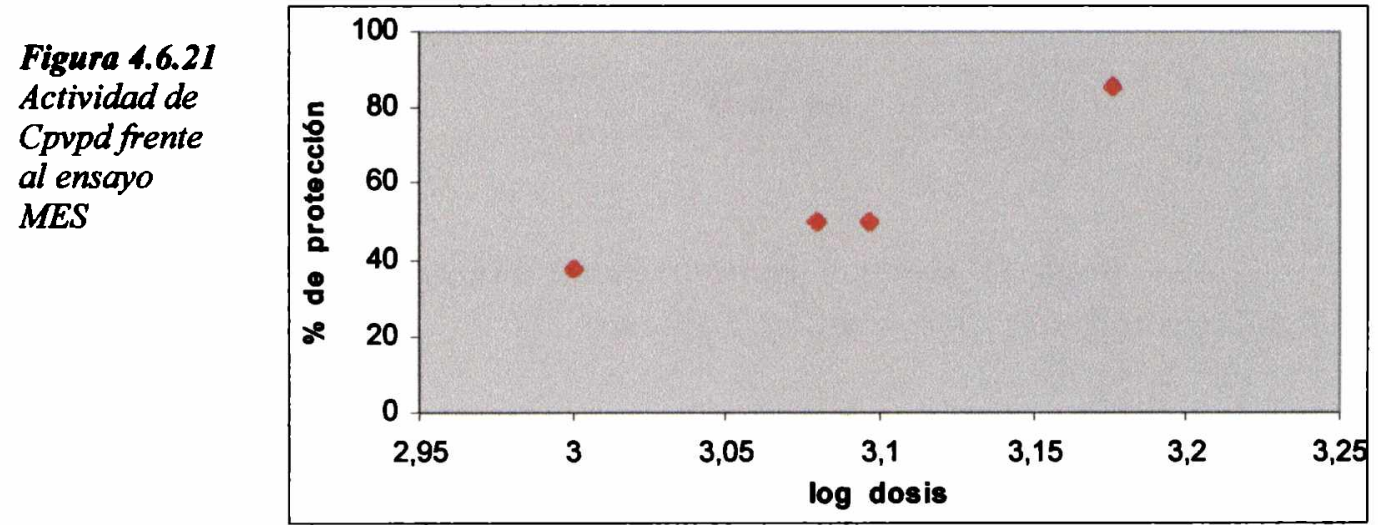


Se obtuvo una ED50 $=1225 \mu \mathrm{mol} / \mathrm{kg}(1107-1355)$ con $\mathrm{S}=1.2(1.1-1.4)$.

Frente al ensayo PTZ, se evaluaron cuatro dosis (Tabla 4.6.24), resultando una ED50 $=1817 \mu \mathrm{mol} / \mathrm{kg}(1669-1978)$ $\operatorname{con} \mathrm{S}=1.2(1.1-1.4)$.

\begin{tabular}{|c|c|c|c|c|c|}
\hline PTZ & $\begin{array}{c}\text { dosis } \\
{[\mu \mathrm{mol} / \mathrm{kg}]}\end{array}$ & $\begin{array}{l}\text { tiempo } \\
\text { [horas] }\end{array}$ & $\begin{array}{c}\% \text { de } \\
\text { protección }\end{array}$ & $\begin{array}{c}\mathrm{N}_{\text {protegidos }} / \\
\mathrm{N}_{\text {total }}\end{array}$ & \multirow{4}{*}{$\begin{array}{l}\text { Tabla } \\
\text { 4.6.24 } \\
\text { Actividad } \\
\text { anticomvul- } \\
\text { siva de } \\
\text { ChVpd en } \\
\text { el ensayo } \\
\text { PTZ }\end{array}$} \\
\hline & 1500 & 2 & 25 & $5 / 20$ & \\
\hline & 1880 & 2 & 37.5 & $3 / 8$ & \\
\hline & 2000 & 2 & 57.1 & $4 / 7$ & \\
\hline & 2200 & 2 & 100 & $4 / 4$ & \\
\hline
\end{tabular}

En el caso de esta droga, al igual que como se procedió en el caso del Vpa (página 113), se utilizó la vía i.p. para la administración del PTZ. Por esta razón, se realizó una evaluación posterior al cálculo de la ED50, empleando la vía s.c., con el objeto de corroborar que la vía de administración no influye en los resultados obtenidos. En la figura 4.6.22 pueden observarse todos los datos en conjunto.

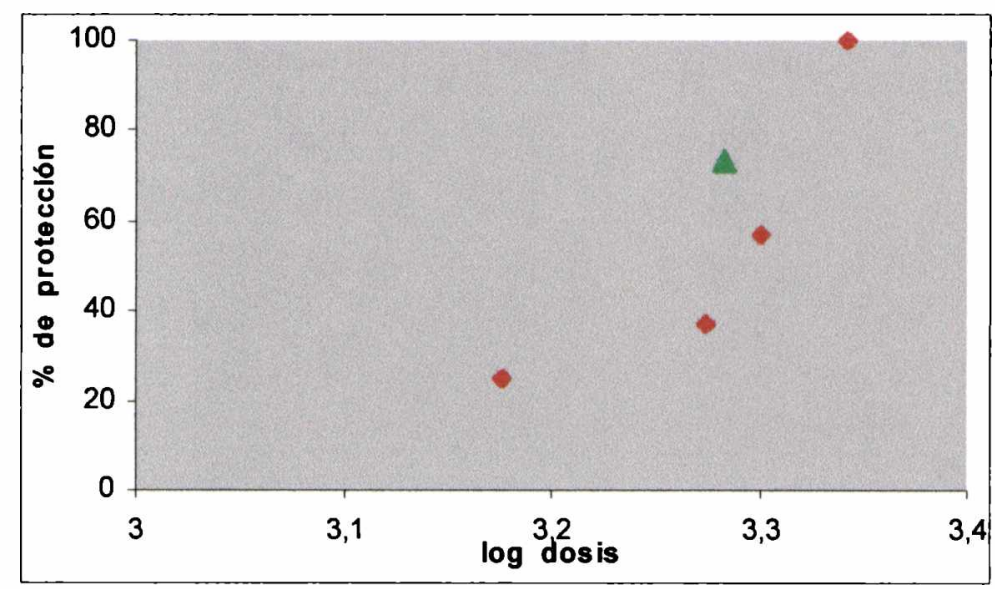

Figura 4.6.22

Actividad de Cpvpd

frente al ensayo PTZ.

En rojo: ensayos

utilizados para el cálculo de la ED50, empleando via i.p. En verde: control posterior, por vía s.c.

La droga no presentó neurotoxicidad ensayada en el ensayo RotoRod a $1500 \mu \mathrm{mol} / \mathrm{kg}$ (Tabla 4.6.25). 
Tabla

4.6.25

Neurotoxi-

cidad de

CpVpd

manifesta-

da en el

ensayo

RotoRod

\begin{tabular}{|c|c|c|c|c|}
\hline RotoRod & $\begin{array}{c}\text { dosis } \\
{[\mu \mathrm{mol} / \mathrm{kg}]}\end{array}$ & $\begin{array}{l}\text { tiempo } \\
\text { [horas] }\end{array}$ & $\begin{array}{c}\% \text { de } \\
\text { toxicidad }\end{array}$ & $\begin{array}{c}\mathrm{N}_{\text {afectados }} / \\
\mathrm{N}_{\text {total }}\end{array}$ \\
\hline & 800 & 2 & 0 & $0 / 7$ \\
\hline & 900 & 2 & 0 & $0 / 6$ \\
\hline & 1000 & 2 & 0 & $0 / 7$ \\
\hline & 1200 & 2 & 0 & $0 / 6$ \\
\hline & 1500 & 2 & 0 & $0 / 4$ \\
\hline
\end{tabular}

\section{$\underline{\text { Discusión }}$}

A modo de resumen de todo lo expuesto, la tabla 4.6.26 presenta las potencias anticonvulsivas de los distintos derivados de Vpa, en los dos ensayos utilizados, como así también los efectos neurotóxicos asociados a las dosis ensayadas. También se consignan los índices de protección (PI), las potencias relativas, y las categorías de los distintos compuestos.

Como apreciación general, puede notarse que las modificaciones funcionales introducidas en la molécula de Vpa condujeron en general a compuestos activos.

Una forma de comparar los nuevos derivados con respecto al compuesto líder de partida, el $\mathrm{Vpa}$, es en relación a las categorías que describe la Fase 1 del Anticonvulsant Screening Project (ASP) del Programa $\mathrm{ADD}^{4}$ (ver sección 4 del presente capítulo). Según esta clasificación de los nuevos compuestos en base a su capacidad anticonvulsiva y acciones neurotóxicas asociadas, aquéllos categorizados como 1 pasan directamente a Fase 2, los de categoría 2 pueden o no considerarse, mientras que los de categoría 3 se consideran inactivos y se descartan. Puede observarse en la tabla 4.6.26 que todos los derivados entran en la categoría 1, la más favorable, excepto el derivado MoVpd que es inactivo (categoría 3) y el CpVpd que se incluye en la categoría 2, al igual que el Vpa. Esto indica que, sometidos a los ensayos iniciales del ASP del Programa $\mathrm{ADD}^{4}$, incluso la droga líder Vpa no resulta tan activa como podría esperarse de un fármaco de uso clínico, estando el derivado CpVpd en las mismas condiciones, mientras que $\mathrm{MoVpd}$ no seria considerada para continuar con su evaluación preclínica. Sin embargo, como se discutirá más adelante, este compuesto inactivo brindará información útil en el momento de la definición de las características moleculares asociadas a la actividad. 


\section{Capitulo 4}

132

Tabla 4.6.26

Actividad biológica de los compuestos derivados de Vpd en estudio

\begin{tabular}{|c|c|c|c|c|c|c|c|c|c|c|c|}
\hline Compuesto & TPE & $\begin{array}{c}\text { EDSO } \\
{[\mu \mathrm{mod} / \mathrm{kg}]}\end{array}$ & $\begin{array}{l}\text { MES } \\
\text { [mg/kg] }\end{array}$ & $\begin{array}{c}\text { EDSO } \\
{[\mu \mathrm{mol} / \mathrm{kg}]}\end{array}$ & $\begin{array}{l}\text { PTZ } \\
{[\mathrm{mg} / \mathrm{kg}]}\end{array}$ & $\mathbf{T P E}_{\mathcal{N}}$ & $\begin{array}{c}\text { TDS0 } \\
{[\mu \mathrm{mo} / \mathrm{kg}]}\end{array}$ & $\begin{array}{l}\text { RotoRod } \\
\text { [mg/kg] }\end{array}$ & $\mathbf{P r}$ & $\begin{array}{c}\text { Put } \\
\text { Redint" }\end{array}$ & Coneg" \\
\hline Vpa & 0.25 & $\begin{array}{c}1008 \\
(792-1282)\end{array}$ & $\begin{array}{c}145 \\
(114-185)\end{array}$ & $\begin{array}{c}1261 \\
(1155-1377)\end{array}$ & $\begin{array}{c}182 \\
(166-198)\end{array}$ & 0.25 & $17 \%$ a 1700 & $17 \%$ a 245 & $1.1-1.7$ & 1 & 2 \\
\hline Vpd & 1 & $\begin{array}{c}353 \\
(267-460)\end{array}$ & $\begin{array}{c}50.5 \\
(38.2-66.6)\end{array}$ & $\begin{array}{c}490 \\
(447-537)\end{array}$ & $\begin{array}{c}70.1 \\
(63.9-76.8)\end{array}$ & 2 & $25 \%$ a 600 & $25 \%$ a 85.8 & $1.3-1.4^{*}$ & 2.9 & 1 \\
\hline IpVpd & 1 & $\begin{array}{c}384 \\
(300-492)\end{array}$ & $\begin{array}{c}70.3 \\
(54.990 .0)\end{array}$ & $33 \%$ a 450 & $33 \%$ a 82.4 & - & $0 \%$ a 450 & $0 \%$ a 82.4 & $>1.2$ & 2.6 & 1 \\
\hline BuVpd & 1 & $\begin{array}{c}487 \\
(412-576)\end{array}$ & $\begin{array}{c}96.9 \\
(820-115)\end{array}$ & $0 \%$ a 600 & $0 \%$ a 119 & 0.5 & $40 \%$ a 600 & $40 \%$ a $\mid 19$ & $>1.2$ & 2.1 & 1 \\
\hline MoVpd & - & $0 \%$ a 1500 & $0 \%$ a 320 & $0 \%$ a 1500 & $0 \%$ a 320 & - & $25 \%$ a 1500 & $25 \%$ a 320 & - & - & 3 \\
\hline ChVpd & 2 & $\begin{array}{c}6 ! \\
(44-85)\end{array}$ & $\begin{array}{c}13.7 \\
(9.9-19.1)\end{array}$ & $0 \%$ a 65 & $0 \%$ a 14.6 & - & $0 \%$ a 65 & $0 \%$ a 14.6 & $>1.1$ & 17 & 1 \\
\hline CpVpd & 2 & $\begin{array}{c}1225 \\
(1107-1355)\end{array}$ & $\begin{array}{c}322 \\
(291-404)\end{array}$ & $\begin{array}{c}1817 \\
(1669-1978)\end{array}$ & $\begin{array}{c}479 \\
(439-520)\end{array}$ & - & $0 \%$ a 1500 & $0 \%$ a 395 & $>1.2$ & 0.8 & 2 \\
\hline
\end{tabular}

\footnotetext{
- P1 (protective index) significa indice de procección = TDS0 / EDS0, considerando la potencia anticanvulsiva fente al ensayo MES.

- Potencia relativa al Vpa es decir EDS0 ve / EDS0 soe, considerando la potencia anticonvulsiva frente al ensiyo MES.

- Crtegaria correapandiente a la clasificación de Fase I del Anticonvulsart Screenang Project del Programa ADD.

segin bibliografia
}

Los resultados de Fase 2, donde se cuantifican las acciones anticonvulsiva y neurotóxica, se consignan en la tabla 4.6.26 como las ED50 y TD50, respectivamente. Con respecto a la protección frente al ensayo MES, todos los compuestos activos, excepto el $\mathrm{CpVpd}$, son entre 2 y 3 veces más potentes que el $\mathrm{Vpa}$, mientras que la $\mathrm{ChVpd}$ es 17 veces más activa que el Vpa (ver potencias relativas en tabla 4.6.26) y casi 6 veces más activa que la Vpd.

Ninguno de los derivados de $\mathrm{Vpd}$, excepto el CpVpd, resultó ser activo frente al PTZ a las dosis evaluadas. La tendencia parece apuntar hacia una conservación de la actividad anti-MES pero no de la capacidad de protección frente al PTZ, lo cual indicaría que de los posibles mecanismos de acción asociados al $\mathrm{Vpa}$ y $\mathrm{Vpd}$, sólo alguno se retiene.

En cuanto a los efectos medidos en el ensayo RotoRod, puede observarse en la tabla 4.6.26 que ninguno de los compuestos manifiesta acciones neurotóxicas a dosis 
anticonvulsivas (ED50s). Sin embargo, hasta las dosis ensayadas, no fue posible lograr una mejora en los PI con respecto a los del Vpa y Vpd. Debido a que las TD50s no pudieron ser calculadas por problemas de solubilidad a altas dosis, los PI pueden estimarse, en el sentido de que puede considerarse que son mayores a $1.1-1.2$. A pesar de que los PI de Vpa y Vpd son bastante bajos (entre 1.1 y $1.7^{1,2,3,4,5,6,7,8}$ y entre 1.3 y $1.4^{7,8}$, respectivamente), no se puede asegurar que los nuevos derivados sean más seguros que éstos, al menos con la batería de ensayos empleados en esta etapa de la evaluación preclínica.

Analizando comparativamente los nuevos derivados de Vpd planteados, se puede afirmar que IpVpd, BuVpd y ChVpd presentan ventajas con respecto al Vpa, no sólo en cuanto a su mayor potencia anticonvulsiva, sino también por el hecho de que son potenciales drogas no teratogénicas por carecer del grupo carboxilato libre del Vpa. Además, por su sustitución en el $\mathrm{N}$ amídico, probablemente no serán compuestos inhibidores de la $\mathrm{mEH}$, lo cual constituye una ventaja no sólo sobre Vpa sino también sobre la Vpd.

A pesar de no haberse realizado estudios de farmacocinética para los derivados analizados, con el objeto de confirmar que la acción observada no se deba a la biotransformación a Vpa, el espectro farmacológico observado en todos ellos indica que están actuando como tales. Si el Vpa fuera en realidad la especie activa frente al ensayo MES, debería observarse además cierta actividad frente al ensayo PTZ. Asimismo, las características estructurales de los compuestos estudiados, precisamente la sustitución del $\mathrm{N}$ amídico, constituye, como se señaló en la sección 2, una clave para evitar la hidrólisis amida - ácido, aún en especies animales superiores.

En conclusión, puede afirmarse que los resultados biológicos obtenidos para estos nuevos derivados de Vpd han sido satisfactorios no sólo por el potencial que presentan como drogas antiepilépticas, sino principalmente porque permitirán profundizar en el conocimiento de los procesos involucrados en su acción anticonvulsiva y finalmente en el diseño de nuevas estructuras mejoradas. De esta forma, el análisis de los resultados farmacológicos obtenidos hasta este punto sirve como punto de partida para sacar conclusiones con respecto a las características que este grupo de compuestos tiene en común, dirigiendo el estudio hacia el planteo de un grupo farmacóforo. Suponiendo que un perfil farmacológico similar es indicativo de un mecanismo de acción común, se plantean en la siguiente sección, metodologías indirectas de diseño de fármacos para dilucidar las características del farmacóforo. 
134

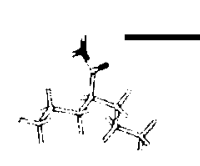

\footnotetext{
${ }^{1}$ Edafiogho, I.; Scott, K. Cap.39: Anticonvulsants. En: Wolff, M. (Eds.), Burger's Medicinal Chemistry and Drug Discovery $5^{\text {th }}$ Edición Vol.3: Therapeutic Agents, John Wiley \& Sons Inc. (1996) pp. 175-254 ${ }^{2}$ Gladding, G.D.; Kupferberg, H.J.; Swinyard, E.A. Apéndice Cap. 12: Antiepileptic Drug Development Program En: Handbook Exp. Pharm. Vol.74 Antiepileptic Drugs (1985) pp. 341-347

${ }^{3}$ Swinyard, E.A.; Woodhead, J.H.; White, H.S.; Franklin, M.R. Cap. 5: Experimental Selection, Quantification, and Evaluation of Anticonvulsant En: Levy, R.; Mattson, R.; Meldrum, B.; Penry, J.K.; Dreifuss, F.E. (Eds.) Antiepileptic Drugs, $3^{\text {rd }}$ Ed., Raven Press, Ltd., New York (1989) pp. 85102

${ }^{4}$ Porter, R.J.; Cereghino, J.J.; Gladding, G.D.; Hessie, B.J.; Kupferberg, H.J.; Scoville, B.; White, B.G. Clev. Clin. Q. (1984) 51: 293-305

${ }^{5}$ Scriba, G.K.E. Arch. Pharm. Pharm. Med. Chem. (1996) 329: 554-5

${ }^{6}$ Tantisira, B.; Tantisira, M. H.; Patarapanich, C.; Sooksawate, T.;

Chunngam, T. Research Communications in Molecular Pathology and Pharmacology (1997) 97(2): 151-64

${ }^{7}$ Bialer, M.; Haj-Yehia, A.; Badir, K.; Hadad, S. Pharmacy World \& Science (1994) 16(1): 2-6

${ }^{8}$ Loscher, W.; Nau, H. Neuropharmacology (1985) 24(5): 427-35

${ }^{9}$ Bojic, U.; Elmazar, M.M.A.; Hauck, R.S.; Nau, H. Chemical Research in Toxicology 9 (5): 866-70

${ }^{10}$ Abbott, F.S.; Acheampong, A.A. Neuropharmacology (1988) 27(3): 287 94

${ }^{11}$ Shek, E.; Murakami, T.; Nath, Ch.; Pop, E.; Bodor, N. J. Pharm. Res. (1989) 78(10): 837-43

${ }^{12}$ Ho, B.; Venkatarangan, P.M.; Cruse, S.F.; Hinko, C.N.; Andersen, P.H.; Crider, A.M.; Adloo, A.A.; Roane, D.S.; Stables, J.P. Eur. J. Med. Chem. (1998) 33: 23-31

${ }^{13}$ Bechar, E.; Astroug, H. Arch. Pharm. Pharm. Med. Chem. (1997) 330: 273-6
} 


\section{MODELADO MOLECULAR \\ DE VALPRAMIDAS \\ Y OTRAS DROGAS ANTI-MES}

Ya se ha descrito en las secciones anteriores el por qué de la elección de los derivados $\mathrm{N}$-sustituidos de Vpd (Figura 4.7.1). También se presentó su síntesis y los resultados de su evaluación como potenciales drogas antiepilépticas frente a los modelos más representativos de acción anticonvulsiva.<smiles>CCCC(CCC)C(N)=O</smiles>

VPD<smiles>CCCC(CCC)C(=O)NC1CCCCC1</smiles>

Figura 4.7.1

Estructura de Vpd y de los derivados $N$-sustituidos analizados.

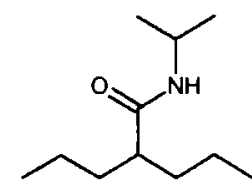

IPVPD<smiles>CCCC(CCC)C(=O)N1CCOCC1</smiles>

MOVPD<smiles>CCCCNC(=O)C(CCC)CCC</smiles>

BIVPD
CPVPD

A partir de los resultados biológicos obtenidos, se observa que todos los compuestos excepto MoVpd, son activos frente al ensayo MES. Este comportamiento farmacológico particular, distinto al del resto de los derivados, condujo a la realización de un exhaustivo estudio teórico de todas las estructuras con el objeto de encontrar las posibles causas que conducen a esta diferente respuesta biológica. Dado que el empleo de descriptores clásicos de los distintos efectos (hidrofóbico, estérico, electrónico) no brinda una explicación de la distinta actividad observada en el caso de derivados de Vpa y compuestos relacionados ${ }^{1,2,3}$, se procede a la ejecución de un análisis químico cuántico del conjunto de estructuras estudiadas.

Un mismo perfil farmacológico, en relación con el carácter anti-MES de las drogas, fue el criterio elegido para 
incorporar estructuras de drogas clásicas conocidas al presente estudio teórico de los derivados de Vpd. Así, con el objeto de facilitar la determinación de una conformación activa, se incorporan PHE y $\mathrm{CZ}$ (carbamazepina) como análogos rígidos, y otras cinco drogas antiepilépticas que permiten establecer los requisitos necesarios para la actividad anti-MES (Figura 4.7.2).

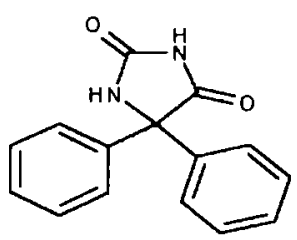

PHE, fenitoina

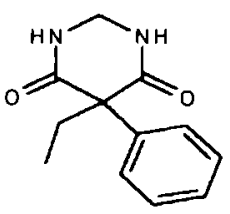

PRM, primidons

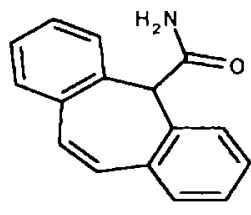

CZ, carbamazepina

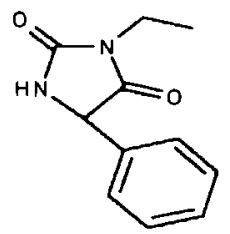

ETT, etotoina

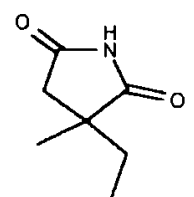

ETH, etosuximida

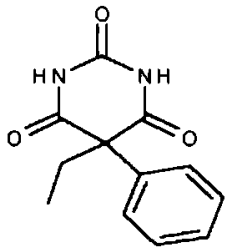

PB, fenobarbilat

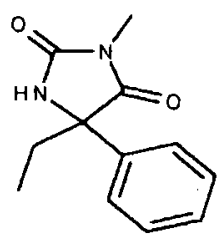

MPH, mefenitoina

\section{Figura 4.7.2}

Estructuras de los antiepilépticos clásicos incorporados al estudio de compuestos con acción anti-MES.

\section{Descripción de la metodología teórica}

Para el estudio teórico de las estructuras se emplean diversos programas de química computacional. Entre ellos podemos mencionar:

\footnotetext{
$\checkmark$ Hyperchem $5.1^{4}$,

$\checkmark$ PC Spartan Plus ${ }^{5}$,

$\checkmark$ AMSOL $^{6}$,
} 


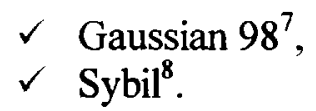

Se emplean las computadoras del Laboratorio de Farmacoquímica (varias PCs funcionando bajo entorno Windows y una Silicon Graphics Octane funcionando bajo entorno Unix).

\section{Análisis conformacional.}

Las estructuras 3D de partida se construyen mediante el

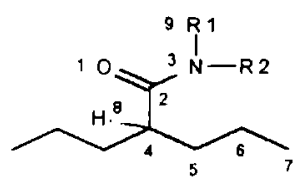

VPD y derivados

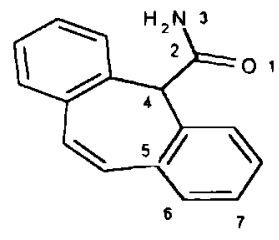

$C Z$, carbamazepina

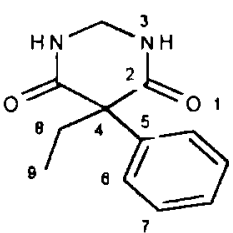

PRM, primidon a

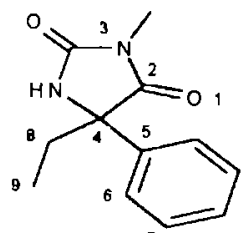

M PH, mefenltoina

Figura 4.7.3

Definición de los ángulos de torsión o diedros para cada una de las estructuras. El diedro definido por los átomos 1-2-4-5 se define siempre como $\tau_{1}, \tau_{2}$ esta siempre el definido por 2-4-5-6, y $\tau_{3}$ por 4-5-67. empleo del programa HyperChem ${ }^{1}$.

Generación de las geometrías iniciales de Vpd y sus derivados

Dentro de las distintas

PHE, fenitoina<smiles>CCC1(c2ccccc2)C(=O)NC(=O)NC1=O</smiles>
técnicas de muestreo de la hipersuperficie de energía potencial, la que mejor se adapta a nuestro objetivo es la asociada al análisis sistemático del espacio conformacional. La conformación de las cadenas hidrocarbonadas del resto valproilo se conoce en base a estudios previos de dinámica molecular'. Se sabe que está definida por ángulos de torsión próximos a $180^{\circ}$. Por lo tanto, para el caso de Vpd y sus derivados, a pesar de tratarse de estructuras con un número considerable de ángulos diedros rotables, el estudio se centró en aquellos diedros involucrados en las rotaciones del sustituyente unido al $\mathrm{N}$ amídico. Las geometrías de partida de Vpd y ETH, etosuximid sus derivados se crean mediante modificaciones de
los ángulos de torsión $\mathrm{O}_{1} \mathrm{C}_{2} \mathrm{C}_{4} \mathrm{H}_{8}$ y $\mathrm{O}_{1} \mathrm{C}_{2} \mathrm{~N}_{3} \mathrm{C}_{9}$ (Figura 4.7.3), variando estos ángulos en pasos de $90^{\circ}$ entre $0^{\circ}$ y $360^{\circ}$. Como se verá más adelante, no se justifica partir de conformaciones iniciales con valores intermedios de estos ángulos diedros, ya que luego de la minimización éstos adquieren valores cercanos a $0^{\circ}$ o $180^{\circ}$. La orientación preferencial de las cadenas hidrocarbonadas se confirmó, sin embargo, para cada uno de los compuestos, ya que un sustituyente voluminoso en la porción amida, podría 
condicionar esta situación. Por tal razón, se buscaron confórmeros iniciales distintos utilizando una metodología estocástica. Se realizaron corridas de dinámica molecular de 10 ps a $600 \mathrm{~K}$ con un paso de integración de 0.0005 ps. Aquellas conformaciones resultantes que fueron visiblemente distintas de las ya generadas por el análisis sistemático, se eligieron como punto de partida para las minimizaciones. Se consideraron diferencias tanto en la conformación de las cadenas propílicas como en las características del sustituyente en $\mathrm{N}$.

\section{Generación de las geometrías iniciales de los antiepilépticos clásicos}

Se utiliza también una metodologia sistemática para la generación de las conformaciones de partida de las drogas antiepilépticas clásicas. Los ángulos diedros seleccionados para tal fin dependen de cada estructura en particular (Figura 4.7.3). Para $C Z, \tau_{1}$ se varía en pasos de $15^{\circ}$, entre $0^{\circ}$ y $180^{\circ}$, dejando inicialmente la molécula totalmente plana. Las optimizaciones conducen a tres conformaciones estables diferenciables principalmente por el valor de $\tau_{2}\left(-152^{\circ},-132^{0}\right.$ ó $-90^{\circ}$ ), siendo $2,7 \mathrm{kcal}$ la mayor diferencia energética entre estos tres confórmeros. Para cada uno de ellos, no asociados ya a conformaciones planares, se volvió a analizar el efecto de modificar $\tau_{1}$, esta vez en pasos de $60^{\circ}$ desde $0^{\circ}$ hasta $360^{\circ}$. Para PB, PRM, ETT y MPH, se analizan variaciones de $\tau_{2}$ en $45^{\circ}$, considerando sólo el rango entre $0^{\circ}$ y $180^{\circ}$, debido a la simetría del anillo bencénico. Para cada uno de esos valores, $\mathrm{C}_{2} \mathrm{C}_{4} \mathrm{C}_{8} \mathrm{C}_{9}\left(\mathrm{C}_{2} \mathrm{C}_{3} \mathrm{C}_{8} \mathrm{C}_{9}\right.$ para ETT $)$ se varía también en pasos de $45^{\circ}$, entre $0^{\circ}$ y $360^{\circ}$. Para PHE, $\tau_{2}$ y $\mathrm{C}_{2} \mathrm{C}_{4} \mathrm{C}_{8} \mathrm{C}_{9}$ se modifican en pasos de $45^{\circ}$, entre $0^{\circ}$ y $180^{\circ}$, por involucrar dos anillos bencénicos simétricos. En el caso de ETH, $\tau_{2}$ se varía en pasos de $45^{\circ}$, entre $0^{\circ}$ y $360^{\circ}$.

\section{Optimización de geometrias}

Durante las optimizaciones se dejan completamente libres todos los parámetros geométricos. Se utiliza un algoritmo de minimización basado en gradientes conjugados (PolakRibiere $^{10}$ ) y la optimización se continúa hasta convergencia de RMS del gradiente a $0.05 \mathrm{kcal} /$ Amol.

\section{Consideración de geometrías finales}

Se evalúan las distintas conformaciones finales y se tienen en cuenta fundamentalmente las de menor energía (confórmeros más estables), ya que principalmente en el caso de las Vpds existen muchas conformaciones energéticamente similares y por lo tanto mutuamente interconvertibles. 
Búsqueda de la conformación activa.

Como criterio de accesibilidad a una determinada conformación de interés, se evalúa el costo energético para evolucionar a ésta desde la conformación más estable, a la cual se asocia la mayor probabilidad de existencia.. Para ello se analizan las barreras de energía asociadas a la rotación alrededor de los enlaces involucrados en el cambio de conformación. Este cálculo se efectúa mediante sucesivas variaciones del ángulo de torsión de interés en pasos bien definidos (no mayores a $10^{\circ}$ ), y posteriores optimizaciones. El ángulo de torsión estudiado se mantiene congelado durante la optimización, mientras que para el resto de la molécula se permite la relajación total.

\section{Método de cálculo.}

El espacio conformacional se analizó empleando metodología semiempírica para el muestreo inicial. Se emplea un hamiltoniano AM1 para la optimización de las geometrías.

La elección del método se basa en un minucioso estudio teórico de la molécula que define la porción funcionalmente más representativa de la molécula de Vpd y sus derivados $\mathrm{N}$-sustituidos: la acetamida. Esta molécula se estudió en su geometría y características electrónicas empleando distintos niveles de cálculo: AM1, PM3, MNDO y ab initio, empleando bases $6-31+G(d, p), 6-311+G(d, p)$ e incluyendo correlación electrónica a nivel MP2 y CISD ${ }^{11}$.

Para las estructuras de las DAEs clásicas incorporadas al estudio, se utiliza también el mismo nivel de cálculo.

El método AMl se utilizó, entonces, para el análisis conformacional de todas las moléculas, basado en la optimización de sus geometrías y el cálculo de las energías asociadas. Las barreras energéticas relacionadas a la rotación alrededor de enlaces simples se calculan también empleando un hamiltoniano AM1.

Las conformaciones activas obtenidas para cada una de las estructuras se refinan mediante una optimización restringida empleando metodología DFT B3LYP con bases 6$31+G(d, p)$. Para ello, se mantiene congelada la conformación de la porción farmacofórica y se deja relajado el resto de la molécula, ya que no interesa encontrar el mínimo absoluto en la superficie de energía potencial, sino un mínimo relativo asociado a la estructura capaz de interaccionar con el receptor.

\section{Densidades de carga.}

Las distribuciones de carga se calculan, para las conformaciones activas provenientes de las optimizaciones restringidas descriptas, mediante un análisis poblacional de 
Mulliken y mediante el cálculo del potencial electrostático $(\text { ChelpG })^{12}$ sobre los átomos que definen el farmacóforo. Sin embargo, se consideran para la evaluación sólo las cargas derivadas de potenciales electrostáticos, debido a la conocida imprecisión del análisis poblacional de Mulliken para la descripción de los enlaces polares.

\section{Resultados $y$ discusión del estudio teórico}

Para comenzar a detallar los resultados del estudio teórico, comenzaremos describiendo aquéllos derivados del cálculo de la molécula más sencilla de la serie, la Vpd. Como ya se ha comentado, la geometría más estable de las cadenas propilicas del Vpa es aquélla en la que éstas se disponen formando ángulos de torsión de aproximadamente $180^{\circ}$ en todos los casos ${ }^{9}$. Como era predecible, lo mismo ocurrió para la Vpd. Cuando los ángulos diedros adquieren valores cercanos a $180^{\circ}$ generan una conformación antiperiplanar de mínima energía (a la que llamaremos "toda anti") (Figura 4.7.4). En cuanto a la función amida, el plano definido por este grupo se dispone en forma perpendicular a la línea de las cadenas hidrocarbonadas, ya que es la forma más favorable de evitar la repulsión entre el grupo amida y los restos propilo (Figura 4.7.5). En cuanto a la orientación espacial del $\mathrm{O}$ y el $\mathrm{N}$ del grupo amida con respecto a las cadenas propílicas, a partir del análisis conformacional surgen mínimos que corresponden a conformaciones que difieren entre sí en la rotación del plano de la amida (conformaciones 1 y 2, figura 4.7.4). Así, la diferencia entre estas dos geometrías radica en que en una de las conformaciones, el $\mathrm{O}$ carbonílico se dispone alejado de las cadenas propílicas definiendo así un diedro $\mathrm{OCCH}$ de $0^{\circ}$ (conformación 1 o synperiplanar), mientras que en la otra el $\mathrm{O}$ se mantiene cercano a los $\mathrm{C}$ adyacentes de los restos hidrocarbonados, formando un diedro OCCH próximo a $180^{\circ}$ (conformación 20 antiperiplanar) (Figuras<smiles>CC1CC2CCC(C1C)C2C</smiles>

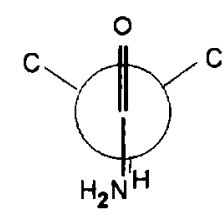

antiperiplanar

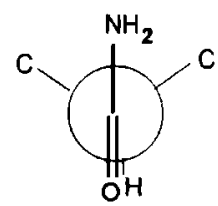

synperiplanar

\section{Figura 4.7.4}

Ejemplos de proyecciones de Newton de conformaciones antiperiplanares y synperiplanares 4.7.4 y 4.7.5). 


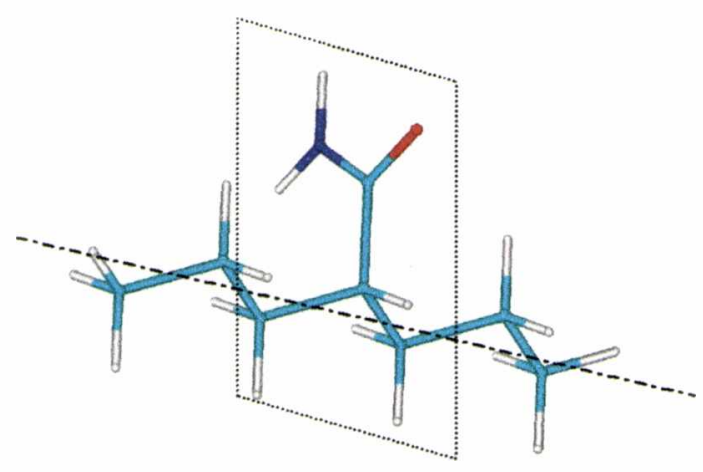

\begin{tabular}{c|c|c|c}
$\begin{array}{c}\text { Confor- } \\
\text { mación }\end{array}$ & $\begin{array}{c}\Delta \mathrm{E} \\
{[\mathrm{kcal}]}\end{array}$ & $\begin{array}{c}\text { toda } \\
\text { anti? }\end{array}$ & $\tau_{1}$ \\
\hline 1 & 0.00 & $\mathrm{si}$ & $0^{\circ}$ \\
2 & 0.83 & $\mathrm{si}$ & $180^{\circ}$
\end{tabular}

Figura 4.7.5

Características conformacionales de Vpd.

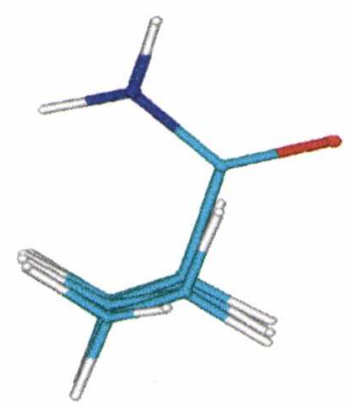

conformación 1

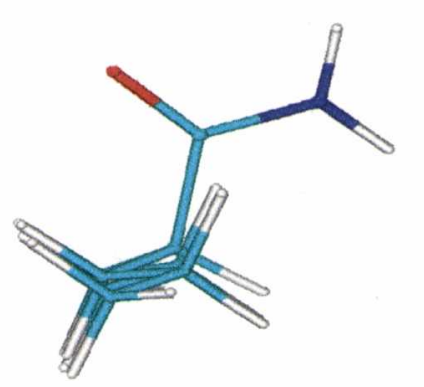

conformación 2

La diferencia de $0.83 \mathrm{kcal}$ en la estabilidad de estas dos geometrías que sólo se diferencian en la conformación de la porción amida, puede explicarse por la menor repulsión estérica entre los $\mathrm{H}$ del $-\mathrm{NH}_{2}$ y el $\mathrm{H}$ más cercano de la porción hidrocarbonada en la conformación 1, que la hace más estable que la conformación 2. Aparecen luego otras conformaciones de energía algo mayor, en las cuales los grupos propilo adquieren geometrías distintas de la "toda anti".

La exploración del espacio conformacional realizada para cada uno de los derivados $\mathrm{N}$-sustituidos de $\mathrm{Vpd}$, dio lugar en todos los casos a numerosos mínimos muy similares en energía, y por lo tanto igualmente probables. La razón fundamental es que se trata de moléculas con un alto grado de flexibilidad, con al menos 5 enlaces rotables a lo largo de sus estructuras, cuyas variaciones generan conformaciones significativamente diferentes entre sí. Además, también se encuentran numerosos mínimos isoenergéticos debido a geometrías equivalentes, ya que las moléculas presentan grupos simétricos. La mayor parte de los mínimos se asocian a cambios conformacionales del sustituyente en el $\mathrm{N}$, aunque también se observaron unas pocas variaciones en la conformación de los propilos unidos en posición 4, en donde algunos de los diedros toman valores distintos de $180^{\circ}$, especialmente en el caso de aquellos derivados con 
sustituyentes voluminosos en el $\mathrm{N}$, como el MoVpd y el ChVpd, donde la repulsión estérica entre los grupos ya adquiere importancia.

En la tabla 4.7.1 y en la figura 4.7.6 se presentan las características conformacionales que poseen las geometrias de menor energía de cada una de las estructuras estudiadas, asociadas a mínimos en el espacio conformacional. Debido al gran número de mínimos encontrados, solamente se presentan en la tabla 4.7.1 las geometrías cuya energía se encuentra dentro del rango de $1 \mathrm{kcal}$ por encima del mínimo absoluto $(\Delta \mathrm{E}$ $<1 \mathrm{kcal})$.
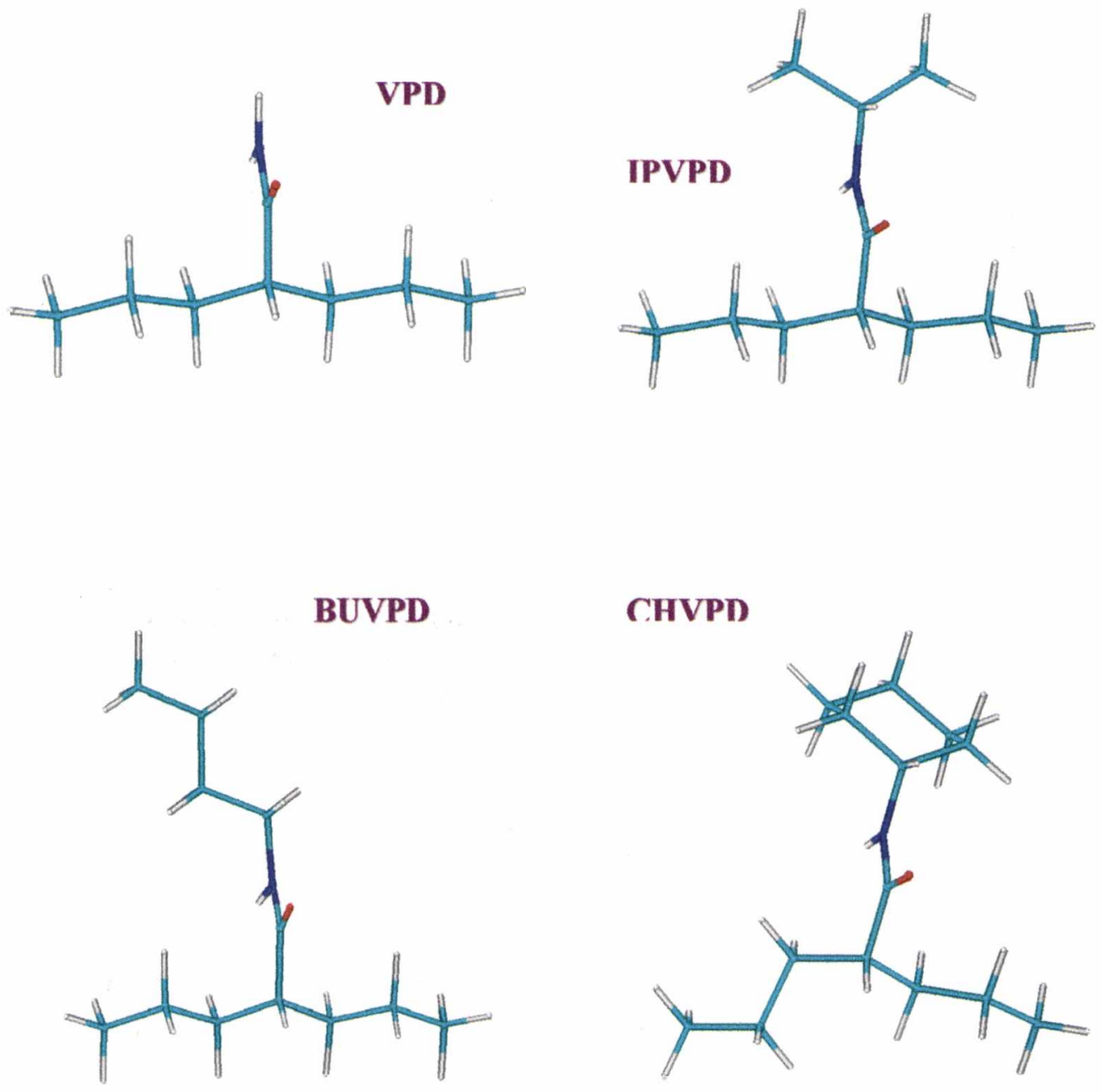

Figura 4.7.6 (continúa en la página siguiente)

Conformaciones de mínima energía de cada una de las estructuras estudiadas. Estas conformaciones están asociadas a minimos absolutos en la hipersuperficie de energía potencial según surge del análisis conformacional realizado. 


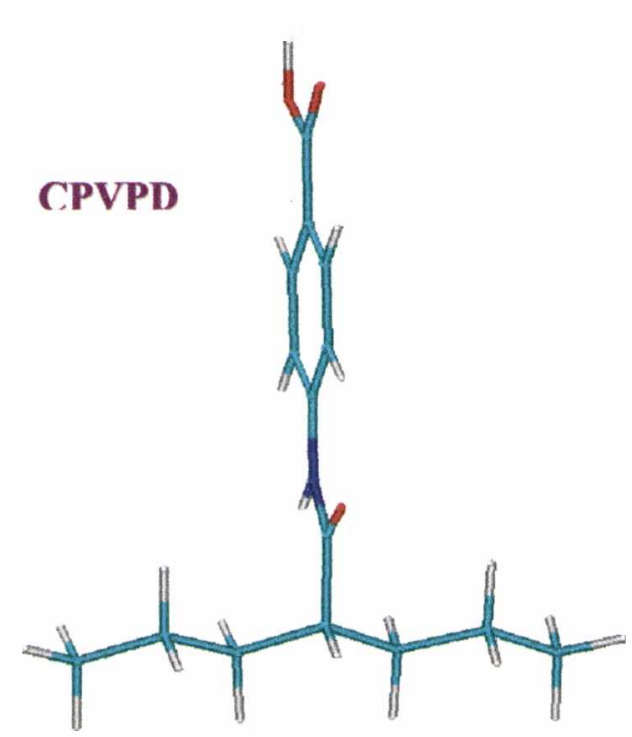

\begin{tabular}{|c|c|c|c|c|}
\hline Molécula & $\begin{array}{c}\Delta \mathrm{E} \\
{[\mathrm{kcal}]}\end{array}$ & $\begin{array}{l}\text { toda } \\
\text { anti? }\end{array}$ & $\mathrm{OCCH}$ & OCNC \\
\hline \multirow[t]{2}{*}{ VPD } & 0.00 & si & $0^{\circ}$ & \\
\hline & 0,83 & si & $180^{\circ}$ & \\
\hline \multirow[t]{2}{*}{ IPVPD } & 0,00 & si & $-1^{\circ}$ & $2^{\circ}$ \\
\hline & 0,79 & si & $177^{\circ}$ & $2^{\circ}$ \\
\hline \multirow[t]{9}{*}{ BUVPD } & 0,00 & si & $2^{\circ}$ & $-9^{\circ}$ \\
\hline & 0.00 & si & $-1^{\circ}$ & $8^{\circ}$ \\
\hline & 0,08 & si & $1^{\circ}$ & $-9^{\circ}$ \\
\hline & 0,21 & si & $1^{\circ}$ & $-6^{\circ}$ \\
\hline & 0,56 & si & $-7^{\circ}$ & $-13^{\circ}$ \\
\hline & 0.63 & no & $-9^{\circ}$ & $10^{\circ}$ \\
\hline & 0.80 & $\mathrm{si}$ & $-177^{\circ}$ & $-9^{\circ}$ \\
\hline & 0.79 & si & $177^{\circ}$ & $8^{\circ}$ \\
\hline & 0,85 & si & $-164^{\circ}$ & $-11^{\circ}$ \\
\hline \multirow[t]{3}{*}{ CHVPD } & 0,00 & no & $7^{\circ}$ & $2^{\circ}$ \\
\hline & 0.20 & si & $-1^{0}$ & $1^{\circ}$ \\
\hline & 0,98 & si & $180^{\circ}$ & $1^{\circ}$ \\
\hline \multirow[t]{4}{*}{ MOVPD } & 0,00 & no & $-160^{\circ}$ & $-3^{\circ}$ \\
\hline & 0,37 & si & $168^{\circ}$ & $1^{\circ}$ \\
\hline & 0,37 & si & $-168^{\circ}$ & $2^{\circ}$ \\
\hline & 1,00 & no & $-11^{\circ}$ & $-5^{\circ}$ \\
\hline \multirow[t]{2}{*}{ CPVPD } & 0,00 & si & $0^{\circ}$ & $0^{\circ}$ \\
\hline & 0,89 & si & $-177^{\circ}$ & $0^{\circ}$ \\
\hline
\end{tabular}

Tabla 4.7.1 Conformaciones de menor energía $(E<1 \mathrm{kcal})$ para cada una de las estructuras estudiadas. Las conformaciones "toda anti" cuyos ángulos $\mathrm{OCCH}$ y OCNC son iguales, se diferencian en los ángulos del sustituyente en $N$ (no mostrados en esta tabla).

En todos los casos se obtiene el mismo patrón de comportamiento en cuanto a la disposición del $\mathrm{O}$ carbonilico con respecto al $\mathrm{H}$ del $\mathrm{C} \alpha$. Puede observarse en la tabla 4.7.1 que el diedro $\mathrm{OCCH}$ siempre toma valores cercanos a $0^{\circ}$ o $180^{\circ}$ sin estabilización de conformaciones intermedias. El primer caso define una conformación synperiplanar del $O$ con respecto al $\mathrm{H}$ (ver figura 4.7.4) a la cual se denominará de aquí en más conformación "syn", y el segundo caso se asocia a una conformación antiperiplanar (ver figura 4.7.4) o "anti".

En cuanto a la orientación del grupo sustituyente en el $\mathrm{N}$, se observa que una conformación synperiplanar del $\mathrm{O}$ con respecto al primer $\mathrm{C}$ del sustituyente $\left(\mathrm{OCNC}=0^{\circ}\right)$ está siempre 
favorecido con respecto a la antiperiplanar $\left(\mathrm{OCNC}=180^{\circ}\right)$ debido a una menor repulsión estérica en el primer caso. Esta menor estabilidad de la conformación antiperiplanar es menos notoria en el caso de los derivados con sustituyentes menos voluminosos (IpVpd y BuVpd) en donde la diferencia de energía con respecto al mínimo absoluto es de alrededor de 1,8 kcal, incrementándose esta diferencia para las demás estructuras con grupos de mayor tamaño.

\section{Relación entre la flexibilidad molecular y la actividad biológica de Vpd y sus derivados $\mathrm{N}$-sustituidos. \\ Podemos relacionar estas características conformacionales de las estructuras con los resultados biológicos que se comentaron anteriormente, específicamente con el comportamiento distintivo que muestra MoVpd frente al ensayo MES con respecto a todos los demás derivados.}

\begin{tabular}{|c|c|c|c|}
\hline Molécula & $\begin{array}{l}\text { Actividad } \\
\text { anti MES }\end{array}$ & $\begin{array}{l}\text { conformación } \\
\text { de minima } E\end{array}$ & $\begin{array}{l}\text { Tabla } 1.7 .2 \\
\text { Relación entre la } \\
\text { capacidad de protección }\end{array}$ \\
\hline VPD & activo & syn & $\begin{array}{l}\text { frente al ensayo MES y } \\
\text { las caracteristicas de la }\end{array}$ \\
\hline IPVPD & activo & syn & $\begin{array}{l}\text { conformación más } \\
\text { estable. }\end{array}$ \\
\hline BUVPD & activo & syn & \\
\hline CHVPD & activo & syn & \\
\hline MOVPD & inactivo & anti & \\
\hline CPVPD & activo & syn & \\
\hline
\end{tabular}

Los derivados activos poseen conformaciones de mínima energía synperiplanares, mientras que el MoVpd es antiperiplanar y no es activo (Tabla 4.7.2). Esto nos puede llevar a pensar en primera instancia que esta disposición particular del $\mathrm{O}_{1}$ con respecto al $\mathrm{H}_{8}$ es un requisito para la actividad. Pero como ya se comentó, estas conformaciones de mínima energía no son mínimos energéticamente aislados, sino que por el contrario existen muchas conformaciones de estabilidades similares. Si analizamos específicamente la diferencia de energía que existe entre la conformación syn más estable y la anti más estable en cada caso $(\Delta \mathrm{E} \mathrm{S} / \mathrm{A}$, tabla 4.7.3), veremos que ésta es siempre del orden de $1 \mathrm{Kcal}$, o sea que ambas podrian coexistir en equilibrio. 


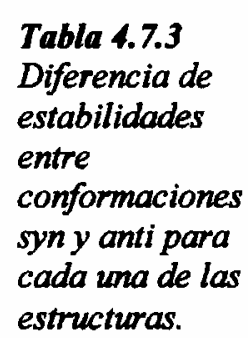

\begin{tabular}{cccc} 
Molécula & $\begin{array}{c}\text { Actividad } \\
\text { anti MES }\end{array}$ & $\begin{array}{c}\text { conformación } \\
\text { de mínima E }\end{array}$ & $\begin{array}{c}\Delta \mathbf{E ~ S / A} \\
\text { [kcal] }\end{array}$ \\
\hline VPD & activo & syn & $\mathbf{0 . 8 3}$ \\
IPVPD & activo & syn & $\mathbf{0 . 7 9}$ \\
BUVPD & activo & syn & $\mathbf{0 . 8 0}$ \\
CHVPD & activo & syn & $\mathbf{0 . 9 8}$ \\
MOVPD & inactivo & anti & $\mathbf{1 . 0 0}$ \\
CPVPD & activo & syn & $\mathbf{0 . 8 9}$
\end{tabular}

Pero para poder afirmar que existe un equilibrio entre ambas conformaciones no basta con demostrar que la diferencia de estabilidades $(\Delta \mathrm{E} \mathrm{S} / \mathrm{A})$ es despreciable. Es necesario demostrar que efectivamente la evolución desde una conformación syn a una anti (o viceversa) es energéticamente factible.

Figura 4.7 .7
Energía
asociada a la
rotación
alrededor del
diedro
OCCH.

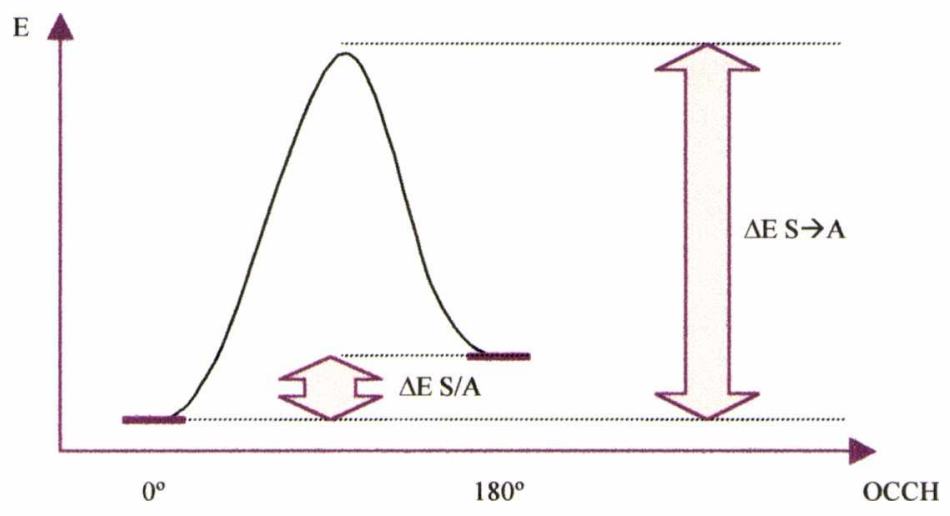

Para analizar la probabilidad de esta evolución se define el ángulo diedro $\mathrm{OCCH}$ como coordenada de reacción y se evalúa la energía asociada a su variación entre $0^{\circ}$ y $180^{\circ}$ (Figura 4.7.7). En la figura 4.7.7 $\Delta \mathrm{E} \mathrm{S} / \mathrm{A}$ representa la diferente estabilidad de los confórmeros, mientras que el $\Delta \mathrm{E}$ $S \rightarrow A$ representa el verdadero costo energético para pasar de una conformación a la otra, que generalmente es mayor que $\Delta \mathrm{E} \mathrm{S} / \mathrm{A}$.

El análisis de esta interconversión entre conformaciones involucra la cuantificación de las barreras energéticas asociadas a la rotación alrededor del enlace $\boldsymbol{C}_{2} \boldsymbol{C}_{4}$. La representación gráfica de los resultados obtenidos para cada uno de los derivados se muestra en la figura 4.7.8, en forma similar a la figura 4.7.7. 

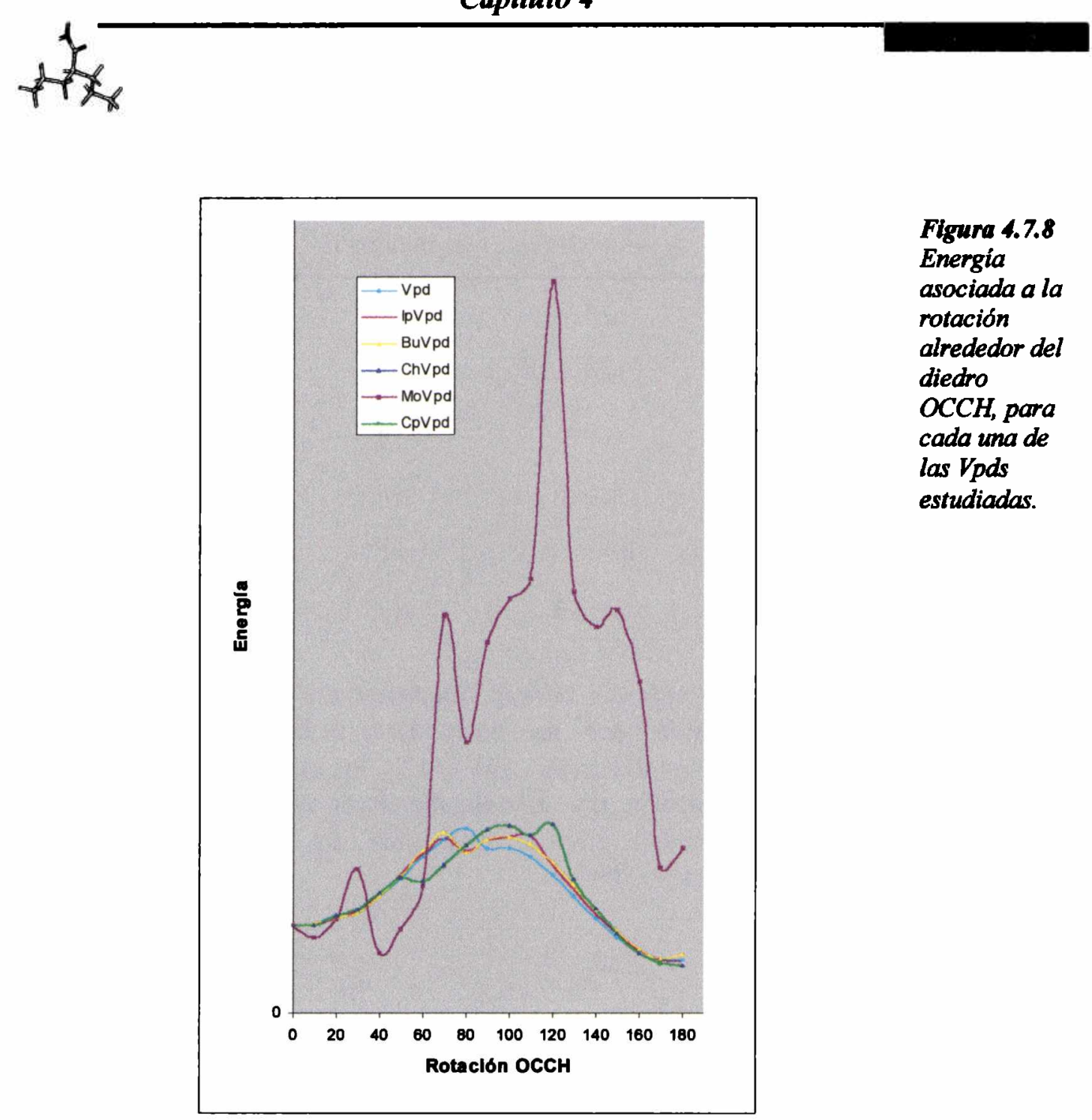

Figura 4.7.8

Energía asociada a la rotación alrededor del diedro OCCH, para cada una de las Vpds estudiadas.

Según se observa en la tabla 4.7.4, Vpd, IpVpd, BuVpd, ChVpd y CpVpd presentan $\triangle E \mathrm{~S} \rightarrow \mathrm{A}$ menores a 2,4 kcal, por lo tanto pueden rotar libremente alrededor de este enlace, mientras que MoVpd tiene una barrera mucho mayor que los demás ( $16 \mathrm{kcal} / \mathrm{mol})$, que no le permite la rotación. De manera que se puede inferir que la causa de la falta de actividad del derivado MoVpd, es la rigidez conformacional que presenta en torno al enlace $\mathrm{C}_{2} \mathrm{C}_{4}$. Todos los compuestos activos serían capaces de adoptar la conformación necesaria para interaccionar con el receptor en el sitio de acción, excepto el MoVpd, impedido de rotar y adquirir la conformación activa. 


\begin{tabular}{|c|c|c|c|c|c|}
\hline \multirow{7}{*}{$\begin{array}{l}\text { Tabla } 4.7 .4 \\
\text { Relación } \\
\text { entre la } \\
\text { actividad } \\
\text { anti } M E S y \\
\text { la } \\
\text { flexibilidad } \\
\text { entorno al } \\
\text { enlace } \\
C_{8} C_{4}\end{array}$} & Molécula & $\begin{array}{l}\text { Actividad } \\
\text { anti MES }\end{array}$ & $\begin{array}{l}\text { conformación } \\
\text { de mínima } \mathrm{E}\end{array}$ & $\begin{array}{c}\Delta \mathrm{E} \mathrm{S} / \mathrm{A} \\
{[\mathrm{kcal}]}\end{array}$ & $\begin{array}{c}\Delta \mathbf{E} S \rightarrow \mathbf{A} \\
\quad[\text { kcal] }\end{array}$ \\
\hline & VPD & activo & syn & 0.83 & 2.20 \\
\hline & IPVPD & activo & syn & 0.79 & 2.33 \\
\hline & BUVPD & activo & syn & 0.80 & 2.10 \\
\hline & CHVPD & activo & syn & 0.98 & 2.10 \\
\hline & MOVPD & inactivo & anti & 1.00 & 16.00 \\
\hline & CPVPD & activo & syn & 0.89 & 2.30 \\
\hline
\end{tabular}

\section{Inclusión de un análogo rígido.}

La flexibilidad de las moléculas activas no permite conocer la conformación en el momento de la interacción, ya que en el caso de análogos flexibles, ésta estará fuertemente determinada por las características del receptor. Por otro lado, el hecho de que la conformación antiperiplanar sea la más estable en el caso de MoVpd, no significa que ésta sea la que se genere en la síntesis del derivado. En estas condiciones, no es posible discernir si la conformación activa será preferentemente syn o anti.<smiles>CCCC(CCC)C(=O)N(C)C</smiles>

syn

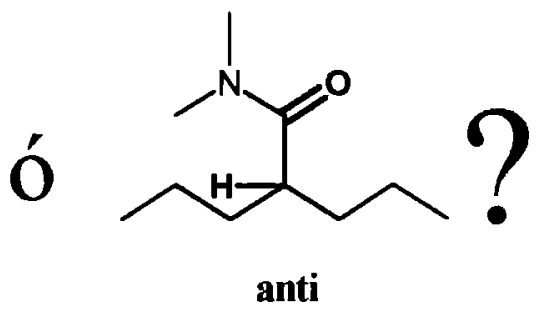

anti

A fin de conocer las características de la conformación activa, es necesario recurrir al empleo de análogos rígidos. Como se describió en la sección "Diseño Racional" del capítulo 1, los análogos rígidos son moléculas que tienen una conformación bien definida (usualmente lograda por rigidización) y una actividad biológica conocida.

Según se concluyó a partir de los resultados presentados en la sección 6 ("Resultados de la evaluación anticonvulsiva $y$ neurotóxica"), los derivados de Vpd estudiados manifiestan el mismo perfil farmacológico, siendo activas frente al ensayo MES y no frente al ensayo PTZ. Este comportamiento es típico del conocido antiepiléptico PHE, lo cual indica que posiblemente actúan mediante el mismo mecanismo de acción. Analizando la molécula de PHE, se 
observa que tiene porciones rigidizadas por ciclación. $\boldsymbol{E l}$ anillo hidantoinico restringe las posibles conformaciones a únicamente una conformación antiperiplanar del $\mathrm{O}$ con respecto al $\mathrm{N}$ (Figura 4.7.9).

Se elige entonces a la fenitoína como análogo rígido,<smiles>O=C1NC(=O)C(c2ccccc2)(c2ccccc2)N1</smiles>

anti
Figura 4.7.9

Fenitoina (PHE), análogo rígido que sólo presenta la conformación "anti".

y por comparación de las estructuras activas y no activas mediante técnicas de superposición molecular, es posible identificar las porciones estructurales comunes y los requerimientos conformacionales asociados a la actividad. Si

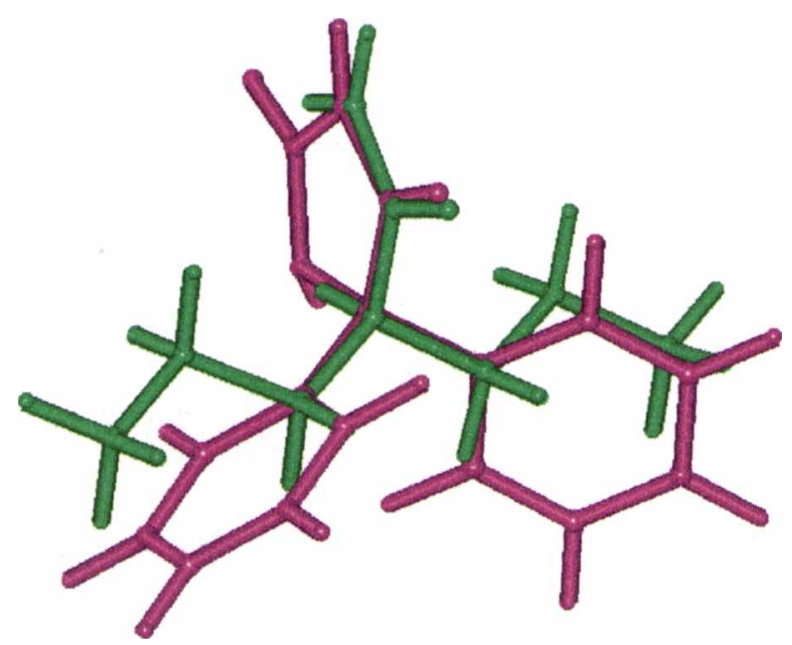

Figura 4.7.10

Superposición de PHE (en violeta) y VPD (en verde) en conformación antiperiplanar.

se superpone la PHE con la estructura de Vpd y sus derivados, se observa que la geometría de las amidas capaz de superponerse en la región del enlace amídico y del enlace $\mathrm{C}_{2} \mathrm{C}_{4}$, es la antiperiplanar $\mathrm{y}$ por lo tanto ésta define la conformación activa de esta serie de derivados (Figura 4.7.10).

De modo que cualquiera sea la conformación que resulte de la síntesis de las Vpds, éstas deberán poder rotar libremente y adquirir la conformación antiperiplanar con poco gasto energético, para lograr ser activas. El morfolin derivado, por su estructura rígida, está impedido de rotar y permanecerá en la conformación que adquiere por síntesis. 
Se podría pensar que el mecanismo de sintesis que sigue el MOVPD lo conduce a una conformación syn, que luego no puede rotar, debido al impedimento estérico. Como ya se describió en la Sección "Síntesis", en la reacción de síntesis del derivado MOVPD intervienen el haluro del VPA y la morfolina. Esta reacción, al ser una reacción de Nacilación, es factible que ocurra por un mecanismo SN1, en donde el radical acilo se aproxima al hidrógeno unido al nitrógeno de la morfolina. Esta interacción favorece más la formación del confórmero synperiplanar del MOVPD que la del antiperiplanar, debido a que en el primero es menor la repulsión estérica entre el grupo voluminoso morfolino y el $\mathrm{H}_{8}$ (Figura 4.7.3) del resto valproílo en el momento de la reacción. Por lo tanto, es muy probable que la estructura synperiplanar sea la que se genere preponderantemente. Hasta el momento, los métodos fisicoquímicos utilizados (NMR , ${ }^{13} \mathrm{C},{ }^{1} \mathrm{H}$ ) no han brindado datos experimentales que puedan avalar esta consideración.
De manera que en
base al análisis de superposición molecular de los distintos confórmeros de los derivados de Vpd con el análogo rígido $\mathrm{PHE}$, se logró inferir que la estructura de la porción amidica se asocia a conformaciones antiperiplanares capaces de superponerse. El siguiente paso se orienta a discernir si la superposición puede incluso extenderse a las cadenas alquilicas del resto valproílo.

Ampliación del conjunto de trabajo.

Con el objeto de ahondar en el conocimiento de los requisitos necesarios para la actividad de los derivados de Vpd, se incluyen en el estudio compuestos estructuralmente distintos a los ya estudiados. Así como hemos incorporado a la PHE como análogo rígido, por ser uno de los antiepilépticos más ampliamente usados y con un mecanismo de acción extensamente estudiado, resulta útil incorporar en este punto estructuras que sean drogas conocidas y que muestren el mismo perfil farmacológico que los derivados de Vpd. De esta manera, aparecen como primeros candidatos CZ, PB y PRM, por ser los más potentes antiepilépticos anti-MES ${ }^{13}$ (ver tabla 4.4.1 en la sección "Elección de los ensayos biológicos").

PHE y CZ tienen un espectro farmacológico similar, en cuanto a que son activas frente al ensayo MES pero no frente al ensayo de PTZ. PRM y PB son antiepilépticos ampliamente usados, con acción en ambos ensayos. PB es además uno de los principales metabolitos de PRM. También se incluyen en este nuevo conjunto de trabajo dos potentes hidantoínas similares a PHE, ETT y MPH, activas frente a MES y PTZ.

ETH es una droga de uso clínico pero con un espectro totalmente distinto en los ensayos de evaluación anticonvulsiva: es activa frente al ensayo de PTZ e inactiva frente al ensayo MES, aunque curiosamente posee una gran similitud estructural con varios de los compuestos 
mencionados. Por esta razón la utilizamos como análogo inactivo, ya que es útil en el momento de obtener conclusiones sobre los requerimientos mínimos para la actividad frente al ensayo MES.

El estudio se orienta en principio a ver si estas nuevas estructuras planteadas, efectivamente satisfacen los requisitos propuestos para la actividad anti-MES, en relación a los requerimientos de la porción amida. Una simple inspección muestra que todas ellas poseen al menos un grupo amida que puede correlacionarse estructuralmente con el que presentan los derivados de Vpd (átomos 1, 2 y 3 en la figura 4.7.3).

Por otro lado, el análisis conformacional de las estructuras que poseen un ciclo que rigidiza la porción carboxamida (PHE, PB, PRM, ETT, MPH, ETH), revela varias estructuras estables compatibles con esta restricción y diferenciables por los ángulos definidos por los otros sustituyentes que gozan de gran flexibilidad al poder rotar en torno a enlaces simples. La imposibilidad de rotación del grupo amida se ve reflejada en el estrecho rango de valores que $\tau_{1}{ }^{*}$ puede tomar $\left(\Delta \tau_{1}\right.$, tabla 4.7.5).

En la tabla 4.7.5 y en la figura 4.7.11 se presentan las conformaciones de mínima energía para cada una de las estructuras.

\begin{tabular}{|c|c|c|c|c|c|}
\hline Molécula & $\begin{array}{l}\text { Actividad } \\
\text { anti MES }\end{array}$ & $\Delta \tau_{1}$ & $\tau_{1}^{*}$ & $\begin{array}{l}\Delta \mathrm{E} \tau_{1} \\
{[\mathrm{kcal}]}\end{array}$ & $\begin{array}{l}\text { Tabla } 4.7 .5 \\
\text { Caracteristicas }\end{array}$ \\
\hline PHE & activo & $-57^{\circ} /-69^{\circ}$ & $-64^{\circ}$ & 0.00 & $\begin{array}{l}\text { geometrías de mínima } \\
\text { energía en la porción del }\end{array}$ \\
\hline $\mathrm{CZ}$ & activo & $-70^{\circ} / 173^{\circ}$ & $-1^{\circ}$ & 2.68 & $\begin{array}{l}\text { grupo amida. Se detalla el } \\
\text { rango de valores que toma }\end{array}$ \\
\hline PB & activo & $-45^{\circ} /-87^{\circ}$ & $-79^{\circ}$ & 0.35 & $\begin{array}{l}\text { el ángulo diedro } \tau_{1} \text { luego de } \\
\text { las optimizaciones }\left(\Delta \tau_{1}\right) \text {. }\end{array}$ \\
\hline PRM & activo & $-53^{\circ} /-94^{\circ}$ & $-88^{\circ}$ & 1.30 & $\begin{array}{l}\text { asi como también el valor } \\
\text { en el minimo absoluto }\end{array}$ \\
\hline ETT & activo & $-60^{\circ} /-65^{\circ}$ & $-64^{\circ}$ & 0.00 & $\left(\tau_{1}^{*}\right)$ \\
\hline MPH & activo & $-57^{\circ} /-69^{\circ}$ & $-67^{\circ}$ & 0.01 & \\
\hline ETH & inactivo & $-57^{\circ} /-64^{\circ}$ & $-59^{\circ}$ & 0.04 & \\
\hline
\end{tabular}

- $\tau_{1}$ está definido por los átomos 1-2-4-5 para todas las estructuras, como se detalla en la figura 4.7.3. 


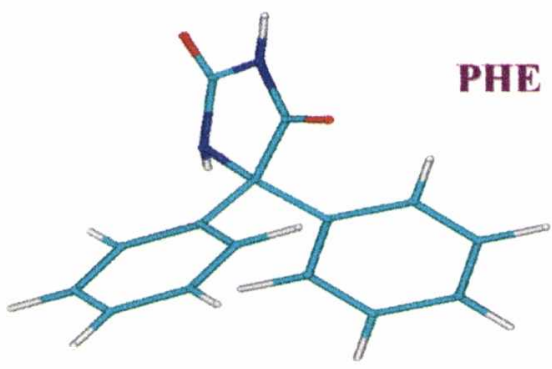

Figura 4.7.11

Conformaciones más

estables de las drogas

incluidas en el estudio.
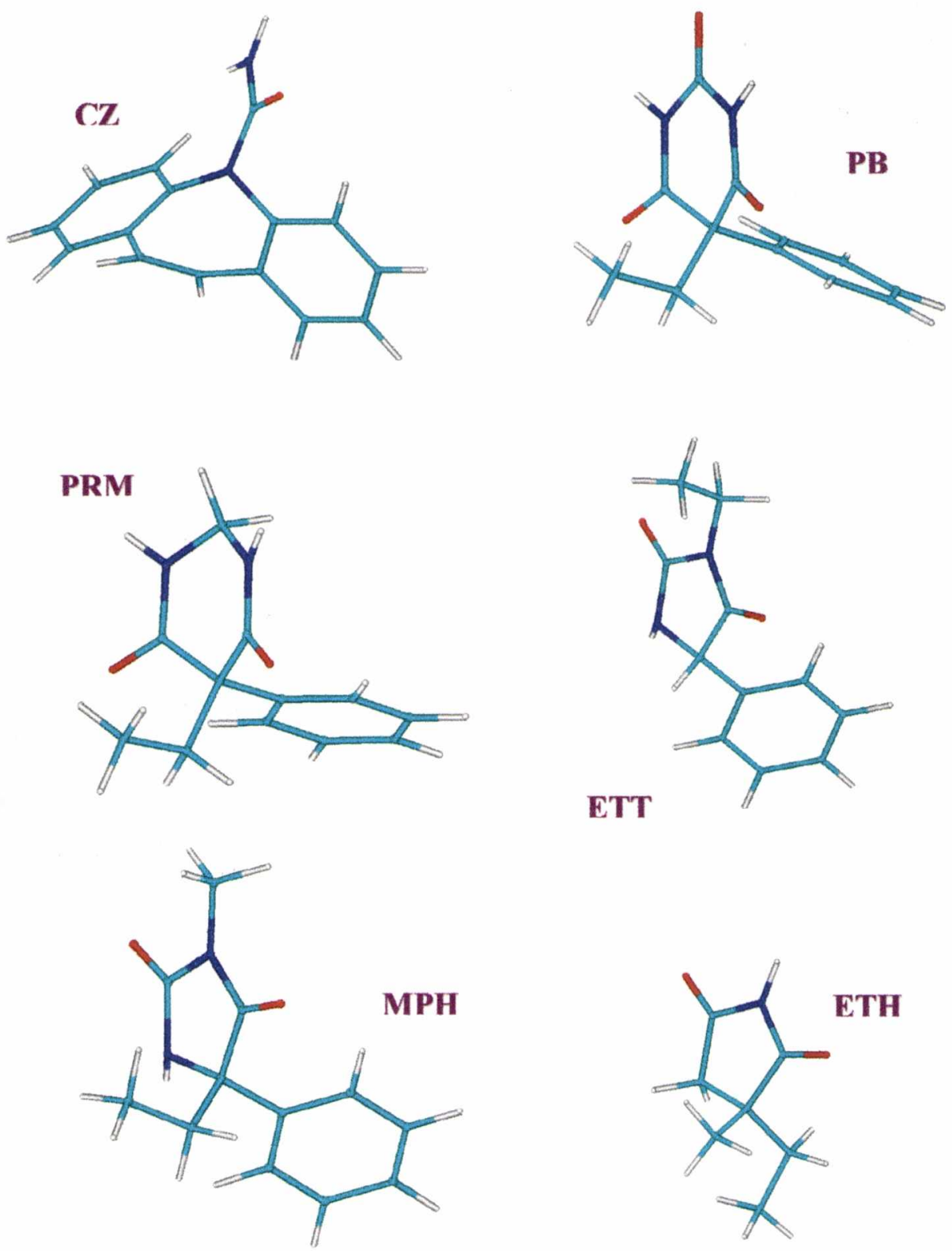
PHE fue tomado como análogo rígido en la comparación con las Vpds flexibles, y en este nuevo grupo son varias las estructuras que podrían cumplir el rol de análogo rígido. Aunque en estas estructuras $\tau_{1}$ varía siempre dentro de un estrecho rango de valores, tomamos el valor que adquiere en el mínimo absoluto de PHE $\left(\tau_{1}=-64^{\circ}\right)$ para definir las características de esta porción en la conformación activa. La factibilidad de adoptar la conformación activa se evalúa, para cada uno de los compuestos, mediante el cálculo del costo energético necesario para su conversión a partir de la conformación más estable. Este cálculo para la rotación de $\tau_{1}$ desde el valor en el mínimo absoluto $\left(\tau_{1}{ }^{*}\right)$ hasta el valor de la conformación activa se muestra en la tabla 4.7.5 ( $\left(\Delta \mathrm{E} \tau_{1}\right)$ para cada uno de los compuestos.

Todos los derivados son capaces de adoptar la conformación activa definida por el conjunto de los derivados de Vpd y PHE. Para una mejor comprensión, la orientación del grupo amida se define ahora con respecto a una de las cadenas hidrocarbonadas, como $\tau_{1}=\mathrm{O}_{1} \mathrm{C}_{2} \mathrm{C}_{4} \mathrm{C}_{5}=-64^{\circ}$ (Figura 4.7.3). Este diedro es equivalente a la orientación antiperiplanar del $\mathrm{O}$ con respecto al $\mathrm{H}$ para el conjunto de las valpramidas $\left(\mathrm{O}_{1} \mathrm{C}_{2} \mathrm{C}_{4} \mathrm{H}_{8}=-180^{\circ}\right)$. Los compuestos rigidizados en la porción amida tienen forzada esta conformación mientras que $\mathrm{CZ}$ puede rotar libremente en torno al enlace $\mathrm{C}_{2} \mathrm{C}_{4}$ (Figura 4.7.3) adquiriendo muchas conformaciones estables que difieren en ese giro $\left(\Delta \tau_{1}\right)$, y pudiendo adoptar fácilmente la conformación activa definida por las demás estructuras ( $\Delta \mathrm{E} \tau_{1}=2.68 \mathrm{kcal}$, tabla 4.7.5).

Con la idea de encontrar los requisitos asociados a los sustituyentes en posición 4, el estudio se centra en el resto de las estructuras. Dos grupos propilo en el caso de las Vpds contrastan en principio con los restos aromáticos característicos de las estructuras antiepilépticas clásicas, aunque también aparecen porciones alifáticas en algunas drogas tales como PB, PRM y MPH. De la comparación con el análogo inactivo ETH surge que evidentemente es necesario un aporte hidrofóbico considerable, ya sea de origen alifático o aromático, en posición 4. La diferencia principal entre la estructura inactiva ETH y el resto de las drogas es su carencia de restos lipofilicos. Por otro lado, la estructura de la ETT pone en evidencia que es necesaria la existencia de sólo uno de los sustituyentes hidrocarbonados para la actividad.

Así, el análisis de semejanza descrito, fundamentado en la superposición de estructuras activas y no activas, conduce a la identificación de los requisitos estructurales y conformacionales para la actividad, en cuanto a que es 
necesaria la presencia de un grupo amida orientado en conformación anticlinal (ángulo diedro de $-60^{\circ}$ ) en relación $a$ un resto hidrocarbonado de al menos 3 átomos de $C$. La consideración de ETH en la comparación, la cual, siendo no activa satisface los requisitos conformacionales en la porción carboxamida, evidencia la necesidad de un sustituyente voluminoso en posición 4.

En relación a la disposición en el espacio de los sustituyentes en el $\mathrm{C}_{4}, C Z$ impone un requerimiento conformacional en relación a la rotación de los fenilos. Al estar rigidizados por ciclación, los anillos bencénicos solamente pueden adoptar ciertas posiciones, a diferencia del resto de las estructuras, en las que tanto los restos alifáticos como también los fenilos poseen gran flexibilidad alrededor de los enlaces simples.

$\mathrm{El}$ análisis conformacional revela para $\mathrm{CZ}$ conformaciones estables vinculadas a hibridaciones próximas a sp2 ó sp3 del Na. Siendo sus energías comparables $(2,7$ $\mathrm{kcal}$ ), la conformación en la que el $\mathrm{N}$ posee mayor carácter

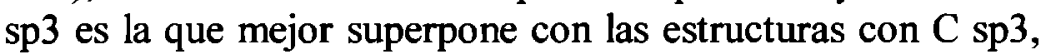
por lo tanto, consideramos esta conformación como definitoria de las características de la conformación activa en la porción hidrocarbonada.

Si consideramos la rotación alrededor del enlace $\mathrm{C}_{4} \mathrm{C}_{5}$, definida como la variación del diedro $\tau_{2}{ }^{*}$, se observa en la tabla 4.7.6 que esta variación está limitada a solamente unos pocos valores permitidos en el caso de $\mathrm{CZ}\left(\Delta \tau_{2}\right)$, no ocurriendo lo mismo para el resto de los derivados.

Tabla 4.7 .6

Características conformacionales de las geometrias de minima energia en la porción del grupo amida. Se detalla el rango de valores que toma el ángulo diedro $\tau_{2}$ luego de las optimizaciones $\left(\Delta \tau_{2}\right)$, asi como también el valor en el minimo absoluto $\left(\tau_{2}^{*}\right)$.

\begin{tabular}{cccc} 
Molécula & $\Delta \tau_{2}$ & $\tau_{2}{ }^{*}$ & $\begin{array}{c}\Delta E \tau_{2} \\
{[\mathrm{kcal}]}\end{array}$ \\
\hline PHE & $-1^{\circ} /-167^{\circ}$ & $-1^{\circ}$ & 0.43 \\
$\mathbf{C Z}$ & $-\mathbf{1 5 1}^{\circ} /-\mathbf{1 5 2}^{\circ}$ & $-\mathbf{1 5 2}^{\circ}$ & $\mathbf{0 . 0 0}$ \\
PB & $-1^{\circ} /-179^{\circ}$ & $-128^{\circ}$ & 0.94 \\
PRM & $-42^{\circ} /-172^{\circ}$ & $-162^{\circ}$ & 0.39 \\
ETT & $-1^{\circ} /-179^{\circ}$ & $-2^{\circ}$ & 0.47 \\
MPH & $-63^{\circ} / 129^{\circ}$ & $-168^{\circ}$ & 0.36 \\
ETH & $-53^{\circ} / 178^{\circ}$ & $178^{\circ}$ & 1.74
\end{tabular}

\footnotetext{
+ $\tau_{2}$ está definido por los átomos 2-4-5-6 para todas las estructuras, como se detalla en la figura 4.7.3. Debe destacarse que el ángulo diedro $\tau_{2}$ puede definirse de dos formas equivalentes, ya que pueden considerarse cualquiera de los dos carbonos adyacentes al C5. Se considera de aquí en más el C6 en la definición de este diedro, de donde surge el valor $\tau_{2}=-$ $152^{\circ}$, pero o por ello hay que descartar la otra posibilidad $\left(\tau_{2}=28^{\circ}\right)$.
} 
La rotación alrededor del enlace entre el $\mathrm{C}_{5}$ y uno de los carbonos sucesivos $\left(\mathrm{C}_{6}\right)$, definido por el ángulo diedro $\tau_{3}{ }^{*}$, está también restringida por formación de ciclos no solamente en $\mathrm{CZ}$, sino también en las demás estructuras de los antiepilépticos clásicos anti-MES (Tabla 4.7.7).

\begin{tabular}{ccc} 
Molécula & $\Delta \tau_{3}$ & $\tau_{3}{ }^{*}$ \\
\hline PHE & $-179^{\circ} / 179^{\circ}$ & $179^{\circ}$ \\
CZ & $177^{\circ} / 178^{\circ}$ & $178^{\circ}$ \\
PB & $-177^{\circ} / 178^{\circ}$ & $180^{\circ}$ \\
PRM & $-178^{\circ} / 179^{\circ}$ & $-178^{\circ}$ \\
ETT & $-178^{\circ} / 179^{\circ}$ & $180^{\circ}$ \\
MPH & $-178^{\circ} / 178^{\circ}$ & $-179^{\circ}$
\end{tabular}

Tabla 4.7.7

Caracteristicas conformacionales de

las geometrias de minima energia en

la porción del grupo amida. Se detalla el rango de valores que toma el ángulo diedro $\tau_{3}$ luego de las optimizaciones $\left(\Delta \tau_{3}\right)$, así como también el valor en el minimo absoluto $\left(\tau_{3} *\right.$.

En la tabla 4.7.8 se reportan, para cada una de las estructuras estudiadas, los costos energéticos calculados $(\Delta \mathrm{E})$ necesarios para alcanzar la conformación activa definida por los análogos rígidos.

\begin{tabular}{cccccccc} 
Molécula & $\begin{array}{c}\text { Actividad } \\
\text { anti MES }\end{array}$ & $\tau_{1}^{*}$ & $\begin{array}{c}\Delta \mathrm{E} \tau_{1} \\
{[\mathrm{kcal}]}\end{array}$ & $\tau_{2}{ }^{*}$ & $\begin{array}{c}\Delta \mathrm{E} \tau_{2} \\
{[\mathrm{kcal}]}\end{array}$ & $\tau_{3}^{*}$ & $\begin{array}{c}\Delta \mathbf{E} \\
{[\mathrm{kcal}]}\end{array}$ \\
\hline VPD & activo & $118^{\circ}$ & 2.20 & $-61^{\circ}$ & 1.03 & $178^{\circ}$ & $\mathbf{3 . 2 3}$ \\
IPVPD & activo & $117^{\circ}$ & 2.33 & $-61^{\circ}$ & 0.97 & $178^{\circ}$ & $\mathbf{3 . 3 0}$ \\
BUVPD & activo & $120^{\circ}$ & 2.10 & $-59^{\circ}$ & 1.02 & $180^{\circ}$ & $\mathbf{3 . 1 2}$ \\
CHVPD & activo & $125^{\circ}$ & 2.10 & $-63^{\circ}$ & 1.03 & $-179^{\circ}$ & $\mathbf{3 . 1 3}$ \\
MOVPD & inactivo & $104^{\circ}$ & 16.00 & $-72^{\circ}$ & 1.05 & $-178^{\circ}$ & $\mathbf{1 7 . 0 5}$ \\
CPVPD & activo & $118^{\circ}$ & 2.30 & $-60^{\circ}$ & 1.06 & $179^{\circ}$ & $\mathbf{3 . 3 6}$ \\
PHE & activo & $-64^{\circ}$ & 0.00 & $-1^{\circ}$ & 0.43 & $179^{\circ}$ & $\mathbf{0 . 4 3}$ \\
CZ & activo & $-1^{\circ}$ & 2.68 & $-152^{\circ}$ & 0.00 & $178^{\circ}$ & $\mathbf{2 . 6 8}$ \\
PB & activo & $-79^{\circ}$ & 0.35 & $-128^{\circ}$ & 0.94 & $180^{\circ}$ & $\mathbf{1 . 2 9}$ \\
PRM & activo & $-88^{\circ}$ & 1.30 & $-162^{\circ}$ & 0.39 & $-178^{\circ}$ & $\mathbf{1 . 6 9}$ \\
ETT & activo & $-64^{\circ}$ & 0.00 & $-2^{\circ}$ & 0.47 & $180^{\circ}$ & $\mathbf{1 . 4 7}$ \\
MPH & activo & $-67^{\circ}$ & 0.01 & $-168^{\circ}$ & 0.36 & $-179^{\circ}$ & $\mathbf{0 . 3 7}$ \\
ETH & inactivo & $-59^{\circ}$ & 0.04 & $178^{\circ}$ & 1.74 & --- & $\mathbf{1 . 7 8}$
\end{tabular}

- $\tau_{3}$ está definido por los átomos 4-5-6-7 para todas las estructuras, como se detalla en la figura 4.7.3. 
Tabla 4.7.8 (página anterior)

Actividad anticonvulsiva y caracteristicas conformacionales de cada una de las estructuras incluidas en la determinación del farmacóforo para la acción anti-MES.

$\Delta E i$ representa la energía parcial que corresponde a la evolución de $\tau_{1}$ desde el valor en el minimo absoluto $\left(\tau^{*}\right)$ hasta el valor en el análogo rígido $\left(\tau_{1}=-64^{\circ}, \tau_{2}=-152^{\circ}, \tau_{3}=\right.$ $180^{\circ}$ ). $\triangle E$ representa la suma $\triangle E 1+\Delta E 2$. $\tau_{3}$ se mantiene constante para todos los derivados en valores cercanos a $180^{\circ}$, aún en aquéllos que no están rigidizados en esa porción, por lo cual no fue necesario el cálculo de las barteras para la rotación de este diedro.

Tabla 4.7 .9

Densidades locales de carga sobre los átomos del grupo amida
Se incluyen en la tabla 4.7.8 tanto las drogas clásicas como las Vpds, para una mejor apreciación comparativa de las características conformacionales de todo el conjunto de estructuras anti-MES, MoVpd y ETH.

Los valores de $\Delta \mathrm{E}$ calculados evidencian que, exceptuando el derivado $\mathrm{MoVpd}$, el costo energético requerido para alcanzar las conformaciones necesarias para la interacción con el receptor es bajo, y por lo tanto todos los derivados pueden adoptar fácilmente la conformación activa.

\section{Densidades de carga.}

Las densidades locales de carga se analizan con el objeto de ver si existe un patrón común de distribuciones de carga a lo largo de toda la serie. En la tabla 4.7 .9 se reportan las cargas obtenidas a partir de potenciales electrostáticos para las conformaciones activas de cada una de las estructuras. 
Su análisis revela que la distribución de carga en torno al grupo amida se mantiene constante en todos los derivados, definiendo densidades de carga positivas sobre el $\mathrm{C}$ carbonilico y negativas sobre el $\mathrm{O}$ y el $\mathrm{N}$.

\title{
Definición del farmacóforo para la acción anti-MES.
}

El procedimiento empleado, basado en un análisis de semejanza que considera PHE y $\mathrm{CZ}$ como análogos rígidos, nos ha permitido definir un grupo farmacóforo para la actividad anti-MES. asociado a:

El farmacóforo propuesto (Figura 4.7.12) está

$\checkmark$ un grupo amida, caracterizado por dos centros atómicos negativamente cargados unidos a un centro de densidad positiva, y

$\checkmark$ un resto hidrocarbonado de al menos 3 átomos de $\mathrm{C}$ (ver recuadro gris, en página siguiente). La disposición relativa de los átomos involucrados está definida por:

$\checkmark$ un valor de $\tau_{1}$ cercano a $-64^{0}$,

$\checkmark$ un valor de $\tau_{2}$ de aproximadamente $-152^{\circ}, \mathrm{y}$

$\checkmark$ un valor de $\tau_{3}$ próximo a $180^{\circ}$.

\author{
Figura 4.7.12 \\ Esquema del \\ farmacóforo \\ propuesto para la \\ actividad anti-MES
}

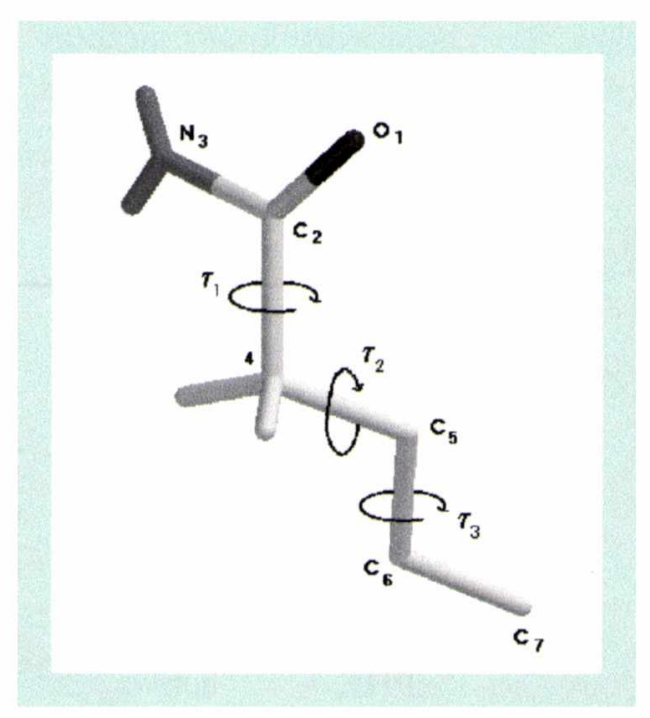

Teniendo en cuenta que lo que percibe el receptor son distribuciones de carga que a él se aproximan, la constancia de esta distribución en la porción amida puede indicar que ésta es la porción relevante para el anclaje inicial drogareceptor, siendo los otros requisitos necesarios para un 
eficiente acople, o vinculados, como en el caso de la longitud de la cadena, a requerimientos lipofilicos.

Debe destacarse que el resto hidrocarbonado debe contar con al menos 3 carbonos, ya que longitudes de cadena menores anulan la actividad $y$, como se detalló en la sección 2 (página 74), la presencia de dos restos propilo en posición 4 hacen del Vpa la estructura óptima para la manifestación de actividad. Por lo tanto, hay que resaltar que posiblemente sea necesaria la presencia, en posición 4 , de un aporte hidrofóbico suficiente como requisito para la aparición de acción anticonvulsiva.
Debe resaltarse, como conclusión, que los requerimientos conformacionales inicialmente planteados para un grupo de estructuras limitado a las valpramidas $\mathrm{N}$ sustituidas, estaban asociados principalmente a una orientación anticlinal de la función amida relativa a las cadenas hidrocarbonadas. La consideración de un conjunto más amplio de derivados que incluye antiepilépticos clásicos de amplio uso en clínica, permite precisar la definición del patrón farmacofórico de derivados antiMES, que no se contrapone a la definición anterior, sino que la contiene y, por tanto, la valida.

\footnotetext{
${ }^{1}$ Bruno-Blanch, L.E. Comunicación personal

${ }^{2}$ Bruno-Blanch, L.E.; Estiú, G.L. Int. J. Quantum Chem. (1995) 22: 39 49

${ }^{3}$ Elmazar, M.M.A.; Hauck, R.S.; Nau, H. Journal of Pharmaceutical Sciences (1993) 82(12): 1255-8

${ }^{4}$ Hyperchem 5.1 for Windows. Hypercube Inc., Gainesville FL (1997)

${ }^{5}$ PC Spartan Plus Version 1.4. Wavefunction Inc., Irvine CA (1997)

${ }^{6}$ AMSOL-version 3.0.1 (basado en AMPAC-version 2.1)

${ }^{7}$ Gaussian 98, Revision A.9, M. J. Frisch, G. W. Trucks, H. B. Schlegel, G. E. Scuseria, M. A. Robb, J. R. Cheeseman, V. G. Zakrzewski, J. A. Montgomery, Jr., R. E. Stratmann, J. C. Burant, S. Dapprich, J. M.
} Millam, A. D. Daniels, K. N. Kudin, M. C. Strain, O. Farkas, J. Tomasi, V. Barone, M. Cossi, R. Cammi, B. Mennucci, C. Pomelli, C. Adamo, S. Clifford, J. Ochterski, G. A. Petersson, P. Y. Ayala, Q. Cui, K.

Morokuma, D. K. Malick, A. D. Rabuck, K. Raghavachari, J. B.

Foresman, J. Cioslowski, J. V. Ortiz, A. G. Baboul, B. B. Stefanov, G.

Liu, A. Liashenko, P. Piskorz, I. Komaromi, R. Gomperts, R. L. Martin, D. J. Fox, T. Keith, M. A. Al-Laham, C. Y. Peng, A. Nanayakkara, M. Challacombe, P. M. W. Gill, B. Johnson, W. Chen, M. W. Wong, J. L. Andres, C. Gonzalez, M. Head-Gordon, E. S. Replogle, and J. A. Pople, Gaussian Inc., Pittsburgh PA (1998)

${ }^{8}$ Sybil. Tripos Inc., San Diego, CA.

${ }^{9}$ Chang, Y.T.; Loew, G.H.; Rettie, A.E.; Baillie, T.A.; Otiz de Montellano, P.R. Int. J. Quantum Chem., Quantum Biology Symp.(1993) 20: 161

${ }^{10}$ Chapter 5: Geometry Optimizations and Transition State Searching En:

Hyperchem, Computational Chemistry, Hypercube Inc., Canadá (1996)

pp. 57-68

${ }^{11}$ Estiú, G.L. J. Mol. Structure (Theochem) (1997) 401: 157-64

${ }^{12}$ Breneman, C.N.; Wiberg, K.B. J. Comp. Chem. (1990) 11: $361-9$

${ }^{13}$ Loscher, W.; Schmidt, D. Epilepsy Research (1994) 17: 95-134 


\section{DISEÑO DE NUEVOS DERIVADOS EN BASE AL FARMACÓFORO PROPUESTO}

Gracias a la identificación del patrón farmacofórico para la actividad anti-MES, es posible postular nuevas estructuras potencialmente activas.

Los nuevos compuestos diseñados a partir de este conocimiento deben cumplir los requisitos estructurales, electrónicos y conformacionales descriptos. Se deben proponer, por lo tanto, estructuras que posean un grupo amida o bien otro grupo similar en cuanto a sus características electrónicas, es decir, que posea un centro positivo unido a dos centros de densidad negativa, como por ej. un grupo carboxilico. Este planteo no significa que no sea necesario el estudio teórico para corroborar el cumplimiento de los requisitos electrónicos, previamente a la continuación de las etapas del diseño (síntesis y evaluación biológica). Se debe considerar también, mediante el análisis conformacional, que los compuestos sean capaces de adoptar, sin un costo energético excesivo, la conformación activa antiperiplanar exigida por el farmacóforo.

Con el objeto de continuar indagando en los resultados derivados de los cambios en la porción amídica polar, se decide mantener constante la porción restante de la molécula, es decir las cadenas propílicas. El hecho de que esta porción hidrocarbonada es, como ya se comentó (en la sección 2, "Estado de la investigación en el tema"), la óptima para obtener el mejor margen entre actividad y efectos colaterales, apoya esta decisión.

Si bien los requerimientos del farmacóforo planteado se refieren tanto a factores estructurales, conformacionales y electrónicos, no hay que olvidar el hecho de que del conjunto de compuestos analizados surge un patrón común, pero que las características de estos factores no son de ninguna manera excluyentes. Es decir, el haber encontrado características comunes a todos los compuestos, como la presencia de un grupo amida, no indica necesariamente que éste sea un requisito indispensable para la actividad. En tal sentido, se consideró oportuno indagar en la posibilidad de un

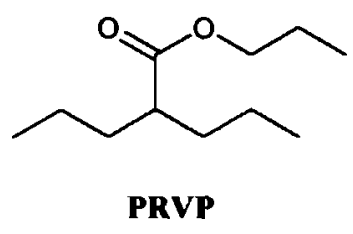

PRVP cambio en el grupo amida, planteándose el diseño de un derivado estérico del Vpa. Así, surge el planteo del éster propílico (propilvalproato, $\operatorname{PrVp}$ ). 
Habiéndose ya reportado el comportamiento de varios ésteres del $\mathrm{Vpa}$, en donde el éster propílico figura como el único que presentaba alguna actividad $^{1,2}$, decidimos corroborar si realmente los ésteres son más débiles anticonvulsivos que el Vpa.

Otra característica común a todos los compuestos activos es la presencia de un $\mathrm{H}$ libre unido al $\mathrm{N}$, capaz de establecer un puente $\mathrm{H}$ en la interacción con el receptor. Anteriormente, como se ha visto en la sección 2, "Estado de la investigación en el tema", se habían planteado los derivados 75 y 76, doblemente sustituidos en el $\mathrm{N}$, combinando $\mathrm{Vpa}$ con nipecotamida y ácido nipecótico respectivamente. Estos compuestos que carecen de este $\mathrm{H}$ al igual que $\mathrm{MoVpd}$, también resultaron inactivos, aunque los autores atribuyen este hecho a su comportamiento farmacocinético ${ }^{3}$. Con el objeto de averiguar si la falta de este $\mathrm{H}$ aceptor de electrones es un factor causante de la falta de actividad, como ocurre con MoVpd y los derivados del ácido nipecótico, se planteó otro derivado doblemente sustituido en el N: la $\mathbf{N}, \boldsymbol{N}$-dimetilvalpramida (DmVpd). Simultáneamente surge el planteo de su isómero monosustituido en el N: la $N$ etilvalpramida (EtVpd). Otro punto importante que se debe considerar es la hidrofobicidad de los derivados a sintetizar,<smiles>CCCC(CCC)C(=O)N(C)C</smiles>

DMVPD<smiles>CCCC(CCC)C(=O)NCC</smiles>

ETVPD siendo necesaria una hidrofobicidad tal que permita la solubilización de los compuestos. En el caso de los derivados de Vpd estudiados, como ya se ha explicado en la sección 6 del presente capítulo, no fue posible continuar con la evaluación biológica de la neurotoxicidad debido a problemas de solubilidad en la preparación de la solución a inyectar. Pero además, hay que tener en cuenta que la lipofilia debe ser lo suficientemente<smiles>NS(=O)(=O)Cc1cc2ccccc2o1</smiles>

zonisamida<smiles>CC1(C)OC2COC3(COS(N)(=O)=O)OC(C)(C)OC3C2O1</smiles>

topiramato<smiles>CCCC(CCC)C(=O)Nc1ccc(S(N)(=O)=O)cc1</smiles>

SUVPD

elevada como para permitir el pasaje a través de la BHE, ya que se trata de drogas que deben actuar a nivel del SNC. Por tal 
razón es que nos hemos inclinado por plantear derivados con cadenas laterales cortas, como EtVpd y DmVpd, con hidrofobicidad menor que la de los derivados con cadenas propilica (IpVpd), butilica (BuVpd) y ciclohexilica ( $\mathrm{ChVpd}$ ) descriptos en la primera etapa de este trabajo.

Por otro lado, la relativamente pobre actividad encontrada para el derivado $\mathrm{CpVpd}$ nos llevó a proponer cambios en su estructura para ver si se logra mejorar su actividad. El surgimiento reciente de los nuevos antiepilépticos con grupos sulfonamida $\left(-\mathrm{SO}_{2} \mathrm{NH}_{2}\right)$ topiramato y zonisamida nos incitó a plantear el derivado 4(valproilamido)bencensulfonamida (SuVpd), en donde reemplazamos el PABA, presente en el $\mathrm{CpVpd}$, por su análogo estructural sulfanilamida. La sulfanilamida impide la incorporación del PABA durante la biosíntesis del ácido fólico por inhibición competitiva con él, y se utiliza como agente antibacteriano.

\footnotetext{
' Hadad, S.; Vree, T.B.; van der Kleijn, E.; Bialer, M. Journal of Pharmaceutical Sciences (1992) 81(10): 1047-50

${ }^{2}$ Bialer, M.; Haj-Yehia, A.; Badir, K.; Hadad, S. Pharmacy World \& Science (1994) 16(1): 2-6

${ }^{3}$ Bialer, M.; Kadry, B.; Abdul-Hai, A.; Haj-Yehia, A.; Sterling, J.;

Herzig, Y.; Shirvan, M. Biopharmaceutics \& Drug Disposition (1996) 17:

$565-75$
} 


\section{ESTUDIO TEÓRICO, SÍNTESIS, Y EVALUACIÓN BIOLÓGICA DE LOS NUEVOS DERIVADOS}

\section{Estudio teórico}

Se discute, en el presente item, el modelado de los nuevos compuestos diseñados. En base al resultado de este estudio, se decide continuar con la síntesis y evaluación farmacológica de las estructuras.

Se emplea para este estudio la misma metodología utilizada en el caso de los compuestos anti-MES, descripta en la sección 7 del presente capítulo.

La exploración del espacio conformacional realizada para cada uno de los nuevos derivados de Vpa, reveló varios mínimos energéticamente similares. $\mathrm{Al}$ igual que con los derivados de Vpd, en todos los casos se obtiene el mismo patrón de comportamiento anti o syn en cuanto a la disposición del $\mathrm{O}$ carbonilico con respecto al $\mathrm{H}$ del $\mathrm{C} \alpha$.

En la tabla 4.9.1 se presentan los valores de $\tau_{1}, \tau_{2}$ y $\tau_{3}$ (ver figura 4.7.3) correspondientes a las conformaciones más estables de cada uno de los derivados.

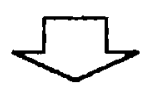

\begin{tabular}{lccccccc} 
Molécula & $\begin{array}{c}\text { conformación } \\
\text { de mínima E }\end{array}$ & $\tau_{1}{ }^{*}$ & $\begin{array}{c}\Delta \mathrm{E} \tau_{1} \\
{[\mathrm{kcal}]}\end{array}$ & $\tau_{2}{ }^{*}$ & $\begin{array}{c}\Delta \mathrm{E} \tau_{2} \\
{[\mathrm{kcal}]}\end{array}$ & $\tau_{3}{ }^{*}$ & $\begin{array}{c}\Delta \mathbf{E} \\
{[\mathrm{kcal}]}\end{array}$ \\
\hline DMVPD & anti & -55 & 0.01 & -73 & 1.06 & -177 & $\mathbf{1 . 0 7}$ \\
ETVPD & syn & 118 & 0.65 & -75 & 1.03 & -177 & $\mathbf{1 . 6 8}$ \\
SUVPD & syn & 120 & 3.15 & -66 & 1.06 & -178 & $\mathbf{4 . 2 1}$ \\
PRVP & anti & -60 & 0.01 & -62 & 1.02 & -177 & $\mathbf{1 . 0 3}$
\end{tabular}

Tabla 4.9.1 Caracteristicas conformacionales de las geometrías más estables y costos energéticos para alcanzar la conformación activa. $\triangle E$ i representa la energía parcial que corresponde a la evolución de $\tau_{t}$ desde el valor en el minimo absoluto $\left(\tau_{t}^{*}\right)$ hasta el valor correspondiente a la conformación activa definida por el farmacóforo. $\Delta E$ representa la suma $\triangle E 1+\Delta E 2 . \tau_{3}$ se mantiene para todos los derivados en valores cercanos a $180^{\circ}$, por lo cual no fue necesario el cálculo de las barreras para la rotación de este diedro.

Como puede observarse en la tabla 4.9.1, todos los derivados muestran valores de $\Delta \mathrm{E}$ bajos y por lo tanto 
podrán adoptar fácilmente la conformación definida por el farmacóforo.

El análisis de las densidades locales de carga sobre los átomos involucrados en el grupo farmacóforo (tabla 4.9.2) reveló también que la distribución de carga en torno al grupo amida se mantiene constante en todos los derivados, definiendo densidades de carga positivas sobre el C carbonilico y negativas sobre los átomos 1 y 3 .

\begin{tabular}{|c|c|c|c|c|}
\hline Molécula & $q_{1}$ & $q_{2}$ & $q_{3}$ & \multirow{4}{*}{$\begin{array}{l}\text { Tabla 4.9.2 } \\
\text { Densidades de } \\
\text { carga obtenidas } \\
\text { a partir de } \\
\text { potenciales } \\
\text { electrostáticos }\end{array}$} \\
\hline DMVPD & -0.59 & +0.80 & -0.77 & \\
\hline ETVPD & -0.60 & +0.76 & -0.88 & \\
\hline SUVPD & -0.53 & +0.80 & -0.75 & \\
\hline PRVP & -0.53 & +0.75 & -0.60 & \\
\hline
\end{tabular}

Así, en base a los cálculos realizados, los nuevos derivados constituyen drogas potencialmente activas. Se procede así a su síntesis y posterior evaluación farmacológica.

\section{Síntesis}

Los procedimientos ya descriptos en la sección 3 del presente capítulo para la síntesis de los derivados de Vpd, se aplican para la síntesis de los tres nuevos derivados de Vpd: DmVpd, EtVpd y SuVpd.

En la preparación del derivado éster PrVp se recurrió al uso de una técnica clásica de preparación de ésteres. Se hizo reaccionar el Vpa con n-propanol usando ácido sulfúrico como catalizador, y benceno como solvente. El agua generada se retuvo en una trampa Dean-Stark. Se purificó por destilación a presión reducida $65-66^{\circ} \mathrm{C} / 1 \mathrm{mmHg}$. Se identificó por NMR ${ }^{1} \mathrm{H},{ }^{13} \mathrm{C}$ y análisis elemental. Detalles adicionales de la síntesis, aislamiento, caracterización e identificación figuran en la referencia ${ }^{3}$. 


\section{Resultados de la evaluación de la actividad anticonvulsiva v neurotóxica}

En este ítem se presentan los resultados de los ensayos farmacológicos a los que fueron sometidos los nuevos derivados DmVpd, EtVpd, SuVpd y PrVp. Los datos se presentan en forma similar a la sección 6 del presente capítulo, y se siguen como en aquel caso las metodologías descriptas en el ASP del programa ADD (descripto en la sección 4).

\section{N,N-dimetilvalpramida (DmVpd).}<smiles>CCCC(CCC)C(=O)N(C)C</smiles>

La DmVpd presenta su mayor actividad anticonvulsiva a los $\mathbf{3 0}$ minutos luego de inyectada i.p., según surge de la evaluación de los porcentajes de protección frente al MES y al ensayo PTZ (Figura 4.9.1).

Figura 4.9.1 Estimación del TPE para Dmvpd, empleando el ensayo MES (en azul) y el ensayo PTZ (en amarillo)
Tabla 4.9.3 Estimación del TPE

para

Dmvpd en

el ensayo

MES

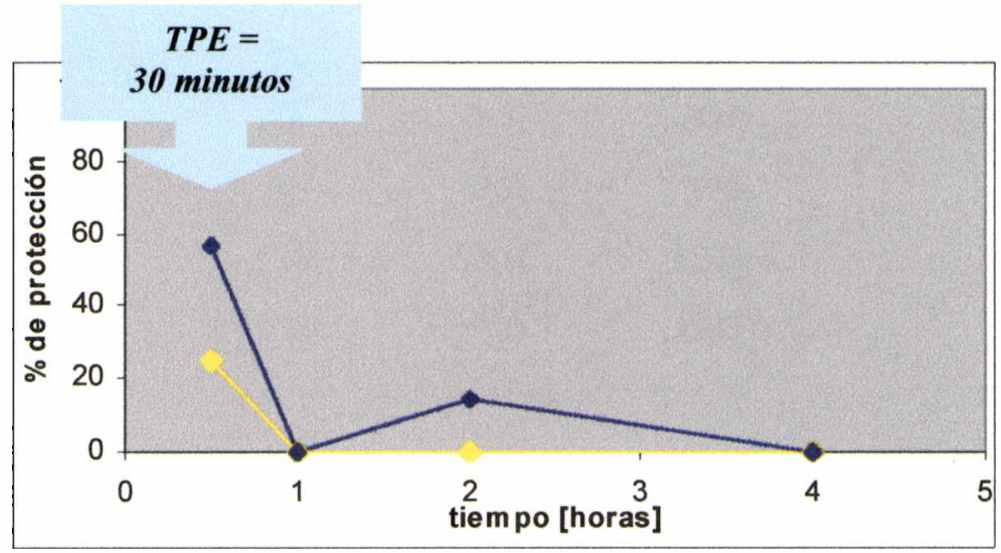

\begin{tabular}{|c|c|c|c|c|}
\hline MES & $\begin{array}{c}\text { dosis } \\
{[\mu \mathrm{mol} / \mathrm{kg}]}\end{array}$ & $\begin{array}{l}\text { tiempo } \\
\text { [horas] }\end{array}$ & $\begin{array}{c}\% \mathrm{de} \\
\text { protección }\end{array}$ & $\begin{array}{c}\mathrm{N}_{\text {protegidos }} / \\
\mathrm{N}_{\text {total }} /\end{array}$ \\
\hline & 500 & 0.50 & 57.1 & $4 / 7$ \\
\hline & 500 & 1 & 0 & $0 / 5$ \\
\hline & 500 & 2 & 14.3 & $1 / 7$ \\
\hline & 500 & 4 & 0 & $0 / 3$ \\
\hline
\end{tabular}

La débil acción manifestada en el ensayo MES a las 2 horas (Tabla 4.9.3), no debe atribuirse a Vpa hidrolizado, ya que la curva de protección frente al PTZ en función del tiempo 
(Figura 4.9.1), muestra que a ese tiempo la actividad es nula a una dosis mayor $(700 \mu \mathrm{mol} / \mathrm{kg}$ ) (Tabla 4.9.4).

\begin{tabular}{|c|c|c|c|c|}
\hline$P T Z$ & $\begin{array}{c}\text { dosis } \\
{[\mu \mathrm{mol} / \mathrm{kg}]}\end{array}$ & $\begin{array}{l}\text { tiempo } \\
\text { [horas] }\end{array}$ & $\begin{array}{c}\% \text { de } \\
\text { protección }\end{array}$ & $\begin{array}{c}N_{\text {protegidos }} \\
N_{\text {total }}\end{array}$ \\
\hline & 700 & 0.5 & 25 & $1 / 4$ \\
\hline & 700 & 1 & 0 & $0 / 4$ \\
\hline & 700 & 2 & 0 & $0 / 5$ \\
\hline & 700 & 4 & 0 & $0 / 5$ \\
\hline
\end{tabular}

Tabla 4.9.4 Estimación del TPE para Dimpden el ensayo $P T Z$

La cuantificación de la potencia anticonvulsiva frente al ensayo MES se evaluó midiendo el porcentaje de protección obtenido a cada una de cinco dosis distintas (Tabla 4.9.5).

\begin{tabular}{|c|c|c|c|c|}
\hline MES & $\begin{array}{c}\text { dosis } \\
{[\mu \mathrm{mol} / \mathrm{kg}]}\end{array}$ & $\begin{array}{l}\text { tiempo } \\
\text { [horas] }\end{array}$ & $\begin{array}{c}\% \text { de } \\
\text { protección }\end{array}$ & $\begin{array}{c}\mathrm{N}_{\text {protegidos }} / \\
\mathrm{N}_{\text {total }}\end{array}$ \\
\hline & 200 & 0.5 & 25 & $1 / 4$ \\
\hline & 300 & 0.5 & 50 & $4 / 8$ \\
\hline & 400 & 0.5 & 50 & $3 / 6$ \\
\hline & 500 & 0.5 & 57.1 & $4 / 7$ \\
\hline & 600 & 0.5 & 87.5 & $7 / 8$ \\
\hline
\end{tabular}

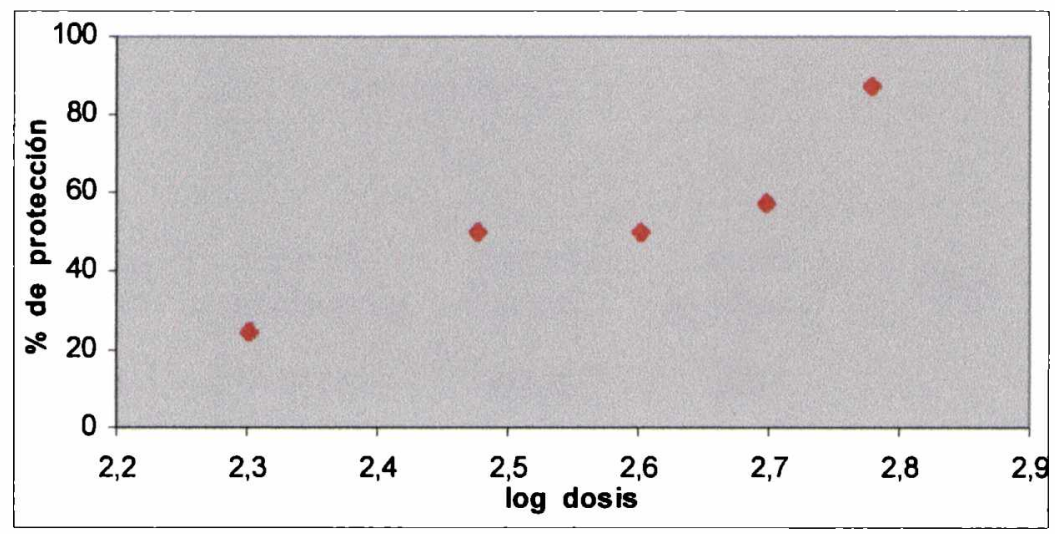

Tabla 4.9 .5 Actividad anticonvulsiva de Dimpden el ensayo MES

Figura 4.9.2 Actividad de Dmvpd frente al ensayo MES

El análisis de estos datos, graficados en la figura 4.9.2, permite la obtención de la ED50 $=347 \mu \mathrm{mol} / \mathrm{kg}(266-452)$ y de la $S=1.7(1.1-2.7)$.

A pesar de mostrar una cierta acción frente al ensayo PTZ a $700 \mu \mathrm{mol} / \mathrm{kg}$, a dosis mayores $(\mathbf{1 0 0 0} \mu \mathrm{mol} / \mathrm{kg})$, DmVpd no mostró un aumento en la actividad (Tabla 4.9.6). 
Tabla 4.9 .6 Actividad anticonvulsiva de Dmvpd en el ensayo $P T Z$

$\boldsymbol{P T Z} \begin{array}{cccc}\begin{array}{c}\text { dosis } \\ {[\mu \mathrm{mol} / \mathrm{kg}]}\end{array} & \begin{array}{c}\text { tiempo } \\ {[\text { horas] }}\end{array} & \begin{array}{c}\% \text { de } \\ \text { protección }\end{array} & \begin{array}{c}\mathrm{N}_{\text {protegidos }} / \\ \mathrm{N}_{\text {total }}\end{array} \\ 700 & 0.5 & 25 & 1 / 4 \\ 1000 & 0.5 & 25 & 1 / 4\end{array}$

Los efectos neurotóxicos manifestados en el ensayo RotoRod son pronunciados (Tabla 4.9.7), pero recién cuando se emplean dosis elevadas $(\mathbf{1 0 0 0} \mu \mathrm{mol} / \mathrm{kg})$, y a tiempos tempranos, como puede observarse en la figura 4.9.3.

\begin{tabular}{|c|c|c|c|c|c|}
\hline \multirow{12}{*}{$\begin{array}{l}\text { Tabla } 4.9 .7 \\
\text { Neurotoxi- } \\
\text { cidad de } \\
\text { Dmvpd } \\
\text { manifesta- } \\
\text { da en el } \\
\text { ensayo } \\
\text { RotoRod }\end{array}$} & \multirow[t]{12}{*}{ RotoRod } & $\begin{array}{c}\text { dosis } \\
{[\mu \mathrm{mol} / \mathrm{kg}]}\end{array}$ & $\begin{array}{l}\text { tiempo } \\
\text { [horas] }\end{array}$ & $\begin{array}{c}\% \text { de } \\
\text { toxicidad }\end{array}$ & $\begin{array}{c}\mathrm{N}_{\text {afectados }} / \\
\mathrm{N}_{\text {total }}\end{array}$ \\
\hline & & 300 & 0.5 & 0 & $0 / 8$ \\
\hline & & 400 & 0.5 & 0 & $0 / 5$ \\
\hline & & 500 & 0.5 & 0 & $0 / 5$ \\
\hline & & 500 & 1 & 0 & $0 / 6$ \\
\hline & & 500 & 2 & 0 & $0 / 7$ \\
\hline & & 700 & 2 & 0 & $0 / 5$ \\
\hline & & 700 & 4 & 0 & $0 / 5$ \\
\hline & & 1000 & 0.5 & 89 & $8 / 9$ \\
\hline & & 1000 & 1 & 75 & $3 / 4$ \\
\hline & & 1000 & 2 & 25 & $1 / 4$ \\
\hline & & 1000 & 4 & 0 & $0 / 4$ \\
\hline
\end{tabular}

Figura 4.9.3

Estimación del TPE para Dmvpd

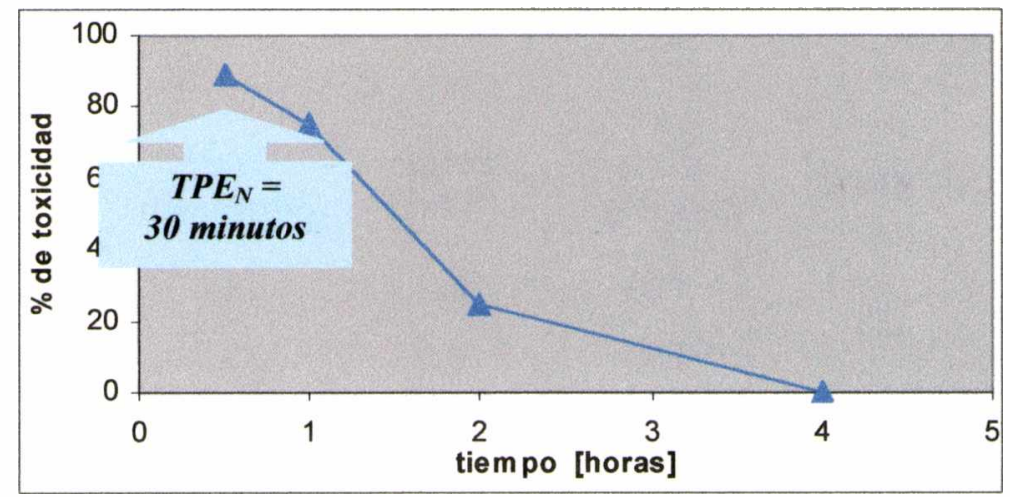




\section{N-etilvalpramida (EtVpd).}

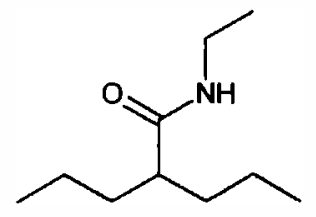

La evaluación frente al ensayo MES muestra que el mayor efecto anticonvulsivo se logra inicialmente, a los 30 minutos (Figura 4.9.4 y tabla 4.9.8).

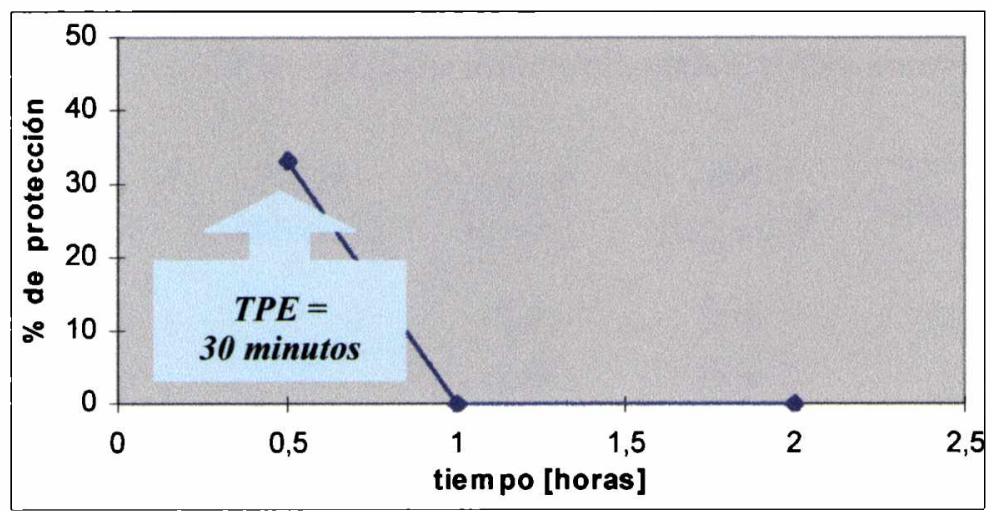

Figura 4.9.4

Estimación del TPE para Etvpd

\begin{tabular}{|c|c|c|c|c|c|}
\hline \multirow[t]{4}{*}{ MES } & $\begin{array}{c}\text { dosis } \\
{[\mu \mathrm{mol} / \mathrm{kg}]}\end{array}$ & $\begin{array}{l}\text { tiempo } \\
\text { [horas] }\end{array}$ & $\begin{array}{c}\% \text { de } \\
\text { protección }\end{array}$ & $\begin{array}{c}\mathrm{N}_{\text {protegidos }} / \\
\mathrm{N}_{\text {total }}\end{array}$ & \multirow{4}{*}{$\begin{array}{l}\text { Tabla } 4.9 .8 \\
\text { Estimación } \\
\text { del TPE } \\
\text { para Etvpd } \\
\text { en el } \\
\text { ensayo } \\
M E S\end{array}$} \\
\hline & 150 & 0.5 & 33.3 & $3 / 9$ & \\
\hline & 150 & 1 & 0 & $0 / 4$ & \\
\hline & 150 & 2 & 0 & $0 / 3$ & \\
\hline
\end{tabular}

La evaluación a media hora de cinco dosis distintas entre el 0 y el $100 \%$ de protección frente al ensayo MES (Tabla 4.9.9), permitió obtener una ED50 $=\mathbf{2 0 0} \mu \mathrm{mol} / \mathrm{kg}$ (148-272) y una $\mathrm{S}=2.0(1.3-3.2)$ (Figura 4.9.5).

\begin{tabular}{|c|c|c|c|c|c|}
\hline \multirow[t]{6}{*}{ MES } & $\begin{array}{c}\text { dosis } \\
{[\mu \mathrm{mol} / \mathrm{kg}]}\end{array}$ & $\begin{array}{l}\text { tiempo } \\
\text { [horas] }\end{array}$ & $\begin{array}{c}\% \text { de } \\
\text { protección }\end{array}$ & $\begin{array}{c}\mathrm{N}_{\text {protegidos }} / \\
\mathrm{N}_{\text {total }}\end{array}$ & \multirow{6}{*}{$\begin{array}{l}\text { Tabla } 4.9 .9 \\
\text { Actividad } \\
\text { anticonvul- } \\
\text { siva de } \\
\text { Etvpd en el } \\
\text { ensayo } \\
\text { MES }\end{array}$} \\
\hline & 100 & 0.5 & 28.6 & $2 / 7$ & \\
\hline & 150 & 0.5 & 33.3 & $3 / 9$ & \\
\hline & 300 & 0.5 & 44.4 & $4 / 9$ & \\
\hline & 350 & 0.5 & 71.4 & $5 / 7$ & \\
\hline & 400 & 0.5 & 75 & $6 / 8$ & \\
\hline
\end{tabular}




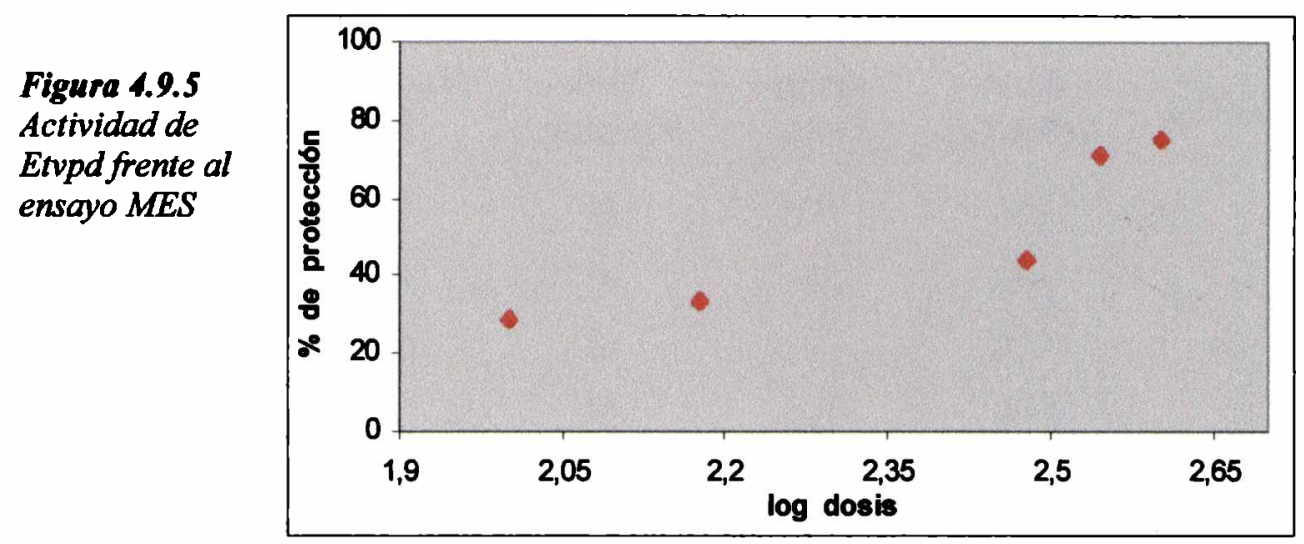

La capacidad de protección frente a PTZ se comprobó a dosis hasta $800 \mu \mathrm{mol} / \mathrm{kg}$, pero los resultados obtenidos muestran que a pesar de aumentar las dosis la actividad siempre se mantiene baja (Tabla 4.9.10).

Tabla
4.9.10
Actividad
anticonvul-
siva de
Etvpd en el
ensayo PTZ

PrT

$\begin{array}{cccc}\begin{array}{c}\text { dosis } \\ {[\mu \mathrm{mol} / \mathrm{kg}]}\end{array} & \begin{array}{c}\text { tiempo } \\ {[\text { horas] }}\end{array} & \begin{array}{c}\% \text { de } \\ \text { protección }\end{array} & \begin{array}{c}\mathrm{N}_{\text {protegidos }} / \\ \mathrm{N}_{\text {total }}\end{array} \\ 400 & 0.5 & 25 & 1 / 4 \\ 450 & 0.5 & 14.3 & 1 / 7 \\ 600 & 0.5 & 11.1 & 1 / 9 \\ 700 & 0.5 & 20 & 1 / 5 \\ 800 & 0.5 & 0 & 0 / 3\end{array}$

En cuanto a los efectos neurotóxicos manifestados en el ensayo RotoRod, también éstos aparecen a los 30 minutos de la inyección i.p. (Figura 4.9.6 y tabla 4.9.11).

Figura 4.9.6

Estimación del TPE $E_{N}$ para Etvpd

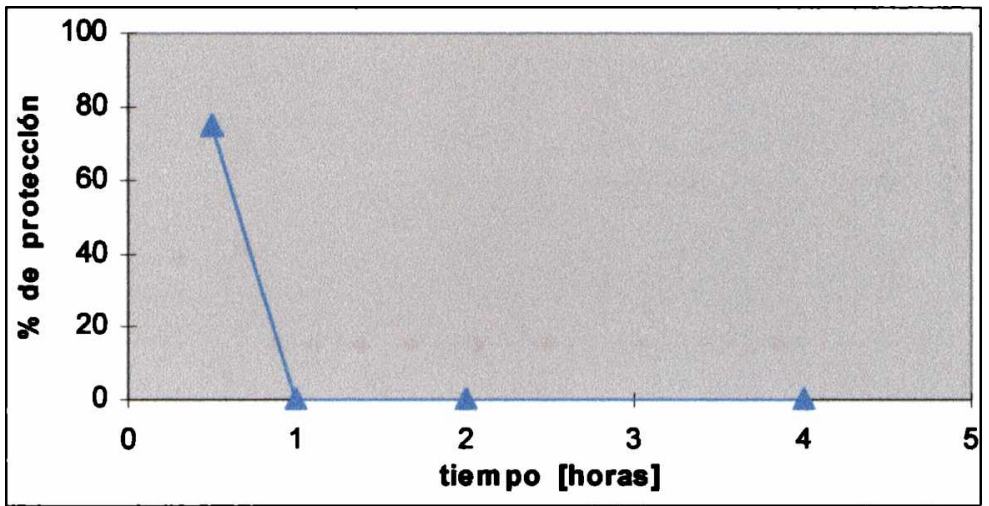




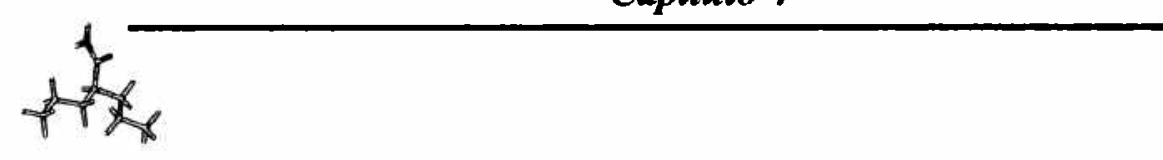

\begin{tabular}{ccccc|l|} 
RotoRod $\begin{array}{c}\text { dosis } \\
{[\mu \mathrm{mol} / \mathrm{kg}]}\end{array}$ & $\begin{array}{c}\text { tiempo } \\
\text { [horas] }\end{array}$ & $\begin{array}{c}\% \mathrm{de} \\
\text { toxicidad }\end{array}$ & $\begin{array}{c}\mathrm{N}_{\text {affectados }} / \\
\mathrm{N}_{\text {total }}\end{array}$ & $\begin{array}{l}\text { Tabla } \\
\text { 4.9.11 } \\
\text { Estimación } \\
\text { del TPE } E_{N}\end{array}$ \\
150 & 0.5 & 0 & $0 / 7$ & para \\
150 & 1 & 0 & $0 / 4$ & Etvpd \\
150 & 2 & 0 & $0 / 4$ & \\
500 & 0.5 & 25 & $1 / 4$ & \\
500 & 1 & 0 & $0 / 4$ & \\
500 & 2 & 0 & $0 / 4$ & \\
700 & 0.5 & 60 & $3 / 5$ & \\
700 & 1 & 33.3 & $1 / 3$ & \\
800 & 0.5 & 75 & $3 / 4$ & \\
800 & 1 & 0 & $0 / 3$ & \\
800 & 2 & 0 & $0 / 4$ & \\
800 & 4 & 0 & $0 / 3$
\end{tabular}

Para esta droga, fue posible evaluar dosis más altas que para muchas de las Vpds ensayadas inicialmente, gracias a su mayor solubilidad en los solventes de administración. Así, se obtuvieron puntos suficientes (cinco) como para completar el cálculo de TD50 (Figura 4.9.7). Como puede observarse en la tabla 4.9.12, la neurotoxicidad comienza a manifestarse recién a partir de los $500 \mu \mathrm{mol} / \mathrm{kg}$.

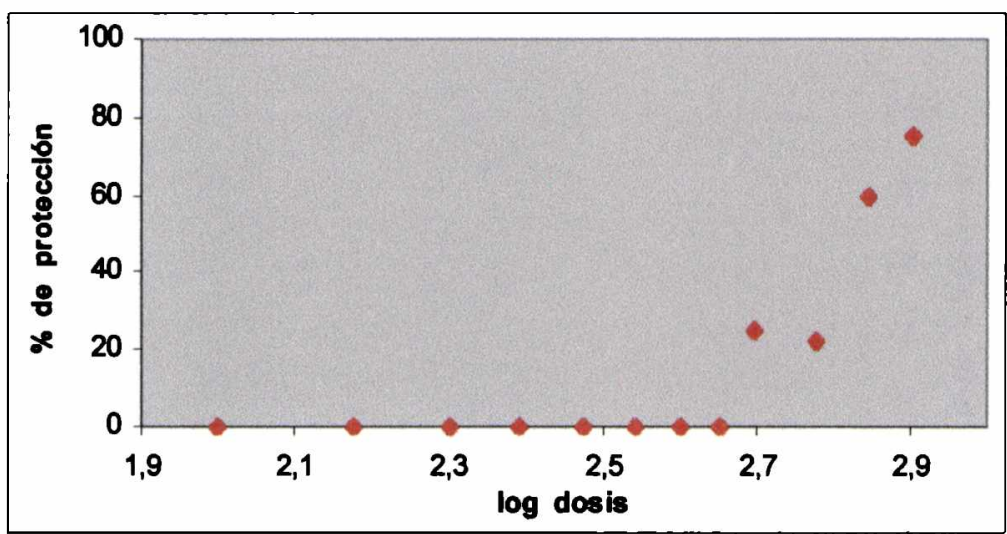

Figura 4.9.7

Neurotoxicidad de Etvpd manifestada en el ensayo RotoRod 


\begin{tabular}{|c|c|c|c|c|c|}
\hline \multirow{13}{*}{$\begin{array}{l}\text { Tabla } \\
4.9 .12 \\
\text { Neurotoxi- } \\
\text { cidad de } \\
\text { Etvpd } \\
\text { manifesta- } \\
\text { da en el } \\
\text { ensayo } \\
\text { RotoRod }\end{array}$} & RotoRod & $\begin{array}{c}\text { dosis } \\
{[\mu \mathrm{mol} / \mathrm{kg}]}\end{array}$ & $\begin{array}{l}\text { tiempo } \\
\text { [horas] }\end{array}$ & $\begin{array}{c}\% \text { de } \\
\text { toxicidad }\end{array}$ & $\begin{array}{c}\mathrm{N}_{\text {afectados }} / \\
\mathrm{N}_{\text {total }}\end{array}$ \\
\hline & & 100 & 0.5 & 0 & $0 / 5$ \\
\hline & & 150 & 0.5 & 0 & $0 / 7$ \\
\hline & & 200 & 0.5 & 0 & $0 / 7$ \\
\hline & & 246 & 0.5 & 0 & $0 / 8$ \\
\hline & & 300 & 0.5 & 0 & $0 / 7$ \\
\hline & & 350 & 0.5 & 0 & $0 / 6$ \\
\hline & & 400 & 0.5 & 0 & $0 / 5$ \\
\hline & & 450 & 0.5 & 0 & $0 / 8$ \\
\hline & & 500 & 0.5 & 25 & $1 / 4$ \\
\hline & & 600 & 0.5 & 22.2 & $2 / 9$ \\
\hline & & 700 & 0.5 & 60 & $3 / 5$ \\
\hline & & 800 & 0.5 & 75 & $3 / 4$ \\
\hline
\end{tabular}

Surge a partir de estos datos, una TD50 $=\mathbf{6 3 2} \mu \mathrm{mol} / \mathrm{kg}$ $(550-727)$ y una $S=1.3(1.1-1.5)$.

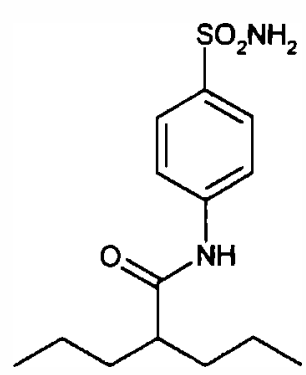

\section{N-(4-sulfonamidofenil)valpramida (SuVpd).}

La actividad de SuVpd frente al ensayo MES se va incrementando con el tiempo hasta mostrar un pico de acción luego de 4 horas de su administración, como se ve representado en la figura 4.9.8. La curva se prolongó hasta las 6 horas para lograr ver el decaimiento en el efecto (Tabla 4.9.13).

\section{Figura 4.9.8}

Estimación del TPE para Suvpd, mediante el ensayo MES (en azul) y el ensayo PTZ (en amarillo)

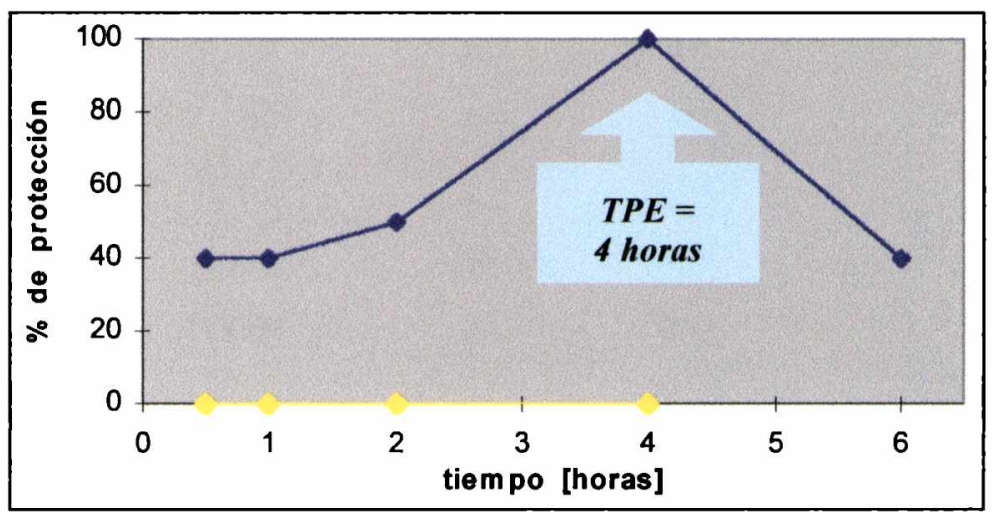




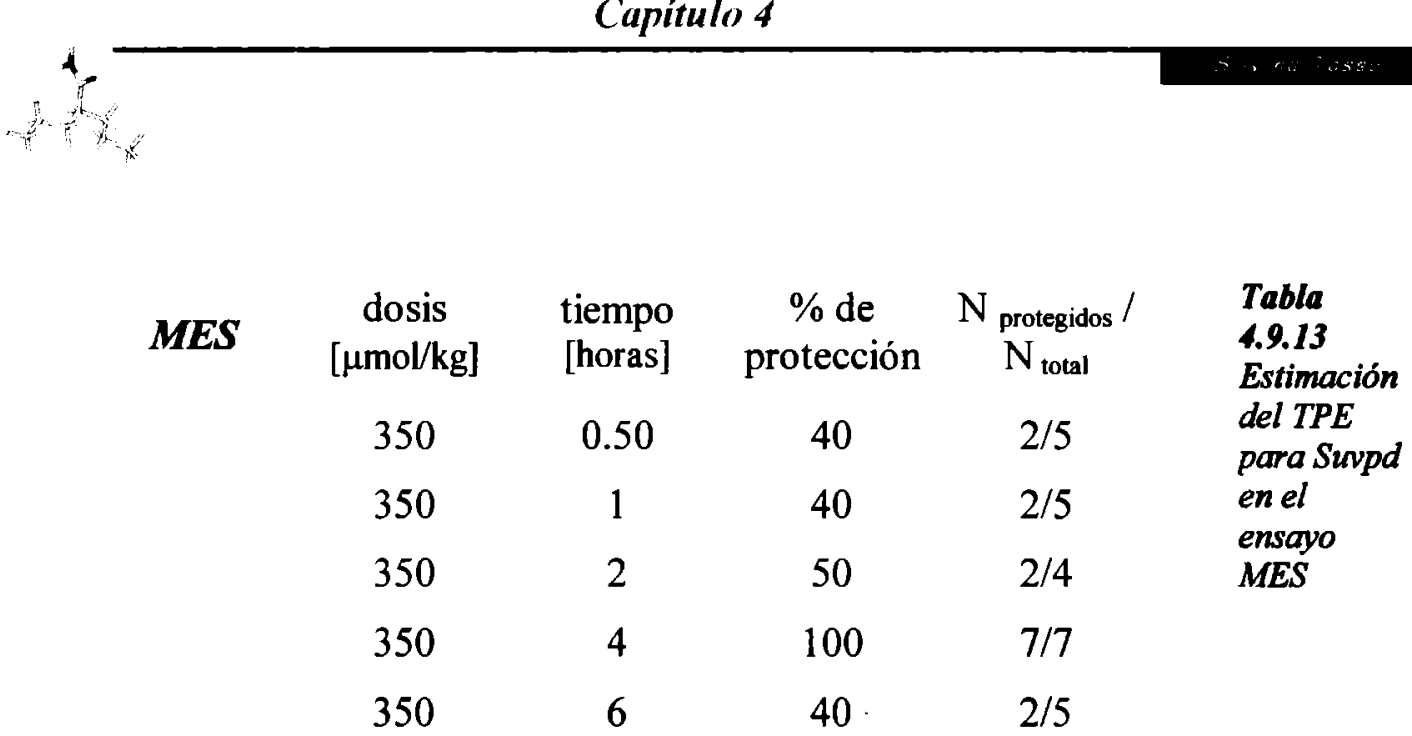

Como se observa en la figura 4.9.8, la droga no es activa frente a PTZ a ninguno de los tiempos ensayados, incluso a concentración elevada $(\mathbf{1 0 0 0} \mu \mathrm{mol} / \mathrm{kg})$ (Tabla 4.9.14).

\begin{tabular}{|c|c|c|c|c|c|}
\hline$P T Z$ & $\begin{array}{c}\text { dosis } \\
{[\mu \mathrm{mol} / \mathrm{kg}]}\end{array}$ & $\begin{array}{l}\text { tiempo } \\
\text { [horas] }\end{array}$ & $\begin{array}{c}\% \mathrm{de} \\
\text { protección }\end{array}$ & $\begin{array}{c}\mathrm{N}_{\text {protegidos }} / \\
\mathrm{N}_{\text {total }}\end{array}$ & \multirow{5}{*}{$\begin{array}{l}\text { Tabla } \\
\text { 4.9.14 } \\
\text { Estimación } \\
\text { del TPE } \\
\text { para Suvpd } \\
\text { en el } \\
\text { ensayo } \\
\text { PTZ }\end{array}$} \\
\hline & 1000 & 0.50 & 0 & $0 / 4$ & \\
\hline & 1000 & 1 & 0 & $0 / 4$ & \\
\hline & 1000 & 2 & 0 & $0 / 3$ & \\
\hline & 1000 & 4 & 0 & $0 / 4$ & \\
\hline
\end{tabular}

Se cuantificó la actividad anticonvulsiva manifestada frente al ensayo MES, mediante el ensayo de seis dosis distintas (Figura 4.9.9 y tabla 4.9.15).

$\begin{array}{cccccl}\text { MES } & \begin{array}{c}\text { dosis } \\ {[\mu \mathrm{mol} / \mathrm{kg}]}\end{array} & \begin{array}{c}\text { tiempo } \\ \text { [horas] }\end{array} & \begin{array}{c}\% \text { de } \\ \text { protección }\end{array} & \begin{array}{c}\mathrm{N}_{\text {protegidos }} / \\ \mathrm{N}_{\text {total }}\end{array} & \begin{array}{l}\text { Tabla } \\ \mathbf{4 . 9 . 1 5} \\ \text { Actividad }\end{array} \\ 19 & 4 & 14.3 & 1 / 7 & \begin{array}{l}\text { anticonvul- } \\ \text { siva de }\end{array} \\ 38 & 4 & 50 & 4 / 8 & \begin{array}{l}\text { Suvpd en el } \\ \text { ensayo }\end{array} \\ 75 & 4 & 70 & 7 / 10 & \text { MES } \\ 150 & 4 & 80 & 8 / 10 & \\ 300 & 4 & 100 & 10 / 10 & \\ 350 & 4 & 100 & 7 / 7 & \end{array}$




\section{Figura 4.9.9}

Actividad de Suvpd frente al ensayo MES

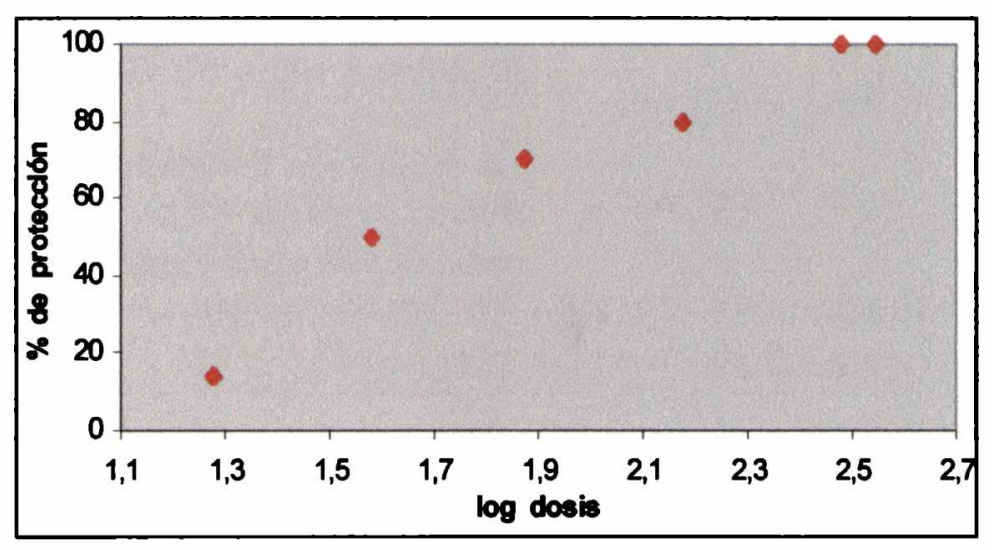

A partir de estos datos se calcula una ED50 $=\mathbf{5 3}$ $\mu \mathrm{mol} / \mathrm{kg}(33-87)$ con $\mathrm{S}=2.8$ (1.7-4.8).

Como se observa en la tabla 4.9.16, no se presentan efectos neurotóxicos, inclusive a las más altas dosis evaluadas $(1000 \mu \mathrm{mol} / \mathrm{kg})$.

\begin{tabular}{|c|c|c|c|c|}
\hline RotoRod & $\begin{array}{c}\text { dosis } \\
{[\mu \mathrm{mol} / \mathrm{kg}]}\end{array}$ & $\begin{array}{l}\text { tiempo } \\
\text { [horas] }\end{array}$ & $\begin{array}{c}\% \text { de } \\
\text { toxicidad }\end{array}$ & $\begin{array}{c}\mathrm{N}_{\text {affectados }} / \\
\mathrm{N}_{\text {total }}\end{array}$ \\
\hline & 19 & 4 & 0 & $0 / 7$ \\
\hline & 38 & 4 & 0 & $0 / 8$ \\
\hline & 75 & 4 & 0 & $0 / 7$ \\
\hline & 150 & 4 & 0 & $0 / 8$ \\
\hline & 250 & 0.5 & 0 & $0 / 4$ \\
\hline & 250 & 1 & 0 & $0 / 4$ \\
\hline & 250 & 4 & 0 & $0 / 8$ \\
\hline & 300 & 4 & 0 & $0 / 7$ \\
\hline & 350 & 0.5 & 0 & $0 / 5$ \\
\hline & 350 & 1 & 0 & $0 / 4$ \\
\hline & 350 & 2 & 0 & $0 / 4$ \\
\hline & 350 & 4 & 0 & $0 / 6$ \\
\hline & 350 & 6 & 0 & $0 / 5$ \\
\hline & 1000 & 1 & 0 & $0 / 4$ \\
\hline & 1000 & 2 & 0 & $0 / 4$ \\
\hline & 1000 & 4 & 0 & $0 / 4$ \\
\hline
\end{tabular}

Tabla

4.9.16

Neurotoxi-

cidad de

Sivpd

manifesia-

da en el

ensayo

RotoRod 
Propil valproato (PrVp).

La evaluación a distintos tiempos frente al ensayo MES revela dos picos de efecto máximo: uno a los 15-30 minutos y otro a las 4 horas posteriores a la inyección ip (Figura 4.9.10, en azul, y tabla 4.9.17).

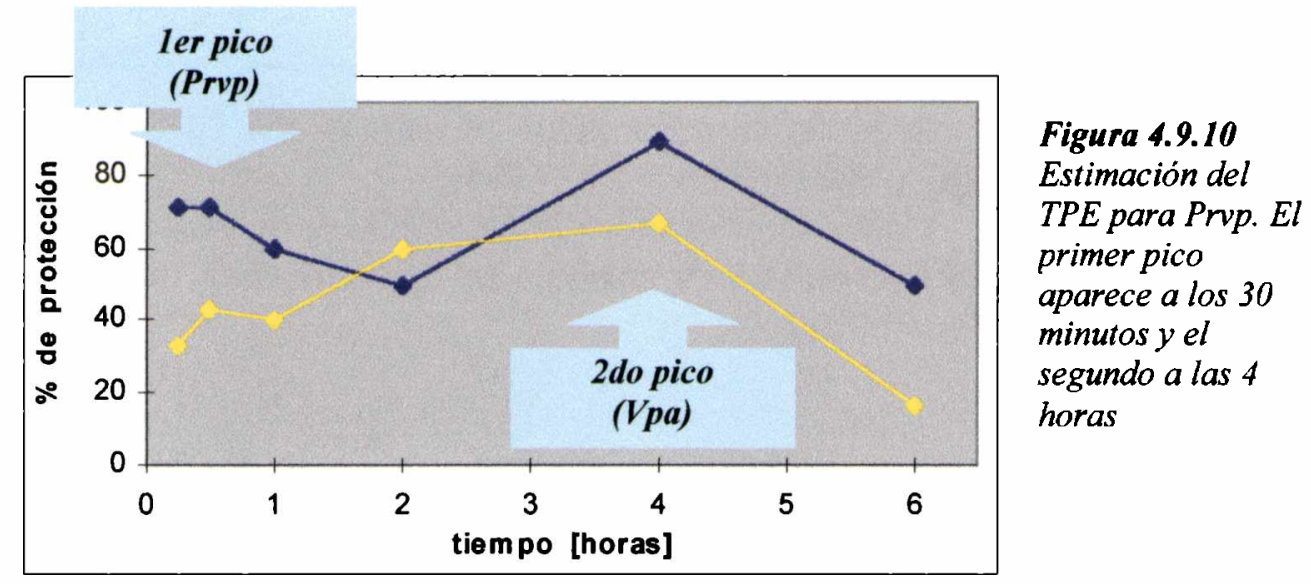

$\begin{array}{cccccl}\text { MES } & \begin{array}{c}\text { dosis } \\ {[\mu \mathrm{mol} / \mathrm{kg}]}\end{array} & \begin{array}{c}\text { tiempo } \\ {[\text { [horas] }}\end{array} & \begin{array}{c}\% \text { de } \\ \text { protección }\end{array} & \begin{array}{c}\mathrm{N}_{\text {protegidos }} / \\ \mathrm{N}_{\text {total }}\end{array} & \begin{array}{l}\text { Tabla } \\ \mathbf{4 . 9 . 1 7}\end{array} \\ 200 & 0.25 & 71.4 & 5 / 7 & \begin{array}{l}\text { Estimación } \\ \text { del TPE }\end{array} \\ 200 & 0.5 & 71.4 & 10 / 14 & \begin{array}{l}\text { para Prvp } \\ \text { en el }\end{array} \\ 200 & 1 & 60 & 9 / 15 & \text { ensayo } \\ 200 & 2 & 50 & 8 / 16 & \text { MES } \\ 200 & 4 & 88.9 & 8 / 9 & \\ 200 & 6 & 50 & 2 / 4 & \end{array}$

Este hecho indica que existen dos especies químicas capaces de proteger frente al MES. Podemos en primera instancia suponer que corresponden al éster y al ácido proveniente de su hidrólisis. El primer pico a los 30 minutos debe corresponder a la protección debida al éster intacto. La posterior hidrólisis del éster da lugar a la aparición de la especie ácida (Vpa) con un máximo de actividad a 4 horas.

La forma de la curva de protección frente a PTZ en función del tiempo (Figura 4.9.10, en amarillo, y tabla 4.9.18) apoya además esta hipótesis, ya que aparece un solo pico a 
apoya además esta hipótesis, ya que aparece un solo pico a las 4 horas coincidente con la máxima actividad correspondiente a $\mathrm{Vpa}$ frente al ensayo MES:

Tabla
4.9 .18
Estimación
del TPE
para Prvp
en el
ensayo
PTZ

\begin{tabular}{|c|c|c|c|}
\hline $\begin{array}{lc}\text { PTZ } & \begin{array}{c}\text { dosis } \\
{[\mu \mathrm{mol} / \mathrm{kg}]}\end{array}\end{array}$ & $\begin{array}{l}\text { tiempo } \\
\text { [horas] }\end{array}$ & $\begin{array}{c}\% \text { de } \\
\text { protección }\end{array}$ & $\begin{array}{l}\mathrm{N}_{\text {protegidos }} / \\
\mathrm{N}_{\text {total }}\end{array}$ \\
\hline 200 & 0.25 & 33.3 & $2 / 6$ \\
\hline 200 & 0.5 & 42.9 & $3 / 7$ \\
\hline 200 & 1 & 40 & $4 / 10$ \\
\hline 200 & 2 & 60 & $6 / 10$ \\
\hline 200 & 4 & 66.7 & $8 / 12$ \\
\hline 200 & 6 & 16.7 & $1 / 6$ \\
\hline
\end{tabular}

Es decir que el Vpa manifiesta sus acciones luego de transcurridas 4 horas de la administración ip de la droga, observándose un $89 \%$ y un $67 \%$ de protección frente al MES y al ensayo PTZ, respectivamente. Los resultados en el Laboratorio de Farmacoquímica revelan para Vpa (sección 6 del presente capítulo) una potencia anticonvulsiva algo mayor en el ensayo MES (ED50 $=1008 \mu \mathrm{mol} / \mathrm{kg}$ ) que en el ensayo PTZ $($ ED50 $=1261 \mu \mathrm{mol} / \mathrm{kg})$. Este comportamiento también se presenta en la actividad anticonvulsiva observada a las 4 horas de administrado el $\operatorname{PrVp}$, lo cual ratifica que la especie activa es efectivamente el Vpa, más allá de que la dosis sea mucho menor. Justamente el hecho de que a $200 \mu \mathrm{mol} / \mathrm{kg}$ de $\operatorname{PrVp}$, el Vpa proveniente de su hidrólisis sea capaz de manifestar efectos anticonvulsivos es una excelente ventaja, ya que está indicando una localización específica de la droga en cerebro.

El éster como tal presenta un perfil similar a aquél de Vpa y de Vpd, ya que es más potente frente a la protección contra el electroshock que contra el PTZ. Se cuantifica entonces su actividad frente al ensayo MES a los 30 minutos, mientras que para la cuantificación de la potencia del Vpa generado se evalúa a distintas dosis, mediante el ensayo PTZ a las 4 horas.

Los resultados de la evaluación de cuatro dosis distintas frente al ensayo MES, 30 minutos después de la inyección, permitieron evaluar la potencia anticonvulsiva del éster actuando como tal (Figura 4.9.11 y tabla 4.9.19). 


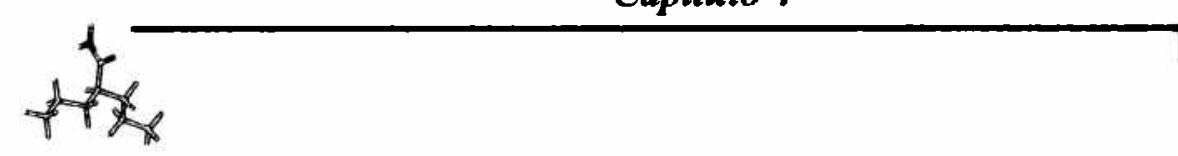

\begin{tabular}{ccccc|l} 
MES & $\begin{array}{c}\text { dosis } \\
{[\mu \mathrm{mol} / \mathrm{kg}]}\end{array}$ & $\begin{array}{c}\text { tiempo } \\
\text { [horas] }\end{array}$ & $\begin{array}{c}\% \text { de } \\
\text { proteción }\end{array}$ & $\begin{array}{c}\mathrm{N}_{\text {protegidos }} / \\
\mathrm{N}_{\text {total }}\end{array}$ & $\begin{array}{l}\text { Tabla } \\
\text { 4.9.19 } \\
\text { Actividad } \\
\text { anticonvul- } \\
\text { siva de }\end{array}$ \\
50 & 0.5 & 42.9 & $3 / 7$ & $\begin{array}{l}\text { Prvp en el } \\
\text { ensayo }\end{array}$ \\
75 & 0.5 & 50 & $4 / 8$ & MES \\
100 & 0.5 & 66.7 & $6 / 9$ & \\
200 & 0.5 & 71.4 & $10 / 14$ &
\end{tabular}

Surge luego del análisis estadístico de estos datos (Figura 4.9.11), una ED50 = $96 \mu \mathrm{mol} / \mathrm{kg}(69-134)$ y una $\mathrm{S}=$ 2.1 (1.3-3.4) para la potencia anticonvulsiva del PrVp.

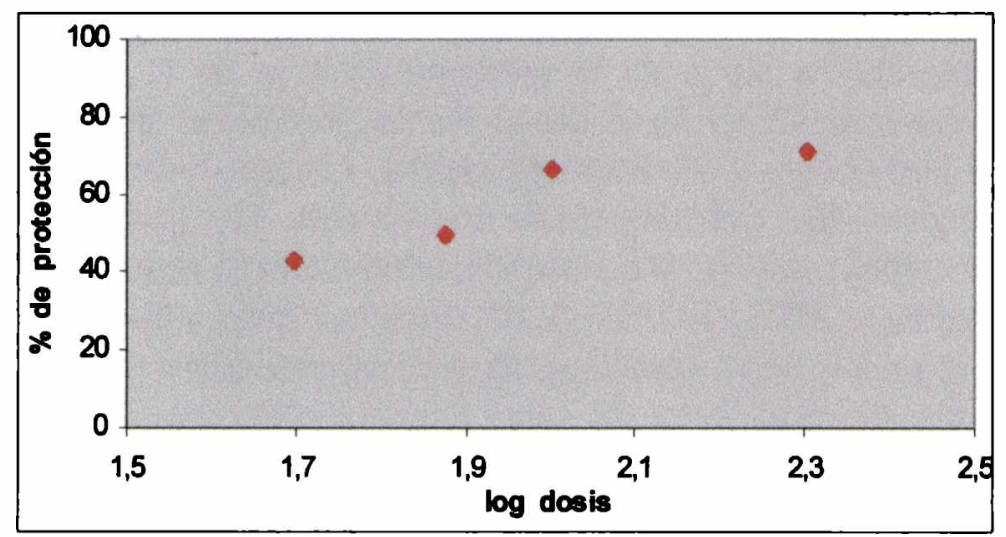

Figura 4.9.11 Actividad de Prvp frente al ensayo MES

La cuantificación de la actividad a las 4 horas frente al ensayo PTZ se realiza mediante el ensayo a cuatro dosis distintas (Figura 4.9.12 y tabla 4.9.20).

\begin{tabular}{|c|c|c|c|c|}
\hline PTZ & $\begin{array}{c}\text { dosis } \\
{[\mu \mathrm{mol} / \mathrm{kg}]}\end{array}$ & $\begin{array}{l}\text { tiempo } \\
\text { [horas] }\end{array}$ & $\begin{array}{c}\% \text { de } \\
\text { protección }\end{array}$ & $\begin{array}{c}N_{\text {protegidos }} / \\
\mathrm{N}_{\text {total }}\end{array}$ \\
\hline & 50 & 4 & 28.6 & $2 / 7$ \\
\hline & 100 & 4 & 50 & $4 / 8$ \\
\hline & 150 & 4 & 55.6 & $5 / 9$ \\
\hline & 200 & 4 & 66.7 & $8 / 12$ \\
\hline
\end{tabular}

\section{Tabla}

4.9.20 Actividad anticonvulsiva de Prvp en el ensayo PTZ 
Figura 4.9.12

Actividad de

Prup frente al ensayo PTZ

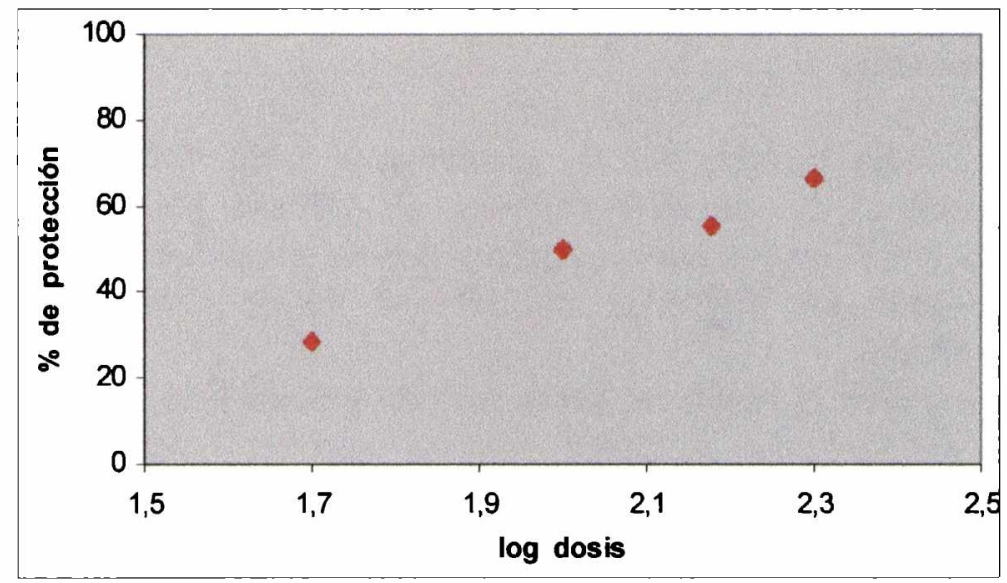

Se calculó una $\mathbf{E D 5 0}=100 \mu \mathrm{mol} / \mathrm{kg}(73-138)$ y una $\mathrm{S}=2.0$ (1.3-3.1) para la actividad anticonvulsiva del PrVp a 4 horas, debida a la generación del Vpa.

A dosis superiores a las necesarias para manifestar una acción anticonvulsiva significativa, esta droga no presenta efectos indicativos de neurotoxicidad. Como puede observarse en la tabla 4.9.21, no hay ataxia ni sedación manifestada en el ensayo RotoRod, a ninguno de los tiempos ensayados y a las dosis más altas evaluadas (200 y 250 $\mu \mathrm{mol} / \mathrm{kg}$ ).

\begin{tabular}{|c|c|c|c|c|c|}
\hline \multirow{13}{*}{$\begin{array}{l}\text { Tabla } \\
\text { 4.9.21 } \\
\text { Neurotoxi- } \\
\text { cidad de } \\
\text { Prvp } \\
\text { manifesta- } \\
\text { da en el } \\
\text { ensayo } \\
\text { RotoRod }\end{array}$} & RotoRod & $\begin{array}{c}\text { dosis } \\
{[\mu \mathrm{mol} / \mathrm{kg}]}\end{array}$ & $\begin{array}{l}\text { tiempo } \\
\text { [horas] }\end{array}$ & $\begin{array}{c}\% \text { de } \\
\text { toxicidad }\end{array}$ & $\begin{array}{c}\mathrm{N}_{\text {afectados }} / \\
\mathrm{N}_{\text {total }}\end{array}$ \\
\hline & & 50 & 0.5 & 0 & $0 / 7$ \\
\hline & & 75 & 0.5 & 0 & $0 / 8$ \\
\hline & & 100 & 0.5 & 0 & $0 / 9$ \\
\hline & & 100 & 4 & 0 & $0 / 8$ \\
\hline & & 200 & 0.25 & 0 & $0 / 12$ \\
\hline & & 200 & 0.5 & 0 & $0 / 32$ \\
\hline & & 200 & 1 & 0 & $0 / 23$ \\
\hline & & 200 & 2 & 0 & $0 / 25$ \\
\hline & & 200 & 4 & 0 & $0 / 20$ \\
\hline & & 200 & 6 & 0 & $0 / 9$ \\
\hline & & 250 & 0.5 & 0 & $0 / 4$ \\
\hline & & 250 & 4 & 0 & $0 / 4$ \\
\hline
\end{tabular}




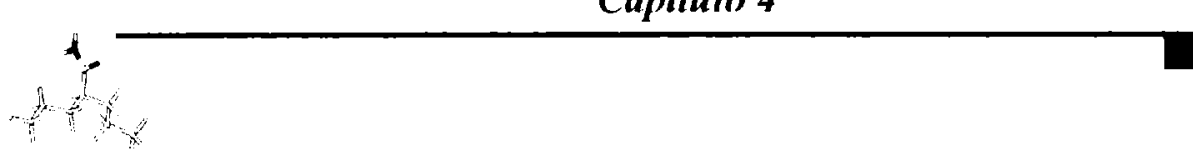

\section{Discusión.}

En la tabla 4.9.21, similar a la tabla 4.6.26 de la sección 6 del presente capítulo, se ordenan por potencia anticonvulsiva los nuevos compuestos estudiados, incluyendo asimismo los derivados anteriores a fin de comparar los resultados.

Por el hecho de haber surgido gracias a la aplicación de metodologías de diseño racional (sección 8 del presente capítulo), era esperable que estos compuestos resultaran activos. Efectivamente, todos ellos manifiestan una considerable actividad frente al ensayo MES, lo cual permite clasificarlos como de categoría 1 (Tabla 4.9.21), es decir que son capaces de mostrar actividad a menos de $100 \mathrm{mg} / \mathrm{kg}$.

El orden por potencia decreciente de la tabla 4.9.21 ubica a estos cuatro nuevos compuestos obtenidos por diseño en la parte superior, lo cual permite apreciar que se ha logrado una substancial ventaja, en cuanto a la optimización de la actividad, con respecto al grupo inicial de derivados de Vpa. Ciertamente, se ha alcanzado el derivado más potente de la serie, la SuVpd, 19 veces más activo que Vpa y casi 7 veces más activo que $\mathrm{Vpd}$. El éster PrVp también ha resultado muy activo frente al ensayo MES, presentando una potencia relativa de 11 con respecto al $\mathrm{Vpa}$, y de 3.7 con respecto a Vpd. Los compuestos EtVpd y DmVpd también presentaron importantes mejoras en la actividad, principalmente con respecto a $\mathrm{Vpa}$ (potencias relativas de $5 \mathrm{y}$ 2.9 respectivamente).

Análogamente al conjunto anterior de derivados Nsustituidos de $\mathrm{Vpd}$, las tres nuevas amidas diseñadas no han manifestado acción frente al ensayo PTZ a dosis elevadas, muy superiores a las necesarias para manifestar acción frente al ensayo MES, e inclusive tóxicas, como puede apreciarse observando los resultados obtenidos frente al ensayo RotoRod en el caso de EtVpd y DmVpd (Tabla 4.9.21). Esto indica que el aumento de actividad anticonvulsiva frente a uno de los ensayos (ensayo MES) probablemente va acompañado de una mayor especificidad de acción, ya que desaparece (al menos a las dosis consideradas) uno de los mecanismos de acción presente en los compuestos padres Vpa y Vpd, es decir aquellos elementos responsables de la respuesta protectora frente al agente convulsivo PTZ. 
Tabla 4.9.21 Actividad biológica de las drogas estudiadas

\begin{tabular}{|c|c|c|c|c|c|c|c|c|c|c|c|}
\hline Compuesto & $\begin{array}{l}\text { TPE } \\
\text { [hs] }\end{array}$ & $\begin{array}{c}\text { EDEO } \\
\text { [umol/kg] }\end{array}$ & $\begin{array}{l}\text { MES test } \\
\text { [me/kg] }\end{array}$ & $\begin{array}{c}\text { EDE0 } \\
{[\mu \mathrm{mol} / \mathrm{kg}]}\end{array}$ & $\begin{array}{l}\text { PIZ test } \\
\text { [mg/kg] }\end{array}$ & $\begin{array}{l}\mathbf{T P E}_{\mathrm{N}} \\
\text { [hs] }\end{array}$ & $\begin{array}{c}\text { TDEO } \\
{[\mu \mathrm{mol} / \mathrm{kg}]}\end{array}$ & $\begin{array}{l}\text { RotoRod } \\
\text { test } \\
\text { [mg/kg] }\end{array}$ & $\mathrm{H}^{*}$ & Pete. & Cons" \\
\hline Surpd & 4 & $\begin{array}{c}53 \\
(33-87)\end{array}$ & $\begin{array}{c}15.8 \\
(9.8-25.9)\end{array}$ & $0 \%$ a 1000 & $0 \%$ a 298 & - & $0 \%$ a 1000 & 0\%а 298 & $>19$ & 19 & 1 \\
\hline Chvpd & 2 & $\begin{array}{c}61 \\
(44-85)\end{array}$ & $\begin{array}{c}13.7 \\
(9.9-19.1)\end{array}$ & $0 \%$ a 65 & 0\%a 14.6 & - & $0 \%$ a 65 & 0\%a 14.6 & $>1.1$ & 17 & 1 \\
\hline Prvp & $\begin{array}{l}0.5 \\
y 4\end{array}$ & $\begin{array}{c}96 \\
(69-134)\end{array}$ & $\begin{array}{c}17.9 \\
(12.824 .9)\end{array}$ & $\begin{array}{c}100 \\
(33-138)\end{array}$ & $\begin{array}{c}18.6 \\
(13.6-25.7)\end{array}$ & - & $0 \%$ a 250 & $0 \% \mathrm{a} 46.5$ & $>26$ & 11 & 1 \\
\hline Etvpd & 0.5 & $\begin{array}{c}200 \\
(148-272)\end{array}$ & $\begin{array}{c}34.2 \\
(25.346 .5)\end{array}$ & $0 \%$ a 800 & \%a 137 & 0.5 & $\begin{array}{c}632 \\
(550-727)\end{array}$ & $\begin{array}{c}108 \\
(94.1-124)\end{array}$ & 3.2 & 5.0 & 1 \\
\hline Denvpd & 0.5 & $\begin{array}{c}347 \\
(266-452)\end{array}$ & $\begin{array}{c}59.3 \\
(45.5-7.3)\end{array}$ & $25 \%$ a 1000 & 25\%a 171 & 0.5 & $89 \%$ a 1000 & $89 \%$ a 171 & $\begin{array}{c}\text { entre } 20 \\
y 29\end{array}$ & 29 & 1 \\
\hline Vpd & 1 & $\begin{array}{c}353 \\
(267466)\end{array}$ & $\begin{array}{c}50.5 \\
(38.2-66.6)\end{array}$ & $\begin{array}{c}490 \\
(447-537)\end{array}$ & $\begin{array}{c}70.1 \\
(63.976 .8)\end{array}$ & 2 & $25 \%$ a 600 & $25 \%$ a 85.8 & $1.3-1.4^{4}$ & 2.9 & 1 \\
\hline Ipvpd & 1 & $\begin{array}{c}384 \\
(300-492)\end{array}$ & $\begin{array}{c}70.3 \\
(54.990 .0)\end{array}$ & $33 \% a$ & $33 \%$ a 82.4 & - & $0 \%$ a 450 & $0 \% \mathrm{a} \$ 2.4$ & $>1.2$ & 2.6 & 1 \\
\hline Burpd & 1 & $\begin{array}{c}487 \\
(412-576)\end{array}$ & $\begin{array}{c}96.9 \\
(82.0-115)\end{array}$ & $0 \%$ a 600 & 0\%a 119 & 0.5 & $40 \% a$ & $40 \%$ a 119 & $>1.2$ & 2.1 & I \\
\hline Vpa & 0.25 & $\begin{array}{c}1008 \\
(792-1282)\end{array}$ & $\begin{array}{c}145 \\
(114185)\end{array}$ & $\begin{array}{c}1261 \\
(1155-1377)\end{array}$ & $\begin{array}{c}182 \\
(166-198)\end{array}$ & 0.25 & $17 \%$ a 1700 & $17 \%$ a 245 & $1.1-1.7^{\star}$ & 1 & 2 \\
\hline Cpvpd & 2 & $\begin{array}{c}1225 \\
(1107-1355)\end{array}$ & $\begin{array}{c}322 \\
(291-404)\end{array}$ & $\begin{array}{c}1817 \\
(1669-1978)\end{array}$ & $\begin{array}{c}479 \\
(439-520)\end{array}$ & - & $0 \%$ a 1500 & 0\%a 395 & $>1.2$ & 0.8 & 2 \\
\hline Movpd & - & $0 \%$ a 1500 & $0 \%$ a 320 & $0 \%$ a 1500 & $0 \%$ a 320 & - & $25 \%$ a 1500 & $25 \%$ a 320 & - & - & 3 \\
\hline
\end{tabular}

* PI (potective index) sigrifica indice de protección = TD50 / ED50, considerando la patencia antionnulsiva freme al MES test

- Potencia relativa al Vpa, es decir ED50 vpe / EDS0 drog, ocnsiderando la potencia artionvulsiva frente al MES test

- Calegaría currespondiente a la clasificación de Fase I del Antionvulsant Screcning Project del ADD Program

- segin biblicgrafia

A diferencia de las amidas, los datos demuestran que el $\operatorname{PrVp}$ manifiesta una acción anticonvulsiva muy potente tanto frente al ensayo MES como al ensayo PTZ, aunque la actividad protectora medida frente al ensayo PTZ está en realidad asociada al Vpa que se genera por hidrólisis. Luego de 4 horas de administrado, el PrVp presenta una potencia muy superior a la del Vpa cuando se lo administra como tal, siendo 10 veces más activo que éste y casi 5 veces más activo que Vpd frente al ensayo PTZ. 
prodroga libera la especie activa localizándola específicamente en su sitio de acción en cerebro.

En conclusión, se han obtenido en todos los casos ventajas importantes en cuanto a la potencialidad de estos nuevos compuestos como drogas antiepilépticas. Pero dentro del contexto del presente trabajo, la información obtenida será de utilidad de aquí en más para el estudio de las características asociadas a la acción anticonvulsiva, tanto en cuanto al planteo de relaciones QSAR incluyendo estos nuevos derivados, como así también a la propuesta de posibles mecanismos de acción para estas drogas.

\footnotetext{
${ }^{1}$ Badir, K.; Haj-Yehia, A.; Vree, T.B.; van der Kleijn, E.; Bialer, M. Pharmaceutical Research (1991) 8(6): 750-3

${ }^{2}$ Hadad, S.; Vree, T.B.; van der Kleijn, E.; Bialer, M. Journal of

Pharmaceutical Sciences (1992) 81(10): 1047-50

${ }^{3}$ Moon, S.Ch. Comunicación personal
} 


\section{ANALISIS QSAR DE DROGAS ANTI-MES}

Bajo el contexto del análisis extratermodinámico de Hansch (ítem "QSAR" del capítulo 1), las metodologías QSAR (quantitative structure - activity relationships), ampliamente usadas en el campo del diseño de nuevas drogas, se basan fundamentalmente en la búsqueda de algoritmos matemáticos, de base estadística o de redes neuronales, que relacionan la actividad biológica de una serie de compuestos con descriptores de los distintos efectos (hidrofóbico, electrónico, estérico) que caracterizan a sus estructuras.

\section{$\mathrm{AB}=f($ estructura $)$}

\section{$\mathrm{AB}=\boldsymbol{f}($ efecto hidrofóbico $)+f($ efecto estérico $)+$ $f$ (efecto electrónico)}

Usualmente el efecto hidrofóbico se cuantifica mediante el coeficiente de partición octanol/agua $(\operatorname{logP})^{1}$, experimental o calculado, mientras que para la expresión de los efectos electrónicos y estéricos se emplean preferentemente descriptores calculados empleando esquemas clásicos o metodologías químico cuánticas ${ }^{2,3}$.

La ecuación QSAR que resulta del análisis de los datos debe ser lo más simple posible a fin de permitir una interpretación y planteo de un modelo fisicoquímico de la interacción ${ }^{4}$. Sin embargo, al estar la respuesta biológica influenciada no sólo por los fenómenos de interacción con el receptor (afinidad y potencia farmacológica), sino también por complejos procesos de absorción, distribución, metabolismo y excreción, resulta generalmente complicado llegar a expresiones cuantitativas de la respuesta biológica en función de pocas variables descriptoras. Se derivan frecuentemente correlaciones que nuclean descriptores moleculares vinculados tanto a los procesos del transporte hasta el sitio receptor como a su interacción con éste. En el caso de las drogas cuyo sitio de acción se encuentra en el $\mathrm{SNC}$, como es el caso de los derivados en estudio, su actividad está condicionada por el traspaso efectivo de la barrera hematoencefálica. Un valor adecuado del parámetro $\log \mathrm{P}$ es, por tanto, decisivo para la manifestación de la actividad biológica. 
A partir de la evaluación biológica como anticonvulsivos frente al ensayo MES se ha logrado cuantificar, mediante la obtención de las ED50, la potencia de varios derivados de Vpd y de fenitoína. Habiendo identificado ya el grupo farmacóforo asociado a la actividad anti-MES, el próximo paso está orientado a encontrar los valores de los descriptores moleculares para luego ver si existen correlaciones con la acción biológica.

Se analizan en el presente estudio todos los compuestos activos incluidos en la definición del farmacóforo para la acción anti-MES (Figuras 4.7.1 y 4.7.2), excepto MPH y ETT, por no encontrarse en bibliografia datos cuantitativos confiables sobre su actividad biológica. Se incluyen además las tres $\mathrm{Vpds}$ diseñadas en base al farmacóforo propuesto, mientras que no se considera el derivado PrVp por tratarse, como ya se comentó (sección 9 del capítulo 4), de una prodroga de Vpa.

\section{Metodología aplicada}

\section{Cálculo de los descriptores moleculares.}

Los descriptores calculados se muestran en la tabla 4.10.1, agrupados de acuerdo al efecto que representan.

Los valores calculados para los descriptores corresponden a las conformaciones activas de cada uno de los compuestos, es decir, aquéllas que satisfacen los requisitos del farmacóforo propuesto.

Se utilizó metodología semiempírica AM1 para el cálculo de los descriptores cuánticos (energía de los orbitales, densidades de carga, momento dipolar y calor de formación).

Los descriptores del efecto hidrofóbico $\left(\log \mathrm{P}^{5}\right.$ y energía de hidratación ${ }^{6}$ ), área ${ }^{7,8}$, volumen ${ }^{7}$, peso molecular, refractividad molecular ${ }^{5}$ y polarizabilidad ${ }^{9}$, se calcularon mediante el empleo del programa Chemplus ${ }^{10}$.

Las distancias entre átomos surgen directamente del examen de las conformaciones activas de cada una de las estructuras.

\section{Datos biológicos.}

En la selección de los datos biológicos se prestó especial atención a las técnicas empleadas en la evaluación de las drogas, ya que es de fundamental importancia que los procedimientos experimentales sean idénticos en la evaluación de todos los compuestos. Los datos de ED50 para las Vpds $\mathrm{N}$-sustituidas y para PHE fueron obtenidos en el Laboratorio de Farmacoquímica, de la forma que ya se describió (secciones 6 y 9 del capítulo 4), mientras que los 
valores para los demás antiepilépticos fueron tomados de bibliografia para las mismas técnicas de evaluación de actividad anticonvulsiva.

Tabla 4.10.1 Descriptores moleculares de los distintos efectos.

Descriptor molecular

Efecto estérico Area superficial

Volumen

Peso molecular

Refractividad molar

Distancias entre los centros atómicos que definen el farmacóforo:

$\checkmark$ distancia $\mathrm{C}_{2}-\mathrm{O}_{1}\left(\mathbf{d}_{21}\right)$

$\checkmark$ distancia $\mathrm{C}_{2}-\mathrm{N}_{3}\left(\mathbf{d}_{23}\right)$

$\checkmark$ distancia $\mathrm{O}_{1}-\mathrm{N}_{3}\left(\mathbf{d}_{13}\right)$

Efecto hidrofóbico Indice hidrofóbico logP

Energía de hidratación

Efecto electrónico Polarizabilidad

Energía del orbital molecular ocupado de mayor energía ( $\mathbf{E}_{\text {номо }}$ )

Energía del orbital molecular desocupado de menor energía ( $\mathbf{E}_{\text {LUMo }}$ )

Diferencia de energía entre HOMO y LUMO

Cargas a partir de análisis poblacional de Mulliken:

$\begin{array}{ll}\checkmark & \mathbf{q} \mathbf{O}_{\mathbf{1}} \mathbf{M} \\ \checkmark & \mathbf{q \mathbf { C } _ { 2 }} \mathbf{M} \\ \checkmark & \mathbf{q X _ { 3 } \mathbf { M }} \\ \checkmark & \mathbf{q X _ { 4 }} \mathbf{M}\end{array}$

Cargas a partir de potenciales electrostáticos:

$\checkmark$ qO $\mathbf{O}_{1}$ PE

$\checkmark \mathbf{q C}_{2} \mathbf{P E}$

$\checkmark \mathbf{q X} \mathbf{X}_{\mathbf{3}} \mathbf{P E}$

$\checkmark \quad \mathbf{q X} \mathbf{X}_{4} \mathbf{P E}$

Calor de formación

Momento dipolar

\section{Correlación con la actividad biológica.}

Se analizaron estadísticamente las correlaciones de la actividad biológica expresada como ED50, 1/ED50 y $\log (1 / \mathrm{ED} 50)$ con los descriptores planteados. Se obtuvieron expresiones lineales, parabólicas y bilineales, mono y multiparamétricas, calculando las matrices de intercorrelación entre las variables. Se empleó para tal fin el programa "Análisis de Hansch y Modelo Bilinear" desarrollado por el Dr. Hugo Kubinyi. De acuerdo al número de compuestos que componen el conjunto analizado, no se 
incluyeron simultáneamente más de dos variables independientes en cada regresión ${ }^{11}$.

\section{Resultados y discusión}

El análisis de más de 150 correlaciones (lineales, parabólicas y bilineales) con los tres tipos de descriptores muestra al efecto electrónico como el más importante asociado a la manifestación de la actividad. Particularmente los descriptores electrónicos de origen cuántico son los que mejores correlaciones han mostrado.

Por otro lado, no se encuentra una buena correlación con los descriptores del efecto hidrofóbico. El $\log P$ da cuenta de la capacidad de penetración a través de las membranas biológicas y condiciona siempre, por lo tanto, la posibilidad de localización y acción de la droga. Se considera que una droga debe tener un valor de $\log \mathrm{P}$ superior a 1.5 para poder llegar al sistema nervioso central ${ }^{12}$. A pesar de no conducir a una buena correlación con la actividad en este caso, el valor de $\log \mathrm{P}$ es suficientemente elevado en todos los compuestos analizados, para asegurar el pasaje de la barrera hematoencefálica. Como se observa en la tabla 4.10.2, todos los compuestos presentan valores de logP superiores a 1.9.

\begin{tabular}{ll} 
Molécula & $\log P$ \\
\hline VPD & 1.91 \\
IPVPD & 3.08 \\
BUVPD & 3.53 \\
CHVPD & 3.91 \\
CPVPD & 2.62 \\
PHE & 3.06 \\
CZ & 3.37 \\
PB & 2.51 \\
PRM & 2.15 \\
DMVPD & 2.68 \\
ETVPD & 2.67 \\
SUVPD & 3.03
\end{tabular}

Tabla 4.10.2 Valores de logP.

Los descriptores del efecto estérico no conducen tampoco a una buena correlación con la respuesta biológica manifestada. 
Las mejores correlaciones se obtienen cuando la actividad biológica se expresa en términos de $\log (1 / \mathrm{ED} 50)$ y se indican en la figura 4.10.1.

La mejor correlación obtenida muestra una fuerte dependencia de la actividad biológica con la energía del LUMO ( $\left.\mathrm{E}_{\text {LUMO }}\right)$, siendo mayor la actividad a medida que esta energía aumenta (ecuación $a$, figura 4.10.1). Esta correlación lineal con la $\mathrm{E}_{\mathrm{LUMO}}$, se interpreta tradicionalmente como indicativa de una interacción aceptor-donor involucrando una transferencia electrónica hacia el ligando. En las estructuras analizadas el LUMO se asocia, casi sin excepción, al orbital $\pi$ antienlazante del gnupo carbonilo de la porción carboxamida (Figura 4.10.2).

En el caso de PHE y PRM este orbital no es el LUMO, sino el LUMO+2, el cual se encuentra dentro de un rango de $10 \mathrm{kcal}$ del primero. Interpretando que la actividad

(a)

$$
\begin{aligned}
& -\log (E D 50)=-11.471 \mathrm{E}_{\text {LUNO }}+1.228 \\
& (\mathrm{n}=12 ; \mathrm{r}=0.913 ; \mathrm{s}=0.228 ; \mathrm{F}=49.76)
\end{aligned}
$$

Figura 4.10.1

Mejores

correlaciones

obtenidas

(b)

$$
\begin{aligned}
& -\log (E D 50)=-11.106 \mathrm{E} \pi^{*} \mathrm{co}+1.299 \\
& (n=12 ; \mathrm{r}=0.784 ; \mathrm{s}=0.346 ; \mathrm{F}=15.93)
\end{aligned}
$$

(c)

$$
\begin{aligned}
& -\log (E D 50)=14.189 q O_{1} M+12.683 q_{2} \mathrm{M}+1.901 \\
& (n=12 ; r=0.848 ; s=0.312 ; F=11.47) \\
& -\log (E D 50)=14.396 q O_{1} P E+4.179 q_{C_{2}} P E+5.526 \\
& (n=12 ; r=0.761 ; s=0.381 ; F=6.18)
\end{aligned}
$$$$
\text { (d) }
$$

biológica correlaciona en realidad con el orbital pi antiligante en lugar de con el LUMO, la correlación no se ve afectada (ecuación $b$, figura 4.10.1). En el caso de $\mathrm{CZ}$, el $\pi^{*}$ co se encuentra mas alto en energía (35kcal), definiendo el LUMO+4. Lejos de considerar CZ como una excepción, nos preguntamos en qué grado la proximidad del receptor puede modificar la distribución de energía de los orbitales directamente involucrados en la interacción con él. 
En el momento de la interacción, no sólo la conformación puede cambiar, sino también los valores relativos de los orbitales de frontera. El modelo usado en los análisis QSAR sufre de las imprecisiones que son comunes al tratamiento de sistemas biológicos.

Además, la evaluación de la correlación de la actividad biológica con la $\mathrm{E}$ del orbital $\pi^{*}$ co (ecuación $b$, figura 4.10.1) confirma nuestra interpretación.

Confirmación adicional se obtiene de la correlación de la actividad con las cargas sobre los centros involucrados en la definición del orbital $\pi^{*} \mathrm{co}, \mathrm{qC}_{2}, \mathrm{qO}_{1}$. Su significancia estadística se mantiene independientemente de la metodología empleada para el calculo de las cargas (análisis poblacional de Mülliken - cargas a partir de potenciales electrostáticos) (ecuaciones $c$ y $d$, figura 4.10.1).

El análisis QSAR indica al grupo carbonilo, y en particular a sus características electrónicas, como definitorio de la actividad biológica de las moléculas de la serie analizada. Estando este grupo incluido en el farmacóforo previamente identificado, los resultados QSAR llevan a inferir una atracción electrostática droga receptor que puede cumplimentar un docking efectivo cuando se satisfacen los requerimientos lipofilicos.

Figura 4.10.2

$L U M O$ en la VPD, que consiste mayoritariamente en el orbital $\pi^{*}$ del carbonilo

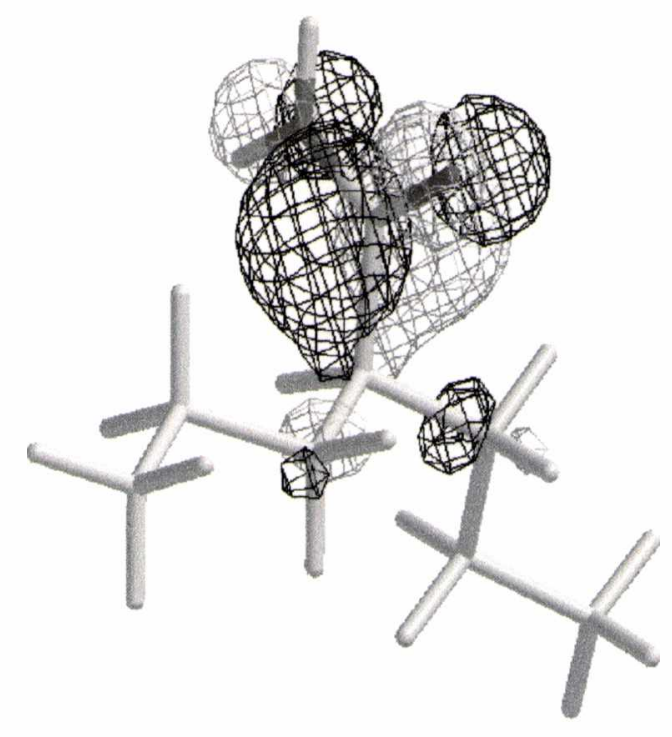

De esta manera, el análisis QSAR ha permitido ahondar en el conocimiento de los mecanismos involucrados en la interacción droga-receptor para los compuestos de esta serie, aún cuando no se conoce el sitio receptor. 


\footnotetext{
${ }^{\prime}$ Leo, A.J. Chem. Rev. (1993) 93: 1281

${ }^{2}$ Dykstra, C.E.; Augspurger, J.D.; Kirtman, B.; Malik, D.J. Chapter 3 In: Lipkowitz, K.B.; Boyd, D.B. (Eds.) Reviews in Computational Chemistry, Vol.1, VCH Publishers, New York (1990) pp. 83-118

${ }^{3}$ Martin, Y.C.; Bures, M.G.; Willett, P. Chapter 6 En: Lipkowitz, K.B.; Boyd, D.B. (Eds.) Reviews in Computational Chemistry, Vol.1, VCH Publishers, New York (1990) pp. 213-263

${ }^{4}$ Plummer, E.L. Chapter 4 En: Lipkowitz, K.B.; Boyd, D.B. (Eds.)

Reviews in Computational Chemistry, Vol.1, VCH Publishers, New York (1990) pp. 119-168

${ }^{5}$ Viswanadhan, V.N.; Ghose, A.K.; Revankar, G.N.; Robins, R.K. J. Chem. Inf. Comput. Sci. (1989) 29:163

${ }^{6}$ Ooi, T.; Oobatake, M.; Nemethy, G.; Scheraga, H.A. Proc. Natl. Acad. Sci. USA (1987) 84: 3086

${ }^{7}$ Bodor, N.; Gabanyi, Z.; Wong, C. J. Am. Chem. Soc. (1989) 111: 3783

${ }^{8}$ Gavezotti, A. J. Am. Chem. Soc. (1983) 10: 5220

${ }^{9}$ Miller, K.J. J. Am. Chem. Soc. (1990) 112: 8533

${ }^{10}$ Chemplus. Hypercube Inc., Ontario, Canadá (1993)

11 Topliss, J.G.; Edwards, C. J. Med Chem. (1979) 22: 1238

${ }^{12}$ Hacksell, U. Structural and Physiological Factors in Drug Action. En: Krogsgaard-Larsen, P.; Liljefors, T.; Madsen, U. (Eds.) A Textbook of Drug Design and Development, $2^{\text {nd }}$ Edition. Harwood Academic Publishers, Amsterdam (1996) pp. 35-59.
} 


\section{$\leftrightarrow$ CAPÍtulo $5 \propto$}

\section{MODELADO MOLECULAR DE LIGANDOS BLOQUEANTES DEL CANAL DE SODIO}

Como ya hemos comentado, dentro de los posibles mecanismos de acción que las drogas antiepilépticas pueden presentar se encuentra la interacción con canales iónicos, responsables directos de los cambios en la excitación neuronal. Específicamente el bloqueo de los canales de sodio neuronales ha demostrado ser un mecanismo común a varias drogas antiepilépticas estructuralmente diversas ${ }^{\prime}$.

Los mecanismos de los antiepilépticos se conocen actualmente con mayor precisión que en años anteriores. Esto ha permitido relacionar algunos comportamientos farmacológicos observados en animales, con mecanismos de acción específicos. Más precisamente, se ha observado que los compuestos bloqueantes de sodio previenen las convulsiones provocadas por el Electroshock Máximo ${ }^{1,2}$. De manera que es probable que una droga que presenta un patrón de actividad anti-MES, como los derivados de Vpd desarrollados en el Laboratorio de Farmacoquímica, manifieste sus acciones gracias a una acción bloqueadora de los canales de sodio neuronales.

Los mecanismos de acción de la mayoría de los antiepilépticos no se conocían con certeza sino hasta hace relativamente pocos años, a pesar de ser éstos utilizados ampliamente $\mathrm{y}$ de conocerse totalmente sus espectros farmacológicos. Actualmente es posible, mediante estudios in vitro, funcionales o de binding, determinar si un mecanismo de acción en particular está involucrado o no en la acción de una droga.

Dentro de este contexto, es totalmente válido y conveniente encarar el estudio de drogas con un mecanismo de acción determinado. En tal sentido, se considerarán en el trabajo que se describe a continuación, compuestos cuya acción bloqueadora de los canales de sodio neuronales haya sido reportada, y que además sean drogas antiepilépticas ya comercializadas o en vías de serlo, ya que existen muchos compuestos que siendo bloqueantes de sodio presentan acciones farmacológicas distintas, como los antiarrítmicos (mexitilene) y los anestésicos locales (lidocaína). 
Una vez obtenido un farmacóforo para la acción bloqueante de sodio, se relacionará éste con el obtenido para la acción anti-MES (sección 7 capítulo 4), pudiendo así inferir si los derivados de $\mathrm{Vpd}$ estudiados anteriormente actuarán mediante este mecanismo de acción.

\section{Descrioción del canal de sodio}

Como ya se comentó en el capítulo 3 , los canales iónicos representan una clase heterogénea de complejos proteicos, responsables de la generación y mediación de señales de y entre membranas celulares excitables. Los canales de sodio dependientes del voltaje (VGSCs*) responden a cambios en el potencial de membrana.

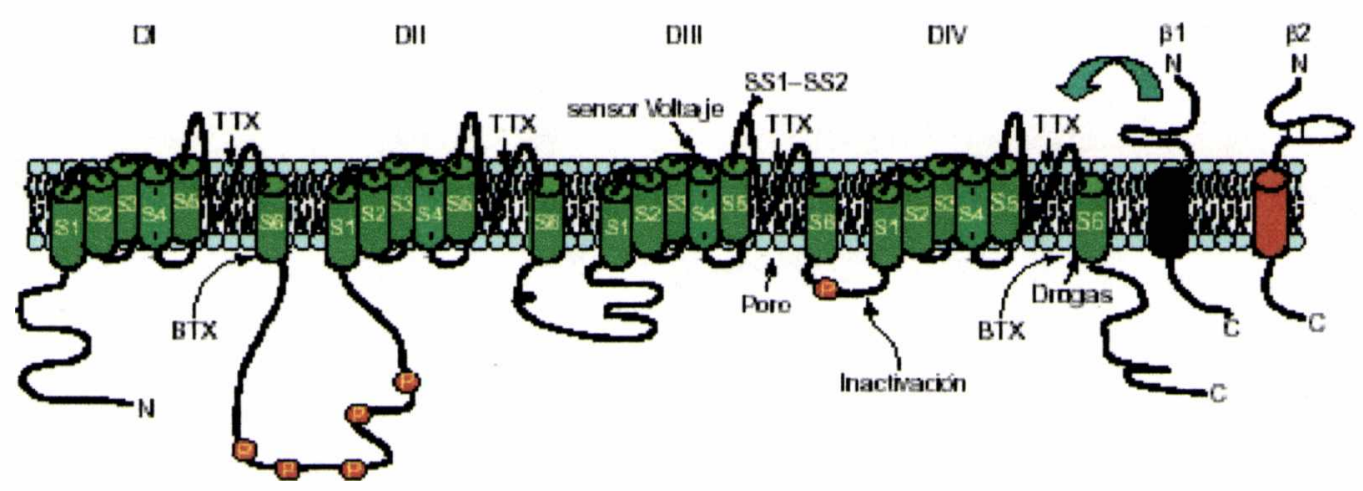

Figura 5.1 Dominios estructurales y sitios de unión en los VGSCs. Para mayor claridad, el sensor de voltaje, la región SS1-SS2, y el poro se indican sólo en el dominio III, pero están presentes también en los otros dominios. Los círculos rojos con la letra $P$ representan los sitios de fosforilación conocidos. La flecha verde muestra la zona de interacción de las subunidades $\alpha-\beta_{l}$. Además, se indican los sitios de unión a TTX, BTX y drogas, como asi también la compuerta de inactivación situada entre los dominios III y IV

(tomado de Clare, J.J. y col. ${ }^{4}$ )

Los antiepilépticos, tanto clásicos como nuevos, que inhiben este canal, generan una estabilización de la membrana ${ }^{3}$.

- VGSCs: Voltage Gated Sodium Channels: canales de sodio regulados por voltaje. 
El VGSC está formado por una subunidad $\alpha$, una subunidad $\beta_{1}$ y una subunidad $\beta_{2}$. La subunidad $\alpha$ tiene cuatro dominios que conforman el poro de sodio. Cada dominio está formado por seis segmentos transmembrana, de los cuales el cuarto segmento actúa como sensor de voltaje. Los segmentos 5 y 6 de los cuatro dominios forman el poro del canal (Figura 5.1). En el cerebro se han descrito cuatro subunidades $\alpha$ (I, II, IIA, y NaCh6). La subunidad $\alpha$ es operativa por sí sola. Las cargas negativas de los carboxilos del glutámico le confieren su selectividad por cationes, y los residuos de lisina y alanina hacen que sea permeable para el sodio (más pequeño), pero no para el calcio (más grande) ${ }^{3}$. El asa hidrofóbico SS1-SS2 o "región P" es la que contiene el filtro selectivo de iones ${ }^{4}$. La actividad del canal es regulada por fosforilación de proteínas y por proteínas $\mathrm{G}^{5}$. La inactivación rápida del canal está relacionada con el asa que une los dominios III y IV IV $^{3}$ Fenitoína y los anestésicos locales parecen unirse a un sitio en el sexto elemento transmembrana del dominio IV, del lado intracelular, según lo indicaron experimentos de mutagénesis ${ }^{3,4}$. Las subunidades $\beta_{1}$ y $\beta_{2}$ parecen tener un papel modulador ${ }^{3}$.

En el estudio funcional de los VGSCs se han usado como herramientas una gran variedad de toxinas que los modulan. Así, estos canales frecuentemente se subdividen de acuerdo a su sensibilidad a la tetrodotoxina (TTX). Un solo residuo aminoacídico es crítico para la resistencia a TTX. El sitio de unión de batrachotoxina (BTX), un alcaloide aislado del veneno de una especie de rana, se superpone con el sitio de unión de drogas, generando interacciones alostéricas ${ }^{4}$. En esto último se basa el ensayo in vitro de binding al sitio 2 de BTX, al que se someten las potenciales drogas anticonvulsivas. El sitio 2 de neurotoxinas se encuentra en los segmentos 6 de los dominios I y IV, y allí se unen veratridina, aconitina y BTX (prototipo de este grupo), provocando una prolongada activación ${ }^{4}$.

Sin embargo, a pesar de que se sabe bastante acerca del VGSC, aún no ha sido posible construir un modelo del sitio activo en donde actúan las drogas antiepilépticas en base a este conocimiento. 


\section{Elección del coniunto de compuestos a estudiar}

Se decidió entonces tratar de identificar un patrón farmacofórico para la acción bloqueadora de los canales de

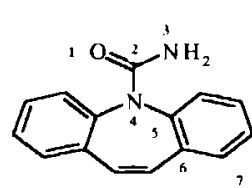

C. $Z$<smiles></smiles>

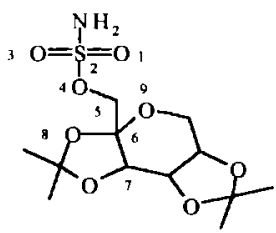

TOP

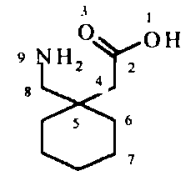

G B P

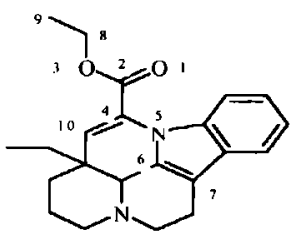

VIN

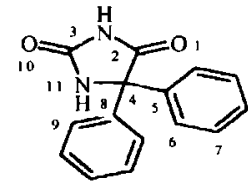

PHE

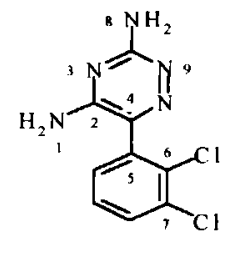

L. A M

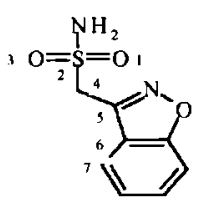

zov

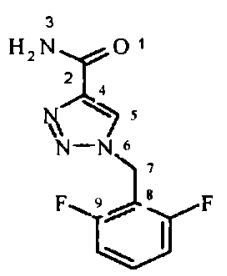

R U F

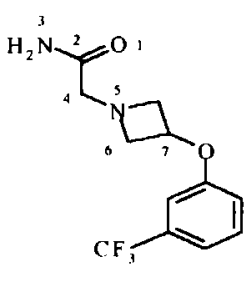

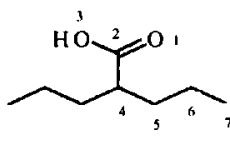

VPA
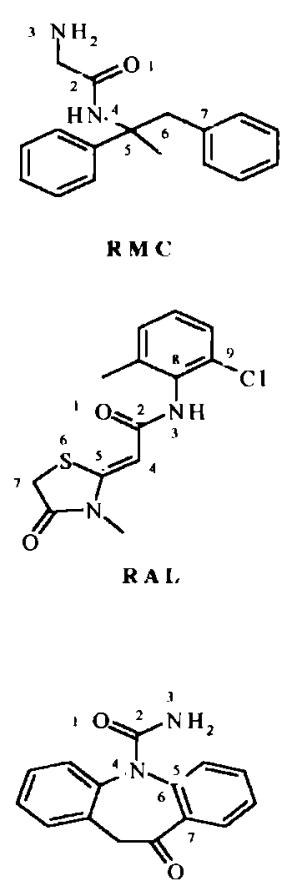

ocz

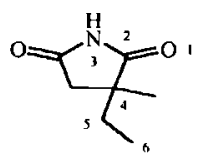

E'T H

Figura 5.2

Estructuras de antiepilépticos clásicos y

nuevos,

bloqueantes de los VGSCs:

carbamazepina (CZ),

fenitoina

(PHE),

ácido valproico

(VPA),

felbamato

(FLB),

lamotrigina

(LAM),

remacemida

(RMC),

topiramato

(TOP),

zonisamida

(ZON).

ralitolina

(RAL),

gabapentin

(GBP),

rufinamida

(RUF),

oxcarbazepina

(OCZ),

vinpocetina

$(V D N)$,

dezinamida

(DEZ),

etostaximida

(ETH).

Los ángulos

diedros se

definen asi:

$\tau_{1}: 1-2-4-5$,

$\tau_{2}: 2-4-5-6$,

$\tau_{3}:$ 4-5-6-7,

$\tau_{4}: 1-2-3-8$

$\tau_{5}: 2-3-8-9$,

$\tau_{6}:$ 4-5-8-9,

$\tau_{7}:$ 5-6-7-8,

$\tau_{8}:$ 6-7-8-9. para el presente estudio aquéllas para las cuales se ha reportado su acción sobre los VGSCs ${ }^{6,7,8,9,10,11,12,13,14,15,16}$, lo 
cual no implica que éste sea el mecanismo de acción principal. Así, deben incluirse a PHE, CZ y Vpa (Figura 5.2) entre las drogas clásicas bloqueantes de sodio (ver tabla 3.4 sobre los mecanismos de acción de las DAEs).

Dentro de las drogas nuevas ya comercializadas se incluyen (ver tabla 3.4): felbamato (FLB), lamotrigina (LAM), topiramato (TOP), zonisamida (ZON), gabapentin (GBP), oxcarbazepina (OCZ) y vinpocetina (VIN) (ésta última se comercializa pero para otras afecciones) ${ }^{17}$ (Figura 5.2). Se incluyen también otras prontas a ser comercializadas y que actualmente se encuentran en distintas fases de los estudios clínicos: remacemida (RMC) ${ }^{1}$, rufinamida (RUF) ${ }^{1}$, ralitolina (RAL) ${ }^{18}$ y dezinamida (DEZ) ${ }^{18}$ (Figura 5.2).

Como vemos, algunas de las estructuras ya habían sido incluidas en el conjunto utilizado para el estudio de los requisitos asociados a la actividad anti-MES (sección $7 \mathrm{del}$ capítulo 4). Esto es lógico, ya que como dijimos, una acción anti-MES está íntimamente ligada a un posible mecanismo a través del bloqueo de canales de sodio. Así mismo, se considerará nuevamente a la droga ETH (Figura 5.2) como análogo inactivo por ser uno de los antiepilépticos principales usados en crisis de ausencia ${ }^{19}$ (ver tabla 3.2 sobre el empleo de las DAEs según el tipo de convulsión), que no presenta acción sobre los canales de sodio ${ }^{20,21}$.

\section{Descripción de la metodología}

Para el estudio teórico de las estructuras se emplean los programas y facilidades del Laboratorio de Farmacoquímica, ya descriptos en la sección 7 del capítulo 4 .

\section{Análisis conformacional.}

Las estructuras 3D se generaron mediante el empleo del programa HyperChem ${ }^{22}$.

Generación de conformaciones iniciales

$\mathrm{El}$ análisis conformacional de CZ, PHE y ETH fue ya descripto en la sección 7 del capítulo 4. Para el análisis del resto de las estructuras se utilizó tanto metodología sistemática como estocástica, dependiendo de la flexibilidad de cada uno de los compuestos. La metodología sistemática empleada involucró la modificación de todos los ángulos de torsión rotables de cada molécula, excepto en el caso de $\mathrm{Vpa}$, para el cual la orientación de las cadenas laterales ya se conoce en base a estudios previos ${ }^{23}$ ), como ya se comentó en la sección 7 del capítulo 4 . En consecuencia, se consideró sólo la variación de $\tau_{1}$ para $\mathrm{Vpa}$, al igual que para $\mathrm{OCZ}$ y LAM. Dadas las características de ZON, se modificaron en 
este caso $\tau_{1}$ y $\tau_{2}$. Además de estos dos ángulos, se varió también $\tau_{3}$ en el caso de TOP, $\tau_{6}$ para GBP, y $\tau_{4}$ y $\tau_{5}$ en el caso de RAL. Además de $\tau_{1}$, se variaron $\tau_{4}$ y $\tau_{5}$ en el caso de VIN, y $\tau_{7}$ y $\tau_{8}$ para RUF (Figura 5.2). Para las estructuras más flexibles del conjunto (RMC, FLB y DEZ) se eligió un procedimiento estocástico para la generación de las conformaciones iniciales, efectuando corridas de dinámica molecular de hasta $20 \mathrm{ps}$, a $300-600^{\circ} \mathrm{K}$, con un paso de 0.0005 ps. Las estructuras "enfriadas" fueron luego optimizadas.

En el caso de TOP, el análisis conformacional reveló que en las conformaciones más estables había formación de enlaces de hidrógeno entre el $\mathrm{O} 8$ o el O9 y el N (Figura 5.2), siendo $0.3 \mathrm{kcal} / \mathrm{mol}$ más estable la conformación que involucra al $\mathrm{O} 8$ en el puente de hidrógeno. Para confirmar la formación de estos enlaces de $\mathrm{H}$ se estudiaron estas conformaciones a nivel 3-21G (Gaussian $98^{24}$ ). Para tal fin, se optimizó la geometría de una porción representativa de la molécula, que mantiene las características locales del fragmento involucrado en el puente de hidrógeno. En este estudio se simuló la influencia del solvente, modelado como un continuo mediante el modelo de Onsager. El modelo de Onsager está implementado en Gaussian $98^{24}$ y consiste en una simulación del solvente como un continuo de constante dieléctrica uniforme dentro del cual se sitúa el soluto inserto en una cavidad esférica.

\section{Optimización de geometrías}

Durante las optimizaciones se dejan completamente libres todos los parámetros geométricos. Se utiliza un algoritmo de minimización basado en gradientes conjugados (PolakRibiere $^{25}$ ) y la optimización se continúa hasta convergencia de RMS del gradiente a $0.05 \mathrm{kcal} /$ Amol.

\section{Consideración de geometrias finales}

Se evalúan las distintas conformaciones finales y se consideran aquéllas de mínima energía, es decir las más probables.

\section{Búsqueda de la conformación activa.}

Como se describió para los compuestos anti-MES en la sección 7 del capítulo 4, para analizar la viabilidad de los distintos compuestos de alcanzar la conformación activa a partir de la más estable, se calcularon los costos energéticos asociados con las modificaciones de los diedros involucrados en la porción farmacofórica. Para esta evaluación, cada uno de los ángulos se modificó en pasos de 4-10 ${ }^{\circ}$ hasta alcanzar el valor deseado, manteniéndolo congelado en cada paso mientras los otros grados de libertad se optimizaron 
totalmente. Los compuestos deben ser capaces de soportar esta modificación a un bajo costo energético.

\section{Método de cálculo.}

En forma análoga al estudio previo para los derivados anti-MES, se empleó un hamiltoniano AM1 para el estudio del espacio conformacional, y para el cálculo de las barreras energéticas de rotación alrededor de enlaces simples. Una vez obtenidas las conformaciones activas para cada una de las estructuras, éstas se refinan realizando optimizaciones restringidas en dicha conformación. Se emplea para ello metodología DFT B3LYP con bases 6-31+G(d,p). En el caso de TOP y LAM también se realizaron cálculos HF-MP2 (con las mismas bases) para confirmar la validez de los resultados obtenidos por DFT, obteniéndose resultados comparables. Por razones de costo computacional el cálculo HF-MP2 sólo se efectuó para las estructuras completas de TOP y LAM, mientras que para el resto dicho cálculo se realizó sobre una porción estructural menor (de 8-11 átomos) representativa de la zona polar farmacofórica de cada una de las estructuras.

\section{Densidades de carga.}

Las distribuciones de carga se calcularon mediante el análisis del potencial electrostático (ChelpG). Se consideraron las conformaciones activas provenientes de las optimizaciones con metodología DFT descriptas.

\section{Resultados y discusión}

La observación de las estructuras (Figura 5.2) sugiere que existen dos determinantes moleculares de distinta hidrofobicidad que se repiten en todas las estructuras: una parte polar y una parte hidrofóbica. La porción polar está definida por los átomos 1, 2 y 3 (Figura 5.2). La porción hidrofóbica se refiere a los grupos, aromáticos o alifáticos, unidos en posición 4 (Figura 5.2). La hidrofobicidad del Vpa puede asociarse a una o dos cadenas alquilicas. Sin embargo, en ligandos como FLB, RAL, DEZ, TOP, ZON aparece sólo una cadena hidrocarbonada en posición 4. El análisis comparativo sugiere que es necesaria una hidrofobicidad mínima. ETH, el análogo inactivo, muestra al igual que en el estudio sobre drogas anti-MES, que este grupo hidrofóbico debe contener al menos 3 átomos.

$\mathrm{Al}$ igual que para los compuestos anti-MES, las estructuras de PHE y CZ son tomadas para definir un análogo rígido, y se toman como punto de partida para la superposición realizada mediante el empleo del programa 
Sybil $^{26}$. La conformación activa está dada por la superposición de estos análogos rígidos, y puede definirse en términos de valores estrictos de los diedros $\tau_{1}, \tau_{2}$ y $\tau_{3}$, o bien en términos de distancias, por ejemplo la distancia que separa el grupo polar del grupo no polar.

Para determinar si es factible para los demás compuestos alcanzar la conformación activa, se evalúan como se describe en el item de metodología, las energías involucradas en los movimientos torsionales alrededor de los enlaces 4-2, 5-4 y 5-6, que definen los ángulos $\tau_{1}, \tau_{2}$ y $\tau_{3}$, hasta alcanzar los valores asociados a la conformación activa. Los compuestos que lo logran a un bajo costo energético son dables de existir en la conformación activa. Para esa conformación, la superposición de las estructuras con el análogo rígido define el patrón farmacofórico. En el momento de la interacción, tanto el ligando como el sitio receptor se acomodan uno al otro para un mejor acople. Sin embargo, mediante le procedimiento descrito, sólo se está evaluando la flexibilidad del ligando. Por ello, se considera que un rango de $10^{\circ}$ en la variación de los ángulos diedros o de una distancia menor a $0.7 \AA$ en la superposición de los átomos da una descripción adecuada de la dinámica del proceso de interacción.

En la tabla 5.1 se presentan los valores asociados a la energía para la rotación de los diedros $\tau_{1}, \tau_{2}$ y $\tau_{3}$, necesaria para alcanzar la conformación activa.

Los datos obtenidos para la energía involucrada en la evolución de la conformación más estable a la del análogo rígido para cada estructura $(\Delta \mathrm{E}$, tabla 5.1$)$, demuestran que ésta es lo suficientemente baja como para que todas las estructuras puedan adoptar la conformación activa. Son capaces, entonces, de acomodarse a las exigencias del receptor y provocar la respuesta biológica. Los valores de energía para el cambio conformacional total mayores de 7 $\mathrm{kcal} / \mathrm{mol}$ son considerados no compatibles con la actividad.

En el caso de TOP, la energía involucrada en la rotación alrededor de $\tau_{2}$ (aproximadamente $6 \mathrm{kcals}$, tabla 5.1) surge de dos contribuciones: por un lado de las interacciones intramoleculares repulsivas debidas a la rotación, y por el otro del proceso de ruptura del enlace de hidrógeno entre el $\mathrm{N}$ y O8 (Figura 5.2) que no se mantiene en la conformación activa. 


\begin{tabular}{ccccccccc} 
Molécula & $\tau_{1}{ }^{*}$ & $\Delta \mathrm{E}_{1}$ & $\tau_{2}{ }^{*}$ & $\Delta \mathrm{E}_{2}$ & $\tau_{3}{ }^{*}$ & $\Delta \mathrm{E}_{3}$ & $\Delta \mathrm{E}$ & $\mathrm{d}_{1-7}(\AA)$ \\
\hline CZ & -70 & 2.68 & -152 & --- & 178 & --- & 2.68 & 5.47 \\
PHE & -64 & --- & -1 & 0.43 & 179 & --- & 0.43 & 5.52 \\
VPA & -64 & 0.00 & -72 & 0.99 & 175 & --- & 0.99 & 5.51 \\
FLB & 9 & 1.85 & 171 & 2.15 & -80 & 0.87 & 4.87 & 5.31 \\
LAM & -3 & 3.29 & -115 & 1.87 & 180 & --- & 5.16 & 5.27 \\
RMC & 5 & 1.47 & 173 & 1.13 & -56 & 4.47 & 7.07 & 5.51 \\
TOP & -23 & 0.03 & -87 & 6.56 & -171 & 0.43 & 7.02 & 5.57 \\
ZON & -144 & 0.24 & -107 & 1.31 & -179 & --- & 1.55 & 5.22 \\
RAL & 61 & 1.69 & -178 & 3.44 & -178 & --- & 5.13 & 5.60 \\
GBP & 98 & 1.27 & -64 & 3.85 & -170 & --- & 5.12 & 5.74 \\
RUF & 1 & 2.67 & 179 & 2.10 & 174 & --- & 4.77 & 5.73 \\
OCZ & 6 & 2.63 & -138 & 0.39 & 180 & --- & 3.02 & 5.42 \\
VIN & -54 & --- & -172 & 1.11 & 153 & 4.35 & 5.46 & 5.40 \\
DEZ & 134 & 4.88 & 178 & --- & 122 & 0.28 & 5.16 & 5.12 \\
ETH & -59 & 0.04 & 178 & 1.74 & $\ldots-$ & --- & 1.78 & 4.55
\end{tabular}

\section{Tabla 5.1}

Características conformacionales de cada una de las estructuras incluidas en la determinación del farmacóforo para la acción bloqueante de sodio.

$\Delta$ Ei representa la energía parcial que corresponde a la evolución de $\tau_{1}$ desde el valor en el minimo absoluto $\left(\tau_{1}^{*}\right)$ hasta el valor en el análogo rígido $\left(\tau_{1}=-64^{\circ}, \tau_{2}=-152^{\circ}, \tau_{3}=180^{\circ}\right)$. $\Delta E$ representa la suma $\Delta E 1+\Delta E 2+\Delta E 3$.

$d_{1-7}$ es la mayor distancia que separa el grupo polar del no polar, definido por la distancia entre el átomo negativamente cargadol y el átomo 7.

De la superposición de las estructuras en sus conformaciones activas, se encuentran las características que definen el farmacóforo. Este está asociado a un arreglo espacial particular del grupo polar con respecto al grupo hidrofóbico, descripto principalmente por los valores de los ángulos diedros $\tau_{1}, \tau_{2} y \tau_{3}$. Esto también establece una distancia de $5.5 \AA\left(\mathrm{d}_{1-7}\right.$, tabla 5.1$)$ entre el grupo polar (específicamente el átomo 1, figura 5.2) y el último átomo de la porción hidrofóbica (el átomo 7, figura 5.2). 
En la figura 5.3 se muestran todas las estructuras, en sus conformaciones activas, superpuestas por la porción farmacofórica.

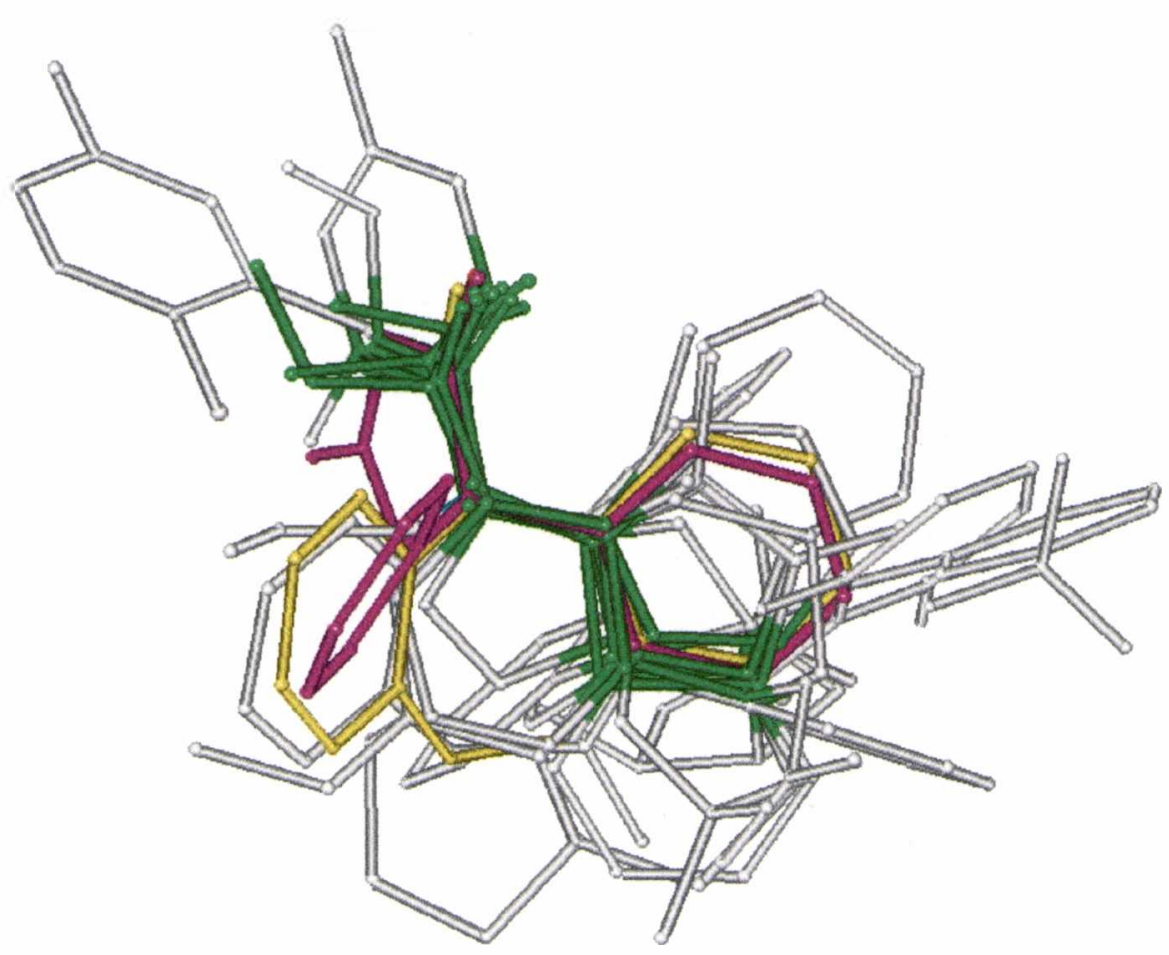

Figura 5.3 Superposición de todas las estructuras bloqueantes de sodio en sus conformaciones activas.

La porción farmacofórica se muestra en verde.

Los análogos rígidos $P H E$ y CZ se muestran en fucsia y amarillo, respectivamente.

La tabla 5.2 muestra las densidades locales de carga sobre los átomos que definen el grupo polar del farmacóforo. Esta descripción electrónica corresponde a la conformación activa de los derivados. El patrón de separación de cargas en los centros positivos y negativos de la porción polar se mantienen a lo largo de la serie tanto a nivel de cálculo semiempírico (AM1) como de funcionales de densidad o ab initio correlacionado (B3LYP, HF-MP2). En todos los casos el centro positivo se sitúa sobre un átomo de carbono o azufre, y los centros negativos sobre átomos de oxígeno o nitrógeno. En el caso de RMC, uno de los centros negativos del grupo polar $\left(\mathrm{N}_{3}\right)$ está separado por dos enlaces del centro positivo (Figura 5.2). Aún así, la superposición de los puntos farmacofóricos de RMC con los análogos rígidos es adecuada (Figura 5.3). 


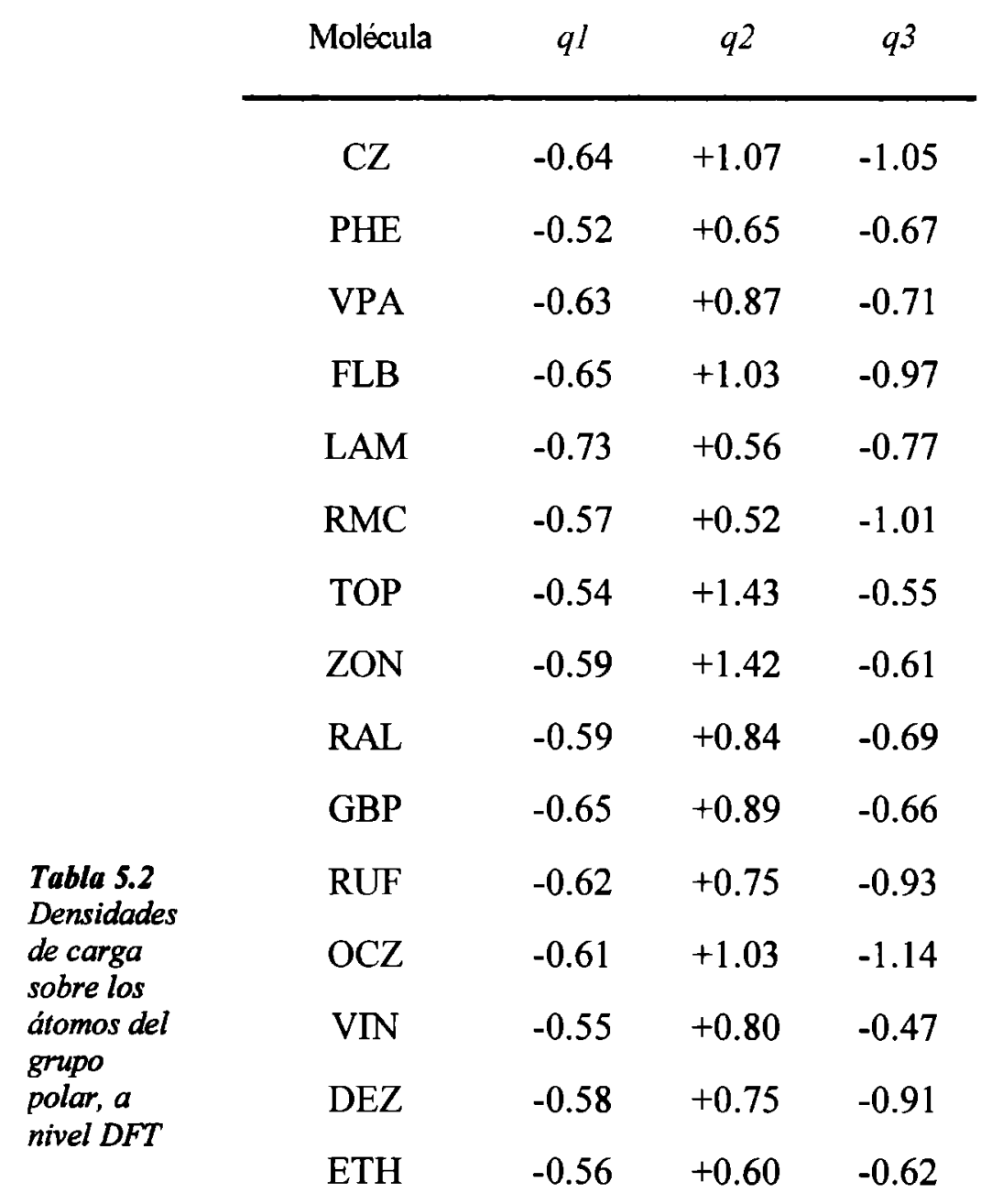

La semejanza de los resultados obtenidos a partir de distintos niveles de cálculo apoya la exactitud de la descripción electrónica. La importancia de encontrar requisitos electrónicos está relacionada con el hecho de que, en el momento de la interacción, el sitio receptor percibe las distribuciones electrónicas que se aproximan ${ }^{27}$. Sobre la base de esta consideración, la constancia en la distribución de cargas sobre los centros atómicos del grupo polar indica que se trata de una parte relevante para la atracción eficaz ligando-receptor.

De manera que el farmacóforo queda definido tanto por requisitos estructurales, electrónicos y conformacionales (Figura 5.4). Los requisitos estructurales y electrónicos consisten en: 
Figura 5.4

Patrón farmacofórico

para la acción

bloqueante de los

canales de sodio

neuronales

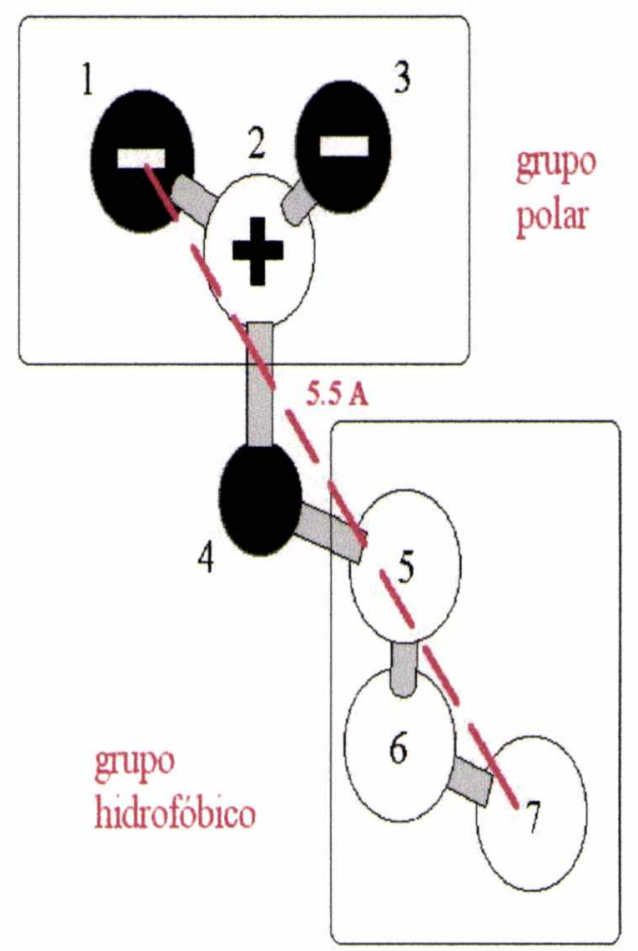

$\checkmark$ una porción de 3 átomos caracterizada por una polarización grande de los enlaces (cargas negativas sobre los átomos 1 y 3 , y positiva sobre el átomo 2), unida a un átomo $\mathrm{sp} 3$, que puede ser nitrógeno ( $\mathrm{CZ}, \mathrm{RMC}, \mathrm{OCZ})$, carbono (Vpa, ZON, RAL, LAM, PHE, GBP, RUF, VIN, DEZ), u oxígeno (TOP, FLB).

$\checkmark$ una porción hidrofóbica coordinada mediante el átomo en posición 4 al centro positivo del grupo polar, que comprende al menos 3 átomos, que pueden ser de naturaleza aromática (PHE, CZ, RAL, ZON, LAM, OCZ) o alifática (Vpa, FLB, TOP, RMC, GBP, RUF, VIN, DEZ).

Los requisitos conformacionales están asociados a la orientación espacial de la porción hidrofóbica en relación al grupo polar, que puede definirse mediante los valores de los ángulos diedros $\tau_{1}, \tau_{2}$ y $\tau_{3}$ de $-64^{\circ},-152^{\circ}$ y $178^{\circ}$ respectivamente, o bien mediante la superposición de los centros atómicos correspondientes. Tanto el centro negativo 1 como la porción hidrofóbica están orientados en el mismo sentido, de manera que son capaces de interaccionar simultáneamente con un grupo aceptor de electrones y un bolsillo hidrofóbico del receptor, respectivamente.

La distancia entre el grupo polar y el hidrofóbico (tomada desde el átomo 1 al 7) se encuentra siempre dentro del rango de 5.1-5.7 $\AA$ (Tabla 5.1). El otro centro negativo 
del resto polar, orientado en sentido opuesto, puede no estar implicado en la interacción, pero juega un rol importante en la estabilización de la separación de carga del grupo polar. Por esta razón se lo incluye en la definición del farmacóforo, aunque en algunos casos su interacción se vea estructuralmente dificultada.

Los resultados obtenidos que conducen a la definición de un farmacóforo para la acción bloqueante de sodio, se condicen con los resultados anteriores sobre el farmacóforo de compuestos anti-MES y el análisis QSAR realizado (capítulo 4). La similitud entre los dos farmacóforos es lógica ya que, a pesar de tratarse de dos conjuntos de compuestos distintos, elegidos en base a distintos criterios, se hace uso de los mismos análogos rígidos. Además, los resultados obtenidos del análisis QSAR también están de acuerdo en cuanto a que indican que el grupo carbonilico del grupo amida es el principal responsable de la actividad anti-MES, coincidente con el grupo polar encontrado en todas las estructuras bloqueantes de sodio analizadas. Estos resultados están de acuerdo con el hecho de que ambos comportamientos farmacológicos están íntimamente ligados.

\section{Acción bloqueante del canal de sodio de derivados de valpramida}

Las drogas analizadas en general muestran un perfil farmacológico similar a PHE en cuanto a que son activas frente al ensayo MES, aunque algunas de ellas también presentan acción cuando se las evalúa frente a PTZ, probablemente debido a que interviene mas de un mecanismo de acción a nivel molecular.

Nuestras Vpds muestran un perfil netamente del tipo PHE: activas frente al ensayo MES e inactivas frente al ensayo PTZ. Su acción anti-MES nos condujo a emplearlas en el desarrollo y planteo de un farmacóforo para este tipo de actividad. El perfil farmacológico que mostraron, conjuntamente con la similitud de ambos farmacóforos (antiMES y bloqueante de sodio), nos llevó a querer verificar el mecanismo molecular asociado a la acción de los derivados de Vpd. Todo lo expuesto parece indicar que el bloqueo de los canales de sodio neuronales constituiría el mecanismo de acción fundamental de estas drogas por el que manifiestan su acción anticonvulsiva. El modo más directo de comprobarlo es sometiendo a la droga en cuestión a ensayos de binding al canal, en células de cerebro de rata. Para tal fin, se utiliza un radioligando $\left(\left[{ }^{3} \mathrm{H}\right]\right.$ batrachotoxina) $\quad$ y $\quad$ se mide su desplazamiento. 
En la actualidad, este ensayo ya ha sido utilizado para comprobar la interacción de distintos compuestos con el sitio 2 del canal de sodio neuronal, aunque como ya se mencionó al comienzo de este capítulo, la diversidad de interacciones alostéricas entre los distintos sitios, complica la situación, siendo dificil asegurar un sitio de unión común a todos los compuestos activos.

Los estudios iniciales realizados, consistentes en el ensayo de una de las Vpds diseñadas dentro de esta investigación, la EtVpd (Figura 5.5.), ha resultado en una actividad positiva para el binding al sitio 2 del canal de sodio neuronal*. La EtVpd mostró un $10 \%$ de inhibición de la unión de BTX a una dosis de $200 \mu \mathrm{M}$. Si se compara con PHE, uno de los más potentes inhibidores de los canales de

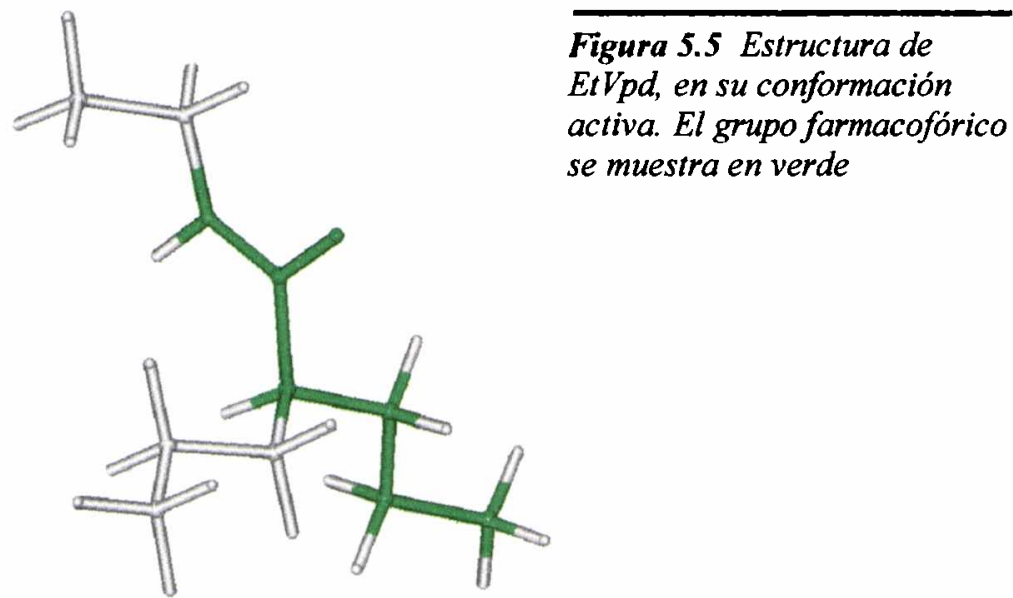

sodio $\left(\right.$ IC50 $\left.=40 \mu \mathrm{M}^{2,20,28,29}\right)$, y a CZ $\left(\right.$ IC50 $\left.=361 \mu \mathrm{M}^{30}\right)$, la EtVpd muestra una acción mucho más leve. Un análisis QSAR para este tipo de drogas podría ayudar a dilucidar los descriptores que afectan cuantitativamente a este bloqueo.

De todas maneras, la demostración de que al menos una de las Vpds muestra una interacción, aunque leve, con el canal de sodio neuronal, da validez a nuestra presunción de los requisitos farmacofóricos que un compuesto debe satisfacer para presentar actividad frente a dicho canal iónico.

\footnotetext{
- Se eligió EtVpd, y no el derivado más potente de la serie ensayada (SuVpd), debido a que este último no cumple con los requisitos de solubilidad necesarios para el ensayo de binding.
} 
${ }^{1}$ Taylor, Ch.P. Cap.69: Mechanisms of New Antiepileptic Drugs. En: Delgado-Escueta, A.V.; Wilson, W.A.; Olsen, R.W.; Porter, R.J. (Eds.), Jasper's Basic Mechanisms of the Epilepsies, $3^{\text {rd }}$ Ed.: Advances in Neurology, Vol.79, Lippincott Williams \& Wilkins, Philadelphia (1999) pp. $1011-1026$

${ }_{2}$ Anger, T.; Madge, D.J.; Mulla, M.; Riddall, D. J. Med. Chem. (2001) 44(2):115-37

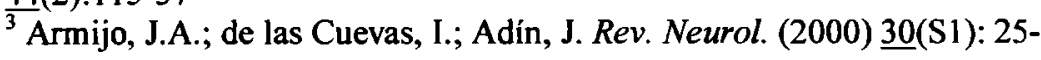
41

${ }^{4}$ Clare, J. J.; Tate, S. N.; Nobbs, M.; Romanos, M. A. Drug Discov. Today (2000) 5(11): 506-20

${ }^{5}$ Catterall, W.A. Molecular Properties of Brain Sodium Channels: An Important Target for Anticonvulsant Drugs. En: Delgado-Escueta, A.V.; Wilson, W.A.; Olsen, R.W.; Porter, R.J. (Eds.) Jasper's Basic Mehanisms of the Epilepsies, $3^{\text {rd }}$ Ed.: Advances in Neurology, Vol.79, Lippincott Williams \& Wilkins, Philadelphia (1999) pp. 441-456

${ }^{6}$ Bazil, C. W.; Pedley, T. A. Annu. Rev. Med. (1998) 49: 135

${ }^{7}$ Leach, J. P. CNS Drugs (1997) $8(5): 366$

${ }^{8}$ Unverferth, K.; Engel, J.; Hofgem, N.; Rostock, A.; Gunther, R.; Lankau, H.; Menzer, M.; Rolfs, A.; Liebscher, J.; Muller, B.; Hofmann, H. J. Med. Chem. (1998) 41: 63

${ }^{9}$ Ragsdale, D. S.; Avoli, M. Brain Res. Rev. (1998) 26: 16

${ }^{10}$ Meldrum, B. S. Epilepsia (1996) 37(6): 4

${ }^{11}$ Loscher, W.; Schmidt, D. Epilepsy Res. (1994) 17: 95

${ }^{12}$ Rogawski, M. A.; Porter, R. J. Pharm. Rev. (1990) 42 (3): 223

${ }^{13}$ Bialer, M.; Johannessen, S. I.; Kupferberg, H. J.; Levy, R. H.; Loiseau, P.; Perucca, E. Epilepsy Res. (1996) 25: 299

${ }^{14}$ Fariello, R. G.; Varasi, M.; Smith, M. C. En: Antiepileptic Drugs, 4 th Edition; Levy, R.; Mattson, R.; Meldrum, B., (Eds.) Raven Press, New York (1995) pp. 581

${ }^{15}$ Taylor, C. P. En: Antiepileptic Drugs, 4th Edition; Levy, R.; Mattson, R; Meldrum, B. (Eds.) Raven Press, New York (1995) pp. 829.

${ }^{16}$ Dam, M.; Ostergaard, L. H. En: Antiepileptic Drugs, 4th Edition; Levy, ${ }_{3}$ R.; Mattson, R.; Meldrum, B. (Eds) Raven Press, New York (1995) pp. 9887.

17 Molnar, P.; Erdo, S. L. Eur. J. Pharmacol. (1995) 273: 303

188 Bialer, M.; Johannessen, S.I.; Kupferberg, H.J.; Levy, R.H.; Loiseau,

P.; Perucca, E. Epilepsy Res. (1996) 25(3): 299-319

${ }^{19}$ Ferrendelli, J.A.; Holland, K.D. Cap. 46: Ethosuximide: Mechanisms of Action En: Levy, R.; Mattson, R.; Meldrum, B.; Penry, J.K.; Dreifuss, F.E. (Eds.) Antiepileptic Drugs, $3^{\text {rd }}$ Ed., Raven Press, Ltd., New York (1989) pp. 653-62

${ }^{20}$ Willow, M.; Catterall, W.A. Mol. Pharmacol. (1982) 22: 627

${ }^{21}$ Willow, M.; Kuenzel, E.A.; Catterall, W.A. Mol. Pharmacol. (1984) 25: 228

${ }^{22}$ Hyperchem 5.1 for Windows. Hypercube Inc., Gainesville FL (1997)

${ }^{23}$ Chang, Y.T.; Loew, G.H.; Rettie, A.E.; Baillie, T.A.; Otiz de

Montellano, P.R. Int. J. Luantum Chem., Quantum Biology Symp.(1993) 20: 161

${ }^{24}$ Gaussian 98 , Revision A.9, M. J. Frisch, G. W. Trucks, H. B. Schlegel, G. E. Sctíseria, M. A. Robb, J. R. Cheeseman, V. G. Zakrzewski, J. A. Montgomery, Jr., R. E. Stratmann, J. C. Burant, S. Dapprich, J. M. Millam, A. D. Daniels, K. N. Kudin, M. C. Strain, O. Farkas, J. Tomasi, V. Barone, M. Cossi, R. Cammi, B. Mennucci, C. Pomelli, C. Adamo, S. Clifford, J. Ochterski, G. A. Petersson, P. Y. Ayala, Q. Cui, K.

Morokuma, D. K. Malick, A. D. Rabuck, K. Raghavachari, J. B.

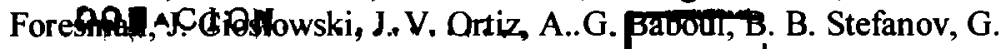

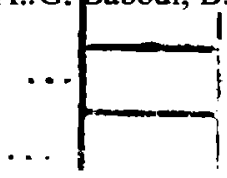


Liu, A. Liashenko, P. Piskorz, I. Komaromi, R. Gomperts, R. L. Martin, D. J. Fox, T. Keith, M. A. Al-Laham, C. Y. Peng, A. Nanayakkara, M. Challacombe, P. M. W. Gill, B. Johnson, W. Chen, M. W. Wong, J. L. Andres, C. Gonzalez, M. Head-Gordon, E. S. Replogle, and J. A. Pople, Gaussian Inc., Pittsburgh PA (1998)

${ }^{25}$ Chapter 5: Geometry Optimizations and Transition State Searching En: Hyperchem, Computational Chemistry, Hypercube Inc., Canadá (1996) pp. 57-68

${ }^{26}$ Sybil. Tripos Inc., San Diego, CA

${ }^{27}$ Balbes, L.M.; Mascarella, S.W.; Boyd, D.B. Chapter 7: A Perspective of Modern Methods in Computer Aided Drug Design En: Lipkowitz, K.B.; Boyd, D.B. (Eds.) Reviews in Computational Chemistry, Vol.5, VCH Publishers, Inc., New York (1994) pp.337-379

${ }^{28}$ Brown, M.L.; Brown, G.B.; Brouillette, W.J. J. Med. Chem. (1997) 40 : 602-7

${ }^{29}$ Taylor, Ch.P.; Meldrum, B.S. TiPS (1995) 16: 309-16

${ }^{30}$ Bonifacio, M.J.; Sheridan, R.D.; Parada, A.; Cunha, R.A.; Patmore, L.; Soares da Silva, P. Epilepsia (2001) 42(5): 600-8 


\section{$\propto$ CAPÍTULO $6 \propto$}

\section{MODELADO MOLECULAR DE LIGANDOS DEL RECEPTOR DE GLUTAMATO MGLUR1}

Otro de los posibles mecanismos de acción de las drogas antiepilépticas es la disminución de las respuestas excitatorias glutamatérgicas. Como se comentó en el capítulo 3 , el glutamato es uno de los principales aminoácidos excitatorios del SNC, capaz de manifestar sus acciones mediante su interacción con distintos tipos de receptores. Estos receptores pueden ser ionotrópicos (iGluR) o metabotrópicos (mGluR). Los primeros han sido extensamente estudiados, especialmente el receptor NMDA, mientras que la investigación relacionada a los receptores metabotrópicos se encuentra actualmente en pleno desarrollo, con la aparición reciente de un gran número de nuevos ligandos de los distintos subtipos de receptores.

Se han identificado 8 subclases diferentes de receptores metabotrópicos de glutamato, que han sido clasificadas en 3 grupos ${ }^{1}$ en base a la identidad de secuencia, a los segundos mensajeros involucrados y al tipo de respuesta metabólica que desencadenan ${ }^{2}$ (Figura 6.1).

Figura 6.1

Clasificación de la familia de receptores mGluR.

La transducción de señales consiste en la estimulación de la fosfolipasa C (PLC) $e$ hidrólisis de

fosfoinosítidos en el caso del grupo I, y en la inhibición de la adenilato ciclasa $(A C)$ en los grupos II y III

(Tomado de Conn, P.J. y col. ${ }^{2}$ )
Identidad de secuencia aminoacídica Grupo Señal

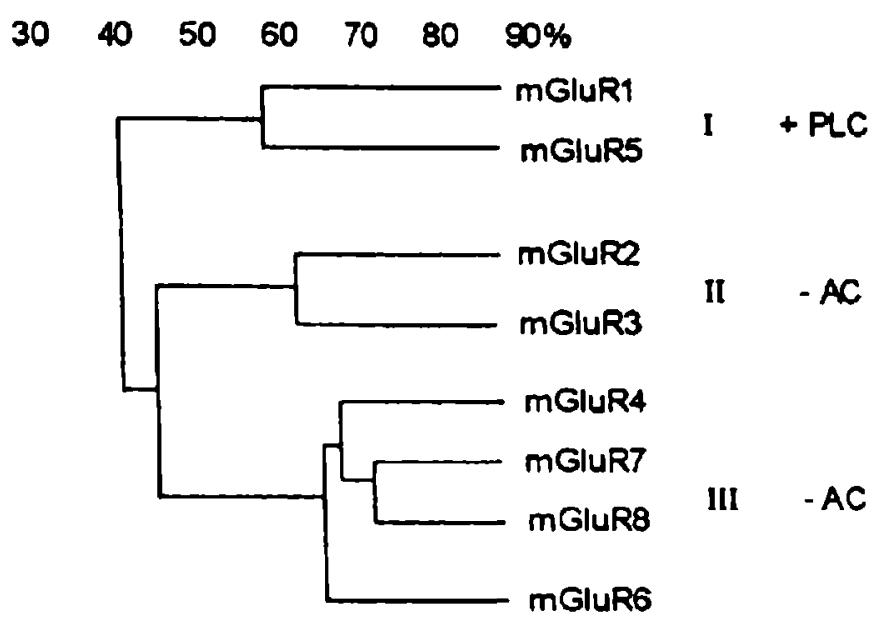

Así, la homología de secuencia es de aproximadamente un $70 \%$ para los distintos subtipos dentro 
del mismo grupo, mientras que sólo alcanza un 40-45\% cuando se comparan grupos. La activación de los receptores pertenecientes al grupo I provoca el incremento de la hidrólisis de fosfoinosítidos, conduciendo a la movilización intracelular de calcio $^{3,4}$. Por otro lado, los subtipos correspondientes a los grupos II y III están negativamente acoplados a la actividad de la adenilato ciclasa-AMPc ${ }^{5,6}$ (Figura 6.1).

El estudio del comportamiento farmacológico que presentan distintos ligandos de los grupos II y III de mGluRs no ha llevado a conclusiones del todo claras en lo que se refiere a la acción anticonvulsiva / proconvulsiva de estos compuestos $^{7,8,9}$. En cambio, los agonistas de los receptores del grupo I inducen un incremento en la excitabilidad neuronal y por lo tanto actividad proconvulsiva, mientras que los antagonistas muestran efectos anticonvulsivos $7,8,10,11,12,13,14,15$.

El presente estudio está motivado por esta nueva línea de investigación recientemente surgida, relacionada con el descubrimiento de agentes antiepilépticos con acción en la vía metabotrópica del glutamato. Específicamente se refiere a la identificación de los requisitos farmacofóricos para la acción anticonvulsiva, de manera de llegar a un mayor entendimiento de estos procesos, y en última instancia poder diseñar nuevas drogas, antagonistas del subtipo 1 (mGluR1) perteneciente al grupo I de mGluRs, con potencial actividad antiepiléptica.

Con este fin, se considerarán en este capítulo diversos ligandos de mGluR1, tanto agonistas como antagonistas, e incluso compuestos incapaces de unirse a este receptor, para determinar las características que conducen a la actividad en este receptor.

\section{Descripción del receptor $m G$ GluR}

Los receptores metabotrópicos de glutamato pertenecen a la gran familia de receptores acoplados a proteínas G (GPCRs). Los GPCRs se caracterizan por poseer un corazón central compuesto de 7 hélices transmembrana conectadas por 3 segmentos intracelulares y 3 extracelulares. Los receptores mGluRs no comparten homología de secuencia con ningún miembro de esta superfamilia, por lo cual constituyen en sí una nueva familia de GPCRs ${ }^{2}$. Los mGluRs son de mayor tamaño, y aunque se mantiene el clásico motivo de los 7 dominios transmembrana, el dominio extracelular $\mathrm{N}$-terminal es sorprendentemente más largo de lo 
usual (Figura 6.2). A diferencia de la mayoría de los GPCRs, el sitio de reconocimiento de agonistas y antagonistas competitivos se encuentra en el extenso extremo Nterminal $^{2}, 16,17,18,19,20$.

A pesar de la escasez de datos estructurales experimentales de los receptores mGluRs, se han propuesto modelos de la porción extracelular $\mathrm{N}$-terminal de $\operatorname{mGluR} 1^{21}$, mGIR2 $2^{22}$, y mGluR $5^{23}$ mediante estudios de modelado por homologia, en donde se emplea para la homología una proteína bacteriana periplásmica de unión de leucina/isoleucina/valina (LIVBP) ${ }^{24}$ estructuralmente conocida por rayos $\mathrm{X}^{25}$.

Figura 6.2

Representación esquemática de un receptor mGIuR, común a los tres grupos.

En la parte superior se

destaca el largo extremo

$N$-terminal y en naranja

los 7 dominios

transmembrana

característicos de todos los receptores GPCRs

(Tomado de Nakanishi, S. y $\mathrm{col}^{43}$ )
mGluR

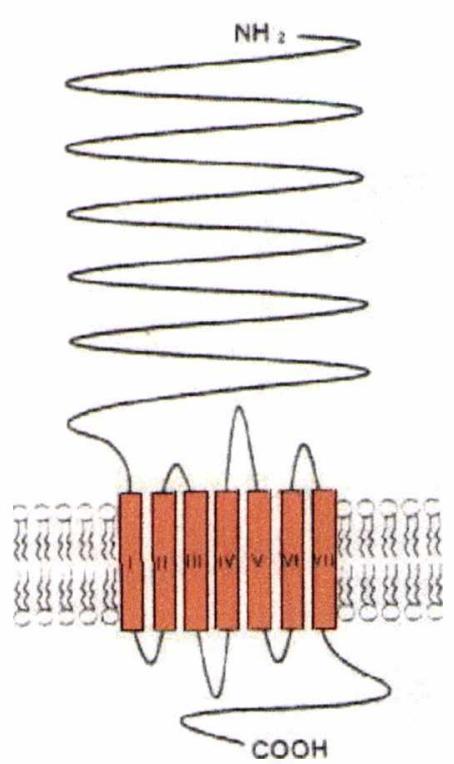

I mGluR1, mGluR5

11 mGluR2, mGluR3

If mGluR4, mGluR6, mGluR7. mGluR8

Según estos modelos, esta porción consiste en dos lóbulos y, al igual que como ocurre con otras proteínas bacterianas periplásmicas $^{26}$, los agonistas se unen al lóbulo mayor dentro de la hendidura, induciendo su cierre y provocando la activación de la región transmembrana ${ }^{27}$ (Figura 6.3).

A pesar del conocimiento acumulado hasta el momento acerca de los factores estructurales conocidos de los mGluRs, y fundamentalmente en relación a los modelos 3D de la porción $\mathrm{N}$-terminal, la información disponible no es capaz todavía de brindar los detalles suficientes como para encarar 
un estudio de diseño racional de drogas desde el punto de vista del receptor.

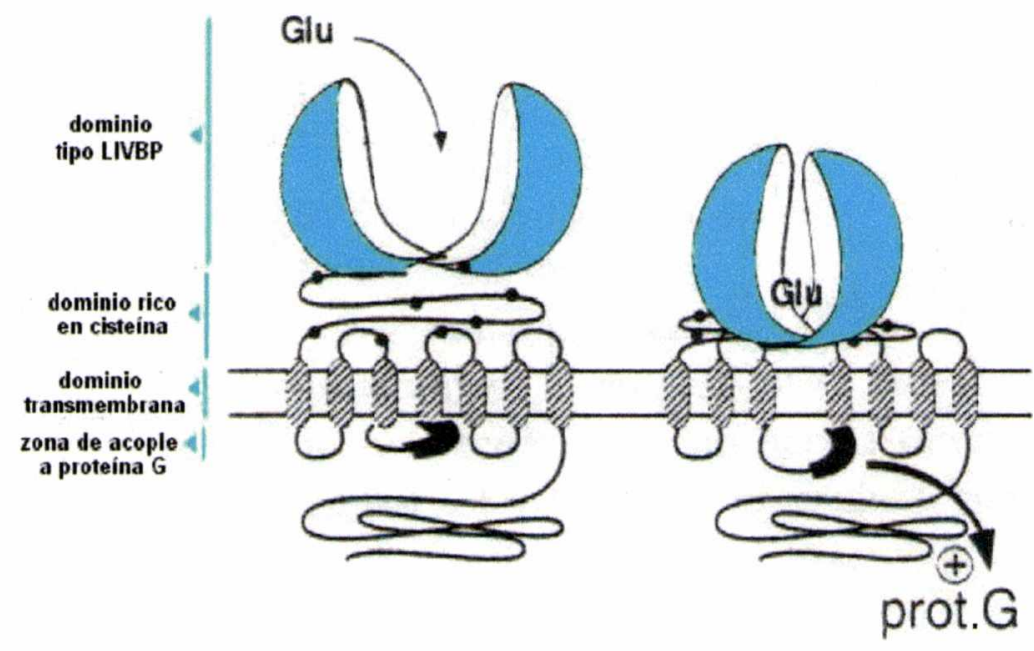

Figura 6.3

Esquema

de la

activación

un receptor

mGluR

(Tomado

de Pin, J.P.

y col. ${ }^{27}$ )

Debe continuarse la investigación en el campo de química medicinal, tanto en cuanto al estudio y confirmación de las porciones del receptor involucradas en la interacción, como así también en relación al diseño y generación de nuevas familias de compuestos con el objeto de contar con mayor información concerniente a las características de las futuras nuevas drogas antiepilépticas capaces de actuar en los receptores mGluRs.

\section{Elección del coniunto de compuestos a estudiar}

Con el objeto de plantear un patrón farmacofórico para la acción sobre el receptor mGluR1, se tomaron datos de bibliografia vinculados a compuestos con afinidades significativas por el receptor mGluR1, tanto agonistas como antagonistas, como así también estructuras no activas por no poseer en absoluto afinidad por este receptor. Se definieron así cuatro conjuntos de estructuras (Figuras 6.4 y 6.5):

$\checkmark$ aquellos compuestos con elevada afinidad ("Binders"),

$\checkmark$ los que presentan afinidad nula ("Non Binders"),

$\checkmark$ aquellos con marcada actividad, manifestada como estimulación de la hidrólisis de fosfoinosítidos (Agonistas), y

$\checkmark$ los ligandos que no presentan actividad (Antagonistas). 
Sólo pudo encontrarse un reducido número de ligandos cuya afinidad se encuentre reportada en bibliografia, tomando como criterio de selección un valor de $\mathrm{Ki}$ (constante de afinidad por el receptor) menor a $1 \mu \mathrm{M}$ (Tabla 6.1).

Binders

Mon-binders
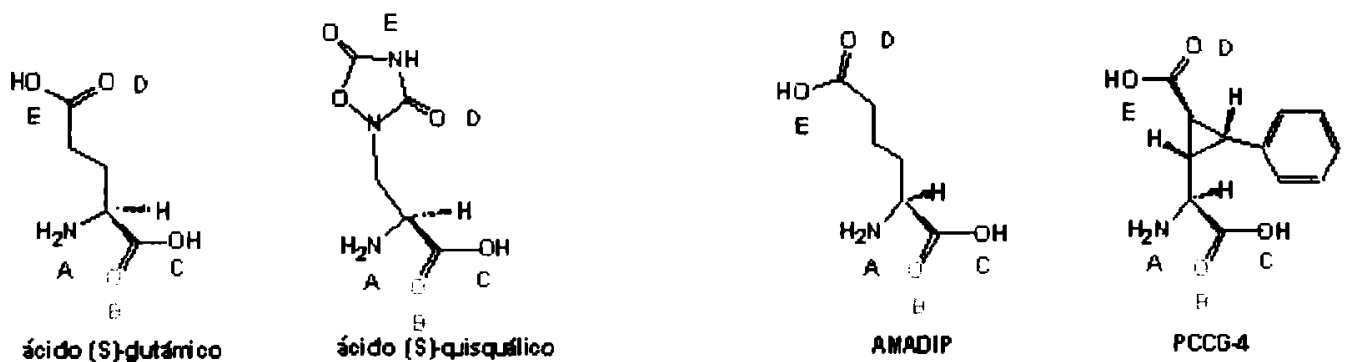

ácido (S)dutárico

ácido [\$] (\$isqúlico
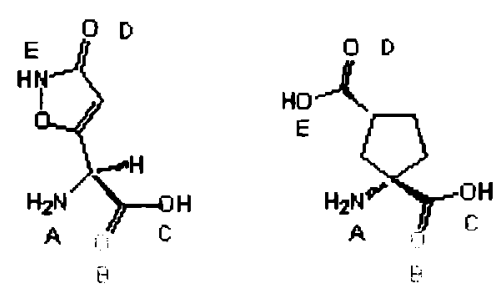

(1S,3R)ACPD
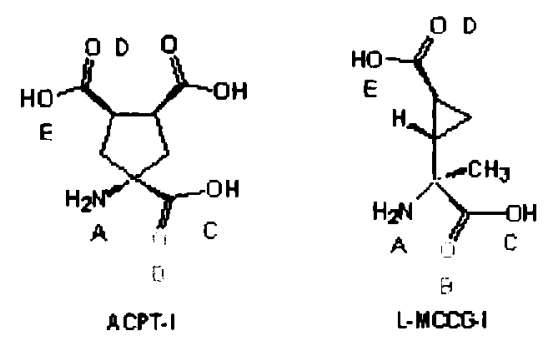

toldo [S\}iboterico

(2)

Figura 6.4 Estructuras incluidas en el conjunto de Binders y Non-Binders.

Binders: ácido (S)-glutámico (GLU), ácido (S)-iboténico (IBO), ácido (S)-quiscuálico (QUIS), y ácido (1S,3R)-1-aminociclopentano-1,3-dicarboxílico (ACPD).

Non-binders: ácido (S)- $\alpha$-aminoadipico (AMADIP), (2S, ' 'S, 2 'S, 3'R)-2-(2'-carboxi-3'fenilciclopropil)glicina (PCCG-4), (2S, 1 S, 2 'S)- $\alpha$-metil-2-(carboxiciclopropil)glicina (MCCG-I), y ácido (IS,3R,4R)-1-aminociclopentano-1,3,4-tricarboxilico (ACPT-I).

En colores y letras se indican las funciones quimicas comunes (ver más detalles en el textol.

Por otro lado, aquellos compuestos que no mostraron ninguna afinidad por el receptor mGluRl $(\mathrm{Ki}>1000 \mu \mathrm{M})$ son los que están incluidos en el conjunto de non-binders (Tabla 6.1).

Como agonistas se seleccionaron los compuestos con mayor potencia farmacológica (ED50 $<2 \mu \mathrm{M}$, tabla 6.1), estando algunos ya incluidos en el conjunto de binders, por ser también los más afines por el receptor mGluR1. 
Agonistas

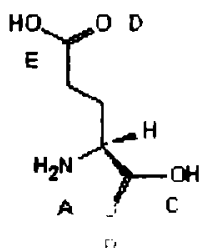

feido (\$) futamleo

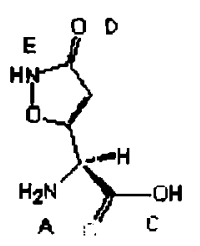

Seldo [S\}ibotirico

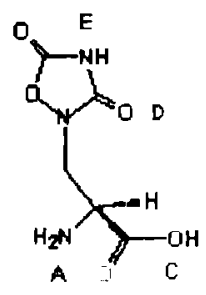

ácido (s)tquisqualico

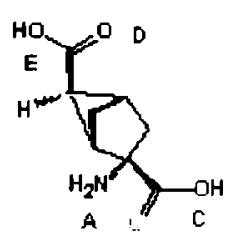

AEHKD-I

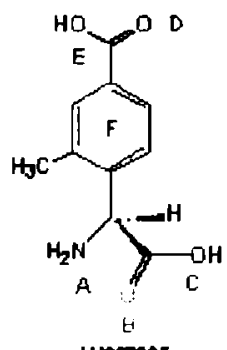

Lr367385

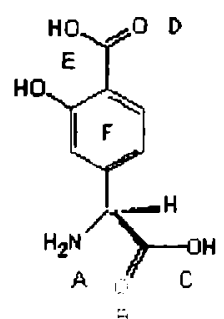

4C3HPG
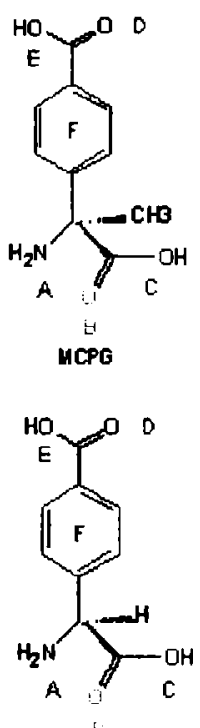

(S)4CPG
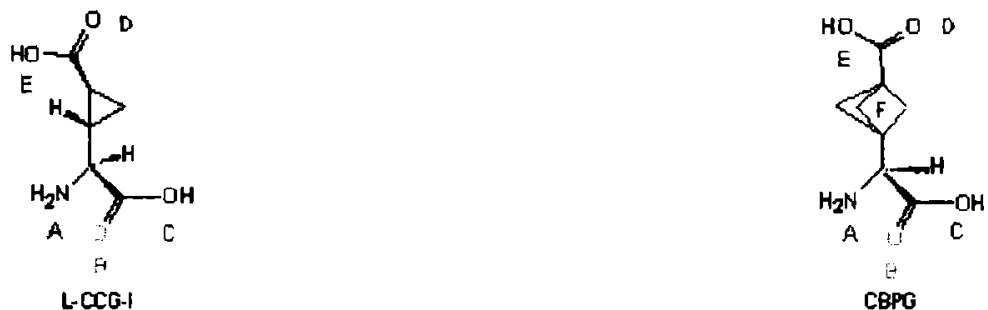

Figura 6.5 Estructuras incluidas en el conjunto de Agonistas y Antagonistas.

Agonistas: ácido (S)-glutámico (GLU), ácido (S)-iboténico (IBO), ácido (S)-quiscuálico

(QUIS), ácido (1S,2S,4S, 5S)-2-aminobiciclo[2.1.1] hexano-2,5-dicarboxilico (ABHXD-I), y (2S,1'S,2'S)-2-(carboxiciclopropil)glicina (CCG-I).

Antagonistas: (S)-2-metil-(4-carboxifenil)glicina (L Y367385), (S)-4-carboxifenilglicina

(1CPG), (S)-2(3'carboxibiciclo[1.1.1]pentil)glicina (CBPG), (S)- $\alpha$-metil-(4-

carboxifenil)glicina (MCPG), y (S)-(4-carboxi-3-hidroxifenil)glicina (4C3HPG).

En colores $v$ letras se indican las funciones auimicas comunes (ver más detalles en el texto).

Los antagonistas más potentes encontrados son aquellos con IC50 $<50 \mu \mathrm{M}$ (Tabla 6.1). 
Tabla 6.1 Actividades biológicas y clasificación de los compuestos en distintos conjuntos

\begin{tabular}{|c|c|c|c|c|}
\hline Compuesto & Clase & $\begin{array}{c}\mathrm{Ki}(\mu \mathrm{M}) \\
\text { Binding de } \\
{\left[{ }^{3} \mathrm{H}\right]} \\
\text { glutamato }\end{array}$ & $\begin{array}{c}\mathrm{ED}_{s 0}(\mu \mathrm{M}) \\
\text { Actividad } \\
\text { agonista } \\
\text { (estimulación } \\
\text { de la } \\
\text { hidrólisis de } \\
\text { PI) }\end{array}$ & $\begin{array}{c}\mathrm{IC}_{50}(\mu \mathrm{M}) \\
\text { Actividad } \\
\text { antagonista } \\
\text { (inhibición } \\
\text { de la } \\
\text { hidrólisis de } \\
\text { PI) }\end{array}$ \\
\hline (S)-glutamato & Binder / Agonista & $0.26-0.3$ & $0.9-184$ & \\
\hline (S)-quiscualato & Binder / Agonista & 0.01-0.09 & $0.03-17$ & \\
\hline (S)-ibotenato & Binder / Agonista & 0.38 & $1.9-62$ & \\
\hline ACPD & Binder & $0.40-0.85$ & $4.7-98$ & \\
\hline ABHxD-I & Agonista & & 1.6 & \\
\hline CCG-I & Agonista & & $1.9-50$ & \\
\hline $4 \mathrm{CPG}$ & Antagonista & 17 & & $40-65$ \\
\hline CBPG & Antagonista & & & 25 \\
\hline LY367385 & Antagonista & & & 8.8 \\
\hline MCPG & Antagonista & & & $40-200$ \\
\hline $4 \mathrm{C} 3 \mathrm{HPG}$ & Antagonista & & & 40 \\
\hline AMADIP & Non binder & $>1000$ & $>1000$ & \\
\hline PCCG-4 & Non binder & & sin efecto & sin efecto \\
\hline MCCG-I & Non binder & & sin efecto & sin efecto \\
\hline ACPT-I & Non binder & & sin efecto & $>1000$ \\
\hline
\end{tabular}

\section{Descripción de la metodología}

Para el estudio teórico de las estructuras se emplean los siguientes programas de química computacional:

$$
\begin{array}{ll}
\checkmark & \text { MSI/Quanta } \\
& 28, \\
\checkmark & \text { MOLMOD }^{29,30}, \\
\checkmark & \text { MOPAC }^{31},
\end{array}
$$

Se utilizan las computadoras (varias Silicon Graphics Indigo y Octane, funcionando bajo entorno Unix) del centro 
de cómputos del Molecular Research Institute (Mountain View, California, Estados Unidos).

\section{Análisis conformacional.}

Las estructuras de todos los compuestos seleccionados se estudiaron en su forma iónica, considerando la forma zwitteriónica para la porción aminoacídica y la forma cargada para los grupos polares distales. Se utilizaron como puntos de partida para el análisis conformacional, las geometrías obtenidas por cristalografía por rayos $\mathrm{X}$, siempre que estuvieran disponibles en la Cambridge DataBase. En su defecto, se partió de las estructuras 3D construidas mediante el uso del programa Quanta ${ }^{28}$.

\section{Generación de geometrías de partida}

Para el análisis conformacional se empleó una metodología sistemática, generando las conformaciones iniciales mediante variación de todos los ángulos diedros capaces de rotar, en pasos de $30^{\circ}$. Se analiza el espacio conformacional en su totalidad (entre $0^{\circ}$ y $360^{\circ}$ ), salvo cuando existe simetría relacionada a esta rotación, en donde el número de pasos se reduce para acelerar el proceso.

\section{Optimización de geometrías}

Durante las optimizaciones, todos los parámetros geométricos se mantuvieron completamente libres. Las minimizaciones se llevaron a cabo empleando el algoritmo "steepest descent" durante los 200 pasos iniciales, seguido del empleo de un algoritmo basado en gradientes conjugados $^{32}$, hasta que el RMSD fue menor a $0.01 \AA$.

\section{Consideración de geometrías finales}

Las geometrías finales obtenidas se ordenaron por energía creciente y se agruparon en familias, tomando como criterio de diferenciación entre familias una diferencia en más de $30^{\circ}$ en al menos uno de los ángulos de torsión ${ }^{29}$. Para los análisis posteriores se consideraron sólo aquellas conformaciones que estuvieran dentro del rango de 3 $\mathrm{kcal} / \mathrm{mol}$ del mínimo absoluto. La elección de este corte de energía se basa en resultados recientemente publicados, en donde se muestra que la conformación bioactiva se encuentra, en la mayor parte de los casos, dentro de ese rango de energía, cuando se estudian mediante $\mathrm{MM}$ pequeños ligandos en solución ${ }^{33,34}$. De manera que para cada compuesto se obtuvo un conjunto de conformaciones únicas y energéticamente accesibles.

\section{Método de cálculo.}

El campo de fuerza Quanta/CHARMm ${ }^{35}$ se utilizó para la minimización de las geometrías iniciales. Como se 
trata de estructuras cargadas, se simula agua como un continuo de constante dieléctrica 80, según está implementado en Quanta/CHARMm.

\section{Selección de la conformación activa.}

Mediante la observación de las estructuras, pueden identificarse en los distintos conjuntos varios determinantes moleculares comunes a todos los derivados. Estas funciones químicas, siempre presentes dentro de cada conjunto, representan probablemente puntos farmacofóricos importantes tanto para los procesos de binding y como de activación. En las Figuras 6.4 y 6.5 se indican en distintos colores y letras estos centros atómicos o grupos de átomos.

Considerando estos grupos como puntos farmacofóricos, es necesario luego identificar cuál es la disposición que adoptan en el espacio para la interacción y activación del receptor, es decir la conformación activa. Para ello se empleó el programa de generación de farmacóforos MOLMOD $^{29,30}$. Este programa se basa en la comparación sistemática de las distancias entre las funciones químicas comunes a todos los compuestos. Básicamente, se necesitan dos conjuntos de datos como puntos de partida para la aplicación de MOLMOD:

$\checkmark$ el conjunto de los potenciales puntos farmacofóricos, comunes a todas las estructuras, $y$

$\checkmark$ la biblioteca conformacional de cada compuesto, es decir, todas las conformaciones provenientes del análisis conformacional.

El programa procede a comparar entre sí los distintos arreglos espaciales que puede adquirir el conjunto de puntos elegidos, a partir del análisis de cada una de las conformaciones de cada molécula. Pueden así surgir una (o varias) disposiciones de los puntos farmacofóricos en el espacio, capaz de ser adoptada por todas las estructuras de un conjunto, ya sea en su conformación más estable o bien alguna que estará dentro del rango de $3 \mathrm{kcal} / \mathrm{mol}$ con respecto a ésta.

Aunque se ha sugerido recientemente que la conformación bioactiva del glutamato corresponde a una geometría extendida ${ }^{36,37}$, la búsqueda conformacional exhaustiva y la determinación del farmacóforo se llevó a cabo con el objeto de verificar que ésta era la única conformación posible común a todos los ligandos.

\section{Cálculo de los descriptores moleculares.}

La conformación activa seleccionada como se describió se utiliza luego como punto de partida para el 
cálculo de descriptores de los distintos efectos. En la tabla 6.2 se enumeran los distintos descriptores y propiedades calculadas, agrupadas de acuerdo al efecto que describen.

Table 6.2 Descriptores moleculares de los distintos efectos.

\begin{tabular}{|c|c|c|}
\hline & Descriptor molecular & Símbolo \\
\hline \multirow[t]{9}{*}{ Efecto estérico } & Volumen total & $\mathrm{V}_{\text {tot }}$ \\
\hline & Area total & $A_{\text {tot }}$ \\
\hline & Area accesible al solvente & SASA \\
\hline & Globularidad molecular & G \\
\hline & Indice de forma de esferoide prolado & PSSI \\
\hline & Eje mínimo del esferoide prolado & EmEP \\
\hline & Indice de forma de esferoide oblado & OSSI \\
\hline & Eje mínimo del esferoide oblado & EmEO \\
\hline & Parámetros de Sterimol & $\mathrm{L}, \mathrm{B} 1, \mathrm{~B} 2, \mathrm{~B} 3, \mathrm{~B} 4$ \\
\hline \multirow[t]{2}{*}{ Efecto hidrofóbico } & Indice hidrofóbico & Hyd \\
\hline & Energía libre de solvatación & $\Delta \mathrm{G}_{\text {solv }}$ \\
\hline \multirow[t]{2}{*}{ Efecto electrónico } & Orbital molecular ocupado de mayor energía & HOMO \\
\hline & Orbital molecular desocupado de menor energía & LUMO \\
\hline
\end{tabular}

Los descriptores del efecto estérico como el volumen total, el área total, el área accesible al solvente, y los parámetros de Sterimol ${ }^{38} \mathrm{~L}, \mathrm{~B} 1, \mathrm{~B} 2, \mathrm{~B} 3$ y B4*, como así también los descriptores de la forma molecular, se calcularon mediante el empleo del programa GRAPHA (Graphics Analysis), el cual usa como inputs los resultados de cálculos semiempíricos realizados en MOPAC $7^{39}$. Para tal fin se utilizó un hamiltoniano AM1 para realizar minimizaciones de las estructuras. El objeto de estas minimizaciones es obtener datos de base cuántica para el cálculo de propiedades, por lo tanto las moléculas deben permanecer en sus conformaciones activas. Para tal fin, se convierten a la forma neutra y luego de la optimización geométrica se controla que las conformaciones coincidan con las obtenidas previamente por CHARMm.

El programa GRAPHA calcula la globularidad G definiéndola como el cociente entre el área de una esfera de volumen equivalente al volumen molecular sobre el área molecular:

\footnotetext{
* L es la distancia molecular máxima, y B1, B2, B3 y B4 son parámetros indicativos del ancho de la molécula. Para mayor detalle consultar la referencia [42jcc]
} 


$$
G=\frac{\left[A^{\mathrm{sP}}\right]_{V}=V_{\mathrm{mad}}}{A}=\frac{(4 \pi)^{1 / 3}\left(3 V_{\mathrm{mol}}\right)^{2 / 3}}{A}
$$

$\mathrm{G}$ toma valores entre 0 y 1 , correspondiendo $\mathrm{G}=1$ a una molécula perfectamente esférica.

Los volúmenes y áreas usan los parámetros de van der Waals determinados por Gavezzotti ${ }^{40}$.

En forma análoga al cálculo de $G$, se computan los indices que dan idea de la proximidad a la forma de esferoide oblado (OSSI) o prolado (PSSI) de la molécula. Para determinar el área de estos cuerpos, se necesitan dos parámetros:

$\checkmark$ el volumen del cuerpo ideal, que se iguala al volumen molecular, $\mathrm{y}$

$\checkmark$ la longitud del eje mayor del cuerpo ideal, que se iguala a la máxima separación entre dos puntos de la superficie molecular (correspondiente al parámetro L de Sterimol).

Las ecuaciones para el cálculo de los índices quedan expresadas así:

$$
\mathrm{PSSI}=\frac{1}{A}\left(2 \pi B^{2} \frac{2 \pi L B}{\varepsilon \sin (\varepsilon)}\right) \quad B=\sqrt{\left(3 V_{\mathrm{mol}} / 4 \pi L\right)}
$$

para la forma de esferoide prolado, y de la siguiente manera para la forma de esferoide oblado:

$$
\text { OSSI }=\frac{\pi L^{2}}{2}+\frac{\pi B^{2}}{\varepsilon} \log \frac{1+\varepsilon}{1-\varepsilon} \quad B=\sqrt{\left(3 V_{\mathrm{mol}} / \pi L^{2}\right)}
$$

donde $\mathrm{B}$ es el eje menor, y $\varepsilon$ la elipticidad:

$$
\varepsilon=\sqrt{\left(L^{2}-B^{2}\right) / L}
$$

A diferencia de $\mathrm{G}$, estos índices pueden tomar cualquier valor positivo.

En cuanto al efecto electrónico, el número de descriptores que es posible calcular es limitado debido a la naturaleza cargada de las estructuras. Los valores de energía de los orbitales de frontera HOMO y LUMO corresponden a los cálculos AM1.

Las geometrías optimizadas por AM1 fueron utilizadas también para el cálculo de la energía libre de solvatación $\left(\Delta \mathrm{G}_{\text {solv }}\right)$, mediante el programa AMSOL 6.5.3 ${ }^{41}$ simulando el solvente como un continuo de constante dieléctrica 80 (agua). 
El índice hidrofóbico (Hyd) se calculó de acuerdo a un método basado en cálculos semiempíricos ${ }^{42}$, incluido en el programa GRAPHA. Este índice depende de la conformación molecular, y tiene en cuenta las densidades de carga y las contribuciones atómicas al área superficial total ${ }^{42}$.

Se realizó un análisis lineal discriminante mediante el empleo del programa S-PLUS 2000 (StatSci Division, MathSoft Inc., Seattle, WA).

\section{$\underline{\text { Resultados } v \text { discusión }}$}

Todas las estructuras poseen dos zonas altamente polares: una función $\alpha$-aminoacídica proximal, $\mathrm{y}$ un grupo

\begin{tabular}{|c|c|c|c|}
\hline Com & $\begin{array}{l}\text { Número de } \\
\text { enlaces } \\
\text { rotables }\end{array}$ & $\begin{array}{l}\text { Número de } \\
\text { conformaciones } \\
\text { únicas }\end{array}$ & $\begin{array}{c}\text { Número de } \\
\text { conformaciones } \\
\text { únicas dentro de } \\
\text { las } 3 \mathrm{kcal} / \mathrm{mol}\end{array}$ \\
\hline
\end{tabular}

Table 6.3

Resultados

del análisis conformacio-

$\begin{array}{cccc}\text { (S)-glutamato } & 4 & 104 & 80 \\ \text { (S)-quiscualato } & 3 & 32 & 27 \\ \text { (S)-ibotenato } & 2 & 11 & 11 \\ \text { ACPD } & 2 & 6 & 6 \\ \text { ABHxD-I } & 2 & 6 & 6 \\ \text { CCG-I } & 3 & 21 & 21 \\ \text { 4CPG } & 3 & 13 & 12 \\ \text { CBPG } & 3 & 38 & 38 \\ \text { LY367385 } & 3 & 8 & 8 \\ \text { MCPG } & 3 & 12 & 12 \\ \text { 4C3HPG } & 3 & 10 & 10 \\ \text { AMADIP } & 5 & 721 & 189 \\ \text { PCCG-4 } & 4 & 106 & 26 \\ \text { MCCG-I } & 3 & 25 & 25 \\ \text { ACPT-I } & 3 & 24 & 24\end{array}$

distal aceptor/donor de hidrógeno. Los puntos A-E en las figuras 6.4 y 6.5 identifican estas cinco funciones químicas comunes a todos los compuestos y el punto $\mathrm{F}$ en la figura 6.5 representa una función adicional común a todos los antagonistas. A se refiere al grupo $\alpha$-amino, B y $\mathrm{C}$ indican los dos átomos de oxígeno del grupo ácido proximal, 
mientras que los dos átomos del grupo polar distal corresponden a D y E, y F representa el centroide de un grupo hidrofóbico.

En la tabla 6.3 se reportan los resultados derivados del análisis conformacional, incluyendo el número de enlaces rotables considerado para cada ligando, el número total de conformaciones únicas obtenidas (es decir, el número de "familias" conformacionales, como se describió en el punto "Análisis conformacional"), y el número de aquéllas comprendidas en el rango de $3 \mathrm{kcal} / \mathrm{mol}$ desde el mínimo absoluto.

Las conformaciones únicas y energéticamente más factibles (última columna de la tabla 6.3) de cada compuesto, son las que se utilizan para la comparación sistemática de la disposición de los potenciales puntos farmacofóricos.

\section{Requerimientos estructurales y conformacionales asociados al reconocimiento y la activación del receptor mGluR1.}

A partir de los resultados obtenidos mediante la aplicación del programa MOLMOD, se identificaron aquellos confórmeros de los binders, que muestran las funciones químicas comunes en la misma disposición en el espacio. En la segunda columna de la tabla 6.4 se reportan los datos referidos al arreglo espacial de los determinantes moleculares correspondientes a los binders, definido mediante las distancias entre estos puntos.

Mediante la cuidadosa selección realizada de los compuestos con más alta afinidad por el receptor mGluR1, es posible entonces determinar la conformación que un compuesto debe adoptar para cumplimentar el proceso de binding, lo cual está de acuerdo con estudios anteriores que sugerían que la conformación activa del glutamato es extendida.

Sin embargo, lejos de considerar a estos requerimientos geométricos como definitorios de un grupo farmacofóro, deben incluirse en el análisis a los compuestos non-binders. Estos compuestos son ligandos de otros subtipos de receptores mGluRs pero no del subtipo mGluR1, como lo demuestran las correspondientes determinaciones de $\mathrm{Ki}$, ED50 ó IC50 (Tabla 6.1). La selección de los non-binders no es arbitraria, sino que han sido elegidos para este estudio justamente por la gran similitud estructural que presentan con las moléculas de alta afinidad, lo cual queda evidenciado comparando por ejemplo ACPT-I con ACPD, ó AMADIP con (S)-glutamato, en donde la única diferencia estructural consiste en un grupo $-\mathrm{COOH}$ ó $-\mathrm{CH}_{2}$ adicional, respectivamente. 


\begin{tabular}{cccc}
$\begin{array}{c}\text { distancias } \\
(\AA)\end{array}$ & binders & agonistas & antagonistas \\
\hline A - B & $3.09+/-0.16$ & $3.08+/-0.15$ & $3.12+/-0.17$ \\
A - C & $3.21+/-0.15$ & $3.21+/-0.14$ & $3.17+/-0.16$ \\
A-D & $5.38+/-0.10$ & $4.86+/-0.54$ & $7.02+/-0.30$ \\
A-E & $5.12+/-0.58$ & $4.47+/-0.53$ & $7.05+/-0.33$ \\
A-F & --- & -- & $3.65+/-0.16$ \\
B-C & $2.09+/-0.002$ & $2.09+/-0.001$ & $2.09+/-0.002$ \\
B-D & $5.87+/-0.34$ & $6.25+/-0.31$ & $7.46+/-0.62$ \\
B-E & $5.55+/-0.52$ & $5.65+/-0.49$ & $7.50+/-0.66$ \\
B-F & --- & --- & $4.26+/-0.47$ \\
C-D & $5.55+/-0.38$ & $6.25+/-0.44$ & $7.37+/-0.60$ \\
C - E & $5.36+/-0.29$ & $5.62+/-0.55$ & $7.41+/-0.62$ \\
C-F & -- & -- & $4.19+/-0.46$ \\
D-E & $2.19+/-0.14$ & $2.17+/-0.11$ & $2.08+/-0.01$ \\
D-F & -- & -- & $3.56+/-0.13$ \\
E-F & --- & -- & $3.62+/-0.22$
\end{tabular}

Tabla 6.4

Resultados de la determinación de arreglos espaciales comunes dentro de cada conjunto

Si dentro del conjunto de binders se incluye arbitrariamente cualquiera de los non-binders, el arreglo espacial de los grupos funcionales comunes no presenta variaciones. Los resultados obtenidos de la comparación de cada una de estas estructuras incapaces de unirse al sitio receptor, muestran que los non-binders pueden adoptar el mismo arreglo espacial común a todos los binders. Como conclusión, puede afirmarse que la falta de afinidad de ciertos compuestos no puede explicarse solamente sobre la base del

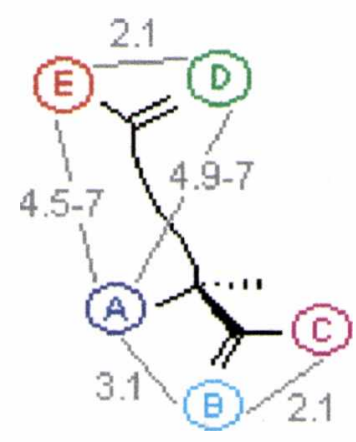

\author{
Figura 6.6 \\ Esquema de la conformación activa. \\ Las distancias interatómicas dentro \\ de cada uno de los grupos \\ aceptores/dadores de protones \\ mantienen constancia entre los \\ grupos de binders, agonistas y \\ antagonistas, mientras que las \\ distancias que separan estos 2 \\ grupos entre si son más variables \\ (Tabla 6.4)
}

análisis de las distancias entre funciones químicas comunes de los compuestos altamente afines.

En la figura 6.6 se muestran esquemáticamente las distancias entre los grupos, detalladas en la tabla 6.4. 
Al tratarse de una conformación única, correspondiente a la conformación extendida del glutamato, y común a todos los compuestos capaces de interaccionar, puede definirse a la geometría descripta en la figura 6.6 como conformación activa, aunque, claramente, otros factores adicionales han de estar involucrados en el proceso de binding.

La figura 6.7 muestra la superposición de todos los ligandos de mGluR1 seleccionados, teniendo en cuenta aquellas geometrías que satisfacen el arreglo espacial común a todas las estructuras.

\section{Figura 6.7}

Superposición de las conformaciones activas de todos los ligandos analizados. Al hacer coincidir los átomos del resto aminoacídico $(A, B$ y C) de todas las estructuras, se logra visualizar la diferencia que existe entre agonistas y antagonistas en las distancias que separan los puntos de los grupos polares proximal $(A, B$ y C) y distal ( $D y$

E). Esta distancia es intermedia para el antagonista $C B P G$

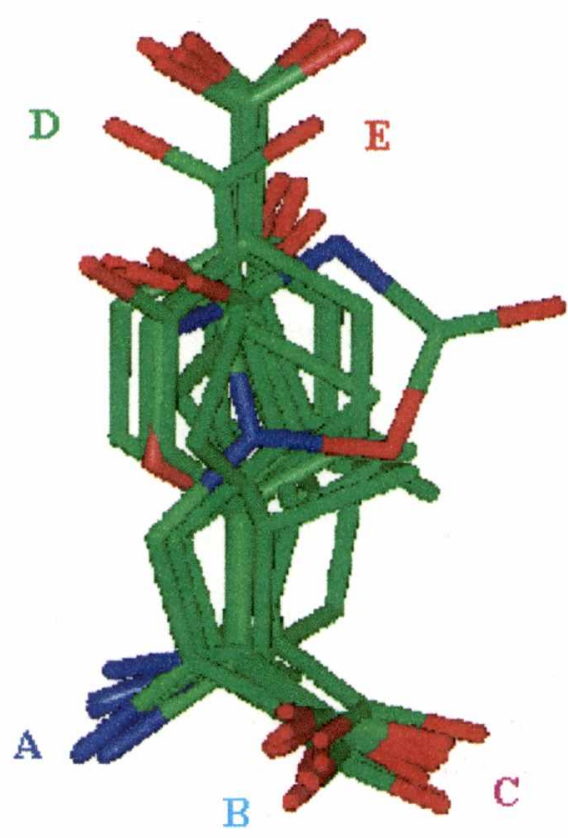

Como se ha podido observar, tanto los agonistas como los antagonistas de mGluR1 son capaces de acomodar las mismas funciones químicas críticas en el espacio casi de la misma forma. Analizando comparativamente los conjuntos de agonistas y antagonistas, surge que la diferencia más llamativa es la presencia de un grupo hidrofóbico, identificado como $\mathrm{F}$ en la figura 6.5 , común a todos los antagonistas. Este grupo provoca una mayor separación entre los grupos polares aceptores/donores de hidrógeno proximal y distal, como puede apreciarse analizando por ejemplo la diferencia que existe entre la distancia que separa el grupo $\alpha$ amino $\mathrm{A}$ y el oxígeno $\mathrm{D}$ en los conjuntos de agonistas y antagonistas (tercera y cuarta columnas de la tabla 6.4, y figura 6.7), aunque esta diferencia no es tan notoria cuando se observa el antagonista CBPG, cuya separación no es tan distinta a la de los agonistas. En la figura 6.7 se observa que 
el grupo carboxilico distal de este compuesto se encuentra a una distancia intermedia entre los grupos polares distales equivalentes del resto de los antagonistas y de los agonistas.

Más allá de la presencia de un grupo hidrofóbico central, no puede encontrarse otra explicación adicional a la distinta actividad, basada en características estructurales y/o conformacionales solamente. De manera que es esperable que puedan existir otros factores, no identificables mediante un análisis de distancias entre potenciales centros farmacofóricos, involucrados en la manifestación de la actividad.

Por tal razón, el siguiente paso en el presente estudio está dirigido a explorar distintas propiedades de las moléculas, con el objeto de encontrar otras razones que justifiquen un comportamiento tan distinto entre ligandos estructuralmente muy relacionados, tanto en lo que se refiere al binding como a la activación del receptor mGluR1.

\section{Descriptores moleculares y análisis lineal discriminante.}

Mientras que de la observación de las estructuras de los binders comparativamente a las de los non-binders no surge ninguna diferencia aparente, no ocurre lo mismo al comparar agonistas con antagonistas. Como se describió, los antagonistas estudiados se caracterizan por poseer un grupo hidrofóbico voluminoso situado en todos en la misma posición (Figura 6.7). Este hecho visiblemente sugiere que pueden estar involucrados factores estéricos y/o hidrofóbicos en el favorecimiento del antagonismo.

Para estudiar esa posibilidad, se calcularon no sólo descriptores estéricos e hidrofóbicos sino también electrónicos para cada uno de los ligandos en consideración, con el propósito de encontrar aquéllos capaces de discriminar entre binders y non-binders y entre agonistas y antagonistas.

Para la evaluación de las propiedades, se consideraron las conformaciones activas de cada una de las estructuras.

Los valores encontrados para cada una de las propiedades analizadas se encuentran detallados en la tabla 6.5 , resaltándose en gris aquéllas capaces de discriminar compuestos binders de non-binders, y en rosado las que discriminan agonistas de antagonistas.

Las propiedades relacionadas a la forma de los compuestos parecen jugar un rol importante en la discriminación entre binders y non-binders. En particular, el índice de forma de esferoide oblado (OSSI) es la propiedad que mejor explica la distinta afinidad. Los resultados sugieren que un valor alto de este índice, acompañado de un valor del eje mínimo del esferoide oblado menor a $1.4 \AA$, caracteriza a 
los compuestos de alta afinidad. Se observa que el descriptor OSSI siempre toma valores mayores a 1 (resaltados en gris en tabla 6.5) para los compuestos capaces de interaccionar con el receptor, mientras que los non-binders poseen OSSI menores a 1 (resaltados en verde en tabla 6.5).

Tabla 6.5 Valores de los descriptores calculados

\begin{tabular}{|c|c|c|c|c|c|c|c|c|c|c|}
\hline campuesto & clase & $V_{\text {tot }}$ & $A_{\text {tot }}$ & SASA & G & PSSI & EmEP & OSSI & EmEO & \\
\hline$\overline{G L U}$ & binder/agon & 122,84 & 164,74 & 317,50 & 0,725 & 0,898 & 1,751 & 1,044 & 1,281 & \\
\hline QUIS & binder/agon & 140,03 & 184,02 & 349,35 & 0,709 & 0,898 & 1,743 & 1,158 & 1,105 & \\
\hline IBO & binder/agon & 120,08 & 159,51 & 316,81 & 0,738 & 0,909 & 1,758 & 1,034 & 1,332 & \\
\hline ACPD & binder & 146,60 & 188,04 & 342,98 & 0,715 & 0,887 & 1,849 & 1,039 & 1,335 & \\
\hline $\mathrm{ABH} \times \mathrm{DDl}$ & agon & 155,49 & 193,34 & 349,06 & 0,723 & 0,911 & 1,827 & 1,143 & 1,200 & \\
\hline OCGl & agon & 131,76 & 177,26 & 331,53 & 0,706 & 0,886 & 1,745 & 1,087 & 1,179 & \\
\hline LY367385 & antag & 178,34 & 221,68 & 391,34 & 0,691 & 0,860 & 1,958 & 1,025 & 1,318 & \\
\hline CBPG & artag & 157,46 & 202,52 & 361,34 & 0,696 & 0,874 & 1,848 & 1,079 & 1,240 & \\
\hline MCPG & antag & 178,55 & 220,25 & 391,37 & 0,696 & 0,876 & 1,919 & 1,091 & 1,272 & \\
\hline $4 \mathrm{CPG}$ & antag & 161,94 & 203,71 & 375,06 & 0,705 & 0,888 & 1,855 & 1,108 & 1,226 & \\
\hline 4C3HPG & antag & 167,98 & 212,45 & 385,63 & 0,693 & 0,876 & 1,861 & 1,118 & 1,195 & \\
\hline MOCGI & mo binder & 148,07 & 194,99 & 346,23 & 0,694 & 0,856 & 1,879 & 0,979 & 1,411 & \\
\hline PCOG4 & no binder & 205,41 & 252,66 & 435,60 & 0,666 & 0,831 & 2,047 & 0,995 & 1,432 & \\
\hline ACPT1 & no binder & 170,37 & 214,14 & 373,85 & 0,694 & 0,850 & 2,001 & 0,945 & 1,578 & \\
\hline AMADXP & mobinder & 139,43 & 183,74 & 333,40 & 0.708 & 0,868 & 1,862 & 0,975 & 1,443 & \\
\hline compuesto & clase & $\mathrm{L}$ & $\mathrm{B} 1$ & $\mathrm{~B} 2$ & $\mathrm{~B} 3$ & B4 & Hyd & $\Delta \mathrm{G}_{\text {solv }}$ & HOMO & LUMO \\
\hline GLU & binder/agon & 9,57 & 5,06 & 3,13 & 2,45 & 244 & $-2,457$ & $-18,88$ & $-10,51$ & $0, \pi$ \\
\hline QUS & binder/agnn & 11,00 & 4,05 & 3,97 & 2,53 & 3,30 & $-3,739$ & $-21,26$ & $-10,49$ & $-0,19$ \\
\hline IBO & binder/agon & 9,28 & 5,23 & 3,27 & 2,94 & 1,77 & $-2,752$ & $-19,34$ & $-10,27$ & $-0,67$ \\
\hline$A(P D)$ & binder & 10,24 & 4,35 & 3,60 & 278 & 227 & $-2,271$ & $-16,65$ & $-10,48$ & 0,73 \\
\hline $\mathrm{ABH}+\mathrm{xDl}$ & agon & 11,12 & 3,81 & 3,50 & 3,00 & 2,88 & $-2,105$ & $-16,86$ & $-10,45$ & 0,74 \\
\hline OOGl & agan & 10,33 & 4,44 & 3,94 & 274 & 2,05 & $-1,961$ & $-18,47$ & $-10,58$ & 0,47 \\
\hline LY367385 & antag & 11,11 & 5,99 & 4,46 & 2,75 & 2,10 & $-0,956$ & $-17,43$ & $-9,96$ & $-0,82$ \\
\hline CBPG & antag & 11,01 & 5,05 & 3,16 & 3,01 & 2,88 & $-1,534$ & $-18,08$ & $-10,45$ & 0,68 \\
\hline MCPG & antag & 11,58 & 5,20 & 3,65 & 280 & 3,29 & $-1,045$ & $-16,23$ & $-10,12$ & $-0,67$ \\
\hline 4CPG & antag & 11,23 & 5,11 & 4,00 & 3,39 & 1,54 & $-1,175$ & $-18,45$ & $-10,28$ & $-0,87$ \\
\hline 4C3HPG & antag & 11,59 & 5,53 & 4,75 & 3,09 & 1,34 & $-1,849$ & $-24,02$ & $-9,73$ & $-0,84$ \\
\hline MOCGil & no binder & 10,01 & 4,19 & 3,63 & 258 & 4,08 & $-1,704$ & $-17, \pi 7$ & $-10,58$ & 0,60 \\
\hline PCOG4 & no binder & 11,71 & 7,08 & 3,85 & 3,05 & 2,47 & $-0,506$ & $-18,20$ & $-9,85$ & $-0,07$ \\
\hline ACPT1 & mo binder & 10,16 & 5,64 & 4,67 & 2,83 & 2,22 & $-3,671$ & $-25,68$ & $-10,67$ & 0,69 \\
\hline AMADIP & no binder & 9,60 & 4,42 & 3,42 & 2,31 & 3,38 & $-2,237$ & $-18,91$ & $-10,29$ & 0,81 \\
\hline
\end{tabular}

En cuanto a la discriminación entre agonistas y antagonistas, el análisis de todas las propiedades sugiere, como era de esperar, un rol crucial de las propiedades estéricas e hidrofóbicas por sobre los factores electrónicos. Varias propiedades, que incluyen el volumen molecular total, el área total, el área accesible al solvente y la globularidad, sumadas al índice hidrofóbico, proveen una discriminación entre agonistas y antagonistas. Valores del volumen total 
mayores a $150 \AA^{3}$ se observan para todos los antagonistas, lo cual está de acuerdo con resultados anteriores ${ }^{36}$. Sin embargo, la máxima discriminación se obtiene cuando se considera el área accesible al solvente (SASA) que siempre es mayor para el caso de los antagonistas (resaltada en celeste para antagonistas y en rosado para agonistas en tabla 6.5), lo cual está probablemente relacionado a la presencia del grupo hidrofóbico central voluminoso.

En las figuras 6.8 y 6.9 se muestran gráficos de los
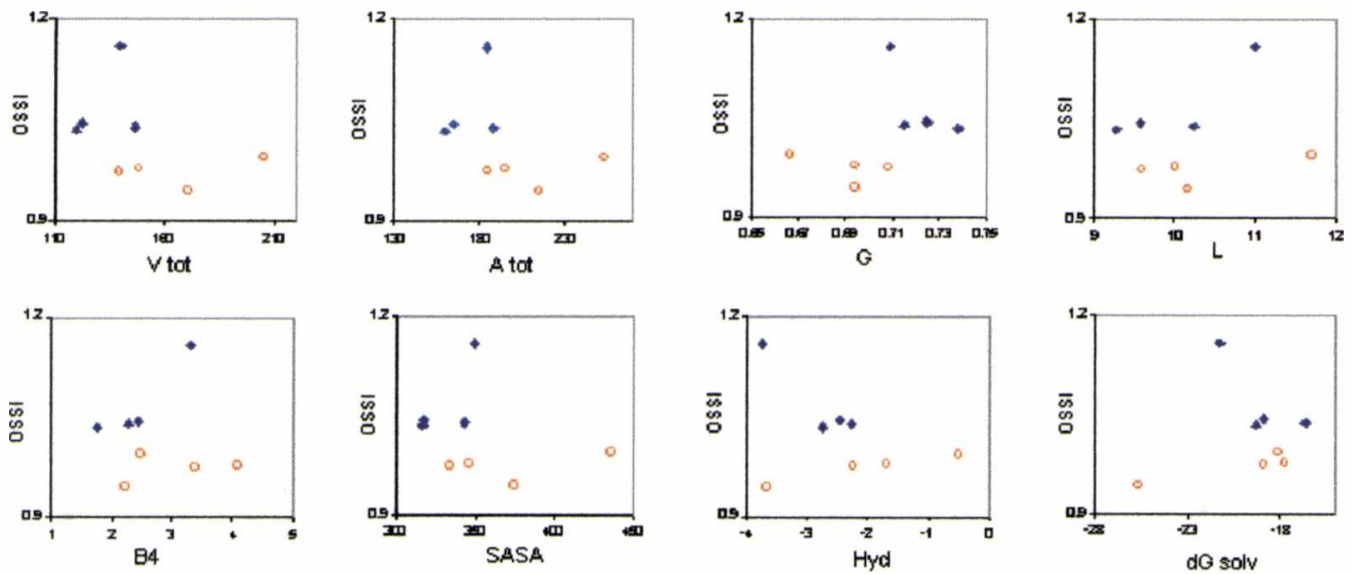

\section{Figura 6.8}

Discriminación

entre binders $y$ non-binders por el descriptor OSSI
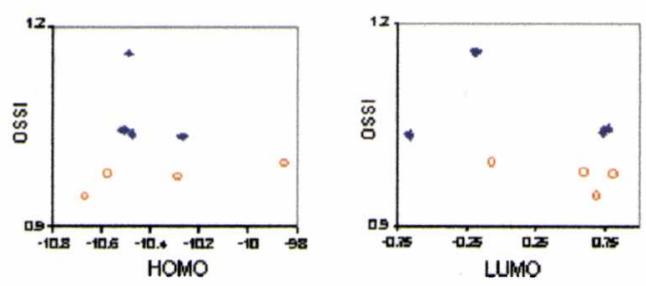

\section{binders}

non-binders

descriptores que mejor discriminan, entre binders y nonbinders y entre agonistas y antagonistas, versus distintas propiedades no correlacionadas.
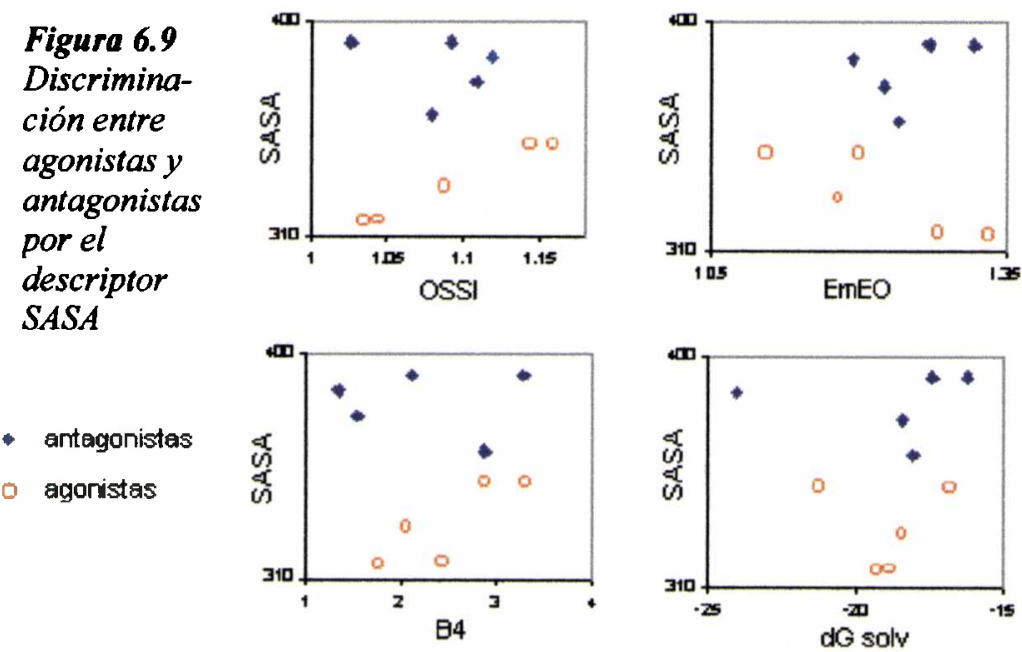
En conclusión, a partir del análisis indirecto de la interacción droga-receptor mGluR1 realizado, pueden definirse los requisitos necesarios para que un compuesto sea capaz de unirse y manifestar actividad al interactuar con los receptores mGluR1. Los resultados parecen indicar que un adecuado contacto entre droga y receptor es decisivo para el proceso de binding, de forma tal que el reconocimiento en el sitio receptor se ve favorecido cuando el compuesto posee preferentemente una forma de esferoide oblado. Además, los datos sugieren que existe un contacto hidrofóbico en el caso de los antagonistas, de tal forma que estas estructuras probablemente deben llenar, al menos parcialmente, un bolsillo hidrofóbico presente en el sitio activo.

El presente trabajo apunta fundamentalmente a la dilucidación de los requerimientos para la manifestación de antagonismo en el receptor mGluR1, ya que éstos serán los compuestos capaces de manifestar efectos anticonvulsivos. Así, los requerimientos asociados a antagonismo pueden definirse mediante:

$\checkmark$ la presencia de un grupo amino, un grupo ácido proximal, y un centro donor/aceptor de protones distal, distribuidos en un arreglo geométrico correspondiente a la conformación extendida del glutamato,

$\checkmark$ una forma molecular tendiente a un esferoide oblado para cumplimentar eficazmente el proceso de binding, $\mathrm{y}$

$\checkmark$ un grupo hidrofóbico voluminoso, lo cual se manifiesta mediante una mayor área accesible al solvente, mayor volumen, y mayor índice hidrofóbico.

Como se comenta al inicio de este capítulo, la inhibición de los receptores mGluR1 se ha asociado recientemente a la prevención de la epilepsia ${ }^{43}$, y en este hecho se basa el interés del presente trabajo. Los resultados aquí obtenidos sirven como guía para el descubrimiento de nuevos compuestos, para su posterior síntesis y evaluación biológica, contribuyendo así al diseño racional de nuevas drogas con alta afinidad y capacidad antagonista en el receptor mGluR1, con el fin último de generar nuevos färmacos con potencial actividad antiepiléptica.

\footnotetext{
${ }^{1}$ Nakanishi, S. Neuron (1994) 13: $1031-7$
} 
${ }^{2}$ Conn, P. J.; Pin, J. P. Annual Reviews in Pharmacology and Toxicology (1997) 37: 205-37

${ }^{3}$ Abe, T.; Sugihara, H.; Nawa, H.; Shigemoto, R.; Mizuno, N.; Nakanishi, S. J. Biol. Chem. (1992) 267: 13361-8

${ }^{4}$ Houamed, K. M.; Kuijper, J. L.; Gilbert, T. L. Science (1991) 252 1318-21

${ }^{5}$ Cartmell, J.; Kemp, J. A.; Alexander, S. P. H.; Shinozaki, H.; Kendall, D. A. Br. J. Pharmacol. (1994) 111: 364-9

${ }^{6}$ Kanabe, Y.; Masa, M.; Ishi, P.; Shugemoto, R.; Nakanishi, S. Neuron (1992) 요 168-79

${ }^{7}$ Tizzano, J. P.; Griffey, K. I.; Schoepp, D. D. Neuropharmacology (1995) 34: 1063-7

${ }^{8}$ Tang, E.; Yip, P.K.; Chapman, A.G.; Jane, D.E.; Meldrum, B.S. Eur. J. Pharmacol. (1997) 327: 109

${ }^{9}$ Ghauri, M.; Chapman, A. G.; Meldrum, B. S. NeuroReport (1996) 7.: 1469-74

${ }^{10}$ Thomsen, C.; Boel, E.; Suzdak, P. D. Neuropharmacology (1994) 267. 77-84

${ }^{11}$ Chapman, A. G.; Yip, P. K.; Yap, J. S.; Quinn, L. P.; Tang, E.; Harris, J. R.; Meldrum, B. S. European Journal of Pharmacology (1999) 368: $17-24$

${ }^{12}$ Chapman, A. G.; Nanan, K.; Williams, M.; Meldrum, B. S.

Neuropharmacology (2000) 39: 1567-74

${ }^{13}$ Camon, L.; Vives, P.; Devera, N.; Martines, E. J. Neurosci. Res. (1998) 51: 339

${ }^{14}$ Dalby, N. O.; Thomsen, C. J.Pharmacol. Exp. Ther. (1996) 276: 51622

${ }^{15}$ McDonald, J.W.; Fix, A.S.; Tizzano, J.P.; Schoepp, D.D. J. Neurosci. (1993) 13: 4445

${ }^{16}$ Takahashi, K.; Tsuchida, K.; Tanabe, Y.; Masu, M.; Nakanishi, S.

J.Biol. Chem. (1993) 268: 19341-5

${ }^{17}$ Wroblewska, B.; Wroblewski, J.T.; Pshenichkin, S.; Surin, A.;

Sullivan, S.E.; Neale, J.H. J. Neurochem. (1997) 69: 174-81

${ }^{18}$ Tones, M.A.; Bendali, H.; Flor, P.J.; Knopfel, T.; Kuhn, R.

NeuroReport (1995) 7: 117-20

${ }^{19}$ Parmentier, M. L.; C. Joly, S. R.; Bockaert, J.; Grau, Y.; Pin, J. P.

Molecular Pharmacology (1998) 53: 778-86

${ }^{20}$ Hammerland, L.; Garrett, J.; Hung, B.; Levinthal, C.; Nemeth, E. Mol. Pharmacol. (1999) 55: 642-8

${ }^{21}$ Costantino, G.; Pellicciari, R. Journal of Medicinal Chemistry (1996) 39: 3998-4006

${ }^{22}$ Yang, P.; Chaney, M.; Baez, M. Soc. Neurosci. Abstr. (1998) 24: 1343

${ }^{23}$ Costantino, G.; Macchiarulo, A.; Pellicciari, R. Journal of Medicinal Chemistry (1999) 42: 5390-401

${ }^{24}$ O'Hara, P. J.; Sheppard, P. O.; Thogersen, H.; Venezia, D.; Haldeman, B. A.; McGrane, V.; Houamed, K. M.; Thomsen, C.; Gilbert, T. L.;

Mulvihill, E. R. Neuron (1993) 11: 41-52

${ }^{25}$ Sack, J.S.; Saper, M.A.; Quiocho, F.A. J. Mol. Biol. (1989) 206: 171-91

${ }^{26}$ Quiocho, F.A. Philos. Trans. R. Soc. Lond. B (1990) 326: 341-51

${ }^{27}$ Pin, J. P.; Colle, C. D.; Bessis, A. S.; Acher, F. European Journal of Pharmacology (1999) 375: 277-94

${ }^{28}$ MSI/Quanta. Biosym/MSI, San Diego, CA

${ }^{29}$ Harris, D. L.; Loew, G. Bioorg. Med. Chem. (2000) 8: 2527

${ }^{30}$ Harris, D. L.; DeLorey, T.; He, X.; Cook, J. M.; Loew, G. H.

Eur. J. Pharmacol. (2000) 401: 271

${ }^{31}$ Stewart, J. J. P. J. Comp. Aid. Mol. Des. (1990) 4 : 1 


\footnotetext{
${ }^{32}$ Chapter 5: Geometry Optimizations and Transition State Searching En: Hyperchem, Computational Chemistry, Hypercube Inc., Canadá (1996) pp. 57-68

${ }^{33}$ Vieth, M.; Hirst, J.D.; Brooks, C.L. J. Comp. Aid Mol. Des. (1998) 12 563

${ }^{34}$ Bostrom, J.; Norrby, P.O.; Liljefors, T. J. Comp. Aid Mol. Des. (1998) 12: 383

${ }^{35}$ Brooks, B. R.; Bruccoleri, R. E.; Olafson, B. D.; States, D. J.;

Swaminathan, S.; Karplus, M. (1983) 4: 187

${ }^{36}$ Costantino, G.; Macchiarulo, A.; Pellicciari, R. J. Med. Chem. (1999) 42: 2816

${ }^{37}$ Bessis, A. S.; Jullian, N.; Coudert, E.; Pin, J. P.; Acher, F. Neuropharmacology (1999) 38: 1543

${ }^{38}$ Verloop, A.; Hoogenstraaten, W.; Tipker, J., Cap.4: Development and Application of New Substituent Parameters in Drug Design, Vol.7 Academic Press, New York (1976) pp. 165-207

${ }^{39}$ Stewart, J. J. P. J. Comp. Aid. Mol. Des. (1990) 4: 1

${ }^{40}$ Gavezzotti, A. J. Am. Chem. Soc. (1983) 10: 5220

${ }^{41}$ Hawkins,G.D.; Giesen,D. J.; Lynch, G.C.; Chambers, C. C.; Rossi, I.; Storer, J. W.; Li, J.; Zhu, T.; Rinaldi, D.; Liotard, D. A.; Cramer, C. J.; Truhlar, D. G. AMSOL, version 6.5.1,

University of Minnesota, Minneapolis (1998)

${ }^{42}$ Kantola, A.; Villar, H. O.; Loew, G. H. Journal of Computational Chemistry (1991) 12: 681-9

${ }^{43}$ Nakanishi, S.; Nakajima, Y.; Masu, M:; Ueda, Y.; Nakahara, K.; Watanabe, D.; Yamaguchi, S.; Kawabata, S.; Okada, M. Brain Res. Rev. (1998) 26(2-3): 230-5
} 


\section{\& SUMARIO Y CONCLUSIONES}

El fin principal de la investigación expuesta en este trabajo de Tesis Doctoral es el descubrimiento de nuevas drogas para el tratamiento de la epilepsia.

La labor realizada abarca diversas facetas vinculadas al Descubrimiento o Diseño de Nuevos Fármacos. La forma de trabajo es netamente interdisciplinaria, requiriendo de la participación de distintas áreas de conocimiento, tanto experimentales como teóricas. Los resultados y conclusiones obtenidos mediante la aplicación de técnicas de farmacología experimental y derivados del estudio teórico de las drogas analizadas, permitieron la elaboración y redacción de este Trabajo de Tesis.

La necesidad de crear nuevos fármacos para tratar la epilepsia se asocia fundamentalmente a la incapacidad de los medicamentos actuales para lograr una respuesta adecuada en la totalidad de los pacientes. Mas aún, el elevado número de personas que sufren este mal (más del $1.5 \%$ de la población mundial), sumado a la importante incidencia que presenta en los países en vías de desarrollo, son factores que demuestran lo imperioso del logro de nuevos tratamientos, más efectivos que los disponibles en la actualidad.

La elección del Acido Valproico (Vpa) como compuesto líder a ser optimizado, se fundamenta principalmente en la sencillez de su estructura química, en comparación con las estructuras heterocíclicas complejas de la mayoria de las drogas antiepilépticas de uso clínico. Al mismo tiempo, este simple ácido carboxílico alifático es capaz de manifestar un amplio espectro de acción anticonvulsiva, siendo capaz de controlar convulsiones de variados tipos. Esta característica del Vpa asegura que las variaciones en su estructura seguramente generen nuevos compuestos que conserven al menos alguno de los mecanismos de acción asociados a éste.

El conocimiento acumulado hasta la fecha del inicio de esta investigación, permite concluir que existen varios aspectos dables de ser optimizados en la molécula de Vpa. En esta investigación se busca evitar efectos adversos, tales como los efectos teratogénicos asociados a la presencia del grupo carboxilato, la hepatotoxicidad generada mayoritariamente por un metabolito insaturado, y la inhibición de la enzima $\mathrm{mEH}$, intentando lograr 
simultáneamente una optimización de la potencia anticonvulsiva. En esta búsqueda, surge el diseño y síntesis de varios derivados $\mathbf{N}$-sustituidos de Valpramida. Entre todos los derivados así diseñados, se incluyen en esta presentación aquellos compuestos sintetizados que permiten una adecuada preparación de muestra para su administración en animales de experimentación.

Como parte de la diagramación de esta investigación se seleccionan cuidadosamente los ensayos biológicos a emplear. Las técnicas más importantes se pusieron a punto, para su realización en el Laboratorio de Farmacoquímica: los ensayos MES y PTZ (inducción de la convulsión en forma eléctrica o química, respectivamente) para la evaluación de la actividad anticonvulsiva, y el ensayo RotoRod para la evaluación de los efectos neurotóxicos mínimos. Se procede siempre de acuerdo a los lineamientos metodológicos planteados por el ASP del Programa ADD (NINCDS - NIH, Estados Unidos). Así, la expresión de los resultados de la evaluación preclínica de acuerdo a estándares internacionales, permite el análisis comparativo de potencias e índices de protección (PI), contrastando nuestros datos con los correspondientes a drogas ya conocidas, y evaluadas en otros laboratorios.

Los derivados IpVpd, BuVpd, MoVpd, ChVpd, y CpVpd integran el conjunto inicial de compuestos derivados de $\mathrm{Vpa}$, diseñados, sintetizados y evaluados biológicamente en el Laboratorio de Farmacoquímica. Los resultados farmacológicos in vivo confirman que la mayoria de ellos muestra la actividad sospechada. Asi, IpVpd y BuVpd son entre 2 y 3 veces más potentes que el $V$ pa frente al ensayo MES, mientras que ChVpd es 17 veces más activa que Vpa y casi 6 veces más activa que $V p d$.

Más allá de la potencialidad de estas nuevas estructuras como drogas antiepilépticas, se orienta el estudio hacia la dilucidación de los requisitos que debe poseer este nuevo tipo de estructuras para manifestar actividad, es decir el planteo de un patrón farmacofórico.

En este marco, el distinto comportamiento presentado por el derivado MoVpd frente al ensayo MES, resultó ser un dato de singular importancia. Los resultados de la investigación teórica mostraron que existe una diferencia notable entre la flexibilidad de MoVpd y el resto de los compuestos, siendo el primero incapaz de evolucionar desde una conformación synperiplanar a una conformación antiperiplanar (ambas mínimos de energía en la superficie de energía potencial de todos los derivados estudiados). Tampoco resulta factible el camino inverso, en oposición al resto de los compuestos, para 
los cuales estas conformaciones son mutuamente interconvertibles.

La incorporación al estudio de un análogo rígido, la droga antiepiléptica de amplio uso fenitoína, permite la definición de una conformación antiperiplanar como definitoria de actividad anticonvulsiva. La definición de requisitos estructurales para la manifestación de actividad anti-MES se completa con la incorporación al estudio de varias drogas antiepilépticas de igual perfil farmacológico (es decir, activas frente al ensayo MES). También la inclusión de un análogo inactivo, la droga antiepiléptica etosuximida, ayuda en la definición de un farmacóforo para la acción antiMES. Este grupo farmacóforo queda entonces definido por un grupo amida orientado en una disposición espacial bien determinada con respecto a un grupo hidrocarbonado, que debe tener un tamaño mínimo de 3 átomos de carbono.

Sobre este conocimiento se diseñan nuevos derivados, que se predicen capaces de satisfacer los requisitos farmacofóricos en base a un análisis teórico electrónicoestructural. Surgen así los derivados EtVpd, DmVpd, SuVpd, y PrVp. EtVpd y DmVpd, isómeros de posición, ostentan la ventaja de presentar una menor hidrofobicidad que los derivados inicialmente planteados. Además, DmVpd posee doble sustitución en el $\mathrm{N}$, al igual que MoVpd, y plantea la hipótesis de la necesidad de la existencia de una monosustitución para el logro de la actividad. El derivado SuVpd, amida del bioisóstero de $\mathrm{CpVpd}$, se diseña con la idea de incluir el grupo $-\mathrm{SO}_{2} \mathrm{NH}_{2}$, potencial responsable de la importante actividad antiepiléptica de las nuevas drogas Zonisamida y Topiramato. Por último, el derivado PrVp, permite conocer el comportamiento de los ésteres del Vpa.

$\mathrm{El}$ análisis teórico confirma que estas drogas son capaces de adoptar los requisitos farmacofóricos, y por lo tanto potencialmente activas. La evaluación biológica muestra que se ha logrado una substancial ventaja, en cuanto a la optimización de la actividad, alcanzando el derivado más potente de la serie, SuVpd, 19 veces más activo que Vpa y casi 7 veces más activo que Vpd frente al ensayo MES. El éster PrVp también ha resultado muy activo, presentando una potencia relativa de 11 con respecto al Vpa, y de 3.7 con respecto a Vpd. Los índices de protección también han sido optimizados en el nuevo grupo de estructuras obtenidas por diseño. Comparativamente al grupo inicial de derivados de $\mathrm{Vpa}$ estudiados, en donde no pudieron asegurarse PI mayores a los de Vpa y Vpd (1.1-1.7 y 1.3-1.4, respectivamente), todos los integrantes del nuevo grupo han demostrado poseer índices mejorados, mayores a 2, siendo el derivado SuVpd más de 10 veces más seguro que Vpa y Vpd (PI > 19). 
El planteo de relaciones QSAR incluyendo a los nuevos derivados, permite determinar que los descriptores del efecto electrónico son cruciales para lograr un aumento en la actividad biológica, definiendo al carbonilo del grupo amida como la porción más importante para la acción anti-MES.

Gracias al creciente progreso en el conocimiento, a nivel molecular, de los mecanismos por los que actúan las drogas, la tendencia actual se inclina hacia un planteo desde un punto de vista mecanístico de las características de los fármacos.

Se conoce que existe una relación entre el perfil farmacológico anti-MES de una droga, y un probable mecanismo de acción relacionado al bloqueo de los canales de sodio neuronales regulados por voltaje. Esto nos lleva a definir un nuevo conjunto de trabajo, constituido por drogas antiepilépticas con conocida acción bloqueante de estos canales iónicos. Como resultado del estudio teórico, se encontraron porciones comunes $y$ requisitos conformacionales y electrónicos, es decir un patrón farmacofórico para la acción bloqueadora de los canales de sodio.

Otra de las formas por las que las drogas antiepilépticas manifiestan sus acciones se relaciona a la disminución de la excitación mediada por el aminoácido glutamato. Específicamente el mecanismo de acción asociado a la interacción con los receptores metabotrópicos de este neurotransmisor, es otro objetivo anhelado en el desarrollo de nuevas drogas anticonvulsivas. Dentro de este contexto, el trabajo realizado como parte de una estadía de investigación en el Molecular Research Institute (Mountain View, California, Estados Unidos), se volcó hacia la dilucidación de las características necesarias para el reconocimiento y la activación del subtipo 1 de los receptores metabotrópicos de glutamato. La acción anticonvulsiva se relaciona con una acción antagonista en los receptores mGluR1, por lo tanto, el estudio teórico se basó en el planteo de los requerimientos moleculares para este tipo de acción. En este caso, los resultados condujeron hacia la postulación de requisitos farmacofóricos asociados a propiedades moleculares, más allá de los requerimientos estructurales y conformacionales que deben existir.

La labor original presentada en este trabajo de Tesis, se centra principalmente en el aporte de nuevos conocimientos sobre las características que deben cumplir estructuras noveles para manifestar acción antiepiléptica, ya sea por bloqueo de canales de sodio neuronales, o debida a una acción antagonista en los receptores mGluR r. Esta comprensión brinda las ventajas de ahorrar tiempo, dinero y 
esfuerzo en la síntesis y evaluación de potenciales drogas anticonvulsivas.

Este trabajo inició además una nueva línea de investigación, que se continúa en la realización de ensayos adicionales de acción anticonvulsiva para las drogas más aventajadas obtenidas en nuestro Laboratorio, ejemplificadas por el derivado SuVpd.

La labor realizada, que permitió la redacción de esta Tesis Doctoral, condujo también a la publicación de 5 trabajos científicos en revistas de nivel internacional, y a la participación en 12 reuniones científicas a nivel nacional y 10 a nivel internacional. A continuación se detalla la producción científica en relación a trabajos publicados:

1. Global Physicochemical Properties as Activity Discriminants for the mGluR1 Subtype of Metabotropic Glutamate Receptors

Filizola, M.; Tasso, S.M.; Villar, H.O.; Loew, G.H. Journal of Computational Chemistry 22(16), 2018-2027 (2001)

2. Pharmacophore Model for Antiepileptic Drugs Acting on Sodium Channels

S. Tasso, L. Bruno-Blanch y G.L. Estiú Journal of Molecular Modeling 7(7), 231-239 (2001)

3. Pharmacophore searching and QSAR analysis in the design of anticonvulsant drugs

S. Tasso, L. Bruno-Blanch, S. Moon y G.L. Estiú Journal of Molecular Structure (THEOCHEM) $504,229-240(2000)$

4. On the origin of the lack of anticonvulsant activity of some valpromide derivatives

S. Tasso, L. Bruno-Blanch, G. Estiú International Journal of Quantum Chemistry 70(6), 1127-1136 (1998)

5. Pharmacophoric Pattern in Valpromide Derivatives

S. Tasso, L. Bruno-Blanch, G. Estiú International Journal of Quantum Chemistry 65(6), 1107-1114 (1997) 